\title{
Lobbying for the ear: the public fascination with and academic legitimacy of the sonification of scientific data
}

Citation for published version (APA):

Supper, A. (2012). Lobbying for the ear: the public fascination with and academic legitimacy of the sonification of scientific data. [Doctoral Thesis, Maastricht University]. Datawyse / Universitaire Pers Maastricht. https://doi.org/10.26481/dis.20120606as

Document status and date:

Published: 01/01/2012

DOI:

10.26481/dis.20120606as

Document Version:

Publisher's PDF, also known as Version of record

Please check the document version of this publication:

- A submitted manuscript is the version of the article upon submission and before peer-review. There can be important differences between the submitted version and the official published version of record.

People interested in the research are advised to contact the author for the final version of the publication, or visit the DOI to the publisher's website.

- The final author version and the galley proof are versions of the publication after peer review.

- The final published version features the final layout of the paper including the volume, issue and page numbers.

Link to publication

\footnotetext{
General rights rights.

- You may freely distribute the URL identifying the publication in the public portal. please follow below link for the End User Agreement:

www.umlib.nl/taverne-license

Take down policy

If you believe that this document breaches copyright please contact us at:

repository@maastrichtuniversity.nl

providing details and we will investigate your claim.
}

Copyright and moral rights for the publications made accessible in the public portal are retained by the authors and/or other copyright owners and it is a condition of accessing publications that users recognise and abide by the legal requirements associated with these

- Users may download and print one copy of any publication from the public portal for the purpose of private study or research.

- You may not further distribute the material or use it for any profit-making activity or commercial gain

If the publication is distributed under the terms of Article $25 \mathrm{fa}$ of the Dutch Copyright Act, indicated by the "Taverne" license above, 
Lobbying for the Ear 
(C) Copyright Alexandra Supper, Maastricht 2012

Universitaire Pers Maastricht

ISBN 9789461591470

The printing of this dissertation has been financially supported by the Netherlands Graduate Research School for Science, Technology and Modern Culture (WTMC). 


\title{
Lobbying for the Ear
}

\author{
The Public Fascination with and Academic Legitimacy of \\ the Sonification of Scientific Data
}

\section{PROEFSCHRIFT}

ter verkrijging van de graad van doctor aan de Universiteit Maastricht, op gezag van de Rector Magnificus, Prof. mr. G.P.M.F. Mols volgens het besluit van het College van Decanen, in het openbaar te verdedigen op woensdag 6 juni 2012 om 14.00 uur

door

ALEXANDRA SUPPER

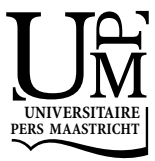


Promotor:

Prof. dr. K.T. Bijsterveld

\section{Copromotor:}

Dr. J.C.M. Wachelder

Beoordelingscommissie:

Prof. dr. S. Wyatt (voorzitter)

Prof. dr. ir. W.E. Bijker

Prof. dr. G.C.G. Dehue (Rijksuniversiteit Groningen)

Dr. W. Halffman (Radboud Universiteit Nijmegen)

Prof. dr. R. van de Vall 


\section{Table of Contents}

$\begin{array}{ll}\text { Acknowledgements } & 7\end{array}$

1. Introduction 9

1.1 Sonification: A Very Short Introduction $\quad 12$

1.2 Sonification in the Hierarchy of the Senses 16

$\begin{array}{ll}1.3 \text { Methodology } & 26\end{array}$

1.4 Outline of the Book 34

2. Sublime Frequencies: The Public Life of Sonification 37

2.1 The Sounds of Science: Examples of Sonification in Five Disciplines 39

2.1.1 Singing Volcanoes and Ringing Auroras: The Sounds of Geoscience 39

2.1.2 Tinkle, Tinkle, Little Star: The Sounds of Astrophysics 41

2.1.3 Little Bangs and Elusive Particles: The Sounds of High Energy Physics 44

2.1.4 Tuning in to the Brain: The Sounds of Neurology 46

2.1.5 The Weltschmerz of the Gene: The Sounds of Genetics 48

2.2 Popularisation and Metaphor $\quad 50$

2.3 Immersion in the Auditory Sublime 58

$\begin{array}{ll}2.4 \text { Conclusions } & 70\end{array}$

3. Jam Sessions and Killer Applications: Disciplines and Boundaries of Sonification $\quad 75$

3.1 Founding Fathers and Pompous Names $\quad 79$

3.2 A Bizarre and Genuinely Friendly Troop $\quad 85$

3.3 "Sonification Is Defined As ..." 92

3.4 "That Might Be a Fairly Significant Killer Application” 101

3.5 Slipping through the Fence between Science and Art 106

$\begin{array}{ll}3.6 \text { Conclusions } & 111\end{array}$ 
4. Trained Ears and Correlation Coefficients: Notions of Objectivity and Scientific Quality in Sonification

4.1 Sonification vs. "the Hard Science":

Amusing, Trivial and Marginally Relevant

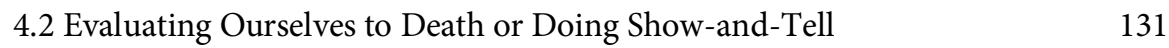

4.3 Interdisciplinary Frictions 142

4.4 Conclusions

150

5. Listening with the Red Button within Reach: Professional Audition in the Gadget Community of Sonification 155

$\begin{array}{ll}5.1 \text { Learning Sonification } & 159\end{array}$

5.2 Choosing and Building Sonification Tools 166

$\begin{array}{ll}5.3 \text { Designing Sonification } & 172\end{array}$

$\begin{array}{ll}5.4 \text { Listening to Sonification } & 179\end{array}$

5.5 Demonstrating Sonification 186

$\begin{array}{ll}5.6 \text { Conclusions } & 190\end{array}$

6. Conclusions 195

$\begin{array}{ll}\text { 6.1 Digital Sounds and Images } & 198\end{array}$

$\begin{array}{ll}6.2 \text { Science and Society } & 206\end{array}$

Appendix A: Participant Observation 213

$\begin{array}{ll}\text { Appendix B: Interviews } & 215\end{array}$

Appendix C: Original Quotes of Translated Material 219

Bibliography 225

Discography 244

$\begin{array}{ll}\text { Samenvatting } & 245\end{array}$

$\begin{array}{ll}\text { Curriculum Vitae } & 253\end{array}$ 


\section{Acknowledgements}

In recent years, a number of science studies scholars have pointed out how important the spatial setting of scientific work is. I hardly touch upon this theme in my dissertation, but I certainly noticed its significance during the process of writing it: I can hardly imagine having written this book anywhere other than in E1.03, with its enormous desks and lovely views of a sex shop and a coffeeshop. And, perhaps most importantly, with the excellent roommates that inhabited it over the years: Constance Sommerey, Eefje Cleophas, Tessa Fox, Ruth Benschop, Ludo Hellemans, and Erik Aarden; and, briefly but no less pleasantly, Annelies Jacobs and Roel van den Oever.

Of course, there is more to doing a $\mathrm{PhD}$ than the process of writing, and thanks to my research subjects in the sonification field, the fieldwork was always a pleasure, not a chore. I could not possibly have chosen a more interesting or friendly bunch of people to study. Many thanks to my interview partners, as well as those I studied during my participant observation stints. Particular thanks go out to Thomas Hermann and his delightful group at Bielefeld University for the invitation and hospitality during my own efforts of learning some sonification basics, Kathi Vogt and everyone at the Science by Ear 2 workshop for allowing me to take part, and the whole ICAD community for three inspiring and fun conference experiences in Paris, Copenhagen and Washington.

Among the many entertaining moments of my fieldwork, one that stands out is when one of my interviewees explained that he decided to do a $\mathrm{PhD}$ with a particular supervisor mostly on the grounds that this professor was so busy with administrative tasks that he would not find the time to meddle with the work of his $\mathrm{PhD}$ students. I chuckled, but not because it reminded me of my own supervisors: while Karin Bijsterveld and Jo Wachelder certainly had their hands full with various administrative matters, it never stood in the way of their supervision activities. And for that I am grateful, as all their meddling with my work was undeniably for the better.

I also thank my colleagues in the Sonic Skills project (as well as the larger Sounders group in Maastricht), who I look forward to continuing to work with in years to come; but especially Joeri Bruyninckx for his careful reading and commenting of my dissertation, and the many literature tips and inspiring conversations. Also owing to Joeri, as well as Karin Bijsterveld, Eefje Cleophas and Annelies Jacobs, my own idiosyncratic version of Dutch in the samenvatting actually resembles something a native speaker might write! 
The Faculty of Arts and Culture in Maastricht provided an excellent research environment over the last four years, thanks to the efforts of academic and support staff alike. My peers in the Graduate School have been particularly helpful in maintaining my sanity over the last four years. Outside of Maastricht, I was lucky to be able to take part in the training and workshops of the Netherlands Graduate Research School of Science, Technology and Modern Culture (WTMC). Special thanks to everyone who read and commented my drafts at the Dissertation Days, as well as to the academic coordinators (past and present) who made it all possible: Sally Wyatt, Willem Halffman, Els Rommes and Teun Zuiderent-Jerak. Ulrike Felt and my former colleagues at the Department of Social Studies of Science in Vienna have been very generous with their intellectual and emotional support during the stressful times of applying for my $\mathrm{PhD}$ position while simultaneously wrapping up my previous studies, and it's always a pleasure to drop by when I'm in Vienna or to run into them at conferences elsewhere. I'm especially grateful for the opportunity to join the Raach Summer School in 2009, where I received many helpful comments. Fran Osrecki has also been a great source of advice from the very beginning, and I much enjoyed our discussions in Vienna, Bielefeld and London.

I have presented earlier versions of the work that culminated in this book at different workshops and conferences over the years, and greatly appreciate many of the comments I received. In particular, Cyrus Mody's thorough discussion at the Sound Studies conference in Maastricht helped me in sharpening not only my contribution to the Oxford Handbook of Sound Studies (Supper 2012, on which chapter 3 is partially based), but this dissertation on the whole.

I thank my friends in Maastricht, Vienna, Strasbourg, Frankfurt, Leuven and Berlin for all the pleasant days and evenings of board games, quizzes, music, walks, dinners and drinks over the last four years that provided much-needed distraction. My brother Christoph and his wife Elsa created some particularly exquisite diversion during the stressful final months, thanks to their lovely wedding and the ensuing chocolate tasting. My parents, Stefanie and Rudolf Supper, have been an incredible source of love, perspective and practical advice all my life, and I am immensely grateful for that, although slightly miffed at the geographical circumstances that preclude me from seeing them in person more often.

I cannot honestly say that making the final, detailed adjustments before submitting was my favourite part of writing a dissertation, but collaborating with Stephen to find alternatives for some of my more awkward and convoluted sentence constructions made the process much more bearable indeed. I thank him for that, and for everything else, too. 


\section{Chapter 1 \\ Introduction}

"A little bit of science fiction." In a recent radio documentary, this is how one interviewee described the practice of sonification (Schubert-Minski 2009). It may not be the most straightforward definition of sonification ever given - something involving a transformation of data into sound might bring across the meaning more directly but it does strike an interesting chord. After all, the idea (if not the term) of sonification has existed in the genre of sci-fi literature for some time. For example, Richard Hey's (1982) post-apocalyptic novel Im Jahr 95 nach Hiroshima contains a description of a physics conference at which scientists present their formulas as musical pieces:

Cold clear light from the dome made every detail lucid: the desks at which the five hundred physicists were sitting, the podium with the conversion equipment and the huge illuminated panel, the platform for the audience on one side of the room, the cabinets with the electronic equipment for the reporters and the simultaneous translation-computers on the opposite side. (...) The next person to step on the podium was a short old man with a bald head and a pointy beard, wearing a black suit that was much too wide and flapped around his body. He spoke a few words in a soft singing voice with the typical cracking sounds of the Danish language, added a few hissing and whistling sounds with the help of his teeth and connected the switching appliance to his acoustic converter. A Far Eastern-sounding monotonous piece of music began to play. At the same time, digits and formulas in various colours started to appear on the illuminated panel. They changed with the music, increased, disappeared, returned. (Hey 1982: 77ff., translated) ${ }^{1}$

Many things about this description of a scientific congress seem unusual to the contemporary reader: the live commentators, the illuminated panels displaying multicoloured formulas, and perhaps above all, the expression of scientific formulae in musical form, which had become standard practice decades earlier in the society described by Hey. Since then, everyone had become "accustomed to understanding

\footnotetext{
${ }^{1}$ Along with other quotes of non-English origin, the original passage is included in Appendix C. All quotes were translated by Alexandra Supper.
} 
physicists' conferences also as musical events" (Hey 1982: 32, translated). The most science-fictional aspect of this account, however, does not lie in the existence of efforts to present scientific findings in acoustic form, but rather in the general acceptance of such practices.

In this regard, Douglas Adams' (1988) Dirk Gently's Holistic Detective Agency with its story of Richard, a computer programmer working on a piece of software that can transform accounting data into music, might be more realistic. The corporate world is mesmerised by this musical representation, but Richard himself finds it rather silly; yet he is fascinated by the idea of "what happens if you leave the accounts out of it. Turn the numbers that represent the way a swallow's wings beat directly into music." (Adams 1988: 24) In other words, he is interested in using the software to transform not just any kind of data, but natural phenomena of scientific interest, into sound: the sonification of scientific data. His boss, however, is less thrilled that Richard wastes time "turning the erosion patterns of the Himalayas into a flute quintet" (Adams 1988: 49), instead of working on applications that actually make a profit.

Unlike Richard Hey, Douglas Adams describes sonification as a contested practice. Although it was written as a piece of fantasy twenty-five years ago, Adams' description is still up-to-date in this respect: while sound is used to express scientific data by a number of dedicated researchers in different countries, its legitimacy and usefulness is still controversial. The contested legitimacy of sonification in science will be one of the two central themes of this dissertation. The other main theme relates to a very simple question: why have examples of sonification proliferated in the last two decades, and why do they seem to hold such allure for so many musicians, scientists and listeners?

Despite some early forerunners - such as the Geiger counter, with its acoustic display of radiation level measurements - the practice of sonification has indeed reached critical mass only since the early 1990s, and public interest in sonification has grown appreciably in the last few years. Sonification is still not an extremely wellknown phenomenon, but many of the friends and colleagues who at first seemed rather puzzled by my choice of dissertation topic have, in the course of the last four years, pointed out examples of sonification they had heard about in newspaper articles, radio programmes or music magazines. There does seem to exist a growing fascination with sonification, and in this dissertation, I want to provide an explanation for it. Not only do I want to discuss why sonification seems to hold such allure at all, but also why it does so at this specific moment in time. Why do we hear of sonification relatively often now, and why haven't we been hearing about it for decades, or 
indeed for the century-and-a-half that the reproduction of sound has been a technical possibility?

The other guiding question of this dissertation relates to its scientific legitimacy and acceptance. While sonification has been getting increased media exposure over the last years, this does not necessarily mean that it has reached the status of being a widely accepted scientific technique. I intend to make no pronouncements of my own about whether sonification is a useful or legitimate approach to dealing with scientific data. Rather, I adopt a perspective informed by science and technology studies (STS) in studying how the practitioners of sonification seek to construct its scientific legitimacy. I do so based on the assumption that scientific acceptance is never selfevident and always has to be created in a social and cultural negotiation process.

In this dissertation, then, I ask how the practitioners of sonification try to establish the legitimacy of sonification. This involves analysing not only the strategies they adopt in order to do so (which I have referred to as 'lobbying for the ear' in the title, for reasons that will become clear in chapter 3), but also the obstacles that they face and the tensions they have to balance in this process of struggling for scientific acceptance. One fundamental tension will come into focus here: on the one hand, the practitioners of sonification propose a technique of data display and analysis that, often quite self-consciously and unapologetically, breaks with entrenched conventions of scientific practice, but on the other hand, they are trying to gain scientific acceptance, which means playing by the rules of the science system.

In order to study this sense of fascination and struggle for scientific recognition, I want to analyse sonification on various levels: not only the nitty-gritty concrete practices at play when people work with sonification, but also the wider structures and discourses that form the context of these practices, such as a broader public and media discourse or the disciplinary and interdisciplinary structures of sonification research. In connecting these different levels, my approach links up to sustained discussions within STS about the need to include the wider institutions and structures to which scientists orient their work, such as academic disciplines, into the studies of the mundane everyday scientific practices that many of the classical STS laboratory studies have focused on (Hine 2007; Keating, Cambrosio, and Mackenzie 1992; Lenoir 1997).

In the remainder of this introduction, I will first give a brief introduction into the field of sonification research, including a discussion of some concrete examples (section 1.1). I will then proceed to give a literature review of work on the role of the senses in scientific practice, and embed my approach towards understanding sonification in this debate (section 1.2). The introduction will conclude with an explana- 
tion of my empirical approach (section 1.3) and an overview of the structure of my dissertation (section 1.4).

\subsection{Sonification: A Very Short Introduction}

Sonification is a relatively young field of scientific research, with systematic work reaching back into the early 1990s (see chapter 3 for a more detailed historiography). Sonification has been applied to a wide variety of data and phenomena, ranging from seismographic data (Dombois 2001; Hayward 1994) to election results (Dayé and de Campo 2006), from molecular structures (Grond et al. 2010) to the electrical activity of the brain (Baier, Hermann, and Stephani 2007a; Hermann et al. 2006). ${ }^{2}$ The different sonifications not only represent a multitude of different kinds of data but also sound very diverse: while some sonifications lull the listeners with the sound of orchestral music, others might prompt them to dance to a techno beat, while yet others stay clear of any musical connotation and instead rely on abstract clicks reminiscent of a Geiger counter.

Sonification does not necessarily have to stand on its own, but may be used to complement existing modes of representation, such as statistical tables, verbal descriptions or visualisations. An underlying assumption of sonification is that an auditory display and analysis of scientific datasets might be helpful for blind scientists, but also that it might yield a more thorough comprehension of certain scientific data and phenomena, for sighted as well as blind scientists. In particular, sonification has been argued to be useful for an exploratory analysis of large, complex datasets, where certain patterns, such as variations on a time or spatial series, might be easier to detect by ear than by eye. As Gregory Kramer (1994b) points out, auditory displays have proven especially helpful for monitoring tasks, where the eyes remain free for other activities, but sound (from any direction) can draw the attention of the user in case of need, such as in the example of a heart monitor during surgery. Another putative advantage of auditory displays is the ability to listen to several data sources in parallel.

But it might be better to consider some concrete examples of sonification applications rather than getting lost in abstract promises. I will discuss examples from two domains here: the sonification of earthquakes, and that of EEG data.

\footnotetext{
${ }^{2}$ It should be noted that sonification - and even more so the broader term of auditory display - is not limited to datasets or phenomena of scientific interest. For the purpose of my dissertation, however, my main interest is in the sonification of scientific data (although the boundary between scientific and other types of data is not always clear-cut, as will become clear in chapter 3 ).
} 
The sonification of earthquakes can look back on a rather long, but mostly informal history, as the seismologist Chris Hayward has noted: "Many geophysicists with the opportunity and equipment have listened to seismograms. Early recordings made on FM tape recorders were often played at high speed to locate recorded earthquakes. From discussions with experienced seismologists of the 1960s, this seems to have been quite common, although it is not well documented." (Hayward 1994: 376) For the most part, Hayward argues, these sonifications were "produced as a curiosity" (Hayward 1994: 372); nonetheless, the quote above already hints at a potential benefit of these sonifications. Seismologists usually study seismic waves in the form of a visual representation, the seismogram; however, due to the enormous amount of data recorded and included in these graphs, they can be hard to browse at a glance. In order to get such a quick overview, ${ }^{3}$ a sonification of the recorded data can be helpful. If the recorded waveforms were played back directly without any changes, their pitch would be too low to be audible to human beings; in order to make them sound, the pitch has to be brought into the human hearing range, and the simplest way of doing so is to speed up the playback, which results in a pitch change. This means that the most straightforward sonification of earthquake data already involves a speeding up of the recorded data, which can help with quickly identifying events of interest among an abundance of data.

In the earliest formally published instances of this type of sonification, it was proposed as a method for discriminating the blasts of atomic bombs from earthquakes (Speeth 1961); more recently, it has been suggested that it may play a role in the prediction of earthquakes (Dombois 2001). Much of Florian Dombois' work has been positioned as artistic research, and led to output ranging from scientific presentations and publications to musical recordings and gallery exhibitions. ${ }^{4}$ In describing the scientific value of earthquake sonifications, Dombois has emphasised the ability to distinguish between different tectonic constellations through listening:

There are three general types of plate movements: spreading zones, subduction zones and shear zones. The sound of earthquakes at spreading

\footnotetext{
${ }^{3}$ Some readers may wonder about my use of terms with strongly visual connotations, such as "overview" here, to discuss sonification. I have decided to embrace the visually dominated language of modern science and philosophy with its "ubiquity of visual metaphors" (Jay 1993: 1) for two reasons. Firstly, the sometimes ironic juxtapositions between visually loaded terms and auditory phenomena are more elegant, yet just as effective as using clumsy neologisms that were coined only to avoid visual language. Secondly, as will become clear in the course of this dissertation, sonification is not a purely auditory phenomenon, but one which is in large part shaped through the visual.

${ }^{4}$ See http://www.auditory-seismology.org/ for listening examples (last access on November $14^{\text {th }}, 2011$ ). Some of his work has also been released as an audio CD, listed in the discography.
} 
zones differs much from earthquakes at subduction zones. Whereas earthquakes produced by plates that are drifting against each other appear as sharp and hard beats, an earthquake from a parting mid ocean ridge sounds more like a plop. Shear quakes sound more or less alike subduction quakes but relax their tension more often in a series of seismic activity. (Dombois 2001:

The type of sonification described above is called audification. Compared to other techniques of sonification, the process of making an audification is quite straightforward; rather than relying on elaborate sound synthesis techniques, the data are directly converted to sound. However, this only works for data that already exist as a waveform, or can be arranged in such a way easily. In practice, this means that a large number of data points which can be meaningfully arranged as a temporal sequence is required for audification. This requirement is met for seismograms. Moreover, they have been described as perfect cases for audification because of the physical similarity between the seismic waves that they measure and the acoustic waveform that the sonification takes. Because of this physical similarity, the result of an audification "will sound like a recording of natural environmental sounds" (Hayward 1994: 370), which has been argued to result in aesthetically pleasing as well intuitively meaningful sounds.

However, audification does not work equally well for all kinds of data. For instance, in a paper for the journal Clinical Neurophysiology, Gerold Baier, Thomas Hermann and Ulrich Stephani argue for the suitability of sonification as a tool for EEG monitoring and feedback. According to them, sound is useful for the identification of rhythmic patterns in the electrical activity of the brain, and has the added advantage that the analyst can monitor what is going on in the EEG without having to actively stare at a screen to visually observe developments. Yet a simple audification of the EEG measurements is not the best technique to accomplish this, the authors argue:

However, if recorded EEG is made audible directly by using the voltage level to drive a speaker membrane (audification), the result is mostly noisy. Such a display is both uncomfortable to listen to for long periods of time and it does not well support the discrimination of rhythmic features from their noisy background. (Baier, Hermann, and Stephani 2007a: 1377)

Instead of using direct audification, the authors therefore propose a more mediated form of sonification, where the data are not made to sound directly, but are instead 
used to drive a sound synthesis algorithm. The particular form that the sonification described in the Clinical Neurophysiology article takes - an event-based sonification, in which sounds are triggered "by pre-defined data features" (Baier, Hermann, and Stephani 2007a: 1377) - is only one example of a long-standing collaboration on the sonification of EEG data between the authors. Like many sonification projects, it is carried out by an interdisciplinary team: Thomas Hermann has a background in physics and computer science and currently leads a research group for ambient intelligence; Gerold Baier was trained as a biochemist and works as a lecturer in systems biology; and Ulrich Stephani is a neuropediatrician working at a university clinic. Within the sonification community, someone like Hermann is often described as a 'sonification expert', that is someone whose expertise mainly lies in the development of the tools and techniques of sonification, while someone like Stephani is referred to as a 'domain scientist' who brings in relevant expertise (and data) for the domain from which the sonified data are taken. Gerold Baier can be found somewhere between these two poles, as he possesses knowledge in the domain from which the data are taken but also exhibits a long-standing engagement with sonification techniques.

Despite the focus on one particular area of research - the study of epileptic seizures measured by EEG - their collaboration shows a lot of the diversity of sonification. To begin with, the bleeping electronic sounds described in the Clinical Neurophysiology article 5 sound nothing like the vocal sonification of EEG proposed elsewhere (Hermann et al. 2006), where the data are expressed as human vowel sounds. ${ }^{6}$ The different sonifications of EEG data also differ in terms of whether they are primarily intended as monitoring tools for clinicians (Baier, Hermann, and Stephani 2007a), or as research technologies that promise an improved understanding of dynamical processes in the brain (Baier and Hermann 2004). While some sonifications focus on the perception of temporal relationships (Baier and Hermann 2004), others also take into account the spatial dimension (Baier, Hermann, and Stephani 2007b). Finally, they are also diverse in terms of the sonification technique employed; some sonifications fall into the category of parameter-mapping sonifications (Hermann et al. 2006), while others are model-based sonifications (Baier and Hermann 2004).

Parameter-mapping sonification is "by far the most frequently heard sonification technique" (Hermann and Ritter 2005: 559); indeed, this approach is so frequently chosen that it has been described as "the usual approach taken to represent data as

\footnotetext{
${ }^{5}$ See http://sonification.de/projects/eegson/CLINPH2007/index.html for listening examples (last access on November $\left.14^{\text {th }}, 2011\right)$.

${ }^{6}$ See http://www.sonification.de/publications/HermannBaierStephaniRitter2006-VSO/ for listening examples (last access on November $14^{\text {th }}, 2011$ ).
} 
sound" (Barrass and Kramer 1999: 26). In parameter mappings, David Worrall explains, "data dimensions are mapped to sound parameters: either to physical (frequency, amplitude), psychophysical (pitch, loudness) or perceptually coherent complexes (timbre, rhythm)" (Worrall 2010: 207). Thomas Hermann has concisely described that in this approach, the sonification is like a musical instrument played directly by the data. On the other hand, in the approach of model-based sonification, a model mediates between data and sonification; rather than the data playing the instrument, "the data is used to build an instrument (...), while the playing is left to the user" (Hermann 2008b: 1).

The aforementioned journal article in Clinical Neurophysiology is worth highlighting because its publication was, as Gerold Baier emphasises, "a giant step forward". After all, Clinical Neurophysiology is "one of the most prestigious neurophysiological or neurological journals, has a high impact [factor], is read by everyone, so it is really widely noticed" (interview Baier 2, translated). The publication of a paper on sonification in such a well-known journal, read by domain experts, is still highly unusual; far more common publication outlets in the field are conference proceedings, or, less often, journals dedicated to sound or to the computer systems that make the sonification possible. According to Baier, the fact that a journal read by neurological specialists has accepted a paper on sonification is a sign of increasing scientific acceptance. Even within the field of sonificiation, argues Baier, many "have not yet realised the significance of this" (interview Baier 2, translated). Being published in a journal of such high standing means that sceptics who are critical of sonification can be told that "even if you don't like this, and if you think this is strenuous, it's nonetheless true that this is doable, and it can be done like this" (interview Baier 2, translated). At the same time, the fact that a single journal publication is such a notable event, and that it is a much-needed weapon in the conflict with critics, already indicates that sonification is still not a widely accepted scientific technique.

\subsection{Sonification in the Hierarchy of the Senses}

Probably the most frequent justification that practitioners of sonification give for the need to express data as sound is based on the idea that we are surrounded by increasingly complex and ubiquitous data all the time, and are at a loss for how to cope with it:

The world around us is full of artificially gathered data. Upon that data we draw conclusions and make decisions, which possibly influence the future of 
our society. The difficulty hereby is not the data acquisition - we already have plenty - but our ability to process it. (Bovermann 2010: 1)

Therefore, it is often argued, better displays for dealing with data are sorely needed. The implication is that the data displays that are currently widespread leave something to be desired, and that their one-sided focus on vision has something to do with it:

There are many software tools available for data exploration and analysis, and often a great deal of student learning and many very promising scientific hypotheses result from interacting with and manipulating the data. However, most data exploration tools in widespread use are exclusively visual in nature, including graphing and plotting software, modeling programs, and 2 or $3 \mathrm{D}$ visualization software. These tools fail to exploit the excellent pattern recognition capabilities of the human auditory system, and they also continue to exclude students and researchers with visual disabilities. (Walker 2000: 16f.)

In response to this predominance of vision, sonification research is often positioned as a "potentially useful alternative and complement to visual approaches" (de Campo 2009: 2). Sonification researchers describe themselves as being engaged in "a battle (...) to prove to the world that audio needs to be used in interfaces in the first place" (Hermann and Hunt 2005: 23) and to "prove that the ear is able to challenge the epistemological power of the eye" (Dombois 2001: 229).

With such rhetoric, the sonification researchers enter an ongoing cultural discourse about the role of sound and its relation to vision, which is also taking place in the social sciences and humanities. For instance, a number of handbooks and readers have been published in the last decade proclaiming the need to turn scholarly (and, in some cases also, design) attention to the subject of sound. Some have declared the existence of an 'acoustic turn' which has already taken place in the practice of media but still lacks scholarly reflection (Meyer 2008), while others have, somewhat more carefully, talked of a 'sonic turn' with a question mark (Schulze 2008: 14f.). Most of them have insisted that the traditional privileging of the sense of vision should not simply be reversed into a "countermonopoly of the ear" (Erlmann 2004: 4). Rather than wanting to "supplant one primary sense with another" (Bull and Back 2003: 3), they have generally opted to talk of a 'democracy of the senses'. Nonetheless, they all use the traditionally higher standing of vision as a starting point and justification of their academic enterprise. And while these essay collections are not usually widely received in the sonification field - although some of the more recent collections do 
indeed contain essays about sonification, written by researchers active in the field (Dombois 2008; Hermann 2008a) - it should nonetheless be clear that the sonification practitioners, with their justification of sonification against a dominant sense of vision, do join a long-standing and intense discussion about sound and vision.

A shared background of this discourse is the idea of a 'hierarchy of the senses', in which vision is traditionally regarded as the highest and most important sense (Jütte 2005). This section provides a literature review of this discourse. However, my intention is not to give a complete historical overview of how vision has come to be widely regarded as the dominant and most important sense; this would go beyond the scope of my undertaking here, and has already been done by other scholars (Jay 1993: chapter 1 and 2; Jütte 2005). Instead, I will treat the questioning of this traditional hegemony in the twentieth century as my starting point. The historian Martin Jay (1993) has done a remarkable job of tracing how the sense of sight was fiercely criticised in twentieth century French thought by scholars such as Foucault, Lacan and Lyotard. The developments he describes, however, are not limited to France - as he acknowledges himself (Jay 1993: 588) - and I will therefore start my literature review with a brief account of this anti-visual discourse outside of France.

Perhaps the most notable such interrogation of vision was expressed by the media theorist Marshall McLuhan and his associates Walter J. Ong and Edmund Carpenter. In their work, they are concerned with the 'ratio' or 'balance' between the senses. Based on a distinction between oral tribal cultures (both historical ones, and those that still exist in non-Western countries today) and advanced civilisation, they argue that the development of scripture, and later of the printing press, have shifted the balance of the senses. As a result of these innovations, the sense of sight has gained much more prominence compared to oral cultures, in which other senses notably sound - are more important: "Writing, and most particularly the alphabet, shifts the balance of the senses away from the aural to the visual, favouring a new kind of personality structure, and alphabetic typography strengthens this shift." (Ong 1991: 30) McLuhan and Ong are clearly critical of these developments, which have led to "the breaking apart of the magical world of the ear and the neutral world of the eye" (McLuhan 1962: 22) and which have left literate men as split and schizophrenic. Only in the advent of the electronic age, with its emphasis on multimedia, do they see a development towards a more balanced ratio again - not a return to the tribal past, but a "mixed sensorium" (Ong 1991: 30).

Similar critiques of visuality have been launched within the field of anthropology of the senses in the last three decades (Classen 1993, 1997; Howes 1991; Stoller 1989). According to David Howes, this sub-field of anthropology is "concerned with how 
the patterning of sense experience varies from one culture to the next in accordance with the meaning and emphasis attached to each of the modalities of perception" (Howes 1991: 4), and is committed to, drawing upon McLuhan and Ong, "approaching other cultures through their own 'sense ratios"' (Howes 1991: 167). Work in this tradition has shown not only that different cultures give varying importance to the different senses (which, in turn, are classified differently in different cultures), but also that these sensory profiles are related to the social order of a given society (Classen 1993).

Scholarship in the anthropology of the senses usually involves a self-conscious breach with Western sensory norms and assumptions, in particular with the hegemony of vision. Sight is associated with being "the sense of science (...). The detachment of sight, distancing spectator from spectacle, makes the cherished objectivity of the scientist possible." (Classen 1993: 6, original emphasis) Breaking with this 'visualism' requires active work and self-reflexivity of the anthropologist; for example, in his work on the Songhay people of Niger, Paul Stoller reflects on how his visually oriented Western perspective, his "narrow gaze" (Stoller 1989: 4), at first stood in the way of properly understanding their culture. David Howes addresses the same problem and concludes that "it is only by developing a rigorous awareness of the visual and textual biases of the Western episteme that we can hope to make sense of how life is lived in other cultural settings" (Howes 1991: 3). He therefore advocates that anthropologists should liberate themselves from the hegemony of sight, because "if we do not 'come to our senses' soon, we will have permanently forfeited the chance of constructing any meaningful alternatives to the pseudo-existence which passes for life in our current 'Civilization of the Image" (Howes 1991: 4). A distinction between vision as neutral, detached, directional, spatial and objective, and hearing as emotional, immersive, spherical, temporal and subjective is usually assumed.

Overall, then, the anthropology of the senses seems to carry on the anti-visual stance of McLuhan and Ong, and specifically, their association of vision with detachment, distance, and a narrow conception of rationality. However, this equation has been problematised by a number of anthropologists. For instance, Constance Classen, herself one of the leading proponents of this research specialisation, has argued that the development of the anthropology of the senses has been impeded by a number of assumptions. One of them is, unsurprisingly, the "bias of Western culture in favour of vision" (Classen 1997: 402) and especially the strong association of sight with science. Another assumption that has proven an obstacle for the field, however, is the very anti-visualist heritage of scholars such as McLuhan and Ong: 
While such approaches have helped prepare the ground for an anthropology of the senses by proposing alternate sensory paradigms for the study of culture, they have one major drawback from the perspective of sensory anthropology. This drawback is that they do not allow for sufficient variation in sensory models across cultures. (...) Furthermore, the oral/literate model of culture tends to assume that the different senses will possess the same social values and have the same social effects across cultures. (Classen 1997: 403f.)

Other anthropologists, such as James Leach with his fieldwork in Papua New Guinea, have also called into question "the usual contrast between vision as objectifying, and hearing as experiential perception" (Leach 2003: 196), arguing that this contrast is "familiar to Western sensibility" (Leach 2003: 203) but should not be imposed onto other cultures.? The media historian Jonathan Sterne also criticises this 'audiovisual litany', which assumes that hearing and seeing differ diametrically where a long list of qualities are concerned. According to Sterne, this litany not only begs the question of what we mean when we talk about hearing and seeing, but it also "renders the history of the senses as a zero-sum game, where the dominance of one sense by necessity leads to the decline of another sense" (Sterne 2003: 16) - an assumption for which, Sterne asserts, there is no scientific basis. A similar line of reasoning has been turned into a scathing critique of the anthropology of the senses in an essay by the anthropologist Tim Ingold:

The common flaw, running through all the work in this field that I have reviewed so far, lies in its naturalisation of the properties of seeing, hearing and other sensory modalities, leading to the mistaken belief that differences between cultures in the ways people perceive the world around them may be attributed to the relative balance, in each, of a certain sense or senses over others. Thus it is supposed that where vision predominates, people will apprehend the world in one way, and where hearing predominates they will apprehend it in another. (Ingold 2000: 281)

\footnotetext{
${ }^{7}$ Indeed, the research of Tom Rice (2008) on stethoscopic listening in a British hospital shows that it might be wrong to assume it as a given even in the Western cultural context, as hearing can also have a function of objectification, distance and disengagement, rather than necessarily standing for intimacy and envelopment. As for the sense of vision and its supposedly distancing effects, research on the diagnostic imaging technique of obstetric ultrasound demonstrates that depictions of the fetus can have fundamental emotional implications for how the parents experience the pregnancy and perceive the unborn child, and can even affect - albeit ambivalently - decisions regarding abortion (Rapp 1997; van Dijck 2005: ch.6; Verbeek 2008). In his research on zoo exhibitions, Gregg Mitman (1996) shows that the same visual technology - a camera - can be used to create both emotional attachment and detached distance.
} 
Ingold questions the assumption that hearing and seeing are diametrically opposed to each other; indeed, he argues that the two are virtually indistinguishable, as it is always the body as a whole, rather than a single sensory organ, that engages in perception. Any assumption that vision is by nature rational and detached, while audition is holistic and engaged "may reflect more upon the preconceptions of anthropological analysts than upon the actual sensory experience of the peoples among whom they have worked" (Ingold 2000: 252). Drawing upon an argument previously made by Don Ihde (2007 [1976]), he argues that the Western association of vision with scientific rationality is not so much the effect of a reduction to vision - that is, of other senses being marginalised at the expense of vision - but rather of a reduction of vision, wherein seeing is reduced to its capability of creating distance and detachment, rather than treating it as the experience of light. Ingold therefore rejects the antivisualist discourse of many anthropologists who blame vision for everything that is wrong with contemporary Western science and society, arguing that "it is as unreasonable to blame vision for the ills of modernity as it is to blame the actor for crimes committed, on stage, by the character whose part he has the misfortune to be playing" (Ingold 2000: 287). His essay concludes with the recommendation that the anthropology of the senses would do well to pay more attention to "the varieties of sensory experience, generated in the course of people's practical, bodily engagement with the world around them" (Ingold 2000: 283), rather than focusing entirely on the overarching and underlying beliefs and ideas that these sensory practices might be taken to stand for.

Indeed, detailed historical studies and empirical work in the social studies of science has tended to complicate the picture that Western science is entirely dominated by the sense of vision. In his work about the visual culture of early modern Europe, Stuart Clark has argued that "ambiguous and negative evaluations of vision" (Clark 2007: 20) have circulated even in the most ocularcentric times; such doubts about the nature and trustworthiness of vision did not end with the advent of the printing press. In a study of early nineteenth century botany, Anne Secord (2002) shows that the use of pictures to introduce novices to the science of botany was contentious, as scientists feared that the images might foster only superficial appreciation of beauty rather than serious scientific interest. While most studies of science and medicine thus acknowledge the special role of visuality, they also show that this statement is often complicated when zooming in for a more detailed account of scientific practice. For instance, Peter Galison's (1997) extensive study of microphysics in the twentieth century shows that the field is characterised by a long-standing split into two traditions, one which relies to a large extent upon images produced by the experimental 
apparatus, and another which rejects images as evidence altogether, instead drawing upon logic and numbers. And in her research on brain mapping techniques, Anne Beaulieu shows that even those researchers who create and work with images often deny that these images actually play a role for their research. Beaulieu sees this as an expression of a hierarchy of different types of evidence in Western science, in which images rank lowly, because they appeal "merely to the senses" rather than to reason (Beaulieu 2002: 57). Studies such as these show that within the supposedly visiondominated scientific enterprise, the status of images, along with other sorts of sensory evidence, is in fact often contested.

Nonetheless, STS studies of visualisation practices ${ }^{8}$ have also helped to understand why images, graphs and diagrams have become so ubiquitous in science, and why they seem to be invested with such persuasive power. For instance, Latour (1986, 1990) has argued that images are powerful 'inscriptions' because of their ability to break down complex realities into flat, two-dimensional representations, which allow for domination and manipulation, comparison and circulation. According to Michael Lynch, visual depictions take on an intermediary role, as "they stand between persons, and between persons and things; they are both material and symbolic; they integrate things with projects; they incorporate verbal references into their frames and supply scenic contexts for interpreting them" (Lynch 2006: 37). Images, held to be "as beautiful and engaging as they are accurate and precise" (de Rijcke and Beaulieu 2007: 734) have also been studied for their potential to bridge the gap between science and art and scientists and laypeople, and even to recruit future scientists (Mitman 1996; Secord 2002). Images are closely intertwined with the notion of 'mechanical objectivity' (Daston and Galison 1992, 2007), which became popular in the nineteenth century: images - and in particular, automated graphs - are taken to be trustworthy and authoritative because they play into the idea of an objectivity uncontaminated by human intervention. The emergence of the graphic method and mechanical objectivity were connected to hopes of finding a universal, neutral language of science (Brain 2002; Hankins and Silverman 1995). If the objectivity and accuracy of such graphical representations seems self-evident now, it is important to keep in mind that they are historically constructed: not only is the idea that objectivity should be characterised by restraint from human intervention a relatively recent development, but graphical representations themselves were at first contested, as

\footnotetext{
${ }^{8}$ I will not attempt to give an exhaustive overview over this huge body of literature. For a starting point, however, see Burri and Dumit, who focus their review on studies of "epistemic practices of the production, interpretation, and use of scientific images” (Burri and Dumit 2008: 298).
} 
critics believed "that in drawing graphs one lost the precision of numbers themselves" (Hankins and Silverman 1995: 120f.).

The idea that science is dominated by the sense of vision is further nuanced by empirical work showing that senses other than vision often do in fact play a role in scientific practice, even if they might be black-boxed or denied in public. As Burri, Schubert and Strübing argue in a recent introductory essay for a special issue on 'The Five Senses of Science', scholars in social studies of science have recently begun taking seriously the idea that "scientific work is conducted with the whole body, involving all senses" (Burri, Schubert, and Strübing 2011: 3). Some recent studies have shown that what we usually consider as 'visualisation' practices in science in fact frequently involves more than just the eyes, as touch and even the whole body of the researcher plays an important role (de Chadarevian 2004; Mayer 2011; Myers 2007). In recent years, a number of researchers have also questioned the existence of a monopoly of vision in science and medicine by pointing out the role of sound in scientific practice (Kursell 2008; Mody 2005), showing that sound "is pervasive in laboratory life and impinges on experimental experience in surprising and often epistemologically significant ways" (Mody 2005: 193).

The role of sound has been studied particularly in the medical field, especially in relation to the stethoscope (Lachmund 1999; Nicolson 1993; Rice 2008, 2010; Sterne 2001, 2003). This work shows that the stethoscope, a device for medical listening, has become "one of the most enduring symbols of modern medicine" (Sterne 2001: 115). In fact, the stethoscope is now so closely intertwined with medical identity that concerns about its declining importance and displacement by newer medical technologies are strongly linked to broader concerns about de-skilling in the medical profession; the stethoscope has come to "stand for an ideal, a way of working, a way of being in which the doctor practises as a skilled, sensitive, resourceful professional and is valued as such" (Rice 2010: 300). The stethoscope example also underlines the previously quoted point by Sterne that the history of the senses is not a zero-sum game in which the increasing importance of one sense necessarily leads to the decline of another: the invention of the stethoscope played a key role in the rise of physical diagnosis as a routine element of the clinical encounter, which had until then been dominated by the patients' narratives and medical history. Once the new technique caught on and physical examination became routine, "a remarkable enhancement of the role played by the physician's senses within the clinical encounter" occurred (Nicolson 1993: 134). Next to the acoustic techniques of percussion and auscultation (both of which involve elements of touch), the visual and manual examination of the body played a much more prominent role than before, for instance with the feeling of 
the pulse and of the body temperature or with the visual inspection of tongue and throat. The rise of the clinical importance of listening thus went hand in hand with a similar development of at least the senses of touch and sight (Lachmund 1998; Nicolson 1993; Porter 1993).

Even historical work on eighteenth and nineteenth century developments in the natural sciences, in which the body and the senses were supposedly replaced by precise mechanical measurements, shows that the senses never quite disappeared from the scene. While the elimination of sensory acuity and tacit skills may have been the professed goal of these scientists, Lorraine Daston argues that it may be more accurate to talk of sensory "repression"; after all, the tacit skills, bodily knowledge and sensory experiences had a stubborn tendency to sneak in through the back door (Daston 2001: 276ff.). In his study of Victorian-era physics, Iwan Rhys Morus rectifies the traditional view that bodily expression and sensory knowledge were eliminated in favour of instrumental measurements and self-discipline: "At best, though, the body was only displaced, rather than entirely removed, with the emergence of new regimes of disembodied precision." (Morus 2010: 807) Morus shows that the importance of the body and the senses lived on, in the tacit skills involved in doing experiments and public performances of science, as well as in the language used to describe these scientific performances. By talking about science "in an aesthetically loaded language of wonder" (Morus 2010: 813), these performances "were intended to appeal to the senses, and their ubiquity throughout the nineteenth century should alert us to the continuing relevance of a pervasive scientific culture of sensation" (Morus 2010: 814) in the Victorian era.

Similarly, Lissa Roberts' account of the transformation of chemistry in the eighteenth century, in the course of which sensory impressions were displaced as acceptable evidence by precise measurements, does not quite support the claim that the senses stopped playing a role altogether: "This is not to say that chemists stopped smelling, tasting, touching, or listening in the service of their analytical activities. But it is to say that unmediated sense evidence played less and less of a public role in the scientific determination of knowledge." (Roberts 1995: 507) Two different points are wrapped into this statement. Firstly, interaction between chemical phenomena and the scientists' bodies and senses increasingly became mediated by technology, and the senses subordinated to scientific instruments; in some cases, scientists "transform[ed] their bodies into appendages of a machine" (Roberts 1995: 519). Secondly, it would not be true to conclude from this that chemists stopped relying on their senses in scientific practice altogether. Rather, they "began erasing the presence of direct sensory evidence from the public records of their discipline's literary and social tech- 
nologies" (Roberts 1995: 507). Like other sensory practices - Roberts especially considers the importance of smell and taste - sound seems to play a role in the laboratories where scientific research takes place, for instance when it comes to monitoring that instruments work properly, but is often purged from public accounts of science, such as write-ups in academic journals. It seems that the walls of the laboratory not only keep the unwanted sounds of the outside world out (Mody 2005; Schmidgen 2008) but also trap the sounds of science inside the lab, out of earshot of the public.

This literature review so far has shown that a broad consensus exists that the sense of vision is of special importance for modern scientific and medical practice. At the same time, I hope to also have shown that it would be far too easy to simply state that science is based on the sense of vision and that all other senses are marginalised to the point of irrelevance. Detailed empirical studies of visual as well as other sensory practices in science have shown both that the sense of vision is itself sometimes contested, and that other senses also play a role in scientific practice. They play a role especially where tacit knowledge and laboratory skills are concerned, but are more likely to be denied in public accounts. This point is forcefully made by Kenneth Gergen in an essay on the rhetorical accomplishment of objectivity, who underlines it with a thought experiment:

The language of objectivity is primarily a language of vision. A typical research description in pyschology, for example, will speak of subjects, questionnaires, tachistoscopes, chimpanzees, and so on - all of which are objects in the visual world. Descriptions of the same "objects" carried out in the terms of any other modality would be viewed with suspicion. If the subjects were described in terms of smell, questionnaires in terms of taste, tachistoscopes in terms of touch, and chimps in terms of sound, the descriptions would rapidly be discounted - merely the personal and subjective experiences of the investigator - potentially biased and unreplicable. (Gergen 1994: 277)

What Gergen proposes here is essentially a breaching experiment in the tradition of ethnnomethodology. This methodological approach was developed by Harold Garfinkel in order to reveal "the socially standardized and standardizing, 'seen but unnoticed', expected, background features of everyday scenes" (Garfinkel 1967: 36) that sociologists usually take for granted. In order to bring them into view, Garfinkel argued, the researcher should try to make trouble; by breaking the conventions that usually guide everyday behaviour - a famous example would be to answer the question "how are you?" with "what do you mean?" - it is possible to find out "how the 
structures of everyday activities are routinely produced and maintained" (Garfinkel 1967: 38). Trevor Pinch and Karin Bijsterveld have adopted this notion of a breaching experiment to think about the introduction of new technologies into musical practice: the debates about the nature of art and of creativity that routinely take place when a new music technology is first introduced "make visible norms and values concerning the art of music and music making that are usually taken for granted" (Pinch and Bijsterveld 2003: 543).

Sonification can be considered an example of such a breaching experiment: by breaching the conventions of scientific representations, the practitioners of sonification expose these often unspoken rules and conventions. Much like Garfinkel's experiments have unveiled social norms that are usually taken for granted by violating them, and Pinch and Bijsterveld's novel music technologies have called into question the seemingly self-evident nature of music, art and creativity, sonification raises questions about what constitutes an acceptable way of representing scientific data. Understanding sonification can help us to understand not only the role and status of sound in science, but also that of vision - and it can, as I will show in my conclusions, contribute to an understanding of broader changes and transformations that are currently occurring in the science system.

At the same time, if the practitioners of sonification engage in breaching experiments, it is not because they enjoy breaking rules for its own sake or to expose the visual character of science; rather, they do so in the hope of being able to change the rules. To do so effectively, they have to play by the rules to a certain extent. In this dissertation, I want to study how they deal with this tension between playing by and breaching the rules.

\subsection{Methodology}

Methodologically, this dissertation draws upon qualitative empirical material broadly classifiable into three categories: qualitative interviews, fieldnotes based on ethnographic observations, and primary literature - collected and analysed between 2008 and 2011. I have combined these different qualitative sources in order to provide a thick description of scientific (and, to a lesser extent, artistic) practice in the field of sonification research.

The ethnographic participant observation research that this dissertation is based upon has followed the approach of multi-sited ethnography. This term has been proposed by the anthropologist George Marcus to describe research that "moves out from the single sites and local situations of conventional ethnographic research de- 
signs to examine the circulation of cultural meanings, objects, and identities in diffuse time-space" (Marcus 1995: 96). As Christine Hine points out, a result is that many multi-sited studies "remain more ambivalent about relevant locations, and (...) make it part of their goal to find out where interesting things might be going on" (Hine 2007: 661). The advantage of such a multi-sited approach to ethnography is that it enables a comparison and juxtaposition of different contexts, without assuming the existence of several distinct and clearly bounded sites, to be identified at the outset, studied separately, and then compared at the end. Instead, multi-sited ethnography can follow its object of study through various settings, without taking fixed contours or stable links between them for granted; thus, it enables the researcher to trace how practitioners of sonification draw the boundaries of their field and how the various segments and locales (such as research settings and artistic performances, or training workshops and scientific conferences) "define and inform one another in dynamic fashion" (Hine 2007: 666). Such a research design has been argued to be particularly useful for contemporary complex societies, where researchers have to deal with what Nadai and Maeder (2005) have referred to as "fuzzy fields" without clear boundaries; it is an approach that seems especially suitable to studying "the complex forms of connection that contemporary science and technology seem to entail" (Hine 2007: 669) which often go beyond the confines of a single laboratory or institution.

My own multi-sited research has taken me to a number of different types of places. These research sites (which are listed in detail in Appendix A) include sonification conferences and workshops (where researchers presented sonification work, collaborated in small teams to develop sonifications, or taught students in sonification), popular science talks involving elements of sonification, concerts and sound art performances based on sonified data, as well as a two-week stay at an institution involved in doing sonification research and a follow-up visit of four days one and a half years later. During these two weeks, I gained first-hand practice in making sonification, which not only allowed me to get to know the working practices of one particular research group active in sonification research, but also opened up a new perspective on the skills needed to do sonification research by struggling with my own limitations. As Latour and Woolgar have noted in their classic study of laboratory life, one should become "a technician, and an incompetent one at that" (Latour and Woolgar 1986 [1979]: 245) in order to become - in part through confrontation with one's own limitations - aware of the otherwise tacit skills of researchers and lab workers, and this is what I did by collecting first-hand experience of developing a sonification. During the short follow-up visit some time later, I did not engage in any 
sonification work of my own, but I was able to observe some being done by others, as well as learning about the new work context of the research group, which had in the meantime undergone institutional reorganisation. Unlike in a traditional laboratory study, the work I participated in and observed did not take place on the lab bench, but rather in front of computer screens.

In all of my participant observation research, I paid particular attention to sensory practices such as listening, seeing, pointing, etc. This type of ethnographic research, which "takes as its starting point the multisensoriality of experience, perception, knowing and practice" (Pink 2009: 1) has been referred to as sensory ethnography. The call for sensory approaches in ethnography is twofold, arguing that ethnography should pay more attention to sensory experience and perception, but also that ethnography is "already necessarily sensory" (Pink 2009: 10, original emphasis) and that this aspect of ethnographic practice should therefore be explicitly accounted for in ethnographic writing and theorising. The key to doing so, according to Veit Erlmann, is to "approach the senses as more than just another 'text' to be read" (Erlmann 2004: 2), and, importantly, to consider the different senses as an "integrated and flexible network" (Erlmann 2004: 4) rather than trying to understand one sense in isolation from all others. Sensory ethnography is therefore more ambitious than the call for "ethnography as engaged listening" recently put forward by Martin Forsey. Forsey posits that ethnography is "more aural than ocular, the ethnographer more participant listener than observer" (Forsey 2010: 561) and suggests to "remove participant observation from its lofty perch" (Forsey 2010: 566) and to instead focus on what the ethnographer can hear - by which Forsey mainly seems to mean the words spoken by the research subjects. In contrast to this, sensory ethnography should look at the interaction between different senses, rather than playing off one sense against another. It's not just about watching research subjects, but neither is it only about listening to what they say. Just like the research subjects always engage several of their senses simultaneously, the researcher has to use all of her senses to make the most out of ethnographic research.

The idea of doing a sensory ethnography, however, is complicated by the fact that we scarcely deal with the unaided, unmediated senses in the modern world. This is certainly true for the sense of hearing: in relation to technologies for sound reproduction, "our experience of listening itself is being transformed" (Ihde 2007 [1976]: 5). As Jonathan Sterne's The Audible Past (Sterne 2003) shows, a recognition of this point does not need to made in a technologically determinist fashion, assuming a technological innovation that magically appears out of nowhere and has profound impacts on the way that we listen. Instead, Sterne suggests looking into the social and 
cultural conditions that gave rise to these technological developments: "If soundreproduction technologies changed the way we hear, where did they come from? Many of the practices, ideas, and constructs associated with sound-reproduction technologies predated the machines themselves." (Sterne 2003: 1) Not only sound, but also modern science is usually technologically mediated. Indeed, scholars of technological mediation, such as the postphenomenological philosophers Don Ihde and Peter-Paul Verbeek, have argued that science is probably the "interpretative framework that has been shaped most profoundly by technological mediation" (Verbeek 2005: 139), as a large variety of scientific instruments have fundamentally altered scientific perception and have not only "strengthen[ed] specific aspects of the reality perceived and weaken[ed] others" (Verbeek 2005: 131) but made visible previously invisible aspects of that reality.

If science and sound have to be understood as technologically mediated, then the same is decidedly true for the sonification of scientific data. This also has implications for sensory ethnography, which simultaneously has to encompass elements of a technography (Burri 2008b; Rammert and Schubert 2006), taking seriously the idea that technical artefacts play an important, and not merely passive (Braun-Thürmann 2006), role in the interactions that we study ethnographically. Chapter 5 will show some examples of sensory ethnography that takes into account the role of technology, for instance by addressing how vision and touch are involved in the listening practices of sonification, and how various technologies - from computer screens to offbuttons - are involved in these sensory practices.

The fact that the longest period of sustained ethnographic research of my project lasted for a period of only two weeks, while most other activities observed lasted between one evening and six days, might seem rather short, but it reflects the nature of the sonification field more than it constitutes a shortcoming in the research design. When I started to do research on sonification, I planned to select a small number of sonification projects to observe for a period of a couple of months each as a researcher in the tradition of laboratory studies (Knorr Cetina 1995; Latour and Woolgar 1986 [1979]). However, I abandoned this idea for a rather simple reason: the kind of research projects I had in mind didn't seem to exist. That is to say, there are very few researchers world-wide who get paid to do sonification work full-time, even if it is for the limited duration of a research project; even those most active in the field of sonification research tend to do their work as a sideline next to other responsibilities. As a result, visiting a particular working group in the hope of observing sonification research may or may not have resulted in actually observing much sonification practice, as such work is often squeezed in between other research. Some of the sonifica- 
tion research projects that I had heard about while doing exploratory research - such as the Austrian SonEnvir or the French CoRSAIRe projects - had either already ended or were, while officially still ongoing, mostly done, with the researchers formerly involved in these projects currently spread throughout Europe or the globe (interviews Dayé, de Campo, Warusfel); while other project proposals that I heard about in the early stage of my research were never realised because of a failure to obtain funding. Since it seemed inefficient to do participant observation research in faraway places without being sure that actual sonification work could indeed be observed, I decided to focus my energies on instances where I could be reasonably sure to experience sonification-related work, and therefore put most of my effort into prescheduled events such as conferences, workshops, concerts or public talks, at the expense of doing much laboratory research. While this meant that "I missed out on some of the purchase that detailed engagement with day-to-day working practice would have afforded" - as Christine Hine (2008: 258) reflects upon her choice to define an entire discipline as her subject of analysis, to be studied in a multi-sited ethnography - it also allowed me to focus on a site for ethnographic research that is underused in STS research: academic conferences and workshops as places in which scientific work can be observed. I focused on the annual International Conferences on Auditory Display (ICAD), attending the ICADs of 2008, 2009 and 2010, but also went to other, smaller-scale workshops.

Conferences are important not just for the networking opportunities they provide but also as forums in which completed research or work-in-progress is presented and explained to an audience, in which questions are asked and debates on principles take place, and in which - and this may be especially true for young and interdisciplinary fields such as sonification research - the nature and the boundaries of the discipline are discussed and defined. With the exception of auto-ethnographic studies (Bell and King 2010; Humphreys 2005; Learmonth and Humphreys 2011; Ntarangwi 2010), in which the scholars "did not participate in the conferences with the instrumental aim of collecting data; instead the research only became a preoccupation retrospectively" (Bell and King 2010: 432), the potential offered by academic conferences as a source for ethnographic studies has been mostly ignored. Contrary to these approaches, I attended conferences and workshops primarily as an observer, and treated frantic note-taking (and, more rarely, making audio recordings) as my main responsibility during these ethnographic encounters. This approach is taken surprisingly rarely in social studies of science. One notable exception is the ethnographic study conducted at a conference (presumably an interdisciplinary gathering in the history and social studies of science) by Heidrun Friese (2001); however, Friese's 
approach loses some of the potential of studying conferences by insisting to treat the conference as an equivalent of a book (e.g. in comparing the introduction round to a table of contents), thus failing to capture some of the ways in which conferences are unlike written discourse. An approach that is closer to what I set out to do in my empirical research is contained in Lisa Messeri's study about the controversy over the proper definition of a planet and the official status of Pluto. One of the scenes of this debate took place at a conference of the International Astronomical Union, where astronomers decided on the planetary definition by majority vote. Messeri vividly describes a session in which a moderator tries to convey what is at stake with the help of “a balloon to represent 'planets', a box of cereal (a pun on the asteroid Ceres) and a stuffed Disney Pluto to represent 'dwarf planets', and a lemon for the 'small solar system objects"' (Messeri 2010: 19). An episode like this makes clear that what happens at conferences cannot be understood by merely focusing on the words that are spoken. Consequently, in my ethnographic work, I paid attention not just to the verbal content (although that was interesting too, especially for some of the more fundamental debates about the nature and future of the field), but also to presentation practices, such as the interplay of words, non-verbal sounds, images, gestures and technologies.

A second type of empirical material used in my analysis were semi-structured qualitative interviews. In total, I have conducted 36 interviews with 34 different individuals ${ }^{9}$ over a period of three years, between February 2008 and January 2011 - a complete list of these interviews can be found in Appendix B. The interviews generally lasted between half an hour and two hours, and all but two of them were recorded and later transcribed for the purposes of analysis. ${ }^{10}$ Most of them took place in person, although eleven were conducted either on the phone or via skype; the interviewing language was usually English, but eleven were conducted in German. ${ }^{11}$

\footnotetext{
${ }^{9}$ This includes one double-interview with two people who collaborate on the same sonification project, as well as follow-up interviews with three people who had been previously interviewed. When referring to interviews with individuals who have been interviewed twice, I have included a " 1 " or " 2 " after the name of the interviewee to indicate whether a quote was taken from the first or the second interview with this person.

${ }^{10}$ I took extensive fieldnotes during or after the two unrecorded interviews, but have not quoted from these notes directly. To the extent that they appear in this dissertation, they do so in the form of my own paraphrases of the conversation, which have been cleared with the interviewees in question before publication.

${ }^{11}$ The snippets of German-language interviews that found their way into this dissertation were translated by the author; the original quotes can be found in Appendix C. For the sake of readability, I have decided against including these quotes in the footnotes of the main text; instead, I have opted to simply indicate that a quote has been translated, thus giving the curious a chance to look up the original quote by searching for the appropriate page number in the appendix. The language of the quoted passages was not "cleaned up", so the snippets are still characterised by the peculiarities of spoken language.
} 
I started selecting potential interviewees in the exploratory phase of my research, and continually refined the selection throughout. I used a snowball method of asking the interviewees I had already talked with to recommend other interesting interview partners, but also contacted people I had found out about through my readings in the field (see below) or during my participant observation research. Since I had decided early on to focus on the International Community for Auditory Display (ICAD) and their aforementioned annual conferences as an institutional embodiment of the sonification community, I talked to the majority of the members of the ICAD board - of the eighteen individuals currently listed on the website, I have interviewed ten. ${ }^{12}$ I made sure to interview the longest-standing members (including two former presidents as well as the current president and secretary), but also one of the most recent additions to the board, as well as a board member who describes his own involvement as that of a "sleeping partner" (interview Brewster). I have also interviewed several of the more recent conference hosts specifically about the experiences with organising the annual conferences. On top of that, I have interviewed others within the sonification community who did not take active roles in the board or in the planning of conferences: newcomers to the field as well as people who used to be, but are no longer, actively involved; and also people who make use of sonification - often for the purposes of science popularisation - without being in any contact with the dedicated sonification research community. Since sonification is an interdisciplinary field, this was also reflected in the selection: the list of interviewees encompasses computer scientists, psychologists, designers, composers, and astrophysicists, among others. Some relevant selection criteria only became evident in the course of the research; for instance, when I noticed that many of my interview partners until that point had been using one particular programming language in the design of their sonifications, I decided to deliberately seek out people using different tools.

In principle, all of these interviews were based on the same topic list, which included questions that can be broadly grouped into four main themes: biographical background of the interviewee, their views on the status of sonification in the scientific and art world, their working practices, and issues related to skills and the transfer of knowledge in sonification research. However, the topic lists were handled quite flexibly, so that certain questions could be skipped or added, according both to the interests and expertise of my interview partners and the current status of my own research. For example, many of the early interviews were focused (although not exclusively) on the interviewees' perspective about the status and acceptance of the

\footnotetext{
${ }^{12}$ See http://icad.org/board (last access on November $14^{\text {th }}, 2011$ ).
} 
research field. Once saturation was reached for this topic, some of the later interviews zoomed in on issues such as tools for sonification research, experiences with research funding and peer review, or the organisation of specific conferences.

A third type of empirical data used were primary documents, most of which are publicly available. The ICAD conference proceedings were an especially important literary source, which I studied up until and including the 2010 conference. Academic journals that are relevant for sonification were also included in the analysis, including engineering, computer science and human-computer interaction journals such as IEEE MultiMedia, Interacting with Computers, Human Factors or ACM Transactions in Applied Perception, as well as journals with an artistic or musical orientation such as Leonardo, the Leonardo Music Journal, the Computer Music Journal or Organised Sound. Some composers who have created musical pieces based on sonification have published books with musings, graphical scores, or even diaries written during the making of a piece; some of these (Adams 2004, 2009; Cage 1961, 1963; Lucier 2005 [1995]) have also been studied for this dissertation. Other published sources include popular science articles (mostly ones found through an online search), as well as websites or radio documentaries made for the purpose of public outreach of science.

Since most of the aforementioned formats, especially the conference proceedings that are such an important resource for most sonification practitioners, require the researchers to present their work in a fairly condensed and concise manner, I have also included $\mathrm{PhD}$ theses in my source material, as these are publications where the authors are not only at liberty to, but are in fact required to provide extensive contextualisation of their work in the larger field. In total, I have analysed ten $\mathrm{PhD}$ theses about sonification, stemming from different disciplinary backgrounds such as computer science, psychology, music or physics; five of them were completed within the first ten years of the existence of ICAD (Ballora 2000; Barrass 1997; Hermann 2002; Vickers 1999; Walker 2000), while the remaining five were completed during the time period in which I worked on my own dissertation (Bovermann 2010; de Campo 2009; Frauenberger 2009; Vogt 2010; Worrall 2009). Finally, I have asked many of my interview partners to allow me to access their funding proposals for sonification projects; while the documents that I have acquired in this way are not explicitly referred to in the dissertation because of the confidential nature of most of these documents, they have nonetheless informed my interpretation. They are interesting sources because they give insight not just into the funding channels that are available for sonification work, but also in the textual strategies employed by its practitioners in order to acquire funding. 
Nearly all of the sources mentioned above - interview transcripts, ethnographic fieldnotes, conference proceedings, $\mathrm{PhD}$ theses - have been coded with the help of the software Atlas.TI, with a coding scheme that started completely openly and was continually refined in the process of analysis. I created separate databases for these four different sets of empirical material, but the coding schemes used for them overlapped a great deal, as the empirical questions put to the different types of material were the same.

These different sources have informed all four of the core chapters. However, the balance between them varies, because I used different sources as a starting point for the analysis in different chapters. As a result, one chapter may be based primarily on interview material while giving only an auxiliary role to ethnographic fieldnotes, while the balance may be reversed in another chapter. The decisions on where to start the analysis were based on the thematic focus of each chapter; to explain these different foci, I will give a brief overview of the structure of the dissertation.

\subsection{Outline of the Book}

Chapter 2, "Sublime Frequencies: The Public Life of Sonification", raises many of the issues that will concern me in the rest of the dissertation, and yet in some ways, it stands on its own. While much of the dissertation is concerned with sonification as a technique of data display for scientific specialists, this chapter focuses precisely on those examples of sonification that were developed for anyone but the scientific specialist. It describes examples of sonification developed for purposes such as science popularisation, didactics and music. The chapter starts with a descriptive account of examples of sonification from a number of different disciplines, before analysing the role of metaphor in these sonifications and in the public discourse surrounding sonification. It then answers the question of why sonification seems to have become so fascinating to a broad audience. As I will show, the public discourse promises that sonification can offer a new experience of science: an auditory sublime. Methodologically, this chapter is predominantly based on the analysis of the popular science sources and of publications in music journals, while other sources have been used as auxiliary material. Theoretically, it builds upon and contributes to literature in the field of public understanding of science, especially to the strand of literature concerned with metaphor in this domain, as well as to literature on the sublime in science and technology and about sound in immersive experiences.

Chapter 3, "Jam Sessions and Killer Applications: Disciplines and Boundaries of Sonification", sketches the development of a community dedicated to sonification, 
focusing on the ICAD. It analyses the community's balancing act between science and art, and their efforts to define sonification. I will show that the community is engaged in boundary work, but rather than attempting to systematically extend or narrow the boundaries of the field, they make use of, but also subvert, the categories and boundaries proposed by other actors. I refer to this mechanism of boundary work as boundary slipping. Methodologically, this chapter primarily draws on a combination of interview transcripts, conference proceedings, $\mathrm{PhD}$ theses and ethnographic fieldnotes. It is based on and adds to scholarly work on the functions of disciplinary histories as well as of expectations for the future, on the relationship between science and art, but especially to a growing body of literature on boundary work in science.

Chapter 4, "Trained Ears and Correlation Coefficients: Notions of Objectivity and Scientific Quality in Sonification", traces negotiations of objectivity within the sonification community. After first establishing that objectivity is often regarded as a problem for sonification research, I will then discuss different strategies of establishing the objectivity of sonification - which I refer to as trained ears and correlation coefficients approaches - that exist within the community. I will explain these different strategies as outcomes of particular research interests, disciplinary perspectives, and conceptions of the users of sonification. The primary sources used for this chapter are a combination of interview transcripts and conference proceedings. Ethnographic fieldnotes and $\mathrm{PhD}$ theses were used as additional sources. It adds to work on the historical construction of objectivity, and of the role of the senses in this construction. Additionally, it builds upon work on quality standards in interdisciplinary collaboration and on configurations of users in technology design.

Chapter 5, "Listening with the Red Button Within Reach: Professional Audition in the Gadget Community of Sonification", focuses on the tools and skills of sonification research. By looking into different contexts of sonification work - from learning how to do sonification to presenting finished sonifications - it describes the sonification community as one which forms itself around certain hardware and software tools, and which is held together by a variety of artistic, technical and scientific skills, which I refer to as the professional audition of the community. By developing the notion of a gadget community, I discuss how the tool-orientation of the community enables, but also impedes, certain kinds of interdisciplinary collaboration. This chapter uses ethnographic fieldnotes as the starting point for the analysis and integrates other sources (especially interview material) into the account where necessary. It contributes to debates about the role of scientific instruments and embodied skills in 
scientific practice, on professional vision and modes of listening, as well as to literature on interdisciplinary collaboration.

The sequence of chapters can be regarded as following a reduction of scale: chapter 2 discusses the status of sonification in the public and media world; chapter 3 discusses how a community dedicated to sonification comes into being, defines itself and positions itself in relation to the outside world; chapter 4 zooms further into that community and asks how it deals with fundamental epistemic issues; and chapter 5 looks into the nitty-gritty practices of working with sonification. At the same time, my discussion of these nitty-gritty practices concludes with an analysis of presentation strategies; that is, at the end of chapter 5, the narrative comes full circle and comes back to where chapter 2 started: sonification in public.

Finally, chapter 6 provides a concluding discussion, in which I take up the theme of the construction of scientific legitimacy for sonification again and discuss the attempts to acquire acceptance in terms of a tension between breaking conventions and fitting in. I look at the interest in sonification in relation to broader changes in the science system related to the introduction of digital technologies on the one hand, and changes in the relationship between science and public on the other hand. 


\section{Chapter 2 \\ Sublime Frequencies: The Public Life of Sonification}

The Emperor's garden was at the shore of a big lake. In the lake, just a bit from the edge, there was a beautiful little island, with trees and flowers and with a quaint summerhouse, and a narrow bridge led from the shore to the island. But not an ordinary bridge, oh no! In one big arch, it led over to the island, and was made of many golden plates lying side by side. Whenever someone walked across the bridge, the plates started to tinkle, and for each person that went across, they sounded different. For one, they acted like tin - clank, clank, clank, - for the next one they made a note every now and then, while in between they rattled like pieces of broken glass, and for yet another one they even started to sing, quietly and with a droning sound, but nonetheless beautiful. And when the Emperor crossed, they sounded like the bells of a big church.

Whenever someone stepped on the bridge, its sound told the Emperor what kind of person was walking over it - a good one, or a bad one, because it only made beautiful sounds if a good person walked over it. (Kayssler-Beblo 1952: 5 , translated)

Anne Kayssler-Beblo's children's tale of the 'sounding bridge' provides a good starting point for a chapter that wants to investigate the public life of sonification. We can think of the bridge as 'sonifying' the character of a person walking across it, giving beautiful sounds (or even magnificent church bells) only for good people. This shows an important aspect of the analysis that I want to present here: how the auditory dimension can be drawn upon in order to create sublime, almost magical experiences. While the examples I will discuss in my analysis of the creation of an auditory sublime will mostly come from the world of popular science and data-music rather than children's literature, Kayssler-Bobo's tale can be considered a precursor of this phenomenon. Along with the literary examples cited in the introduction of this book, it shows that the idea of transforming data or phenomena into sound has gripped the public imagination even before sonification has received systematic research attention, or indeed before the term started to gain currency. 
In this chapter, I want to trace the life of sonification (even if the term isn't necessarily always used in the source material ${ }^{13}$ ) outside of the dedicated research community that will concern me in much of the rest of this dissertation. This involves probing into various different sectors and spheres of public life, considering examples of sonification in concert halls and on music recordings, in popular science talks and in the media. As alluring as the idea of exploring these arena one-by-one might be, such an approach is made problematic by the many interactions between different spheres and by the existence of hybrid formats, such as concerts combined with popular science talks.

Instead, I will start with five short descriptive sections showing how, by whom, and for what purposes data from five different disciplines have been transformed into sound: geoscience, astrophysics, high energy physics, neurology, and genetics. Focusing on these five fields is not meant to imply that these are the only fields where sonification occurs, ${ }^{14}$ but they are the fields where I have found the largest variety of examples. ${ }^{15}$ They also cover quite a broad spectrum of different disciplines - the fact that they all belong to the natural sciences is no coincidence, as sonifications in the social sciences and humanities are few and far between. I do not aspire to make a complete survey of all sonification-related activities in these five fields, nor will I provide a comprehensive discussion of sonification in music, which could be the topic of an entire thesis of its own. Some preliminary work in this direction has been done by Andi Schoon and Florian Dombois (2009), whose website www.sonifyer.org provides a useful (though not exhaustive) database of sonification in music, replete with listening samples.

The descriptive part of the chapter is followed up by two analytically oriented sections. Together, they offer a discussion of the rationale and appeal of sonification for science popularisation and music composition, and of the kind of experience

\footnotetext{
${ }^{13}$ As I will show in chapter 3, what is or is not a sonification is a hotly contested matter. As an analyst, I do not want to impose my own definition, but study how the categories are used by the actors. In order to do so, I decided that anything that would count as a sonification under any of the definitions employed by the actors should qualify for my analysis. Whether the term is explicitly used does not matter for my purposes. After all, sometimes one write-up about a project refers to sonification while another one about the same project does not, and whether the term is mentioned or not is not necessarily a conscious decision at all.

14 Sophia Roosth's (2009) analysis of the use of sonification to probe cellular vibrations shows that nanotechnology research is another interesting case.

${ }^{15}$ High energy physics is an exception here, as my discussion of this field draws upon only a small number of recent examples. However, the exceptional amount of media attention generated by the recent example of sonifications of Large Hadron Collider data at CERN - a project that created such an unexpected amount of publicity that the group's web server caved in under the pressure (interview Asquith) - seems to indicate this field as an up-and-coming domain for data sonification, and thus an interesting case to consider here, next to some of the other fields that can look back on a longer tradition of sonification.
} 
offered by sonification. These parts are not structured in terms of the previously discussed scientific disciplines; instead, I will draw upon examples from all five fields throughout. Nor are they strictly divided between the strands of a data tradition within music on the one hand, and a sonic tradition within science popularisation on the other; a division that would be untenable considering the amount of sonification projects that lie squarely in the middle. The interwovenness of these two phenomena is reflected in the structure of the chapter: some sections will put more emphasis on 'scientific' sonification activities, others more on 'artistic' ones, but no part is ever exclusively about one or the other. Specifically, the first part of the analysis, which positions itself within literature on the role of metaphor in science popularisation, draws more heavily on examples from the scientific end of the continuum. To balance this out, the second part, which explains the experience (expected to be) afforded by sonification with the help of concepts of the sublime and of immersion, begins with a review of some of the musical motivations for working with scientific data, and therefore makes more use of examples from the world of music.

\subsection{The Sounds of Science: Examples of Sonification in Five Disciplines}

\subsubsection{Singing Volcanoes and Ringing Auroras: The Sounds of Geoscience}

You walk in, separate yourself from the world directly outside, sit on the bench, and slip into the red-and-violet, or blue-and-yellow, moods of the five glass panels in front of you. A continual hum greets you, and after a moment you begin to sort out the strands of the complex tapestry that the hum turns out to be. There are sustained chords, an intermittent rattle of deep bells overhead, and an irregular boom of extremely low frequencies that you have to focus on to remain aware of. (Gann 2006)

John Luther Adams' sound installation The Place Where You Go To Listen, installed permanently at the University of Alaska's Museum of the North in Fairbanks, is perhaps the most ambitious sonification project of geoscientific data. Not satisfied with just setting one geophysical phenomenon to music, the composer has opted to tackle several at once, combining seismological, geomagnetic and meteorological datasets. The glass panels described above change their colour according to time of day and season, but the real action lies in the sounds: the sustained chords, the 'Day Choir' and 'Night Choir', track the current position of the sun; a single band of filtered noise 
which changes according to the lunar phases represents the moon; the irregular, deep rumbles are controlled by seismic activities recorded at various seismological stations in Alaska; and the bell sounds represent the aurora borealis, or rather, fluctuations of the magnetic field that correspond to aurora activities (though not necessarily to the visibility of the aurora).

The Place may be the most comprehensive setting of geophysical data to music, but it is not the first. Charles Dodge has made it into the annals of the early history of electronic music with his piece Earth's Magnetic Field (1970), which started when scientists at NASA, after fiddling with their data and realising their musical potential, looked for someone who would set them to music. Dodge did so, letting some aspects of the music (pitches, rhythms) be controlled by the data, but retaining control as a composer over other aspects (Thieberger 1995). Richard Taruskin memorably describes the result as "a series of quirky, catchy tunes that listeners (perhaps with the kind of chemical assistance that prevailed among lovers of 'alternative music' in 1970) could imagine the sun 'playing' on the terrestrial atmosphere. The record sold like hotcakes." (Taruskin 2005: 498) More recent musical recordings of geoscientific data include audifications of geothermal recordings in geysers (Jacob Kirkegaard's Eldfjall) and of fluctuations in air pressure (Felix Hess' Air Pressure Fluctuations), or sonifications of oceanographic data (Bob L. Sturm's Music From the Ocean) and of climate data recorded in Antarctica, combined with field recordings and snippets of interviews with climate researchers (Andrea Polli's Sonic Antarctica) ${ }^{16}$ Audifications of the earth's topography by Jens Brand $^{17}$ and sonifications of the 2011 earthquake in Japan by Micah Frank ${ }^{18}$ have generated a fair amount attention online in the last few years. Several sonification projects have dealt with navigation in an urban environment, such as Christina Kubisch's Electrical Walks, which allow people to tune into the electromagnetic waves of their environment, ${ }^{19}$ or Yolande Harris' Sun Run Sun project, based on GPS data. ${ }^{20}$

Geoscientific sounds can also be heard in non-musical contexts. For instance, earthquake audifications - sometimes as didactic tools for children - can be found on

\footnotetext{
${ }^{16}$ Detailed references for the pieces listed here - as well as for other musical recordings that will be mentioned throughout this dissertation - are listed in a discography at the end of this book.

${ }^{17}$ See http://www.g-turns.com/ (last access on November $14^{\text {th }}, 2011$ ).

${ }^{18}$ See http://micahfrank.com/tagged/tectonic (last access on November $14^{\text {th }}, 2011$ ).

${ }^{19}$ See http://www.cabinetmagazine.org/issues/21/kubisch.php (last access on November 14 ${ }^{\text {th }}, 2011$ ), or Kubisch's (2007) album resulting from the project.

${ }^{20}$ See http://sunrunsun.nimk.nl/ (last access on November $14^{\text {th }}, 2011$ ).
} 
the websites of seismic survey networks. ${ }^{21}$ Other geoscientific sonifications include those of volcanoes, e.g. in a project where Italian scientists and artists transposed seismic waves onto a musical score, which was then played by a digital synthesiser. The resulting sounds were analysed by music pattern recognition software, in the hope that this would help to "learn the signature tune of an imminent eruption" (Fildes 2006). More recently, these sounds were used for a modern dance performance (PhysOrg 2009).

Volcano sounds have also been created by researchers working with infrasound, that is, the study of the low-frequency sounds emitted by volcanoes, most of which are outside the human hearing range. Infrasound studies are also used for phenomena other than volcanoes, including monitoring for nuclear tests to assure compliance with the nuclear test ban treaty - in the words of infrasound researcher Milton Garçes: "Anything that blows up, we pretty much study." (Interview Garçes) In volcanology, infrasound is an alternative to the more traditional method of studying seismic waves as they propagate through the earth; yet the two methods are often used in tandem, as the seismic and infrasound waves can be made comparable through Fourier transformations and visualisation (Hagerty et al. 2000). The study in terms of Fourier analysis and visual inspections of waveforms is indeed the usual practice in infrasonic studies, but some researchers turn the infrasound into audible sound - especially for the purposes of public presentation, but also for their own amusement. Usually, this is accomplished by playing a sped-up version of the recordings (which changes the pitch, thus rendering the recordings audible), but may involve additional processing of the data:

You always want to (...) remove (...) the part of the signal that is noise or unpleasant, and then enhance the part of the signal that is pleasant. (...) And that's an aesthetic exercise, I do it for fun, there's no real scientific prerogative to do it, but it's a thrill. (Interview Garçes)

\subsubsection{Tinkle, Tinkle, Little Star: The Sounds of Astrophysics}

A descending scream, building into a deep rasping roar, and ending in a deafening hiss. A symphony in three movements. That is, according to astronomer Mark Whittle, what the universe sounded like in its early days. In the first million years of its existence, the universe was much smaller than it is now, and matter was spread out

\footnotetext{
${ }^{21}$ See http://earthquake.usgs.gov/learn/listen/allsounds.php and http://www.cisn.org/special/evt.04.09.28/sounds.html (last access on November $14^{\text {th }}, 2011$ ).
} 
evenly instead of forming clusters in stars and galaxies scattered across otherwise empty space; in other words, unlike in the current vacuum of space, sound waves could form and move through the universe during this period. Whittle decided to recreate these sounds of the early universe, based on brightness variations on the maps of cosmic microwave background radiation. The resulting sounds had to be shifted by about 50 octaves in order to be audible to the human ear. In a press release about his project, Whittle (2004) points out that this recreation did involve making choices about the resulting sounds; however, he assures the reader, those choices were not made for artistic purposes, but merely for the sake of clarity. He acknowledges that the purposes are pedagogical rather than providing any new scientific insights, and that cosmology isn't even his own area of research specialisation. The goal was simply to add some new tools of representations to the repertoire of science communication; ones that might help people grasp the concepts and establish an emotional connection to the subject matter. Whittle himself certainly emphasises the emotional component when he interprets that "the Universe's symphony opens, appropriately, with a positive majestic major chord, but as time passes the mood shifts to a sadder one as the minor chord builds" (Whittle 2004: 2).

The microwave background radiation is not the only example of the use of sonification in astrophysics. Sonification is popular in the young field of asteroseismology, dedicated to the study of the internal structure of pulsating stars. The name asteroseismology is an allusion to seismology and its method of finding out details about the core of the earth by studying seismic waves near its surface. Asteroseismologists depend on the observation (from observatories on Earth or, preferably, from space missions) of brightness variations on the surface of a star. The frequency spectra of the observed oscillations are studied, which in turn - with the help of an iterative process of observation and modelling - inform about the star's structure: the speed with which the oscillations propagate is indicative of the composition and size of its core. Conny Aerts, a professor of asteroseismology, likes to explain this process to the uninitiated with the help of two different recorders as well as stellar sonifications. I witnessed this at an introductory lecture for graduate students of astronomy, which Aerts started with a quiz: outside of the room, she played a normal-sized and a piccolo recorder, and made the students say what they had just heard. They identified the sounds correctly, and were also able to tell which of the sounds was produced by the smaller instrument. In a similar way, Aerts explained, a big star would have a different sound than a small star. Aerts used these sounds as a mnemonic for students to give thought to whether the results of their calculations of stellar oscillations actually make sense: in the same way that a piccolo recorder will never produce deep, 
rumbling sounds, a small star does not produce low frequencies either. "When preparing your exams, always remember that I played the recorder!" (Leuven fieldnotes 2010)

Aerts works not just with her recorders, but also with sounds of stellar oscillations: not actual sound recordings of stars, but synthesised, sped-up sounds based on the visual observation of stellar oscillations. The practice rests upon the equation of stellar oscillations with sound; to make the notion and significance of pulsations less abstract, they are compared to the familiar phenomenon of sound waves travelling through matter. These sound examples - a small number of which seem to circulate quite freely among colleagues in the field - are used for popular science talks by a number of asteroseismologists. The idea of stellar oscillations as music also features prominently in a recent textbook introduction into the field of asteroseismology but with a disclaimer that "we do not do science that way" (Aerts, ChristensenDalsgaard, and Kurtz 2010: 6). Not only do scientists usually study these frequency spectra visually rather than listening to the sounds; but in fact, only some of the waves inside a star are pressure waves, akin to acoustic waves. The so-called gravity modes behave differently, driven by buoyancy rather than pressure, a fact that is usually left out during popularisation activities. But even in specialist communication, where the sonifications are usually not used, the idea of stars as musicproducing entities plays a role, as some models of stellar oscillations rest upon the physics of musical instruments (Buchler, Yecko, and Kolláth 1997).

The idea of celestial bodies making sound can look back on a long tradition, predating the field of asteroseismology and reaching back at least to Pythagoras with his idea of the 'music of the spheres', which was most famously picked up by Johannes Kepler (James 1993; Stephenson 1994). This idea of an inaudible, harmonious music created by the movements of celestial bodies gradually lost ground in the increasingly compartmentalised domain of science after Kepler, but continues to be an important resource for science popularisation (Edford 2007: 450). In the history of Western music, cosmological and astronomical inspirations have been a long-standing theme, but the connection to the universe was usually expressed in an associative way rather than by literally transforming astronomical data into sound.

Probably the first example that could indeed be regarded as a sonification of astronomy is John Cage's Atlas Eclipticalis, which he composed in 1961 by transcribing astronomical charts into a graphical score. The score was then played by an orchestra, which presented a "formidable musical challenge" (Piekut 2011: 22) in its own right. Newer examples include a collaboration between composer Robert Alexander and a team of scientists sonifying solar wind data, resulting in two sonifications: one in- 
tended for extended, continuous listening by the scientists studying these data; and a more self-contained one with a definite beginning and end that took some additional artistic licence in the mapping of the data to sound ${ }^{22}$ (interview Alexander). A composition by Marcus Schmickler (with Alberto de Campo and Carsten Goertz), produced for the International Year of Astronomy 2009, sonified a number of different astronomical themes and combined this with visuals. In 2010, an album by Sc.Art (2009) featuring "the sound from the Big Bang, the sound of the Earth's auroral kilometric radiation caused by energy electrons striking the atmosphere and sounds recorded by probes in the planetary environment of the Solar System" ${ }^{23}$ was awarded as the Hungarian Contemporary Classical Album of the Year. And even the sound examples of asteroseismology have found their way into musical compositions, such as the Stellar Music of astrophysicist Zoltán Kolláth and composer Jenõ Keuler: a symphony in which each musical instrument is modelled upon the oscillations of a different star. A very different musical approach based on asteroseismology was taken by Willem Boogman, whose Sternenrest dedicates itself to one specific star and places the audience in the middle of it. ${ }^{24}$ The subtitle of the piece, "stars don't make music", raises important questions about where the music rests, and who has created it, that I will return to towards the end of the chapter.

\subsubsection{Little Bangs and Elusive Particles: The Sounds of High Energy Physics}

Speculations about what the universe might have sounded like just after the big bang are not limited to the field of astronomy, but also pop up in reports about sonification in high energy physics. In these cases, physicists try to re-create the conditions of the early days of the universe under laboratory conditions, and some of them have turned to sound for public outreach purposes. Perhaps this should not be surprising. For example, in superstring theory, metaphors of strings operating like a violin string have long been established as a popularisation strategy (Turney 2004b; Edford 2007).

Two sonifications at particle accelerators have recently made the news: one at the Large Hadron Collider at CERN, and the other at the Relativistic Heavy Ion Collider at Brookhaven National Laboratory. For the latter project, researchers created a website and a youtube video ${ }^{25}$ explaining how the ion collider can collide gold nuclei at

\footnotetext{
${ }^{22}$ See http://www.youtube.com/watch?v=kryCbfRJCyk (last access on November $14^{\text {th }}, 2011$ ).

23 See http://scartmusic.com/index.php/the-well-tempered-universe/the-well-tempered-universe (last access on November $\left.14^{\text {th }}, 2011\right)$.

${ }^{24}$ See http://www.sternenrest.nl (last access on November $14^{\text {th }}, 2011$ ).

${ }^{25}$ See http://soundofthelittlebang.com/ and http://www.youtube.com/watch?v=jF8QO3Cou-Q (last access on November $\left.14^{\text {th }}, 2011\right)$.
} 
nearly the speed of light, thus creating matter as hot and dense as the universe was just after the big bang; these experiments are referred to as 'little bangs'. Since sound waves should be able to travel through the matter of the resulting quark-gluon plasma, the researchers have decided to give them sounds: "The acoustic picture we present is what an observer inside the quark-gluon plasma would hear as the system expands and cools." (Mócsy, Sorensen, and Doig n.d.) The experiments demonstrate the expansion of the acoustic horizon as the matter expands and cools down: only short wavelengths can fit inside the horizon at first and the highest tones can be heard first, then lower tones become audible, and finally, the conditions of vacuum, where no sounds can be heard anymore, take effect.

Another sonification project in high energy physics takes places at the ATLAS experiment at CERN's Large Hadron Collider, ${ }^{26}$ which is designed to shed light on the standard model of particle physics, in particular to observe the Higgs boson, whose existence is predicted by the standard model but has never been observed. The sonification project, a collaboration between physicist Lily Asquith and a team of musicians and software engineers, is also dedicated to the detection of the Higgs boson. Funded as a public outreach project that should bring physics knowledge to the public, the researchers also hope that the method of sonification might be useful for scientists. For Asquith, the sonification might constitute a way "to share the love without sharing the pain" (Asquith 2010a): to make the excitement of working with collisions at LHC palpable without having to simultaneously engage in the hard work and incomprehensible details of the calculations that make them possible. The sonifications are based on a simulation of LHC collision: every type of particle is assigned a particular timbre, with pitch indicating how close or far the energy is from the observer, while volume stands for the amount of energy. These sounds (which are based on simulated data), it is thought, might help scientists detect a collision when and if it actually happens.

Asquith explains that her starting point was an attempt to impersonate different particles for a musician friend, which led to the idea of taking a more systematic approach. A synesthetic experience of the particles lies at the core of the project: Asquith reports that many particle physicists, herself included, "strongly associate different particles with different colours. (...) Some colleagues I have asked have also had strong associations between particle types and sounds." (Asquith 2010b) These associations are often very personal - she quotes a few different descriptions of hadronic activity, such as:

\footnotetext{
${ }^{26}$ See http://lhcsound.hep.ucl.ac.uk/ (last access on November $14^{\text {th }}, 2011$ ).
} 
Hadronization sounds like opening a difficult bag of potato chips. When they hit the detector I imagine the sound in the movie War Games when a missile hits a city (a low computer generated tone).

Hadronic showers sound like a man carrying 12 pints on a tray falling down a long flight of stairs - including the swearing. (Asquith 2010b)

Because of "this weird personification of particles" (Gefter 2010), Asquith thinks, it is important to give people the ability to adjust the parameters of the sonification themselves, so that they can model the sounds in a way that is meaningful to them.

In this sense, it might be possible to think of the sonification of the Higgs boson - with its anthropomorphisation of the particles, its synesthetic efforts of giving certain sensory qualities to a particle that does not even have a (known) physical manifestation - as an auditory extension of the Particle Zoo, in which subatomic particles are given visual and tactile qualities as plush toys. The Higgs boson in the particle zoo, incidentally, is made of dark blue wool felt, filled with gravel for maximum mass, and wears a broad grin: "You'd be smiling too if everyone was looking for you."

\subsubsection{Tuning in to the Brain: The Sounds of Neurology}

When the German psychiatrist Hans Berger published a method for recording the electrical activity of the brain in 1929, few scientists took (positive) note of his innovation, which he named 'electroencephalogram'. The idea that there might be a coherent signal measuring overall brain activity was at odds with the research most neurophysiologists were doing at the time, which was focused on the activity of singular nerve cells rather than overall structures. Only after the renowned British physiologist Edgar Douglas Adrian took up the method in a series of demonstrations and publications five years later, the method started to catch on, eventually entering the pantheon of graphical methods in physiology (Borck 2005, 2008). However, already in one of the first publications on the EEG, Adrian and Matthews (1934) mention not only the graphical, but also the auditory display of brainwaves: with their experiments of amplifying and listening to their own brainwaves (and making a graphical recording of their brain activity whilst doing so), an early forerunner of the audification of brainwaves was born.

\footnotetext{
${ }^{27}$ http://www.particlezoo.net/ (last access on November $14^{\text {th }}, 2011$ ).
} 
Several decades later, brainwave audifications started being employed in musical compositions. An early example of such work is Alvin Lucier's Music for Solo Performer (For Enormously Amplified Brainwaves and Percussion), first performed in 1965. The piece sprouted from the work of Edmond Dewan, a physicist doing research for the US Air Force on alpha brain waves (which are most active in the brain of a person who has their eyes closed, and is in an awake but relaxed state). Based on only a vague notion that it might be interesting to use his research equipment for a musical piece (Kahn 2010), he contacted several composers, without managing to spark their interest (Lucier 2005 [1995]: 32). Finally, Dewan found a willing experimenter in the composer Alvin Lucier, who was interested in part because he saw it as a way out of a creative impasse (interview Lucier). Ignoring suggestions from colleagues that he should use the alpha recordings as raw material for tape music, Lucier used the equipment for a live performance. In Music for Solo Performer, Lucier sat on stage, with electrodes attached to his head. The electrodes were hooked up to an alpha amplifier, which in turn was connected to a set of loudspeakers. A number of percussion instruments were placed in front of these speakers and were 'played' by the pressure of the sound waves emanating from them; unlike in most electronic pieces, the loudspeakers were thus not the final sound-producing elements, but "transducers or triggers for the natural, resonant sounds of percussion instruments" (Mumma 2011: 80). The title is somewhat misleading, as the participation of a second person is required to control the speakers - Lucier tacitly acknowledges as much when, during our interview, he refers to the "other performer" (interview Lucier).

In November 2008, I saw a performance of Lucier's piece, as well as a live sonification of Lucier's brainwaves carried out by Thomas Hermann and Gerold Baier, at the Wien Modern festival for contemporary music. Hermann and Baier, both scientists who usually present their work in academic settings such as the ICAD community (see chapter 3), here presented their work in a musical context, giving a talk, the live sonification with Lucier, and a performance of pre-recorded sonification examples, especially of epileptic seizures. I had heard these sounds before in academic contexts, but the performance was different here: after a brief introductory talk, the lights were turned down completely, a few keywords on a slideshow indicated what we were about to hear, and then it turned pitch-black as we actually heard the sounds. The performance went back and forth between keywords being shown in silence, and sounds being heard in darkness (Wien Modern fieldnotes 2008).

Another notable early example of brainwave music is David Rosenboom's biofeedback work in the 1970s. The project On Being Invisible is "a self-organizing, dynamical system" (Rosenboom 1990: 51) in which the performer's EEG data are meas- 
ured, analysed and used to generate sound signals (according to rules that had previously been created by the composer). These computer-generated sounds are played back to the performer. His brainwaves react as they perceive the music and in turn influence the further course of the music, resulting in an "attention-dependent sonic environment" (Rosenboom 1990: 51).

Most of these examples are based on EEG signals, but a recent project by neurophilosopher Dan Lloyd has sonified data from fMRI scans. The data is processed to distinguish ten different regions of the brain (according to function rather than anatomical location), and a tone is assigned to each of these regions. The tone is louder or softer (or higher and lower, in a different mapping) according the amount of activity going on in the region at a given moment. Lloyd explains that he uses "the properties of the brain actvity itself to determine the properties of the sound. (...) What comes out of it is a whole texture, a whole melodic and harmonic texture." (Smith 2010) The first experiments consisted in a comparison of the fMRIs of healthy and schizophrenic subjects, in which the latter were shown to have much more rapidly oscillating brain activity. Asked about how this informs his work on the nature of consciousness, Lloyd replied that he has been thinking increasingly in terms of holism and the connection between different parts of the brain, which is captured in the polyphony and counter-point of the sonifications (Colin McEnroe Show 2010).

\subsubsection{The Weltschmerz of the Gene: The Sounds of Genetics}

The metaphorical association between genetics and music was popularised by Douglas Hofstadter in his book Gödel, Escher, Bach: An Eternal Golden Braid in the late 1970s:

Imagine the mRNA to be like a long piece of magnetic recording tape, and the ribosome to be like a tape recorder. As the tape passes through the playing head of the recorder, it is 'read' and converted into music, or other sounds. Thus magnetic markings are 'translated' into notes. Similarly, when a 'tape' of mRNA passes through the 'playing head' of a ribosome, the 'notes' produced are amino acids and the 'pieces of music' which they make up are proteins. (Hofstadter 1980 [1979]: 519; original emphasis)

What is clearly just an extended metaphor to Hofstadter has since been spun further by numerous artists and scientists, who have actually set out to make the music of the 
genes audible. ${ }^{28}$ The internet is replete with such sonifications, ranging from the DNA of green fluorescent protein ${ }^{29}$ to red blood cells ${ }^{30}$. Alternatively, in exchange for some cash, you can listen to your very own DNA: "You are a beautiful song waiting to be heard. (...) Your DNA carries the expression of who you are. Your biological sequence (DNA) houses unique identifiers you can now hear through the translation and production of your own genetic musical score!" (Your DNA Song 2009) If your own DNA turns out to be a disappointment, you can always console yourself with the soothing tones of "Ludwig's Last Song": the DNA of Beethoven transformed into a piano piece that sounds rather like something you might come across in a diamond commercial. $^{31}$

These are just a few examples of the phenomenon of DNA music, which can be created with the help of different procedures. Perhaps the simplest approach consists in arbitrarily assigning musical notes to the four bases that make up the double helix of DNA. Most realisations of DNA music, however, give this idea a bit of a spin: electronic music makes it easy to side-step the intervals of standard harmonic scales and compose with tones that fall between the traditional musical notes, and the association between base and pitch need not be assigned randomly. For example, in the collaboration between biologist M. A. Clark and artist John Dunn, pitches were assigned to the 20 amino acids that proteins are made up of. But the pitch mapping was not made randomly: instead, the amino acids were arranged according to their solubility - an important characteristic in determining the folding patterns of the molecules (Dunn and Clark 1999). Peter Gena's work (with geneticist Charles Strom) is based on an even more complex mode of conversion: taking into account both the primary (the exact sequence of amino acids in the protein) and secondary structure (the folding pattern of the protein, which is determined by its solubility in water or lipid, its acid dissociation constant $\mathrm{Pk}(\mathrm{a})$, and its molecular weight), the algorithm devised by Gena and Strom determines not only the pitch, but also the intensity and duration of the genetic music (Gena and Strom 2001).

\footnotetext{
${ }^{28}$ A brief overview over how the metaphor of genes as music has been used is given by López (2007), who then discusses in detail a Canadian exhibition in which this metaphor was employed extensively. Since López is concerned exclusively with the metaphor, he makes no distinction between examples where sound was produced and ones where music was only invoked rhetorically. Another example of musical metaphors for genetics - discussed extensively by José van Dijck (1998) - can be found in Richard Powers' (1992) novel Gold Bug Variations, which draws a parallel between DNA coding and the musical variations in Bach's Goldberg Variations.

${ }^{29}$ http://amas.cz3.nus.edu.sg/music/samples.html (last access on November $14^{\text {th }}, 2011$ ).

${ }^{30} \mathrm{http}: / /$ www.petergena.com/rbdna.html (last access on November $14^{\text {th }}, 2011$ ).

${ }^{31}$ See http://www.youtube.com/watch?v=T_yTytUVDFM (last access on November $14^{\text {th }}, 2011$ ).
} 
Other work is informed by the idea that not all genetic sequences are equally good and therefore shouldn't sound equally harmonious. Accordingly, a bioinformatics project at Harvard School of Medicine has transformed protein and gene expression into music in such a way that "harmony represents good health, and discord indicates disease" (Chu 2008). The reasons for this are not just aesthetic, but perceptual: the method is developed for future health monitoring in clinical contexts, where harmonious sounds can fade into the background, while "inharmonious music (...) catches your attention" (Akst 2009).

The idea of genetic music has found its way into pedagogical applications for pupils (Miner and Villa 1997) and occasionally into specialist journal articles; specifically, a series of articles by the geneticist Susumu Ohno in the 1980s explored the transformation of DNA sequences into music (Ohno 1988; Ohno and Ohno 1986). As the writer of Ohno's obituary in the LA Times would later remark, at that point in his career, Ohno had already achieved enough to have "earn[ed] the freedom to choreograph that scientific arabesque" (Oliver 2000). In Ohno's transformation, each of the four bases of a DNA sequence was assigned two consecutive positions on a musical staff, so that all four together would cover one octave. The position on the staff was determined by molecular mass, as heavier bases were turned into lower musical notes; this is illustrated by the musical notation featured in the journal articles. Ohno's primary motivation was to contradict the assumption of randomness as the tenet of biological thought, emphasising instead the importance of repetition and recurrent patterns in both genetic sequences and music. His claim was not that music and genetics are particularly similar; on the contrary, he stressed the differences between the two, seeing genetics as representative of nature, and music as an expression of nurture. Precisely because music and genes are so different, yet nonetheless share these patterns, Ohno was convinced that all life on earth must be governed by these periodicities (Ohno and Ohno 1986: 71). Ohno gave his interpretation of the musical qualities of genetic materials: "If played on a violin, this transformation is hauntingly melancholy, as though reflecting the Weltschmerz of the gene that persevered for hundreds of millions of years." (Ohno and Ohno 1986: 73)

\subsection{Popularisation and Metaphor}

In the previous five sections, I have given a glimpse of how sonification is used in five different scientific disciplines. Many of the examples discussed so far were used in contexts of public outreach and science popularisation, and it will therefore be fruitful to analyse what role sonification actually plays for the popularisation of scientific 
knowledge. However, the notion of popularisation itself is an odd and not entirely unproblematic category, as Greg Myers highlights:

There is no field that names all discussions of crime and punishment except those published in law journals, or all discussions of God except those given the imprimatur of an established church, or all discussion of politics except those in government documents. Popularization includes only texts about science that are not addressed to other specialist scientists, with the assumption that the texts that are addressed to other specialists are something else, something much better: scientific discourse. (Myers 2003: 265)

Indeed, the assumption that popularisation is a completely distinct and somehow inferior form of communication to specialist discourse, a watered-down and distorted version of knowledge being passed down from the 'real science' of specialist publications, has come under scrutiny in the last few decades (Hilgartner 1990; Shinn and Whitley 1985; Wynne 1995). The old 'dominant view' of science popularisation assumes two stages: first, scientists develop genuine scientific knowledge, and then, it is disseminated to the public in a simplified form. But this view has been shown to be problematic for a number of reasons. Its linearity often does not hold true, e.g. when scientists dodge publishing in scientific journals first and instead directly address the general or popular science press (Bucchi 1996, 1998; Cassidy 2006). The separation between specialist and popular genres is somewhat artificial, as scientific specialists also read popular science publications, especially for fields outside of their own specialisation, and popular accounts thus often stimulate cross-disciplinary fertilisation and feed back into the research process (Bunders and Whitley 1985; Felt 2000; Hilgartner 1990). Not only scientific knowledge, but also the tools of scientific research sometimes start out in the domain of science didactics or as amusing educational toys before being turned into research tools for scientists (Gee 1989; Meinel 2004; Wachelder 2007).

Popularisation has traditionally been considered a low-status activity for scientists, one that might even damage their career, but more recently, it has come to be considered as something of a duty, and scientists increasingly care about how they are represented in the media (Gregory and Miller 1998). The reasons for this development can be found in changing research structures and public attitudes towards science; the emergence of large-scale, high-tech research projects that cost a lot of taxpayers' money led to an growing need to justify these expenses to the public (Nelkin 1994 [1987]: 147f.), and public accountability became an increasingly important 
theme of science policy (Felt 2000: 7). In the light of their political significance, science popularisation initiatives often take on the form of public relations campaigns, and 'public understanding of science' becomes conflated with the public's appreciation and support of science. While scholars have repeatedly pointed out the drawbacks of the 'deficit model' - the assumption that lack of public support for science must be caused by public ignorance - the model has been shown to live on, albeit in a slightly modified form, in science policy (Wynne 2006). Many initiatives that purport to increase public engagement often mainly aim at legitimising or celebrating science.

Perhaps it is not a coincidence, then, that many of the most widely reported examples of sonification emerge from fields that are particularly dependent on extensive public funding: be that in particle physics, where expensive particle accelerators are needed (and have caused controversy about their putative dangers), or in asteroseismology, where the ability to study stellar oscillations requires much-demanded timeslots on huge and expensive telescopes, or space missions that can register brightness variations on the surface of the stars without interference from the atmosphere and light pollution of the Earth. Many of the scientists I interviewed see it as their responsibility to give something back to the public by informing them about the research that their tax money pays for (interviews Kurtz, Heise, Garçes) - and doing so with the help of sonification might not only increase public interest or make the information more graspable, but might even lead people to proudly think: "Oh, my tax dollars have gone to help this!" (interview Garçes) and thus increase public acceptance of the research. Or, as another scientist remarks, a facetious answer to the question of "what is that good for, anyway?" can be that the kids like to dance to it: "Well, we can use the world's biggest telescopes, they cost more than 100.000 Euros a night to use them, and we can make disco music with them." (Interview Kurtz) Given the huge costs, and sometimes fierce competition, for access to such large telescopes ${ }^{32}$ or even space missions, it is not surprising that asteroseismologists are concerned about displaying the fruits of their labour to a tax-paying public. And it's not just about funding, as Zoltán Kolláth emphasises: in a time of waning interest in natural science, "high quality public outreach is essential to get smart students for astronomy" (Kolláth 2006: 421). Sonification is one of the methods he suggests for such highquality public outreach.

We have thus established some of the motivations that lead scientists to popularise their research, and to do so with the help of sonification. The next step will be to

\footnotetext{
${ }^{32}$ In his analysis of the moral economy of large telescopes, McCray describes that "access to telescopes and sufficient time allocated on them" (McCray 2000: 685) are among the most important assets of optical astronomers, and that the distribution of these resources is contested.
} 
analyse what they do when they engage in sonification-aided popularisation, and a fruitful way of doing so might be to look at the functioning of the metaphors that are employed. While metaphors have been considered as mere rhetorical flourish and thus not worthy of serious reflection for a long time, it has been argued that metaphors in fact do matter: they influence the way we understand the world, think and act; they draw upon our experience of the world but in turn also structure the way that we perceive and experience it (Lakoff and Johnson 2003 [1980]). Other authors have pointed out that metaphors do not possess innate meanings, but that any given metaphor "offers a set of diverse potential meanings" (Condit et al. 2002: 303), and that metaphors and their interpretations are established and stabilised not in a purely cognitive, but in a social and cultural process (Hellsten 2002; López 2007; van Dijck 1998). Not only are metaphors and their meanings negotiated in a cultural context; once they are in circulation, they function not only to describe the world, but also to shape it. Sally Wyatt has raised this point in an analysis of the metaphors used to describe the internet, which have more than just a descriptive function: "Metaphors not only help us to think about the future; they are a resource deployed by a variety of actors to shape the future." (Wyatt 2004: 257)

The role of metaphor in science has been studied extensively, with the argument that "much of what scientists do - how they conceive of productive experiments, what they observe, and their interpretations of observations - is governed by metaphorical reasoning" (Brown 2003: 2), and that the public communication of science in particular "displays an extensive use of analogical and metaphorical images" (Bucchi 1998: 22). In some cases, the metaphors created for popularisation - e.g. the notion of a genetic code - even make their way back into specialist discourse (Knudsen 2003, 2005).

So how do metaphors come into play where sonification is concerned? Are entirely new metaphors created to talk about sonified sounds and the phenomena they represent, or are existing ones employed? What are the implications of using a particular metaphor? Let us start by looking at the field where the usage of metaphor has been discussed and analysed most extensively: genetics. An important discussion in this field has focused on how certain metaphors (such as the notion of DNA as the blueprint of life or as a computer program) help to establish or sustain a view of genetic determinism, in which human beings (and other forms of life) are reduced to their genetic material (Nelkin 2001; Nelkin and Lindee 1995; van Dijck 1998). There has been a conscious push for alternative metaphors, but Condit et al. (2002) demonstrate with the example of the metaphor of a cooking recipe that in practice, these do not necessarily live up to the hopes of their anti-deterministic advocates. Musical 
metaphors have been proposed and applied with similar hopes, especially in the context of writing about genetics by scientists from specialisations other than genetics, such as system biologists (Noble 2006) or epidemiologists (Porta 2003), wanting to highlight the role of, respectively, complex interactions within biological systems, or the social construction of health-related risks and the importance of public health initiatives.

Unlike these publications, the genetic sonification examples I have studied do not systematically attempt to explain genetic processes with the help of musical terminology. There are scattered references to a 'score' provided by nature (Dunn and Clark 1999: 27; Gena and Strom 2001: 5) or to the "melody at the base level of DNA" (Mitchell 2010), but overall, the traditional architectural metaphors of 'building blocks' (Boyle 2007; Chu 2007) and 'blueprints' (Gena and Strom 2001; Ricks 1986) dominate. Only Dunn and Clark make systematic use of musical metaphors to explain the synthesis of proteins:

Through the doors of the practice rooms, I can hear fragments of 1000 years of written music, played or sung by the current generation of music students, some with finesse, some with hesitation, some with wild improvisation. I think that if somehow I could walk into a living cell, I would hear something similar - the ribosomes ticking away at the synthesis of proteins, playing out their amino acid sequences, note by note, according to a genetic score that is reproduced sometimes with utter fidelity, sometimes with a few unscheduled substitutions, and sometimes with stunningly inventive flourishes. Every generation of cells in every living organism plays the genetic score of its species. (Dunn and Clark 1999: 25)

The article continues to employ musical similes, for example when proteins are said to be "composed of phrases organized into themes" (Dunn and Clark 1999: 25) like a musical composition, or when substitutions are explained as acting "like a musical key change" (Dunn and Clark 1999: 28). It is hard to position this on a 'genetic determinism' scale: the writers use the metaphor of a genetic score in a way that emphasises variation and the fact that a piece of music isn't always faithful to its score; in this regard, the description bears similarities to the non-deterministic metaphor of the genome as jazz score suggested by Porta (not in any sonification-related context) several years later: "The genome is thus like the innumerable scores that a jazz aficionado would play during all her life, some with great fidelity to the original musical text, many just-but deeply_inspired by it, still many others almost totally invented, 
whether improvised or consciously crafted." (Porta 2003: 30) The essential difference, however, is that Porta emphasises the social factors that influence how the score is played, whereas in Dunn's and Clark's account, these are not mentioned at all; it is the ribosomes themselves who seem to have a penchant for improvisation. While Dunn and Clark emphasise variability and playfulness in their description of genetic processes, they never give any indication that there might be more to life or humanity than its genetic structure; in that regard, they stick with the classical view of genetic essentialism. In this, they are hardly alone among practitioners of genetic sonification; for example, Gena and Strom write that "each individual living organism has a unique order of bases that completely determines its physical structure" (Gena and Strom 1995: 1). This is somewhat in line with what López (2007) has described for the 'Geee! in Genome' exhibition, in which musical metaphors were used as a "aestheticization of genetic reductionism (...) [which] makes it less threatening to contemporary sensibilities" (López 2007: 26) by tapping into our "experience of music as the romantic expression of an individual's inner essence” (López 2007: 26). As López notes, this is not an inherent property of musical metaphors for genes, but rather a meaning that is activated in the context of usage.

Throughout the paper by Dunn and Clark, the musical structure is taken to be already inherent to the proteins, as the "history of genetic music is at least 3.8 billion years in the making" (Dunn and Clark 1999: 25), much older than the human tradition of music-making. Similarly, Stuart Mitchell (the creator of Ludwig's Last Song) considers the parallels between genetic and musical structure as proof that "a musical system [was] already in place before our species even considered what music was" (Mitchell 2010). An article about Jeffrey Miller and Rie Takahashi's sonification of amino acids also assumes that our genetic material is musical, as researchers "discovered short fugues, canons, and musical themes within patterns of proteins" (Chu 2007).

The assumption of an inherent musicality in talking about sonified phenomena is not singular to the field of genetics; indeed, many articles on different applications share a tendency to go back and forth between pointing out how researchers or artists turned a phenomenon into sound, and suggesting that the sounds were already contained in the phenomenon itself. Some articles strongly emphasise that the sounds have been created by humans (e.g. GEANT2 2006), while others 'forget' to mention that a transformation process took place entirely (Lamont-Doherty Earth Observatory 2005). But most articles provide a more ambiguous account. For example, an article might describe researchers "making music out of the seismic rumblings of active volcanoes", thus implying that the music is a human creation, but then contain 
a quote that this was "like putting our ear on a volcano slope, listening directly to its voice" (Vicinanza quoted in Gramling 2007), thus suggesting that the volcano itself communicates in this way. Or a researcher talks about how he transformed brain scans into music, but then poses that "we're all making symphonies all the time" (Lloyd quoted inSmith 2010); thus, he suggests that music is already made when our brain is active, not when brain activity is transformed into sound.

The suggestion of an inherent musical structure is often created by metaphors, such as the voice or signature tune of a volcano, or the symphony of our brains. As Sophia Roosth (2009: 336) points out, whether an oscillation is described as "sound, noise, signals, music, singing, or speaking reveals the ways in which listeners interpret" the phenomenon; in particular, these descriptions are able to ascribe (or deny) agency and subjectivity to the object. Music, songs, symphonies - these are all common descriptions for sonified sounds, and the suggestion is frequently made that the music is created by the phenomena themselves, not by those who make the sonification. Stars, for example, always seem to be busy making music or songs; some even have a "voice" (Mayne 2006), with which they can "sing" (Branton 2006). The beginnings of the universe can be described as a symphony (Whittle 2004) - though not always a pleasant one, as the "cosmic cacophony" (Chandler 2004) seems to suggest. Volcanoes, too, have music and songs, but their music seems less likely to be symphonic and more likely to be vocal: volcanoes frequently have a "voice" (Gramling 2007; McGourty 2003), with which they "sing” (Pendick 1999) - indeed, some volcanoes are better singers than others: "Some are operatic. Others have no singing talent whatsoever." (McGourty 2003) If the suggestion that volcanoes have a voice endows them with "agency to utter sounds that convey information" (Roosth 2009: 336), then this becomes even more explicit when they are said to emit "angry growls" (Pendick 1999), or to chatter:

You have that chatty neighbor - you train yourself to cut out all the chatter and learn to recognize what is important. (Garçes quoted in Sever 2004)

And it was incredible, so much diversity, we're talking about chatter - this thing was just non-stop communicating. And I had no idea what it was saying. And it was really vexing, because I wanted to know what it was saying, to find out what it was trying to tell us about what the volcano is doing. And that's how it started, really, trying to learn this primitive language. (Interview Garçes) 
In these examples, the volcano is described as actively wanting to communicate with humans, but failing: both because it is a little too talkative for its own good - like that annoying neighbour that you learn to blend out most of the time - and because the listener it is trying to communicate with doesn't actually speak its language. But Milton Garçes, at least, seems determined to learn.

This brings us to the notion of the listener. We have already come across the figure of the researcher who puts his ear on the volcano slope, but there is another recurring theme, that of a scientist secretly listening in to something that wasn't intended for her ears. For example, thanks to the sonification of brain scans, we can "eavesdrop on the brain" (Colin McEnroe Show 2010); thanks to the sonification of the Higgs boson we might be able to "eavesdrop on the harmonious background sound of the Universe" (Ghosh 2010); and thanks to infrasound we can eavesdrop on the activity of volcanoes, which might allow us to "reveal a volcano's innermost secrets" (Pendick 1999). We are getting into serious mystical territory here, unlocking at least personal secrets, if not the very secret of creation - a theme that will be explored in the second part of my analysis.

It is important to keep in mind that many of the metaphors invoked when talking about sonification are not created in the discourse about sonification, but recycled from other contexts. For example, seismology, volcanology and asteroseismology all heavily employ the metaphor of musical instruments; stars might oscillate like trumpets, volcanoes like organ pipes. These metaphors are often not born in sonification contexts. For example, Zoltán Kolláth first noticed similarities between equations that describe oscillation modes of stars with the Schrödinger equation in quantum mechanics, which in turn had parallels with models describing the oscillations of wind instruments - a parallel that was even published in a scientific publication (Buchler, Yecko, and Kolláth 1997). It was with this metaphor of a star as a wind instrument in mind that Kolláth started trying to model the stars as musical instruments (interview Kolláth).

The idea of a volcano operating like an organ pipe, similarly, has been around for a while, and isn't employed exclusively when talking about sonification. For example, in an interview published on the PBS website for the popular science TV program Nova, the seismologist Bernard Chouet is introduced as a "good listener" and gives a detailed analogy between the long-period signals in a volcano and the tones of an organ pipe (Volcano's Deadly Warning 2002). The information given about his work indicates that he works not with infrasound but with seismic data, and that he inspects the data visually and mathematically, but not auditorily; while Chouet might indeed be a good listener for all we know, that skill does not seem to be in any direct 
relation to his qualities of a researcher. This is further reinforced by the two animations provided on the PBS website: despite the title 'Volcano Talking', they are silent animations of the lines of a seismogram. It goes to show that musical and acoustic metaphors are employed in this field also outside of the context of sonification, and not only in popular science contexts: the idea of modelling volcano activity on an organ pipe has been around since at least the mid-1980s, and has also been published in specialist publications - without, however, actually providing auditory examples (Chouet 1985; Hagerty et al. 2000; McNutt 1986).

So what sonification does in these cases is to take up existing metaphorical connections between science and music, and reinforce them by actually giving sound to the phenomena in question. While the metaphor itself already is an illustration of an idea, it in turn becomes illustrated by the sonified sounds; e.g. if a metaphor invites thinking of a particular process as comparable to the vibrations of a string instrument, the sonification further illustrates this metaphor by actually assigning a sound to this process. Many sonification examples discussed above seem to fit this pattern.

Does that mean that sonification is ultimately inconsequential, since it doesn't add anything to the discourse? Many of the scientists working with sonification disavow it as a somewhat distorted representation of reality that might nonetheless help to attract an audience to engage with scientific questions. Yet this view downplays the epistemic significance of sonification: at the very least, the sonifications convey metaphors that tell us something about 'the real science', and especially about how the scientists themselves approach their subject. They help to make knowledge tangible and thus comprehensible. But perhaps more than anything, they seem to offer a different experience of science - and it is this that I want to turn to in the next section.

\subsection{Immersion in the Auditory Sublime}

In a quote from the book related to his piece based on geophysical data, the composer John Luther Adams wraps up many of the themes that will concern me in this section:

The music of The Place [Where You Go to Listen] is produced by natural phenomena. But this is not a scientific demonstration of natural phenomena. It is a work of art. The essence of this work is the sounding of natural forces interacting with the consciousness of the listener. This is not a simulated experience of the natural world. It is a heightened form of experience itself. 
(...) Although I tried to minimize the evidence of my hand, I remain the composer. (Adams 2009: 8)

This quote touches upon the distinction between scientific demonstration and work of art; the problem of deciding who counts as the composer and who has control over the outcomes of the sonification process; and the question of what kind of experience is being offered up by the possibility and practice of sonification.

One might be led to believe that the answer to the first question already implies an answer to the second one: surely, if the sonification is meant to act as a demonstration of a scientific phenomenon, then the task of composition remains with the data, whereas a work of art, a piece of music, would ultimately be guided by the hands of a composer? But it is not so simple. For example, Milton A. Garçes' volcano sounds are firmly intended as demonstrations of a natural fact, yet he admits to sometimes "massaging" (interview Garçes) the sounds of the volcanoes: not just speeding them up to make them audible, but enhancing features that are aurally pleasing while removing those that are not. This is unproblematic for him, because it does not stand in the way of the scientific fact he wants to demonstrate: there are sound waves inside the volcano, and studying them tells us something about their behaviour. Might as well make it sound good.

On the other hand, many people who see themselves as composers and consider their pieces as art are less ready to manipulate the resulting sounds. John Luther Adams, quoted above, insists that he remains the composer, as the decisions "about the timbres, tunings, harmonies and melodic curves, the dynamics, rhythms, counterpoint and musical textures" (Adams 2009: 8) were his; but once the piece is up and running, he does not interfere with the resulting sounds, arguing that it as though the musical instruments were "slayed' by forces of nature" (Adams 2009: 115). For his Music For Solo Performer, Alvin Lucier talks about the need to "let alpha be itself" (Lucier 2005 [1995]: 58); when his composer colleagues suggested using his recordings of alpha waves as raw material for tape experiments instead of using them directly, without manipulation, in performances, he was abhorred, comparing that to doing "an imitation of a thing and not the thing itself" (interview Lucier). Elsewhere, Lucier stated that, when setting up a piece of music to be determined by natural forces or chance, it was inadmissible to pick only aesthetically pleasing results; that would be "a weak way of working. It means you don't really believe in the process." (Lucier 2005 [1995]: 232) Marcus Schmickler's Bonner Durchmusterung does contain dramaturgical elements, but only as additional, musical sounds that should be noticeable as such; they were not manipulations of the sonified data themselves: "That was 
rather important to me, staying quite straightforward in this regard, so that there would be no real manipulations." (Interview Schmickler, translated) Aesthetic decisions were, of course, made, but they were decisions of which synthesis methods and parameters to use, rather than editing the resulting sounds.

In other words, many of the composers working with sonification take the idea of "being true to the data" (interview Alexander) quite seriously. The idea of letting the data speak for themselves and not interfering as a composer seems to be very much part of what attracts many composers to sonification. It could be seen as part of a tradition of a "self-denying tendency on the part of many composers", who were compelled by "the possibility of removing the individual from the act of composition" (Willcock 2006: 226). Indeed, the shift from conceptions of music that stress its individuality, subjectivity and expression towards a more materialist and objective one, emphasising detachment and restraint, has been portrayed as one of the defining characteristics of twentieth century music (Morgan 1998), and "the resolute elimination of the artist's ego or personality from the artistic product" (Taruskin 2005: 55) has been presented as the common denominator of otherwise radically different avant-garde scenes in Europe and North America. For example, John Cage's experiments with astronomical charts have to be understood not so much as an attempt to communicate something about astronomy, but as a quest of "discovering means to let sounds be themselves rather than vehicles for man-made theories of expressions of human sentiments. (...) Not an attempt to understand something that is being said, for, if something were being said, the sounds would be given the shapes of words. Just an attention to the activity of the sounds." (Cage 1961: 10) According to Cage, this can be facilitated by drawing upon many different sources, be that random tables used in chance operations, imperfections in the paper upon which one is writing, or geometrical shapes. It is in this way, Essl (2007) argues, that Cage uses the astronomical charts of Atlas Eclipticalis. ${ }^{33}$

Cage's radical denial of any kind of meaning (beyond their sound-ness) of his sounds is an unusually radical stance among composers working with sonified data. For example, Alvin Lucier told me that Cage "didn't like my music so much" (interview Lucier) because Lucier focuses too much on the exploration of natural phenomena, rather than treating them merely as a source of sounds uncontaminated by the

\footnotetext{
${ }^{33}$ Yet I do not want to suggest that this was Cage's sole motivation for making supposedly non-musical phenomena sound: Cage was also fascinated with the sounds that surround us in our environment, including those that, like the sound of mushrooms growing, are not audible to our ears, at least not without technological intervention (Cage 1963: 34). Kahn (1999) provides a good discussion of Cage's occupation with these 'small sounds' and their amplification.
} 
expressivity of a human composer. But even Lucier's experimental interest in the phenomena of his music should not be confused with a scientific approach to the issue: "One of the reasons I'm a composer of this kind is because I don't understand these phenomena really well. And scientists say they do, and they do it to a certain point but I'm not so sure they really understand." (Interview Lucier) The engagement with scientific themes thus stems as much from a distrust of the limited approach of modern science as it does from a fascination with these natural processes and phenomena. What's more, Lucier insists that his Music for Solo Performer isn't even a piece about neurological phenomena, anyway: "It's about resonance more than it is about brainwaves" (interview Lucier).

Marcus Schmickler's Bonner Durchmusterung raises a stronger claim of making a statement about the subject matter at its core (in this case, 10 different astronomical subjects). Schmickler acknowledges that, in terms of the working process, working with scientific data is quite similar to algorithmic composition: "This kind of mode of operation is not so foreign to me, because I have worked a lot with algorithmic procedures and was therefore used to the emergence of a dramaturgy out of an algorithm." (Interview Schmickler, translated) ${ }^{34}$ But for Schmickler, making music based on these astronomical datasets was more than just another way of transferring the onus of making compositional decisions to extramusical processes: "Well, for me it was also about featuring a popular science theme, or about treating this in a popular science way. So I did want people who aren't experts in this domain to be able to comprehend what is going on here." (Interview Schmickler, translated)

The physicist Lily Asquith explains that the composers in her project were fascinated by the fact that the data represent "new sounds (...), new instruments, as it were" (interview Asquith). The composer Jenõ Keuler, who works with the astrophysicist Zoltán Kolláth on the Stellar Music project, was also interested in the sonifications of stars for their specific acoustic and timbral properties (interview Keuler). With this desire to include new, non-musical sounds in music composition, too, sonification fits right into broader developments in twentieth and twenty-first century music. In the past hundred years, composers have started to "focus upon the sonic and timbral properties that the pitch-centred notation system had marginalised" (Hugill 2007: 15), for instance by eliciting novel sounds "by playing the most commonplace instrument in unusual ways" (Brindle 1987 [1975]: 160) or by including machine noises in musical pieces (Bijsterveld 2008). Accordingly, the musical

\footnotetext{
${ }^{34} \mathrm{Schmickler}$ is not alone in drawing a continuity from working with algorithmic processes to modeling music based on data - see e.g. the comments by Andrea Polli $(2004,2005)$.
} 
fascination with sonification can partly be understood in terms of its ability to provide composers with previously unheard sounds.

John Dunn mentions another musical motivation for working with scientific data, describing this as a possibility to give a sense of "deep structure" to electronic music:

Music of all cultures is rich in tradition and convention. Not only do listeners expect to hear musical references they have become familiar with, but cultural and musical tradition also gives music its deep structure. This deep structure is not heard at the conscious level by most listeners, but it is an essential component of any musical work: it is the component that keeps our music fresh on repeated hearings. (Dunn and Clark 1999: 25)

According to Dunn, popular music mostly depends on extra-musical cultural associations to achieve this sense of deep structure, while classical music depends more on multiple layers of abstraction within the music itself. Electronic music, on the other hand, suffers from a lack of dedicated listeners because it has difficulties accomplishing this deep structure; it can borrow it from classical music, but that might mean to miss out on some of the entirely new possibilities that can be afforded by this new medium, which is exactly what Dunn is interested in exploring. Algorithmic processes as a compositional tool are a way of achieving deep structure, but not one that would attract many listeners, as they are "largely alien to our twentieth-century ears" (Dunn and Clark 1999: 27). Working with scientific data, then, seems to be a way out of this impasse, by giving the music a sense of deep structure that listeners relate to. Dunn poses that not all data are equally able to do so; in particular, he thinks that DNA "would resonate with the inner maps of humans, who are built upon this code" (Dunn and Clark 1999: 27).

While sonifications of genetics often play with the metaphor of inner maps of humans, those of astronomy toy with maps of a different kind: maps of the universe. Often, they explicitly link their endeavours to the notion of the 'music of the spheres', the idea of a cosmos where everything is in harmony, and where the movements of celestial bodies make a serene (if inaudible) music. According to Jamie James (1993), this idea has been a foundation of Western culture for many centuries, until it was disposed of in the nineteenth century by the Romantic movement, when cosmological themes in music were abandoned in favour of directing all attention inwards, to the human scale. However, James argues, Romanticism was a mere anomaly in the history of music, and once the composers of the twentieth century made a clean 
break with it, many of them have "returned, in their own eccentric ways, to the great theme that dominated music until the aberrant irruption of Romanticism" (James 1993: 16), to the "belief that the cosmos is a sublimely harmonious system guided by a Supreme Intelligence, and that man has a place preordained and eternal in that system" (James 1993: 19).

Could the sonification examples discussed above, then, be part of such a return to the large cosmological questions that have gone missing in the period of Romanticism? Not necessarily so, or at least not so simply; rather than warming up the old idea of a music of the spheres, I think that the makers and reporters of sonification are creating a specific contemporary form of the sublime, which I will call the auditory sublime.

To clarify, the belief in an underlying universal law, and the repudiation of the popular theory that the universe is governed by random laws and chaotic processes, is indeed what seems to have driven Ohno's work on the music of the genes in the 1980s. But many sonification examples are concerned not so much with absolute laws, nor with assumptions of preordained and eternal places assigned to man in a stable cosmos, but with reflections of changes in the relationship between humans and nature or the universe. For example, at the first performance of Marcus Schmickler's piece Bonner Durchmusterung, a fairly detailed booklet with program notes was handed out, containing brief descriptions of the ten sonified astronomical phenomena and an accompanying essay. The essay starts with a reference to the music of the spheres, but the epistemological reflections contained in it are a far cry from invoking universal laws of the universe; if anything, they raise questions about the extent to which it is possible to make any such statements, in the light of a problematic relationship between objects and the data that supposedly describe them and between images and reality. The piece itself consists of a fairly straightforward sonification of astronomical phenomena, combined with a visualisation that "treats the subjects more freely or more associatively" (interview Schmickler, translated). The visual elements were placed in an urban context, constantly referring to life in the city; at least in my own experience, this almost seemed to subvert any universal claims that could be made by the piece.

Willem Boogman's piece Sternenrest also treats an astronomical subject. The composition was created on the basis of astroseismological data provided by Conny Aerts, who met up with the composer several times to discuss its scientific contents (interview Aerts). But the subtitle of the piece, "stars don't make music", already suggests that Boogman is not trying to reveal the secret, unheard music of the universe. In a talk before a concert performance in Brugge in April 2009, the composer 
posed that the piece was meant not so much to express anything about the star itself, but about the relationship between us and the star, and that the acoustic instruments in the (electro-acoustic) piece should represent human musical tradition (Brugge fieldnotes 2009).

The theme in these astronomical pieces, then, might be less the universe as it exists out there, and more what we, as human beings, project into it. Musical sonifications of geophysical phenomena, too, seem to concern themselves less with the expression of absolute and universal laws that determine life on Earth, but rather, with reflections on how humans relate to the environments that surround them. Yolande Harris' Sun Run Sun project reflects how "different technologies of navigation like the GPS are changing our relationship to the environment" (interview Harris). John Luther Adams' piece The Place Where We Go to Listen is deeply inspired by nature, but in the diary he wrote while working on its conception and other related essays, he spends as much time reflecting on climate change and the effects of human tampering with the Earth as he does observing the wonders of nature: "For decades my music has been grounded in my personal mythology of the North. (...) As global climate change continues to accelerate, my romantic vision of the North as a place apart has been challenged in an inescapable way." (Adams 2009: 102) Global warming is also a recurring theme on Andrea Polli's album Sonic Antartica, especially in the 15-minute track "I Don't Have the Data", which features snippets of interviews with scientists musing about their social and ethical responsibilities, the nature and limitations of objectivity, and the significance of different timescales. In the words of one of the interviewed scientists: "You know, we could completely screw up the Earth, and it would come back. The problem is, it might not come back for a million years. Now, to the earth, a million years, who cares, it's nothing. But in human history, you fucked yourself."

So, if the use of sonification is not a mere return to the earlier themes of the 'music of the spheres', what is it then? How does sonification manage to create an interest in the resulting sounds, how does it create a sense of listener involvement, or, as Dunn (Dunn and Clark 1999) would put it, of 'deep structure'? With his genetic sonifications, Dunn assumes that this interest is inherent in the nature of the data: because humans are made up of genetic material, they experience affinities towards genetic music. I disagree with this notion, and argue that the affinity has to be created; Dunn's suggestion that it is inherent to the data is itself an element of its rhetorical construction. As I will argue in the remainder of this chapter, the fascination with sonification is based on its creation of expectations of sublime experiences. 
Notions of the sublime have famously been explored in the eighteenth century by Immanuel Kant (who calls it "das Erhabene") and Edmund Burke, who have described it as a sense of awe and terror in the face of the wonders of nature and works of art, distinct from the concept of beauty. In the twentieth century, this idea has been expanded by David Nye (1994) to encompass technology, investigating these "repeated experiences of awe and wonder, often tinged with an element of terror, which people have had when confronted with particular natural sites, architectural forms, and technological achievements" (Nye 1994: xvi). More importantly for my purposes, Nye poses that the sublime is socially constructed; there is no inherent tendency towards eliciting sublime emotions contained in any objects of nature, architecture or technology.

The sublime is usually discussed in terms of visual qualities, although Burke already points out that "the eye is not the only organ of sensation, by which a sublime passion may be produced. Sounds have a great power in these as in most other passions. (...) Excessive loudness alone is sufficient to overpower the soul, to suspend its action, and to fill it with terror." (Burke 2008 [1757]: 75) David Nye also acknowledges that the sublime "cannot be comprehended through words and images alone" (Nye 1994: xi); it has to be actually experienced and, preferably, "apprehended with all five senses" (Nye 1994: xx). Unfortunately, neither Nye nor Burke systematically explores the role of the senses in the perception of the sublime. But indeed, the perception of the technological sublime is not a purely visual matter - a good example of the role of sound might be exclamation of the blind eponymous character in Mickey Newbury's song "Cortelia Clark", who, after travelling to witness the first Southbound run of the Bluebird Special train and inquiring whether the engine was black or red, exclaims, "That's the loudest thing I've ever seen!" The capability of sound to convey sublime experience has been recognised by the makers of records targeted at an audiophile market in the 1950s, which "thrilled listeners with sounds of trains, planes, and automobiles, of bullfights and bullfrogs, of storms and surf" (Barry 2010: 117). Similarly, the sounds of rocket launches (interview Kurtz) or of volcano activity (interview Garçes) can evoke a sense of awe. Here, sound is not purely a matter of audition, but of tactility, as "to be surrounded by sound is to be touched or moved by it" (Connor 2004: 153). As Donald Kurtz describes, the sound of a rocket launch "is deeper and louder than thunder, and it shakes the ground like a giant earthquake, and the sound just rumbles and pounds into your body" (interview Kurtz).

These synesthetic elements are often emphasised in sonification, which is frequently a matter of more than just sound, such as in the combination of sound and visuals e.g. in Marcus Schmickler's Bonner Durchmusterung or in John Luther Ad- 
ams' The Place Where You Go to Listen. Adams even describes that in the early phases of the project, he started every day wondering: "How would this light, how would this weather sound?" (Adams 2009: 12; original emphasis) Similarly, as mentioned in the section on the sonification of high energy physics, the sonification of the Higgs boson was motivated in part by synesthetic imaginations. The visual design in Gerold Baier and Thomas Hermann's sonification of EEG data at the Wien Modern festival is another interesting case, precisely because of its minimalism (white letters hovering on a black background to explain the sounds that are about to be heard, e.g. an epileptic absence seizure; complete darkness while the sounds are heard). The darkness might indicate an absence of vision, but it does so in a way that draws attention to the inability to see, resulting in a state where both the attention to sound and the awareness of darkness (not at all the same thing as a mere absence of visual stimuli!) are heightened, creating a somewhat oppressive atmosphere. ${ }^{35}$ After the concert, Gerold Baier asked me what I thought of the performance - but not by enquiring whether I enjoyed it, but by asking, "so, was it intense?" I confirmed that it was, and that I suspected that this was intentional. Baier acknowledged this; the goal was to convey the feeling that one would not be able to withdraw from the experience, just like an epileptic could not withdraw from a seizure (Wien Modern 2008 fieldnotes). This is a perfect example of the sublime in sonification: the sense of aesthetics being conveyed draws not so much on notions of beauty, but on the ability of the combination of (loud) sounds with darkness to elicit a frightening and oppressive atmosphere. Darkness, which has been recognised as an important element of the sublime since Burke (2008 [1757]: 54f., 73f.), heightens the sublime experience.

Invocations of the sublime have been argued to be among the most powerful rhetorical tools available for popular science writing, and can be used to give appeal to even the most abstract scientific theories. For example, in abstract biology, a sense of sublime can be textually experienced for objects and ideas that have no physical manifestation at all, by drawing upon metaphors from tried-and-true sources of the sublime, such as oceans and mountaintops. In this domain, the sublime "can be rendered in words, but the words do not describe something which anyone is ever going to encounter in life, or have any direct sensory engagement with" (Turney 2004a: 96).

Indeed, when scrutinising the sonification examples discussed in this chapter, it becomes noticeable that many of them fall into one of two extremes. On the one hand, sonification seems to proliferate in fields like high-energy physics or genetics, where it - like in the Turney quote above - makes phenomena accessible to the

\footnotetext{
${ }^{35}$ This describes my own experience of the concert, as well as those of several other concert-goers in overheard post-concert conversations.
} 
senses that have hitherto been closed off for sensory perception; elementary particles and genes exist, or are predicted to exist, on a scale that is simply not accessible to human perception. On the other hand, it is especially popular in the study of phenomena that are already familiar sources of (usually visual) sublime imagery, where the sonification provides an additional sensory channel to the perception. For instance, celestial bodies have a long tradition of eliciting sublime emotions, enough to earn astronomy the nickname of 'the sublime science' (Zimmerman 2003); volcanoes have always been a favourite source of the sublime, as they seemingly provide "conduits into the very bowels of the earth" (Williams 1990: 87), and earthquakes - specifically the Lisbon earthquake of 1755 - have even acted as a catalyst in the very development of philosophical ideas on the sublime (Ray 2004; Regier 2010). Sonification thus seems to be especially popular in fields that either have a long tradition of rousing sublime emotions, or that are particularly in need of rhetorical strategies of the sublime because the phenomena they study allow no direct sensory experience in themselves.

Sublime imagery can be found in sonification examples from all of the fields discussed in this chapter. It pops up in relation to the wonders of the cosmos, the dangers of the earth, the inconceivability of particles, the powers of genes, the complexity of the brain. Words like "eerie" are common descriptors of sonified sounds, regardless of discipline (Branton 2006; Courtland 2010; Gann 2006; PhysOrg 2010). The project Sun Run Sun, for instance, promises to treat navigational data in such a way that "your experience of that GPS data was not on a map in location coordinates, but was something much more ethereal, really, something you can't grasp in such a logical way, by using sound" (interview Harris). A sonification project in meteorology provides another telling example of an invocation of the sublime:

Some meteorologists call themselves 'storm hunters.' They travel far and take considerable physical risk in order to experience a hurricane or tornado. Do they take such risks because the physical and emotional exhilaration enhances their scientific understanding of the storm? Storm hunters would most likely answer in the affirmative. They experience the sound, scale and physical properties of the storm as well as its direct effect on the environment. A storm experienced only through visualization, whether animated or still, does not convey this visceral information. Scientists must use their memory and their imagination to understand how a storm might feel to people experiencing it. (Polli 2005: 31) 
The storm, here, is an instance of the sublime: dangerous, surely, but also thoroughly impressive and aesthetic. It needs to be experienced firsthand to be understood; again, a classic property of the sublime. However, sonification - unlike visualisation is thought to be able to bring some of the thrill of experiencing a storm to the listeners at home.

David Nye (1994) points out the religious or quasi-religious character of the sublime, and indeed, the rhetoric of sonification often calls for religious experiences. This is fitting, considering that in the traditional order of the senses, audition "is more in demand in matters involving not so much the recognition of truth as the guarantee of salvation and obedience to God's commandments" (Jütte 2005: 66).

In the diary he kept while working on The Place Where You Go to Listen, composer John Luther Adams wrote: "For me, the practice of music is a practice of faith. Composing is an act of devotion." (Adams 2009: 28) Robert Alexander thinks that his sonification of solar wind data could work as a kind of "collective meditation" (interview Alexander) - and seems to have some success in bringing this across, as it has been described as "appropriately primal and otherworldly" (PhysOrg 2010). The sonifications of the Higgs boson at CERN also come with their share of religious associations. Not only do media reports about the project pick up on the term 'God particle' for the Higgs boson (Taylor 2010), a term that was coined in a popular science book by Leon Lederman (Lederman and Teresi 1993), but the researchers themselves play into this connotation: "And Mr Endrich says that those who have been involved in the project have felt something akin to a religious experience while listening to the sounds. 'You feel closer to the mystery of Nature which I think a lot of scientists do when they get deep into these matters,' he said. 'Its [sic] so intriguing and there's so much mystery and so much to learn."' (Ghosh 2010) Even the physicist Lily Asquith, a self-described atheist who professes to be "very keen to avoid going down that road, actually" (interview Asquith) when asked about the religious connotations that are often brought up in media reports, has been quoted describing the project as a "way of showing the awe-inspiring magnificence of it all" (Asquith quoted in Evans 2010).

Sonification tries to provide these exceptional experiences largely by the promise of a particular sense of presence, of being immersed and soaking in sound. This promise, according to Frances Dyson, is at the very core of audio technology:

Sound is the immersive medium par excellence. Three-dimensional, interactive, and synesthetic, perceived in the here and now of an embodied space, sound returns to the listener the very same qualities that media 
mediates: that feeling of being here now, of experiencing oneself as engulfed, enveloped, absorbed, enmeshed, in short, immersed in an environment. (Dyson 2009: 4)

As Mark Grimshaw (2012) points out, the concept of immersion is notoriously hard to pin down; nobody quite seems to know what it is. One thing it does, in any case, is to connote a presence, a sense of being there, being in the middle. In sonification, this sense is often created by putting the listener in the centre, surrounded by sound.

In some cases, this happens only rhetorically; for example, when M.A. Clark ponders about what it would sound like to "walk into a living cell" (Dunn and Clark 1999: 25) and thus invites listeners to imagine themselves in the middle of a cell. A similar promise is made by the sonifications of the gold collisions in the Relativistic Heavy Ion Collider, which give us an idea of "what this fireball of quarks and gluons would sound like to an observer embedded within it" (Courtland 2010). A neurology sonification by Weinberg and Thatcher also promises to "enable users to perceive and explore the data in an immersive manner, providing a direct and intimate connection to the information" (Weinberg and Thatcher 2006: 9).

In other cases, the sense of immersion is created spatially and technologically; for example, in Willem Boogman's Sternenrest, the audience is surrounded by the 192 speakers of a Wave Field Synthesis loudspeaker system as well as some acoustic musicians: "Thanks to the possibilities inherent in the Wave Field Synthesis loudspeaker system, the audience can imagine itself inside the star" (Boogman n.d.). A similar effect is created in a DNA composition by Thilo Krigar: "The piece is written for a chamber ensemble, and the musicians are expected to move around the room, giving the audience the feeling of being surrounded by the double helix and the biochemical processes in the cell. Loudspeakers projecting computer-generated sound add to the surround effect.” (Mössinger 2005: 280) In Adams' The Place Where You Go to Listen, "when you enter, the 14 speakers envelop you in sound" (Living on Earth 2006).

As these examples already indicate, the sense of immersion depends on a plethora of technology; as Grau (2003) has pointed out, immersion often depends on the creation of an artificial environment. Yet curiously, the sense of immersion and of experiencing the sublime is often heightened by making the technology invisible and transparent. This is not just true for a sense of auditory immersion, but is equally the case for narrative or visual strategies of immersion: "In the literary domain, no less than in the visual arts, the rise and fall of immersive ideals are tied to the fortunes of an aesthetics of illusion, which implies transparency of the medium.” (Ryan 2001: 4) 
In the previous section, we have already discussed one way in which the technology is often made invisible: with the help of metaphors that imply that the musicality is inherent to the data itself. As Lakoff and Johnson (2003 [1980]) point out, metaphors highlight some aspects of a phenomenon and, in doing so, hide others. What is being hidden with these metaphors of star songs, volcano voices and brain symphonies is the fact that the phenomena themselves usually have no sound; a process of sonification, aided by technology and guided by human beings, is necessary to make them sound. These interventions vanish with the metaphors implying that the sound is already engrained in the phenomena. They become even more invisible if the technology used in the process itself is made transparent, which is the explicit goal of some artists working with sonification. For instance, John Luther Adams reflects that "[the computer] allows me to hear and give voice to visible, tactile, invisible and inaudible vibrations of earth and sky. But the most sophisticated technology is transparent. (...) It's perhaps ironic that this imaginary world intended to celebrate our connections to the natural world could not have been created without the machine of the computer." (Adams 2009: 5)

\subsection{Conclusions}

In this chapter, I have given an account of the public life of sonification: its existence in newspapers and magazines, on radio airwaves, in concert halls, on music recordings. I have first given an overview over how sonification is employed in the

public sphere for the data from five different scientific disciplines: the geosciences, astrophysics, high energy physics, neurology, and genetics. I have then analysed these instances in two parts. First, I have looked at the role of sonification in the process of science communication and popularisation, and in particular at the role of metaphors in talking and writing about sonification. I have shown here that sonification is employed as a new strategy of science popularisation, in reaction to an increased need to create public interest and financial support for scientific research. The metaphors used to describe sonification often serve as an illustration and reinforcement of existing metaphors, as a way of strengthening existing models of thought. The question, however, remained of why sonification seems to be able to elicit the kind of fascination it does: if it rarely seems to invite entirely new ways of thinking and talking about scientific phenomena, then what is it that it can offer, what is it that makes it so fascinating to so many different scientists, artists, audiences? Why do scientists turn to sonification instead of - or next to - working with any number of other strategies of science popularisation? 
This question has been answered in the second part of the analysis. I have first examined some of the motivations given by composers and musicians for working with sonified data, showing that the turn to working with data fits into broader musical developments of the twentieth and twenty-first centuries, such as the renunciation of the individuality and expression of the composer, the search for previously unheard timbres and sounds, or the efforts of broadening audience interest in electronic music by giving the listeners something to relate to in otherwise very abstract music. I have then argued that what sonification offers, in popular science as well as in music, is not so much entirely new knowledge or ways of thinking about the world, but rather a new way of experiencing it. This is not meant to downplay or deny the possible epistemological significance of sonification; our experiences of the world, after all, do influence the way that we think of and about it. Yet the promise of a new kind of experience, more so than that of a more thorough understanding of science and nature, seems to be in the foreground when it comes to most sonification examples we might encounter in media reports, public lecture rooms, audio recordings or concert halls.

But what is this different kind of experience that sonification seems to offer? It is emotionally loaded, visceral, perhaps even mythical and spiritual; however, after "a permissible eruption of feeling that briefly overwhelmed reason, only to be recontained by it" (Nye 1994: 5), at least at the best of times it also opens up room for epistemological reflection. I have named this kind of experience an auditory sublime, because of the sense of awe and enthrallment that sonification is supposed to evoke. Of course, the auditory experience offered by sonification is not the same as that of hearing unmediated sounds: for example, hearing the sonification of a volcano is different from being near it and taking in its natural soundscape, and this difference is usually acknowledged. However, certain rhetorical, musical and technological strategies are used to give people the sense that the sonification indeed represents something that is true to the volcano: perhaps not the exact same experience as being near a real-life volcano, but possibly even something better, something that wouldn't even be audible or visible if you were actually near the volcano, something that comes from deeper within the volcano, and from a deeper understanding of the volcano. It's not about sounding like a volcano, per se, but about being true to the volcano - or, perhaps more accurately, about allowing listeners to believe that the sonification is 
true to the volcano. ${ }^{36}$ In some cases, indeed, the metaphorical discourse suggests that it is like being inside the volcano.

My point here is not that sonification is sublime or offers access to sublime experiences by definition; the sublime is not inherent to sonification. Rather, the makers of sonification (and those who report about it in the media) seem to create and evoke this sense of the sublime, this expectation that, when listening, you are about to experience something sublime. The sublime is thus being constructed by various rhetorical, metaphorical, musical, spatial, and technological means. It helps that the notion of an auditory sublime plays into many of the qualities that are traditionally associated with the sense of hearing, where sound is thought to be particularly good at creating immersive and emotional experiences (see chapter 1).

Of course, we know from historical research (Nye 1994) that the creation of an expectation of sublime experiences does not necessarily result in such experiences: the example of the tourist who, after having read extensively about the wonders of the Niagara Falls, finally gets to see them in person and feels nothing, is just one example. The question of how effective the construction of sublime sonification experiences really is was not addressed systematically in this chapter, since the focus was on producers and communicators of sonification, and perhaps their imaginations of ideal listeners, but not on real-life listeners themselves. The proliferation of sonification examples might be an indication that sonification is not entirely ineffective at realising the sublime experiences it hopes to evoke, but this is based largely on speculation and anecdotal evidence.

The sense of sublime afforded by sonification is a thoroughly mediated experience. By various technological means, it offers access to phenomena that are too far away, too close-by, too big, too small, too high, or too low to be experienced in an unmediated way. Curiously, this mediated experience often becomes most convincing if the technology without which it would be impossible, steps into the background, perhaps even becomes transparent and invisible.

I have mentioned various aspects that contribute to the sense of an auditory sublime, such as metaphors that imply an inherent musicality of the data, religious innuendos, and technological practices that heighten synesthetic or immersive experiences. It is important to note that none of these elements are common to all instances

\footnotetext{
${ }^{36}$ This formulation follows Jonathan Sterne's historical musings on the notion of 'perfect fidelity' in audio technologies: in striving for fidelity, according to Sterne, the point was not to produce a perfectly silent apparatus, but rather "to produce an apparatus that listeners could pretend was silent" (Sterne 2003: 259f.; original emphasis). Fidelity was thus a "set of social and sonic relations in which participants could have faith in" (Sterne 2003: 274).
} 
of sonification. For example, the technology is made invisible only in some cases other sonifications, indeed, go the opposite way of basking in the shine of the gadgets that made them possible. This does not pose a problem to my argument, as I am not trying to give a hard-and-fast definition of the auditory sublime that invariably holds true for all instances of sonification in the public sphere. Rather, I think of them as connected by a web of family resemblances. Just as Wittgenstein points out that there is not a single element that connects all proceedings that are referred to as 'games', yet that all games belong to a "complicated network of similarities overlapping and criss-crossing” (Wittgenstein 1969 [1953]: \$67), the auditory sublime is not about the presence of any one particular defining characteristic, and yet there seems to be enough of a family resemblance between the different instances to allow characterising them as such.

In this chapter, I have explained the success of sonification in the public sphere with its promise of offering sublime experiences. In the following chapters, my focus will shift from the public sphere to a specialised scientific community, which seeks to establish sonification as a scientific method. 



\section{Jam Sessions and Killer Applications: Disciplines and Boundaries of Sonification}

"The ear has somehow had a bad lobby for a very long time." (Interview Dombois, translated) With this statement, one of my interviewees describes what he regards as a cultural-historical constellation in which visuality has come to dominate, while the status of listening has been epistemologically marginalised. An important factor in this sensory imbalance, he argues, is the relatively recent development of technologies allowing the reproduction of sound: "If I heard a sound and could not listen to it again, that's not an authority. If I look at a picture and I can look at it again, it becomes an authority." (Interview Dombois, translated) The existence of such a "cultural bias towards visualization" (Hermann 2002: 2) is a recurring theme among sonification researchers, and it is no wonder that they often counter this perceived bias with an emancipatory rhetoric that promises to free the ear from its marginalised status within science, to lobby for the acceptance of sound as an authority and let human listening skills unfold their true potential. This move often involves attacks on the traditional conventions of science, and practitioners frequently take inspiration outside of science, notably in the artistic world.

In this chapter, ${ }^{37}$ I want to discuss the emergence and consolidation of a community dedicated to sonification, focusing on the International Community for Auditory Display (ICAD) and their annual conferences, the International Conferences on Auditory Display (also abbreviated as ICAD). ${ }^{38}$ This community invests considerable energy into 'lobbying for the ear', and in turn, it justifies its own existence in part by the need to engage in such lobbying work. A parallel to the discipline of humancomputer interaction (HCI) can be found here: in a study of the disciplinary rhetoric of this field during its early history, Cooper and Bowers (1995) have shown that the discipline derived much of its legitimacy from its claims that the needs of users have been neglected in traditional computer science and that HCI can represent and advo-

\footnotetext{
${ }^{37}$ This chapter is partially based on my contribution to the Oxford Handbook of Sound Studies (Supper 2012).

${ }^{38}$ I will use the acronym ICAD to refer to the conference as well as the community, and the difference between the two is often insubstantial (after all, the main activity of the community consists in meeting at the conference). Wherever disambiguation is necessary, I will ignore semantic redundancy and refer to the "ICAD community" or "ICAD conference", respectively.
} 
cate for the interests of users. The disciplinary rhetoric of sonification often fits a similar mould, but the interests that it claims to advocate are those of the ear, or more precisely, the neglected listening skills and the epistemological status of knowledge gained through listening. Therefore, I will analyse the strategies employed by the sonification community to transform listening to data into a legitimate way of dealing with scientific information. I will do so by focusing on the boundary work of this community.

The boundaries of science have attracted much interest in the last few decades. Steven Shapin has thrown light on what these boundaries entail:

Bounding a practice is a way of defining what it is, of protecting it from unwanted interference and excluding unwanted participants, of telling practitioners how it is proper to behave within it and how that behaviour differs from ordinary conduct, and of distributing value across its borders. (Shapin 1992: 335)

A notable example of the academic interest in boundaries is the concept of boundary work, developed by Thomas Gieryn (1983, 1995, 1999). Boundary work refers to a mechanism by which scientists, in pursuit of cultural authority, demarcate their own work from other activities, such as politics, engineering or religion, by selectively making rhetorical use of certain characteristics of scientific work. Gieryn (1999: 15ff.) distinguishes three different types of boundary work: expulsion (the boundaries of science are drawn in such a way that opponents are cast out), expansion (actors try to extend their cultural authority into spaces already claimed by others), and protection (the boundaries of science are reinforced to protect its autonomy from outside influence).

The concept of boundary work was developed in response to essentialist approaches in the philosophy and sociology of science, in which particular principles (such as Popper's falsifiability, or Merton's social norms) were declared as universal and defining ingredients of science, which demarcate it from non-science or pseudoscience. In contrast, Gieryn's constructivist approach recognises that the boundaries of science are the shifting and mutable outcome of an ongoing negotiation process:

Constructivists argue that no demarcation principles work universally and that the separation of science from other knowledge-producing activities is instead a contextually contingent and interests-driven pragmatic accomplishment drawing selectively on inconsistent and ambiguous attributes. (...) Essentialists do boundary work; constructivists watch it get 
done by people in society - as scientists, would-be scientists, science critics, journalists, lawyers, and other interested parties accomplish the demarcation of science from non-science. (Gieryn 1995: 393f.)

More recently, the concept has been extended to not only analyse boundary work between science and non-science, but also at the internal boundaries of science, those between disciplines (Amsterdamska 2005; Burri 2008a). This chapter provides an analysis of the boundary work of sonification. In order to position their work and infuse it with legitimacy, the sonification researchers engage in negotiations of the boundaries of their field, attributing it with certain qualities to establish its cultural authority and demarcating it from other endeavours. The boundaries at hand are those between science and non-science (notably art), as well those between sonification and other disciplines.

The topic of boundaries has also received significant attention in recent years outside of the study of science. Lamont and Molnár (2002) provide a thorough literature overview, and I will not attempt to outdo their efforts of comprehensiveness here. Instead, I will only name two particularly fruitful examples of studies of boundaries from fields other than STS: Appelrouth has studied the boundary work in the media discourse about early jazz music, showing that the meaning assigned to jazz varied significantly between different sets of actors, such as members of the world of high art music, popular musicians, civic or political leaders, and general intellectuals. He concludes:

Actors are not free to fashion a limitless range of discursive strategies, nor are they inclined to do so. Instead of being a random or arbitrary affair, efforts to legitimate particular definitions of reality are grounded in the institutional and discursive resources accessible within a given field. These resources reflect the distribution of various forms of capital that hierarchically structure all fields. (Appelrouth 2011:239)

While I will not be following an explicitly Bourdieusian framework in this chapter, as Appelrouth does, it is worth considering that how different actors define a field is not purely random, nor based entirely on personal fancies, but in fact often to a large extent determined by their own position in the field and in larger social and cultural contexts.

Studying the societal discourses about immigration in the United States and Europe - the former dominated by concerns about the rise of importance of Spanish due to immigration, the latter by concerns about the increasing importance of Islam 
- Zolberg and Woon (1999) have focused on how the boundary between "us" and "them" is drawn in these debates. While their analysis of the historical and social circumstances giving rise to current political concerns is impressive in its own right, their main contribution to the study of boundaries is that they make a useful distinction between various types of boundary work. Their classification is quite different from Gieryn's, because it distinguishes not on the basis of different directions of boundary work (expulsion means narrowing the boundaries, expansion means extending them, and protection means reinforcing them in the same position), but rather in terms of how far-reaching and structural the consequences of such boundary work are. Zolberg and Woon distinguish three different patterns of negotiations between immigrants and the receiving society: individuals can cross boundaries, without any fundamental changes in the structure of society (e.g. when they replace their native language with the language of the host country, or convert to the dominant religion of that country); boundaries can be blurred (when multiple memberships and overlapping collective identities become possible); and finally, boundaries can be shifted, which refers to a process of a fundamental redefinition of a group's identity in which the line between members and non-members of the group gets systematically redrawn. This distinction is useful in considering not only how the practitioners of sonification draw the boundaries of their own field, but also to what extent these can have implications for the boundaries of science on the whole. While I do not claim that the dynamics between sonification and the science system are equivalent to those between immigrants and the society into which they enter - for one thing, science is not ruled by overarching governing bodies in the same way that countries are - I think it can be fruitful to consider the extent to which the boundary work of sonification does, or has the potential to, fundamentally restructure the relationship between science and art.

In order to study the boundary work and community formation of sonification, I will proceed in five steps. In the first section, I will study the emergence of a core community dedicated to sonification and analyse how, and with what effects, this community writes its own history. The second section will show how the design of academic conferences is used to give shape to the community and to establish a sense of collective identity. In the third section, I will study debates about how to best define the field, as well as their implications for who may (or may not) legitimately speak for sonification. The fourth section is dedicated to the way in which the community is shaped by its expectations for the future, and specifically by its attempts to find a 'killer application'; where the first section dealt with how the community writes its own past, now its anticipation of the future comes into focus. In the fifth and final 
section, I will zoom in on one particular borderline where (albeit peaceful) boundary conflicts loom large in the domain of sonification: that between science and art.

\subsection{Founding Fathers and Pompous Names}

In this section, I want to look into the history of the sonification community. At times, my account might read as coming dangerously close to rendering the history of sonification as a founder myth, an approach that has been (rightfully) problematised by researchers who have argued that "the teleological unfolding of a 'core idea' or the persistent efforts of single researchers, indeed even single groups of researchers in the same field, are insufficient to 'found' disciplines" (Lenoir 1997: 51f.; also see Bensaude-Vincent 1983). What may appear as a shortcoming of my account is in fact a deliberate choice. My intention is not to re-write the standard history of sonification for improved historical accuracy, but to analyse the historical narratives that are created within the sonification community itself. My undertaking therefore links up to scholarship in the history of science about the legitimising function of disciplinary histories (Graham, Lepenies, and Weingart 1983), and aims to analyse how history is drawn upon to establish a sense of identity and to give shape to a community in the present tense. For this purpose, it is more important to ask what kind of history is passed down to following generations of researchers, be that through historical overviews in scholarly publications or through anecdotes told in informal settings, than to scrutinise these narratives.

If there is such a thing as a date of birth of the sonification community, a moment where "research [started to be] done systematically" (Vogt 2010: 21), it would probably be listed as 1992. In that year, Gregory Kramer organised the first ICAD conference - a fact that earned him the status of the "grandfather or the father of the field" (interview Brazil) in the eyes of many sonification researchers. The first conference is described as laying "the foundations for developing this area of interest into a scientific discipline" (Frauenberger 2009: 57) and as the real starting point of sonification research:

One can say that the history of sonification research officially began with the first International Conference for Auditory Display (ICAD) in 1992, organised by Gregory Kramer to bring all the researchers working on related topics, but largely unaware of each other, into one research community. (de Campo 2009: 16) 
After the initial meeting in 1992, ICAD was held twice more at a biennial interval, before changing to an annual rhythm.39 According to Alberto de Campo, "the yearly ICAD conferences are still the central event for researchers, generating much of the body of sonification research literature" (de Campo 2009: 16).

As Gregory Kramer explained a decade and a half after the initial conference, his interest in sonification took shape while working at the Santa Fe Institute. As an electronic composer exposed to research in chaos theory and complex adaptive systems, he thought of the possibility of "using the tools of electronic music" (interview Kramer) for the purposes of scientific research. At the time, he was working on an electronic music instrument of his own, and had contacted Robert Moog, the inventor of the Moog synthesiser, 40 who promised to build an instrument according to his specifications:

Out of every single key that I would play, I could get an output based on the placement of my finger on each key, left to right, forward back, how much area of my finger on the key, the up-and-down movement of the key, the absolute value, the velocity of the key, the pressure afterwards, and these kinds of things, out of every key. So I was looking at the problem of having all of this data to control all of these output processes. (...) So when I did go on to the Santa Fe Institute, I was steeped in this thinking about data going through a map to control sound. (Interview Kramer)

The data from the complex systems studied at Santa Fe reminded him of the data he was dealing with in his electronic instrument, and from there, it was "just a jump to controlling sound and then try to listen to what's happening in the data" (interview Kramer). The original plan of using his sonification system with the aforementioned instrument did not materialise, as the keyboard was left unfinished; yet the idea of expressing data as sound did take off in other ways. As soon as he started working on this issue, Kramer began to investigate similar work that had already been done:

That was when I went home and started seeing what else was done, and there was no web at the time, so I was doing a lot with phone calls and e-mails and expecting that at any point I would come upon a rich vein of work. And I didn't. (...) But you know, there was a scattered paper here and there, most of

\footnotetext{
${ }^{39}$ However, no full conference took place in 1999, although a one-day workshop was held at a joint conference of the Acoustical Society of America and the European Acoustics Association.

${ }^{40}$ For an extensive history of Moog's instrumental innovations, see Pinch and Trocco (2002).
} 
them had occurred in the mid-'80s, '85, '86, effectively nothing since then. (Interview Kramer)

Soon, having built up a network of disparate researchers who were, or had been, doing sonification work, Kramer set out to organise the first ICAD conference. Despite being labelled an 'international conference', the character of this gathering, with its 36 (predominantly American) attendees, was closer to a workshop, and a rather personable one at that: the participants' names are printed on the back of a t-shirt commemorating the event, and the proceedings volume (Kramer 1994b) comes with a group picture. Gregory Kramer explains that, even prior to the first conference, it was never intended as a one-time congregation; he recalls thinking that

this is a field, this could be, this should be, this will be, a field. (...) So calling it something as pompous as the International Conference on Auditory Display, when really it was a handful of researchers doing something, a handful of researchers not doing anything, and a handful of people who were kind of interested maybe - you know, it's a little bit of a reach, but I trusted it. (Interview Kramer)

This desire to establish a new field along with the conference is noticeable in the book publication of the proceedings (Kramer 1994b). The book, intended to lay "some good theoretical groundwork" (interview Kramer), contains not just a collection of conference papers and an accompanying CD, but also a lengthy, historically informed background paper on auditory displays and an annotated list of resources and publications.

In deciding to found a new field, Kramer made decisions about what the boundaries of the community should be. As one of the participants of the first ICAD put it, "Greg went down and picked out exactly what he wanted in it" (interview Hayward). Retrospectively, Kramer mentions several criteria that were relevant in deciding what shape to give to the new field, some of them of an explicitly strategic nature. For instance, certain actors were approached because their employment at major industrial or governmental institutions seemed promising in terms of institutional recognition and funding (interview Kramer). In terms of the research covered by ICAD, Kramer was concerned with building up critical mass. This meant going beyond his core research interests of using sound in the analysis and display of complex datasets, into issues such as audio in user interfaces and virtual environments: 
And, so, if it had been really just what most interested me, ICAD would have just been data sonification, but I realised it couldn't be, in part because there just weren't that many people doing sonification, so we couldn't get enough critical mass. And also because I was realising that the nature of the field is such that it doesn't have hard and fast boundaries. So for example, if you have a system of computer alerts, as soon as you introduce any dynamic data to that alert, you've crossed the boundary into a little sonification. So where do you draw the lines, you know. And so I decided to be inclusive. (Interview Kramer)

Despite this intention to be inclusive, Kramer did draw a line somewhere, deciding that issues related to audio alarms should not be part of the conference, as alarms were "a huge field, (...) well-established, (...) they didn't need ICAD" (interview Kramer). Even with this restriction, Kramer remarks that at times it was tricky to ensure that data sonification would not get "swamped" by other themes.

To this day, the volume containing the first conference proceedings remains one of the most-cited resources for the sonification community; indeed, it has been referred to as the "main founding document of this research domain" (de Campo 2009: 16), which "defines the field and its objectives" (Ballora 2000: 3). The introductory chapter by Kramer is especially interesting for its historical account of the field and discussion of previous examples of auditory displays, such as the Geiger counter, sonar or heart monitors in the operation room (Kramer 1994a). The paper remains one of the most comprehensive historical overviews, and is frequently referred to when authors give a rundown of the history of the field, such as in the dissertations of Ballora (2000), Hermann (2002) and de Campo (2009). In the latter text, the function of such a historical overview is made explicit: "Employing auditory perception for scientific research was not always as unusual as it is considered in today's visually dominated scientific cultures; in fact, sonification can be said to have had a number of precursors." (de Campo 2009: 14) Several of the examples that follow are not sonifications in a strict sense (involving a transformation from data into sound), but instances of listening to sounds that are already out there, such as doctors listening to the internal sounds of the body or car mechanics listening to machines. These examples are used to construct a sense of continuity with the past and therefore help to legitimate the existence of a field of research. As scholars of disciplinary histories have argued, "disciplines rely in part upon their historiography to demonstrate (...) their descent from an ancient tradition of knowledge" (Ash 1983: 144). 
One moment at which the interest in the historiography of the field became particularly manifest was the commemoration of the tenth ICAD conference. At the occasion of this anniversary, a special issue of the journal ACM Transactions on Applied Perception collected a number of reprinted papers from previous ICAD conferences, with the intention of providing "a historical record representative of the first ten ICADs" (Kramer and Walker 2004: 383), as well as serving as an introduction for newcomers. Each paper was accompanied by a brief supplementary article by the author(s), in which the original contributions were put into historical context and personal perspective, while the entire collection of papers was fronted by a brief introductory article by Kramer and Walker (2004). The most striking feature of this article is how formal it makes the field appear. It does so by outlining, in great detail, the selection process through which the papers for the special issues were chosen and the criteria that were applied to ensure that those papers were "of high quality, contributive to the field of Auditory Display, representative of ICAD as a whole, and include papers from every conference to date." (Kramer and Walker 2004: 384). The special issue aspires to be "a solid indicator of the status of the field" (Kramer and Walker 2004: 384), but I believe that such collections do more than merely passively reflect the current state of the art; rather than passively mirroring the development of the field into a "more unified and continuous line of publication" (Kramer and Walker 2004: 384), these commemorations function to actively create and perform such a sense of continuity and unity.

The editorship of the special issue and authorship of the introductory article marked one of Gregory Kramer's last formal appearances in the field of sonification; his last official role at an ICAD conference took place at the 2005 conference in Limerick, where he took part in the ThinkTank (a semi-regular component of ICAD conferences, usually held before the start of the main conference, at which graduate students present and receive feedback on their work) and gave a short speech on the development and future of the community, which was archived on the conference website. ${ }^{41}$ Kramer still holds a permanent position as chair emeritus on the ICAD board, and continues to view the field with sympathy, albeit at a distance. When we met up for an interview in July 2008 in the midst of a tour where he taught mediation retreats throughout Europe, he explained that he did not intend to go out of his way to attend future conferences, although he might come to one if it happened to be convenient and close-by. Nor was Kramer present at any of the three ICAD confer-

\footnotetext{
${ }^{41}$ See http://www.idc.ul.ie/icad2005/. The link to the recording is contained on the main page and was accessed on May $6^{\text {th }}, 2008$. As of June $16^{\text {th }}, 2011$, it is a dead link.
} 
ences I attended; and yet his absence was often remarked upon as an unusual circumstance in the course of my fieldwork.

This already shows that Kramer, as its somewhat mythical founding father, still carries some weight in the field. Indeed, his vision is regularly invoked by other community members. For instance, the fact that his main interest was in data sonification, rather than other areas of auditory display, is used to legitimise the importance of this type of research within the community: "The people who do sonification, um, love to sort of point out that that's originally what Gregory Kramer was trying to do" (Interview Brock). ICAD secretary Derek Brock also invokes Kramer when talking about the agenda he ran on in elections for the board:

AS: Do you remember what the agenda was?

DB: I do, I do. Gregory Kramer, at the Limerick conference, became fairly exercised about the fact that the conference was (...) acquiring a little bit of a hard science character to it that was (...) a little bit more rigorous or a little bit more, um, frozen in its sort of framework than he was comfortable with. One of the things that he loved about the whole idea of sonification and so forth was that it had a fair amount of sort of art involved in it. (...) And so, anyway, I don't know whether you know this about Gregory, but he's kind of a Buddhist mystic.

AS: I know that, yeah.

DB: And he's gotten completely out of the field, and he's a wonderful guy, and so forth. (...) And so when he says something to us, we kind of listen up. So he was very concerned with this, the fact that (...) our reviewing process had become so rigorous that we were not accepting things. For instance, if somebody had a project that had a lot of subjectivity in it, the reviews were fairly harsh. (...) And so for me, it was a little bit of an epiphany to hear him say this sort of stuff, and having been an artist myself, I was very, very sympathetic to what he was saying. So that was pretty much what my pitch was when I got up in front of the community, and said, you know, this is what I would do if I were elected to the board. (Interview Brock)

Here, Gregory Kramer is described as a personal inspiration, but it is also easy to think of it the other way around: for someone already sympathetic towards artistic approaches to sonification, referring to the fact that Gregory Kramer ("when he says something to us, we kind of listen up") holds the same view can strengthen the speaker's own position. As Edward Tiryakian has remarked in an essay on sociologi- 
cal schools, the next generation of researchers within a tradition can infer some of their authority "from having been associates of the charismatic founder" (Tiryakian 1979: 219). ${ }^{42}$ Another interviewee draws upon Kramer's authority in a similar context:

And I thought, well, is there not anything we can learn in the sonification community from what composers and sound artists do? And this goes all the way back to Greg Kramer's book, in '94, when he was asking that composers be involved in sonification. (Interview Vickers)

Such references to its historical heritage help to establish the coherence of the sonification field from its beginnings to its current status, thereby strengthening its sense of identity. At a time when most of the current conference attendants belong to the "third or fourth generation of researchers" (interview Gröhn) within ICAD, they create a sense of historical continuity. Such historical narratives, argues Dominique Pestre in his discussion of commemorative practices at CERN, tend to "draw a coherent itinerary through the past (...). They are essential to the smooth functioning and perpetuation of scientific communities." (Pestre 1999: 203ff.) They do so by generating, as Robert Alun Jones points out in his work on the historiography of sociology, "a largely mythical past which performs the important functions of legitimating present practice and reinforcing the solidarity of its practitioners" (Jones 1983: 121). References to historical narratives can have a legitimating function in two ways: they can help to establish its scientific authority to outsiders, such as other scientific disciplines, funding agencies, or taxpayers, as well as being "important sources of selfassurance to the members of the disciplines themselves" (Ash 1983: 144). Of course, they are not the only such source. In the next section, I will show how a sense of coherence and identity is created through various activities related to the organisation of the conference itself.

\subsection{A Bizarre and Genuinely Friendly Troop}

A "bizarre troop", which is "avant-garde enough" not to suffer any fears of contact between science and art (interview Dombois, translated); a "broad, inclusive community" (interview Brock); "a crazy mix of science and art” (interview Brazil); "very familiar, everybody knows everybody” (interview Walker); “interdisciplinary, non-

\footnotetext{
${ }^{42}$ Tiryakian compares charismatic scientific leaders to those of religious communities; an interesting parallel, considering Brock's reference to Kramer's career as a "Buddhist mystic".
} 
hierarchical, um, genuinely friendly" (interview Kramer). These are some of the ways in which ICAD members have described their community. In this section, I want to discuss some of the mechanisms with which two set of actors - the members of the ICAD board and the local organisers of the annual conferences - try to ensure that these ideals are set into practice.

The ICAD conferences are organised by a local team of organisers around the world, although the vast majority of them have taken place in the United States or Europe. According to Matti Gröhn, who holds the record for the number of ICAD conferences attended (up to and including the 2010 conference, he had attended 15 out of 16), the number of participants has been relatively stable since the second conference, usually at somewhere around 100 attendants. The interdisciplinary mix of attendants - involving researchers with backgrounds in acoustics, psychology, computer science and musical composition, to name a few - has also remained more or less the same (interview Gröhn). Most conferences are university-based, but there are some exceptions. The 2002 conference was held at the Advanced Telecommunications Research Center in Japan; the 2008 conference was held at Institut de Recherche et Coordination Acoustique/Musique (IRCAM) in Paris, a department for music and acoustic research; ${ }^{43}$ and the 2009 conference in Copenhagen was officially organised by Re:New - Digital Arts Forum, which is an outlet for an annual digital arts festival held in conjunction with a scientific program. ${ }^{44}$ In all of these instances, university researchers were involved in the conference organisation, but non-university actors played a key role.

Then again, non-university actors can also be key actors in conferences officially hosted by a university. For instance, the 2010 conference, although located on the premises of George Washington University, was not primarily organised by academics; of the three conference co-chairs, only one held a university position, while the others represented a commercial audio company and a government laboratory, respectively.

The decision about who will organise a conference is made by the ICAD board, based on an expression of interest by the potential hosts, in which they outline their plans for the conference. In some cases, the decision is based not so much on unbri-

\footnotetext{
${ }^{43}$ Georgina Born provides a comprehensive, if slightly outdated, ethnographic account of this institute and its peculiar culture as the "historical culmination of attempts to integrate musical composition with advanced scientific developments" (Born 1995: 15).

${ }^{44}$ According to Kristoffer Jensen, chair of the 2009 ICAD conference, this practice was started with the International Computer Music Conference two years earlier: "It's a conference where you have the scientific program, but you also have a festival program, every year. (...) And we did that in 2007, and we thought that it was nice to have (...) the conference and the artists at the same time." (Interview Jensen)
} 
dled and unconditional enthusiasm for the application as it is on a lack of alternatives (interviews Brock, Gröhn). The involvement of the board does not end once hosts have been selected, as the board should also ensure that the organisers "get the flavour of the ICAD conference right" (interview Brock). How much intervention is required can vary; if the hosts have little prior experience with ICAD conferences, the board will "try to hold their hands a little bit more to help them make sure that the ICAD that they produce, the conference that they hold, meets the expectations and the preferences of the community" (interview Walker). At the same time, as some ICAD board members have pointed out, communication is especially prone to failure precisely in those cases, as established communication channels are lacking. In cases like this, both sides - the board as well as the local hosts - might end up frustrated with the other side's lack of initiative (interviews Brock, Gröhn, Jensen). Derek Brock, in his function of ICAD board member and secretary, mentions such an example:

And when we got there to the conference, it was so poorly organised, and there had been so little communication. And that was a two-way street. They had not, the people who were organising the conference, had really not tried to stay in touch with us. And then we as a board had tried to get in touch with them a couple of times, but there was, there was sort of communication frictions and misunderstandings. (Interview Brock)

Beyond its (not always successful) efforts to ensure the continuity between conferences, the board is responsible for trying "to keep the ball rolling and try to keep the ICAD on the safe track to go further" (interview Gröhn). This includes finding outlets for sonification-related publications. Currently, the principal outlets are the conference proceedings; the fact that these are freely available online is a point of pride (interview Walker). At the same time, this means that most of the proceedings have not been formally published. This can be problematic for researchers under institutional publication pressure, for whom conferences with formally published proceedings bring more "academic kudos than the ICAD ones do" (interview Brewster). Some interdisciplinary tensions seem to exist here, as the potential value attributed to a conference publication differs between disciplines. For example, in computer science, conference papers are usually taken quite seriously (interview Hermann 2) and can even be considered the "currency of the field" (interview Walker). As a result, quite a bit is at stake in whether the conference is widely considered to be a high- 
quality one with a high threshold for acceptance. This is not true, however, for all of the fields involved in ICAD:

Psychologists and conferences, well, they're just an excuse to go and present a little bit of work and do some networking. Your high-quality work goes into a journal. But in computer science, actually a lot of our high-quality work goes into conferences, so we see conferences as very high-value. So there's always a bit of a, a bit of a tension, that the psychologists don't need it to be high-value, they want journals for that, and there's computer scientists and others who do want it to be high-value, because we want to get good-quality publications. (Interview Brewster)

Outside of the conference proceedings, at present the possibilities to publish about sonification, for instance in journal publications, are sparse (interview Grond 2). This problem has been acknowledged by members of the ICAD board, who are currently working on finding an "avenue for publications in journals" (interview Walker), which should "provide an outlet for that peer-reviewed journal kind of quality of publication for the people, typically the psychology people, who need that" (interview Walker). Two different strategies are being considered: "One was to try and do an independent journal, the second was to try and piggy-back on another journal" (interview Worrall), but in any case, it should be done "in such a way that it gets some academic status" (interview Worrall). In practice, this means that the journal should not be online-only, "because there's something in terms of prestige that comes with print" (Interview Walker). Having a journal is seen as beneficial not just because it would provide an outlet for high-quality publications, but also because it would mark an important step in the establishment and maturation of sonification as a scientific discipline (Interview Hermann 2).

The plans for a new journal can thus be understood as part of a larger process of formalisation and professionalisation of the field. Bruce Walker, the current ICAD president, explains that he is "slowly trying to be a little bit more formal about things" (interview Walker), for instance when it comes to the ICAD website or the keeping of minutes for board meetings. Nonetheless, as the ICAD secretary Derek Brock explains, there currently is "not nearly the amount of archiving going on that there should be" (interview Brock); for instance, details such as exact numbers of conference participants, paper submissions and acceptances are not collected or archived by the board. 
The board is also responsible for giving out a number of awards (usually for the best paper, best poster, and best sound or sonification) each year, which are intended as a subtle way "to encourage excellence in the papers" (interview Walker). Partly based on the peer review from the conference submission process, the board selects the contributions, and then announces the prizes during an awards ceremony.

At the 2010 conference, a new kind of award was introduced for the first time next to the aforementioned categories, given out not for one particular paper but for "sustained and significant contribution to the ICAD community". The first award of this kind was given to Jim Ballas when ICAD came to his hometown of Washington DC, and "it is not necessarily something that's given out annually" (interview Brock). With its name "Gregory Kramer Award", the introduction of this award can be seen as honouring two people at once, its recipient as well as the one whose name it bears. In the decision to give out this award, to name it after Kramer, and to hand the first one to a person who was "a huge part of what was going on" in the early years of ICAD, but who "does something completely different now, he's very deeply involved in some secure internet work for the military" (interview Brock), this award contributes to the historical narrative described in the previous section. It functions to remind the newcomers in the field of the history of ICAD, as well as tying these prominent founding members more closely to the community that they have helped to create but are no longer an active part of. ${ }^{45}$ This became most evident during the awards ceremony, held at the conference banquet, when speeches were held both by long-standing ICAD board member Matti Gröhn and by the recipient of the award. Gröhn brought his ICAD 1992 t-shirt to the occasion, which he held up to point out Jim Ballas' name among the list of participants on the back of the shirt. ${ }^{46}$ Ballas also brought memorabilia: print-outs of the first e-mail correspondence between him and Gregory Kramer, as well as some early e-mails from the mailing list of the ICAD board, which showed the unbureaucratic procedures and the humble financial resources during its early days (ICAD fieldnotes 2010). Such anecdotes can strengthen a scientific community by presenting it as "a family affair" and providing, "through the relation of the glorious and fascinating story of one individual's life, the pleasure of attending a family event" (Pestre 1999: 207).

\footnotetext{
${ }^{45}$ For instance, Jim Ballas attended not only the awards ceremony, but also "attended the conference and asked a bunch of really, really great questions", which he might not have been able to do without the award (interview Brock).

${ }^{46}$ Gröhn's penchant to attend conferences while wearing t-shirts commemorating the early ICADs is notorious in the field. At the same banquet, Gröhn was ceremoniously handed a pair of ICAD socks to add to his collection.
} 
A familiar atmosphere is also created in other ways, including the determination to keep ICAD as a single-track conference (interviews Gröhn, Walker) and the institution of an open mic session towards the end of the conference, during which "people are able to get up, and it's an open microphone, and just state whatever they want" (interview Walker). Various social activities that frame the conference reinforce this atmosphere. There is nothing unusual about this: social activities, such as "communal meals, excursions, visits to museums, and so on" (Friese 2001: 301), are an established part of academic conferences: "Far from being incidental to the conference proceedings these situations are recognized as a context where working partnerships are formed and renewed, ideas are discussed and joint academic projects developed" (Bell and King 2010: 436). Indeed, it has often been remarked that "the most important business [at professional conferences] takes place 'out in the corridor' rather than inside the meeting rooms" (Downey, Dumit, and Traweek 1997: 245), and it is not unusual that conferences deliberately include elements that encourage such 'corridor talk'. Many social elements of ICAD, such as the conference banquet and informal gatherings for drinks (interviews Gröhn, Brock), are organised with this goal in mind. It is remarkable, however, that many of the social events framing ICAD are of a musical nature. For instance, the conference usually involves at least one evening concert. In some cases (discussed in more detail in the last section of this chapter), these concerts involve elements of sonification. In other cases - such as when Gregory Kramer invited Pauline Oliveros to play at an early ICAD - the music was chosen in order to "break open the musical notions and limitations of a lot of the scientists, to expose them to more interesting stuff" (interview Kramer).

One of the frequent components of the social program is a jam session. In stark contrast to the usually experimental and electronic music played at the officially planned concerts, these jam sessions are often of a more traditional jazz/blues type. In one case, a participant remarked that the artists who were scheduled to perform later must be quite shocked to hear their audience playing such traditional music (ICAD fieldnotes 2009). This does not mean, however, that bitter wars between traditional and experimental music are fought at the conferences; in fact, both seem to co-exist quite peacefully. Both the openness towards experimental musical practice and the competence to engage with traditional musical idioms seem to be valued, and both help to create the ICAD identity.

The role of musical expression for the construction of a sense of identity has been studied extensively, both in relation to how individuals use music to construct their self-identity (DeNora 2000; Frith 1996), and to the creation of cultural and collective identities (Applegate and Potter 2002; Waterman 1990), although only rarely in rela- 
tion to scientific communities (Jackson 2003). National anthems, in particular, have been studied as "signs by which nations distinguish themselves from one another or reaffirm their 'identity' boundaries" (Cerulo 1989: 78); yet they are not merely passive reflections, but sites of negotiation for a sense of national identity (Daughtry 2003). Both cited studies on national anthems, however, focus on musical structure and lyrics (and their interplay), rather than the act of playing and singing. In a paragraph about national anthems in his influential work on the social construction of the nation, Benedict Anderson alludes that such a focus might be missing an important point:

No matter how banal the words and mediocre the tune, there is in this singing an experience of simultaneity. At precisely such moments, people wholly unknown to each other utter the same verses to the same melody. The image: unisonance. Singing the Marseillaise, Waltzing Matilda, and Indonasia Raya provide occasions for unisonality, for the echoed physical realization of the imaged community. (...) How selfless this unisonance feels! If we are aware that others are singing these songs precisely when and as we are, we have no idea who they may be, or even where, out of earshot, they are singing. Nothing connects us all but imagined sound. (Anderson 2006 [1983]: 149)

I am not claiming that ICAD jam sessions are direct equivalents of the anthems discussed by Anderson: neither does their musical practice rest upon unisonance, nor is it the act of perfect strangers playing music out of earshot from each other. Since the ICAD community is small enough for most participants to interact personally, it is not an imagined community in Anderson's sense, who devised the concept to explain that "the members of even the smallest nation will never know most of their fellowmembers, meet them, or even hear of them, yet in the minds of each lives the image of their communion" (Anderson 2006 [1983]: 6). I do want to argue, however, that music functions to tie the community closer together and to establish a shared sense of identity. Merely knowing each other in person does not yet create a sense of community; such as a sense has to be fostered by various means. In that sense, one could argue that even communities which are characterised by a substantial amount of personal interaction are still, to some extent, 'imagined', and need to be performed in order to take shape in the minds of its (imagined) members. My point here is that music, along with other conference components, contributes to this realisation of the community. 
This is done not only or even primarily through lyrics that are sung at these sessions - although lyrics to the "ICAD blues" have indeed been improvised on at least one occasion (ICAD fieldnotes 2009) - but also through the very act of collective playing and listening. Importantly, thanks to the complementary performances of concerts and jam sessions, the community presents itself as competent and appreciative of both playing and listening to music, fluent in traditional as well as experimental musical idioms. Yet even the more traditional blues/jazz-tinged music played at the jam sessions emphasises improvisation and interplay between different players, rather than unisonance - in contrast, for example, to the nineteenth century German 'Naturforscher' studied by Myles Jackson (2003), who drew upon choral music in the construction of their scientific identity and persona. As Jackson argues, their choice of popular folk songs (with lyrics adapted to their scientific interests) "demonstrated that the group function was regarded as more meaningful than the self-awareness of the isolated individual" (Jackson 2003: 143). The musical practices at ICAD convey a different message, emphasising improvisation and experimentation (of different individuals, who are self-aware as well as aware of their fellow musicians) rather than complete unanimity.

These musical practices, I have argued, form an element of the identity of the ICAD community. Already in the proceedings volume for the first conference, Gregory Kramer remarked being "struck by how many of [the conference participants] had been involved in music" (Kramer 1994b: XXVI). This seems to be a point of pride for many in the community, and is reinforced by the musical activities built into the conference. And yet, the extent to which the research of the ICAD community should be aligned with music is contested, as will become clear in the following sections.

\section{3 “Sonification Is Defined As ..."}

The question of how to best define sonification is currently "an open question" (interview Brazil). In this section, I will trace the debates about how to define the practice of sonification that have taken place in the community. The implications of such definitions are quite wide-reaching, as they affect how the boundaries of sonification are drawn, especially in its relation to certain strands of electronic music and sound art.

A general argument for paying attention to definitions of science - and, one may assume, to those of specific disciplines - was provided by Pierre Bourdieu, who argues that the power to impose one's definition of science is the central stake in the 
struggle over power, authority and resources that he considers the scientific enterprise to be:

In the struggle in which every agent must engage in order to force recognition of the value of his products and his own authority as a legitimate producer, what is at stake is in fact the power to impose the definition of science (i.e. the delimitation of the field of the problems, methods and theories that may be regarded as scientific) best suited to his specific interests, i.e. the definition most likely to enable him to occupy the dominant position in full legitimacy, by attributing the highest position in the hierarchy of scientific values to the scientific capacities which he personally or institutionally possesses. (Bourdieu 1975: 23)

My analysis in this chapter might be somewhat less concerned with issues of force and domination, but it certainly takes a cue from Bourdieu's observation that actors usually seek to define science in such a way that their own work and position would count as the perfect example of it. My concern here, however, will not be to determine who has the power to impose their own definitions of sonification; an undertaking that would be hopeless in a community that is still very much in flux. Rather, I want to discuss several different definitions of sonification and consider how their acceptance would affect what is considered as particularly accomplished sonification research, and what would fall outside of the boundaries of the field altogether.

The efforts of defining sonification started early in the existence of this community, and already became apparent in the book publication based on the proceedings of the first ICAD (Kramer 1994b). In its preface, Gregory Kramer remarks that a systematic and coherent terminology for the field does not yet exist, and that he did not "attempt to impose my suggested terminology on the authors" (Kramer 1994b: xxvi). As a result, "there are many words being used to describe the same idea" (Kramer 1994b: xxvi), and Kramer spends more time circumscribing the types of research that would fall under the umbrella of auditory display research than establishing definitions. Nonetheless, he provides a concise definition of sonification as "data-controlled sound". The most self-conscious effort to provide a "working definition" of sonification, however, is made in the contribution by Carla Scaletti (1994), who defines sonification as

a mapping of numerically represented relations in some domain under study to relations in an acoustic domain for the purposes of interpreting, 
understanding, or communicating relations in the domain under study (Scaletti 1994: 224)

As Scaletti points out, this definition consists of two principal components, one specifying a technique (a mapping of numerical data into sounds), the other an intent (to communicate, understand or interpret). This definition has been cited widely in the field and is discussed extensively in the dissertation of Stephen Barrass (1997). Barrass rephrases the two parts of the definition as referring to an element of information requirements and one of information representation: "The requirements part addresses issues of usefulness in a task and the selection of useful data relations to display. The representation part addresses the need to ensure that people can hear the required information in the display." (Barrass 1997: 29) He proceeds to modify the definition for his purposes: Barrass merges the three purposes specified by Scaletti under the umbrella term of "information processing activity" and scraps the reference to "relations in an acoustic domain" by pointing out that it is the perception of sound, rather than the mere existence of acoustic vibrations, that counts; if anything, then, the information should be translated into "perceptual relations in the acoustic domain" (Barrass 1997: 30). However, Barrass proposes a more succinct term: sound. Unlike the acoustic vibrations of Scaletti's definition, "sounds exist only in the minds of the listener", and talking about sound therefore means talking about perception. Barrass concludes with a modified and simplified definition based on Scaletti's work, in which sonification is "the design of sounds to support an information processing activity” (Barrass 1997: 30). ${ }^{47}$

While Barrass' definition is introduced as a rephrased version of Scaletti's, the proposed changes do have consequences for how to think about sonification. As David Worrall has pointed out, his approach "emphasises the idea of information (the content) over data (the medium)" (Worrall 2009: 2-2). The definition also eschews talking about acoustic vibrations in favour of auditory perception, and it puts issues of sound design more centrally: while Scaletti's definition starts from numerical relations in data that are mapped onto acoustic properties - a process that sounds rather neutral and impersonal - Barrass' definition poses sonification as a subject of sound design, requiring the active intervention and decision-making of a designer.

The "most widespread" (Vogt 2010: 21) and "widely cited" (Worrall 2009: 2-3) definition of sonification to date has been suggested in a report for the US National

\footnotetext{
${ }^{47}$ Strictly speaking, Barrass suggests this as a definition of auditory information design rather than sonification. However, since he has arrived at the definition by modifying a definition of sonification, it seems reasonable to assume that it could also be applied to define sonification.
} 
Science Foundation. Prepared at a pre-conference workshop in 1997 and credited as a collaborative effort (twenty individuals are listed as co-authors, seven of them as members of the editorial committee), the report provided some stock-taking as well as recommendations for a research agenda, and included the following definition:

Sonification is defined as the use of nonspeech audio to convey information. More specifically, sonification is the transformation of data relations into perceived relations in an acoustic signal for the purposes of facilitating communication or interpretation. (Kramer et al. 1997)

This definition shares several important elements with those proposed by Scaletti and Barrass: it retains the two main elements of the definition by describing a transformation on the one hand, and a purpose for that transformation on the other hand. As in previous definitions, the relational character of sonification (the expression of data relations, rather than precise numerical values) is emphasised. In contrast to Scaletti's definition, and in line with Barrass' interjection, the definition stresses the importance of auditory perception, rather than being concerned merely with the acoustic signal. This has implications for the expertise required in order to design sonifications, as issues of auditory perception are now explicitly declared as relevant to the field of sonification; the definition could therefore be seen as a reinforcement of the position of psychologists of perception within the community. While the definition does not mention the term design, as Barrass does, the process of making the sonification plays a central role. Indeed, as David Worrall has remarked, it focuses on sonification as a process much more than the previous definitions did: while Scaletti's and Barrass' definitions "can be read to mean both the process of representing, and the resulting sonic object" (Worrall 2009: 2-2), the definition contained in the report unambiguously refers to the transformation process. Finally, the definition poses one additional restriction compared to previous efforts: speech displays are explicitly excluded from counting as a sonification.

This definition has been cited widely, but it has also attracted criticism. Notably, Christopher Frauenberger has argued that it loses some of the specificity of Carla Scaletti's definition; while Scaletti reserves the term 'sonification' for instances where numerical data have been translated into sound, the Sonification Report allows cases where the information has semantical rather than numerical value, e.g. in user interfaces working with auditory notifications, to count as examples of sonification (Frauenberger 2009: 27). The definition has also been criticised in the dissertation of Thomas Hermann, who argued that the explicit exclusion of speech was misguided: 
Speech can be a valuable element in auditory displays as it is able to provide annotations or explanations for other acoustic entities without changing the media. Furthermore, there are many prosodic attributes in speech like pitch, articulation, roughness, accentuation which are suited to be driven by data. Such data-driven use of speech-like sounds should also be called sonification. (Hermann 2002: 23)

The type of display mentioned here, in which characteristics of speech sounds are driven by data, would indeed play a role in Hermann's future research (Hermann et al. 2006).

It was also Thomas Hermann who would, several years later, engage in the most conscious and explicit effort to re-define sonification to date. In a paper titled "Taxonomy and Definitions for Sonification and Auditory Display", presented at ICAD 2008, Hermann proposes a new definition, explaining his motivations as follows:

As in every new scientific field, the initial use of terms lacks coherence and terms are being used with diffuse definitions. As the field matures and new techniques are discovered, old definitions may appear too narrow, or, in light of interdisciplinary applications, too unspecific. (Hermann 2008b: 1)

Hermann's goal is to define sonification as "an accurate scientific method which leads to reproducible results" (Hermann 2008b: 3). In doing so, Hermann suggests that "a technique that uses data as input, and generates sound signals (...) may be called sonification, if and only if" (Hermann 2008b: 2) certain conditions are met:

(C1) The sound reflects objective properties or relations in the input data.

(C2) The transformation is systematic. This means that there is a precise definition provided of how the data (and optional interactions) cause the sound to change.

(C3) The sonification is reproducible: given the same data and identical interactions (or triggers) the resulting sound has to be structurally identical.

(C4) The system can intentionally be used with different data, and also be used in repetition with the same data. (Hermann 2008b: 2)

Unlike in the previously quoted definitions, then, the systematicity and reproducibility of sonifications are made explicit here: it's not enough that the sound tells us something about underlying data relations; that relationship has to be thoroughly 
systematic, and the output sound has to be identical when the process is repeated. Whether something is to count as a sonification is determined not by the purpose for which a transformation of data into sound has been created (as was the case in all previously discussed definitions), but by the criteria of objectivity, systematicity, reproducibility, and applicability to different datasets, all of which are built into the transformation itself. This also makes the application of the term sonification somewhat less open to interpretation - for instance, it is still debatable whether a particular piece of data-driven music was created with the purpose of facilitating communication, but whether the transformation was systematic in Hermann's sense (and indeed, whether the process has been disclosed by the composer in enough detail for anyone else to tell if it was systematic or not) is a question that might receive a more unambiguous answer. The definition thus involves drawing a sharper, less permeable boundary between 'scientific sonification' and 'artistic sonification'; or rather, it denies the existence of the latter category altogether: since sonification is a scientific method by definition, "a prefix like in 'scientific sonification' is not necessary" (Hermann 2008b: 3). Defining sonification in such a way means to declare it as the jurisdiction - in Andrew Abbott's (1988) sense - of scientists, in particular, those scientists who have an intimate knowledge of the conventions of sonification research. While contributions by artists and composers are not ruled out categorically, they have to submit to an explicitly scientific logic.

This is not an insignificant point. There is a rich tradition, especially within the domains of contemporary classical music and sound art, of transforming data into sound for musical purposes (Schoon and Dombois 2009). On the other hand, there are also scientists who, without any contact with the sonification community, use sound as a resource for popularisation activities in fields such as volcanology or asteroseismology. Examples of such projects have been discussed extensively in chapter 2 of this dissertation, and I will show in more detail in chapter 4 that many of these researchers regard these sounds as useful tools for popularisation, but are quite sceptical about the objectivity of auditory displays. Since they regard auditory displays with suspicion and consider them something of a distortion of their scientific work (albeit one that is permissible in the name of popular outreach), they invest no particular care in making sure that the sonifications are accurate and reproducible representations of the data (see interviews Aerts, Heise, Kurtz).

In other words, the researchers gathered at ICAD are not the only group of practitioners who transform data into sound. Proposals of a more rigid, scientific definition of sonification serve to establish the ability to produce something that qualifies as a sonification as the exclusive competence of a core sonification community. On 
the other hand, transformations of data into sound for musical purposes, as well as those that were created for the purposes of popular outreach by practitioners who might not be familiar with the conventions of the dedicated sonification community, are positioned as falling outside the domain of sonification. The definition thus has implications not just for what counts as a sonification, but also for who is considered qualified to make one.

Another interesting point about Hermann's proposed definition is that perception does not appear in it. Unlike in the definition by Kramer et al. (1997), which he uses as a starting point, Hermann talks about "sound signals" rather than "perceived relations in an acoustic signal": the main competence for sonification is ascribed to the technical researcher devising and implementing the appropriate methodology and techniques for systematic and objective sonification, rather than to the perception researcher. This is not to say that the role of perception research disappears entirely if sonification is defined according to Hermann's criteria; indeed, Hermann even mentions "psychophysical tests" (Hermann 2008b: 4) as the way to verify the reproducibility of a sonification. Nonetheless, the main responsibility is shifted toward the sonification system-builder; the additional criteria formulated by Hermann pose stronger demands on the making of the sonification, while in comparison marginalising other types of expertise that could play a role for sonification research, such as knowledge of auditory perception or of the communication and interpretation of data. Again, this is not to say that Hermann would deny the importance of such expertise for sonification research; only that, unlike the technical expertise involved in building a sonification system, its importance is no longer built into the definition of sonification itself. Finally, by not referring to mappings or transformations in the main definition, but instead talking about the input (data) and the output (sound), Hermann creates a definition that allows for steps in between input and output, and therefore more explicitly encompasses the type of sonification he is specialised in, in which a physical model mediates between data and sound.

Thomas Hermann's efforts to re-define sonification sparked a lot of interest in the community; after his talk at ICAD 2008, the discussion went far beyond the few minutes reserved for responses at the end of the presentation and reached into various coffee breaks and dinner conversations. Without any prodding on my part, several interviewees have referred to his new definition of sonification, either to express their agreement with his definitional efforts (interview Brazil), or to voice their disagreement, for instance by pointing out that sonificiation is broader than the scientific framing emphasised by Hermann, and should also include artistic or designorienteded approaches (interviews Barrass, Vickers). Although not explicitly refer- 
ring to Hermann's definition, a recent article by Barrass proposes to conceive of sonification not as a scientific method, but as "a popular mass medium for a broad audience" (Barrass 2011). Another recent journal publication by an artist working with sonification rejects Hermann's framing of sonification as a scientific method as a "grave mistake" (Gresham-Lancaster 2011).

For many commentators, what was at stake was not so much the specific criteria proposed by Hermann, but rather the question of whether it is a good idea to try to narrow down the boundaries of the field in any way. Some have argued against this as a matter of principle, suggesting that any definition should be flexible and fluid enough to accommodate future developments of the community, rather than intervening in favour of any one particular conception of the community and its techniques (interview Barrass). Others have declared it a matter of timing; one commentator at the ICAD 2008 session remarked that it was "too early" to restrict the boundaries of sonification, as only very few really convincing examples have yet been found. In the light of this situation, argued the commentator, it would be a mistake to narrow down the definition now. If an artist were to develop a really convincing auditory display that would effectively convey something about a dataset, without fulfilling all of Hermann's criteria, it would be a loss for the field if this example could not count as a sonification (ICAD fieldnotes 2008).

It may be no coincidence that an increased interest in definitions of the field occurs at a time where the community is undergoing a trend of formalisation and professionalisation, as plans of publishing a new handbook and a journal dedicated to sonification are being made. According to Bruce Walker, ICAD president, these developments mean that the next few years will see an increase in definitional efforts:

Now, as soon as you have a journal, (...) you have to have an editorial statement and a mission statement for the journal. And that formalises exactly what that journal is about. Now if that journal is the flagship journal for our community, then that will have the effect of kind of defining what we consider to be representative research, or representative papers. (...). So you will see more and more explicit definition of the field in the next two or three years. (Interview Walker)

In a similar way, the efforts of the last few years of publishing a sonification handbook, explicitly seen as "a follow-on to the original book that Greg Kramer put together" (interview Brock), has been considered an opportunity to create more coherence: 
And with the Sonification Handbook, I actually had the vision of accomplishing the assembly of a canon, which would range from the data side - statistics, data mining - to the procedural side - sonification techniques and to the sound synthesis side and also the evaluation side, to cover the whole spectrum and present this as a homogeneous complete work, also as teaching material. (Interview Hermann 2, translated)

Yet Thomas Hermann, in his function as one of the editors for this handbook, soon concluded that such homogeneity might not be an attainable goal; the idea of creating a handbook that would contain one straightforward definition of sonification, which is reflected in each of the contributions, was ultimately abandoned by the team of editors, because "even ten years after Kramer's book, or 15 years by now, the community is not so consolidated yet that such a sense of coherence could be displayed" (interview Hermann 2, translated). Instead, the editors opted for a different form of publication:

At the end of the day, we developed the attitude that it might even be fundamentally better for the community if we redefine it as a kind of compilation of different perspectives on sonification, which can be, and are, more heterogeneous per se. That's simply the reality of sonification research in 2009. (...) I don't think it will be feasible to create a coherent nomenclature. (Interview Hermann 2, translated)

Clearly, then, the debates about what sonification is, and what it is not, have not reached closure within the sonification community. Ultimately, this is a question not just of where the boundaries of sonification are drawn, but of what the very thing which is being bounded is at its core. Is sonification a scientific discipline, an interdisciplinary community, a cutting-edge practice, a research methodology, a technological tool, a practical application, a popular mass medium? All of these terms have been invoked to describe sonification.

In this section, I have outlined the most influential definitions that have been given over the years, as well as discussing some of the implications that the adoption of one definition over another can have, especially for the attribution of competence and jurisdiction in the field of sonification. For example, the definition by Barrass (1997) emphasises sonification's kinship with sound design, while the one contained in the Sonification Report (Kramer et al. 1997) strengthens the importance of the work of psychologists and perception researchers for sonification research. Compared to this, the more recent definition by Hermann (2008b) puts much more em- 
phasis on specific criteria involved in the technical construction of sonifications, and also draws a firmer boundary between sonification and sound art or experimental music. At the same time, these efforts of drawing a sharp boundary between sonification and music have been met with criticism, as several community members believe that it would be best for the community to remain broad and open, at least until a larger number of successful and convincing sonification applications have been found. This argument already shows that expectations of what the future might bring can shape the contours of the community in the present tense. It is this aspect that I will turn to in the next section.

\section{4 "That Might Be a Fairly Significant Killer Application"}

The role of expectations becomes most manifest in the community's discussion about finding the perfect application for sonification - precisely because, it seems widely agreed upon, this application still has to be found. ${ }^{48}$ As one participant of the first ICAD conference who later lost touch with the field commented, from the very start sonification has essentially been "a tool looking for, you know, the perfect application". He also remarked, however, that researchers in the field have always been deeply convinced of the existence of that perfect application: “It's out there!" (Interview Hayward) While the field has certainly changed over the last two decades, the basic observation that sonification is a research field looking for the perfect application seems to remain true, as I will discuss in this section.

It seems significant that it is an 'application' we are talking about here; the field is conceptualised as dealing in applied knowledge, and is on the lookout for a service that could extend past the core community, into commercial, technical, scientific, artistic or popular domains. Expectations of a perfect application, the so-called 'killer application', are created as a resource for legitimising research and mobilising for funding, publicity and the support of other actors - all of which are functions of expectations discussed by Van Lente (1993) in an STS study on the dynamics of expectations in technological developments. In other studies, expectations have been shown to be drawn upon and created by actors in specific research communities in order to justify and push their field (Guice 1999), or a particular vision of their field (Hedgecoe and Martin 2003), of research. It is this last aspect of expectations that I

\footnotetext{
48 This was especially apparent in discussions at the 2008 workshop on 'Recycling Auditory Displays', organised by Frauenberger and Barrass, and also mentioned in several interviews (interviews Gröhn, Stockman).
} 
want to focus on here: how are expectations for sonification appropriated to shape a particular conception and vision of the sonification community?

The term 'killer application' is borrowed from informatics, where it "refers to an application program so useful that users are willing to buy the hardware it runs on, just to have that program" (Juolo 2008: 76). Juolo gives some historical examples of killer apps, e.g. early spreadsheet software, which showed such promise for bookkeeping and decision-making that businesses bought computers just to be able to run these applications. Similarly, a videogame would be considered a killer app if it were so popular that thousands of gamers would buy a new console just to be able to play it.

For sonification, the term is used in a metaphorical sense. A sonification would be considered a killer app if it were so convincing that it would make people 'buy into' the idea of sonification in general, contributing to its acceptance - not if it made practitioners run out by the million to buy new soundcards or speakers so they could hear the sounds better. Indeed, in many cases it will make sense to keep the cost of entry low by avoiding the need for new technical gadgets altogether: for many scientists, engaging with sonification already requires a leap of faith, so it doesn't help to expect additional expenditures (e.g. new hardware or programming skills) from them. Consequently, Florian Grond, who works on a sonification platform for molecular structures and dynamics, realised after talking to chemists that it would be better to provide this sonification utility in the form of a plug-in for a widely used open source software package for data visualisation, rather than expecting them to learn an entirely new programming language. This means linking the sonification application not only to existing tools, but also to established modes of representing data and the skills required to work with them. Grond acknowledges that the chemists have a point in insisting on a combination with visual displays:

And that's quite obvious, actually - because they have acquired expertise in [working with visualisation], and if you told them now: 'as of tomorrow, only listening and no more seeing', then they would throw away the expertise which they have acquired over many years. I wouldn't accept having to do that, either. (Interview Grond 1, translated)

As a result of this insight, Grond's research venture has first developed from providing standalone sonification solutions to providing options that tie in with existing visualisation software (interview Grond 1), and later developed further into an interest for multimodal data representation (interview Grond 2). He explains that it is 
important for him that sonification should "accompany established modes of representation, because that is the only way, I think, to make sonification well-known and popular" (interview Grond 2, translated). Such a development is not unusual; according to Thomas Hermann, the initial desire to develop sonifications that would replace all existing modes of data representation is common and understandable, albeit misguided:

I think that was, or may have been, a wrong track, but one that can easily be taken in the sweep of enthusiasm: that one gives too much weight to sonification, as though there was nothing else. (...) Or that one wants to develop sonification as a replacement for everything else. And I think that's not productive. (...) I think that the best solution will only be found in the healthy canon of all sensory modalities. (Interview Hermann 2, translated)

An introduction article about sonification by Barrass and Kramer from 1999 also emphasises that "integrating sonification with other display modalities will be a key to their effectiveness and acceptance" (Barrass and Kramer 1999: 26). As another interviewee points out, sonification can be particularly helpful as "augmentation" or "enhancement rather than replacement" of visual displays (interview McAlpine).

These considerations illustrate a lesson that has been pointed out by scholars of science and technology studies: if a (research) technology is to succeed, it has to be adapted to and embedded into existing cultural practices, to be appropriated into specific contexts of use; merely showing abstract promise is not sufficient for the success of a technology or application (Bijsterveld 2004; Borck 2006). If the new technique is too foreign, too far removed from scientists' daily practices, they will be reluctant to give it a chance. This is perhaps one of the reasons that many sonification researchers focus their hopes of developing convincing displays on medical applications. Not only is there the potential of coming up with solutions that might prove beneficial to public health (interviews Brazil, Stockman), but many perceive that they already have a foot in the door in the medical field (interviews Baier 1, Hermann 2), where existing listening practices have helped to prepare medical practitioners for the possibilities of auditory displays. ${ }^{49}$ While many sonification researchers complain about the lack of an education in listening skills, the medical field is one domain where students do learn how to listen (Rice 2010, 2012). Some interviewees have also

\footnotetext{
${ }^{49}$ Indeed, in her research on the establishment of the x-ray image in medicine, Bernike Pasveer (2006) shows that the new images had to be brought into line with existing modes of representation in order to gain credibility, and in particular, with the sounds upon percussion. Here, the more established technique of medical listening served as a point of reference for the new type of medical image.
} 
argued that researchers who are experienced in working with scientific visualisations might be more open to sonification, at least if their visualisation work does not just always follow the same standard procedure. Scientists who in their work with visualisation have proven that they are "very open in how they search for their method. So they have problems and see that there is more than one way of solving them" (interview Vogt, translated) might thus be particularly open-minded about the potential benefits that sonification has to offer.

So although sonification breaks with some of the entrenched conventions of scientific data display, many practitioners recognise that its success will depend on the ability to tie in with existing practices and skills, especially those related to visualisation. Of course, sonification also has to offer some clear benefits over existing approaches to data analysis and representation. Therefore, it often makes sense to start convincing people with relatively accessible cases of sonification, as Alberto de Campo explains:

Well, the examples that obviously deal with dynamic processes, such as seismology and neurology, are quite immediately plausible, because the data there are already very close to physical sounds. Or at least - okay, in neurology it would be electric oscillations, but at least already oscillations, already temporal processes. So that is quite plausible for most people. (Interview de Campo, translated)

Other researchers mention similar aspects as particularly promising avenues of sonification research. For instance, Matti Gröhn mentions that he would not be surprised if the killer application turned out to be related to data containing a temporal dimension (interview Gröhn). And Gerold Baier, who has a long-standing interest in the existence of rhythms in the body and the brain, as well as in the relation between this kind of rhythmicity and music (Baier 2001), thinks that dynamical diseases such as epilepsy might be a particularly interesting application for sonification. Baier explains that epilepsy is the "prototype of a dynamic disease" (interview Baier 2, translated), which only exists in living persons and cannot be seen in a dissected corpse.

While some ideas for the creation of convincing sonifications exist, the demands that are being put to such an application can be quite contradictory and difficult to meet. For example, in order to be of use to visually impaired users, who need to compensate for their lack of vision, a sonification might be at its best if it conveys something that a visual display is good at (interviews McAlpine, Stockman); to a sighted person, it might be more useful if it exploits areas where visual perception is weak or 
existing visualisations do not work well (interviews Gröhn, Hermann 1 and 2). Different user groups might also have different demands for accuracy versus aesthetic appeal (interview Walker). Another question is whether the sonification should be directed at a small community of specialists or appeal to a popular movement; while many projects have gone for the first strategy, there are also attempts to anchor sonification more firmly in popular culture, e.g. in social networking applications (interview Barrass). Others argue that "the only way to succeed will be to carve out a prototype or a convincing example and to demonstrate it on one disease, one symptom, one little corner where you can convince specialists" (interview Baier 2, translated). A third route is to make sonifications for novices in a particular specialisation; for example, the PhD work of Paul Vickers was directed at computer science students learning programming and debugging code in a particular language. As Vickers argues, the needs of such programming novices, who do "not yet possess the repertoires of skills needed to diagnose, or even spot, the symptoms of an incorrectly functioning program" (Vickers 1999: 5), might be rather different than those of experienced computer scientists, and a sonification designed for their purposes might not necessarily be useful to the latter. The demands asked of a convincing sonification thus vary, depending, among other factors, on the users it is envisaged to cater to.

It seems widely believed that most sonification work being done so far consists in "some very interesting prototypes" (interview Brazil), but that there is very little in the way of guidelines or best practice models. Acknowledging that their field is still in its infancy, many practitioners of sonification rely on promises for the future to justify their work. Talk about 'killer applications' generally seems to occur in the future tense: "I think we're still missing the real killer application in that sense in sonification." (Interview Gröhn) Yet it is not projected into the very distant future; it could happen any day. One of my interviewees relates:

And funnily enough, a fortnight ago, on Radio 4, a very mainstream BBC radio station, there was some physicists who had some sonifications of activity going on internally within stars. (...) You know, I thought that might be a fairly significant killer application, it certainly got quite a bit of publicity. (Interview Stockman)

However, when he contacted one of the scientists involved, the reaction was quite disappointing; the researcher replied that the sound was intended as a publicity gag, not as a serious research component: not much of an ally in the search for the killer app. 
Yet this readiness to accept an example from outside of the ICAD community as a possible killer application seems symptomatic. We have witnessed this before in the previous section, when a commentator at ICAD warned against narrowing the boundaries of the field, as this might result in excluding some very convincing sonification examples. To some extent, this openness is built into and explicitly fostered in the community - for example, with sonification concerts organised during the conferences to stimulate involvement by composers, or with the invitation of keynote speakers, who are often not "the kind of person who would come to ICAD unless they were invited or unless the conference was in their city" and who can thus be introduced "to a field that they may not even realise is related to their work" (interview Walker). This openness is partly perceived as being in "the nature of the field" (interview Kramer) and as an asset because of the potential of learning from each other (interview Walker); yet it is also a strategic choice to build momentum through inclusiveness (interview Kramer). As we have seen above, this reasoning is rooted in expectations for the development of the community, in the search for a killer app. Expectations thus not only guide the direction of research conducted in the field by favouring some types of research over others; they are also used as a resource in shaping a conception of sonification that emphasises openness, broadness, and selfreflexivity as characteristics of the community.

\subsection{Slipping through the Fence between Science and Art}

In the previous two sections, it has become clear that the sonification community struggles with the extent of its openness and inclusiveness. On the one hand, the attempts to define sonification as a scientific (objective, reproducible) procedure constitute an effort to draw a sharper boundary around sonification, and to declare sonification as the exclusive comptence of a small community of specialists; but on the other hand, there is a countertendency for a self-conception as an open and inclusive community, which can be seen both in the reservations expressed about such definitional efforts and in the hope of finding a killer application. At the root of this tension lie questions about the relationship between science and art, and I want to address these questions in detail in this section.

This tension might be interpreted as a struggle between different factions within ICAD, one in favour of doing only the most straightforwardly 'scientific' sonifications and cutting the ties to the artistic community, the other stressing the value of artistic contributions and the need for openness. However, this interpretation would be too facile. It would be hard to reconcile, for example, with the performance of 
Thomas Hermann, who would have to be considered a spokesperson of this ostensible 'scientific faction', at the 2008 Wien Modern festival for contemporary music, presenting - with Gerold Baier - a 'live sonification of the human EEG', using the brainwaves of composer Alvin Lucier.

Rather than an issue of stable splinter groups within the community trying to impose their idea of how scientific/artistic sonification should be, I want to show that these boundaries are negotiated in context-specific ways. Take the example of a sonification talk given at a neurological workshop, reported by Gerold Baier: when he and his colleague presented their EEG sonification, one of the 'big names' in neurology demonstratively left the lecture room, soon followed by a number of other researchers. Even those who remained in the hall for the remainder of the lecture displayed reactions that Baier likened to those to free jazz performances during its prime: open mouths, signs of disapproval, confusion about what they were confronted with here. Those who were willing to engage with the presentation at all insisted on addressing it on musical, rather than scientific, terms - to the dismay of the presenters, who were there to discuss their results with epileptic data, not elements of composition. Yet, however undesired it may have been by the presenters, the association of their talk with music was not a complete accident, as the title of their talk (mentioning an "unpredictable concert") itself elicited musical connotations. When asked about this apparent contradiction - not wanting a paper to be associated with music, yet invoking music in its very title - my informant explained that the title was not chosen entirely voluntarily; the musical reference was proposed by the organisers and was for the presenters the label via which the material could be presented at the workshop at all (interview Baier 1).

This is an interesting case because it combines two aspects of boundary work that are often discussed separately. Scholars of boundary work often focus exclusively on rhetorical demarcations of a field (Gieryn 1995), or they interpret interdisciplinarity in terms of a crossing of boundaries (Klein 1996). Here, however, we see that the two go hand in hand; demarcation and boundary-crossing occur simultaneously. As Willem Halffman points out, "boundary work has the double nature of dividing and coordinating" (Halffman 2003: 70), of demarcating as well as specifying conditions under which demarcations can be crossed. Scholars of science popularisation have pointed out that the very activities of public outreach, designed to reach a larger public and thus to cross a boundary, in fact at the same time serve to reinforce the special authority of scientists (Derksen 1997a; Mellor 2003). It is this double nature of boundary work, the simultaneous acts of crossing/breaching and demarcating/reinforcing, that is typical of the science/art boundary work of sonification. 
In the case of the anecdote above, it was the very promise of crossing the boundaries between science and music that opened up possibilities of presenting in this scientific venue in the first place. However, the association with music was not desired by the presenters themselves, who were quick to rhetorically demarcate themselves from being positioned on the artistic end of the science-art spectrum. While the researchers accepted and went along with the musical label to some extent because it provided opportunities for them, in the next step they tried to subvert this categorisation. This shows that the position of sonification in relation to science and/or art is not a given, but becomes a balancing act, dictated as much by strategic decisions and the desire for an audience as it is by the penchants of the practitioners. In other words, the categories of 'science' and 'art' do not refer to distinctly bounded domains; the distinction becomes permeable and mutable, subject to boundary work. In various contexts, researchers cross or reinforce the boundaries between art and science.

Many sonification researchers emphasise the advantages of boundary-crossing between art and science. Musicians and artists are thought to bring various assets to the table, such as the ability to listen for structures (interview Baier 2), certain technological tools (interview Kramer), and the familiarity with a broad spectrum of different kinds of sounds and knowledge of the different possibilities they allow (interview de Campo). Artistic approaches are also valued for the diversity of different realisations of one idea (interviews Barrass, Brewster), and for allowing the freedom to experiment with ideas that are not a guaranteed success (interview de Campo) and to choose one's format of publication (interview Dombois). In a field that is chronically underfunded and barely established in the scientific domain, the possibility of crossing over into artistic territory also opens up opportunities for funding and publicity (interview Vogt). The most commonly mentioned aspect, however, is that the involvement of composers can increase the aesthetic value of sonifications (interviews Baier 2, Dombois, Kramer, Vickers). According to David Worrall, the aesthetic design might make all the difference in determining whether a sonification, once designed, will actually be used or not:

And if you read the literature, the sonification literature, you come across this idea all the time that, yes this was an interesting experiment but when we came back, it had been turned off. (...) A number of people in the field have recognised that this is enough of a problem for the sonifyers to start to listen to the composers. And that's been partly the reason why the ICAD community has started to include more musical work in its program. Because 
they've recognised that there is something about sound design, if I can put it like that, that needs to be taken account if you're going to be able to listen for the sonification purposes. (Interview Worrall)

In the light of these considerations, it is no surprise that sonification frequently branches out into artistic contexts or invites participation from musicians. David Worrall mentioned the increased inclusion of musical work in the conference program, "spearheaded" by a concert organised by Stephen Barrass at the Sydney Opera Hall during ICAD 2004. For this concert, under the title of 'Listening to the Mind Listening', ten concert pieces were performed which sonified a dataset of the electrical activity of the brain of a person listening to a specific piece of music. All pieces had to be based on an explicit, reproducible and time-binding mapping from the data into sounds. Despite these well-defined criteria, the resulting sonifications "ranged through jazz, orchestral, soundscape, glitch, techno and other genres" (Barrass, Whitelaw, and Bailes 2006: 13). The concert has been lauded because "that was really amazing to hear, the kind of completely different things that people did with it" (interview Brewster). It also increased the visibility of the ICAD within the computer music community, as the concert was mentioned in several music-related journals; not only in an article about the organisation and submission process submitted by the organisers to the Leonardo Music Journal (Barrass, Whitelaw, and Bailes 2006), but also in a review of the event published in the Computer Music Journal (Childs 2005). ${ }^{50}$

A similar concert, but with social instead of neurological data, was organised two years later for the London conference. The intention, according to the concert chair of the London conference, was to make the balance between art and science explicit (interview de Campo). Compared to the Sydney concert, the criteria for submissions were less stringent in London and at subsequent ICAD concerts; while the organisers provided datasets for sonificaton, more leeway was given for how to do this, which afforded less comparability between different approaches. Nonetheless, the London concert was also an invitation for sonification researchers to engage in artistic and creative activities, as well as to the music and sound art community to come to the conferences.

\footnotetext{
${ }^{50}$ However, even before the organisation of this concert, electronic music journals occasionally took note of sonification in general and ICAD specifically. Several articles in which authors describe their own sonification projects have found their way into journals such as Organised Sound (Polli 2004; Sturm 2001), and the proceedings volume of the first ICAD was reviewed in the Computer Music Journal as "a good representation of what's happening (good and bad) in the emerging field of auditory display" (Perkins 1995: 110).
} 
At the ICAD conference in Washington DC in 2010, an evening concert with sonification pieces was also organised, although this time without a specified dataset that was used by all participants. On top of that, the conference chair Derek Brock introduced a new category of presentations for the daytime conference activities: next to the paper, poster and demo sessions that are always part of the conference, a category of 'aural submissions' was introduced. Unlike in usual paper submissions, the peer review here is primarily based not on the write-up of the research, but on the sounds themselves; and at the actual presentation, the sounds take more room than they usually do at the conference. During the conference, Brock described this new category as "something novel, something that ICAD as a community kind of brings to the table, that's unique" (ICAD fieldnotes 2010). It was "the kind of thing that people could put on their CVs" (interview Brock): not just peer-reviewed publications, but peer-reviewed sounds, a promising prospect especially to musicians and sound artists. With the introduction of aural submissions, Brock wants to make good on a promise of opening the community to artistic input that he had made when standing for elections to the ICAD board years earlier (interview Brock).

Clearly, a lot of boundary crossing between science and art is going on in these practices. However, boundary crossing goes hand in hand with demarcation, and the practitioners of sonification are often quite adamant about drawing the boundary between sonification and music. Thus, at a talk given in the context of a festival for contemporary music, one sonification researcher greeted his audience with these words: "I am glad to see that you dared to approach this topic, even though it has nothing to do with music." Laughter ensued, but a message had been sent: sonification does not equal music - even if its practitioners might take advantage of the opportunity to present their work in the context of a musical festival (fieldnotes Wien Modern 2008). Similar to science popularisation activities, designed to cross boundaries between science and the public, which end up reinforcing the special authority of science (Mellor 2003), the sonification researchers here make use of the opportunity to cross the boundary between science and art precisely to demarcate; they go to an artistic event, but use it as an opportunity to instil the message that "this is not actually art”.

Other sonification researchers also hesitate to frame their own research too strongly in artistic terms. For instance, when I asked the media artist and researcher Florian Grond whether he would make an art project out of his dissertation project on the sonification of chemical structures, he replied that he might consider it, but would be "very cautious". Grond worries that doing so might muddle the message for the domain scientists he collaborates with: 
If you approach chemists about sonification of chemistry, at first they always believe that it's art anyway, and it takes a long time to convince them that this may have an added scientific value. And then it's counterproductive, of course, if you end up using it as art after all. Because then it's just difficult to communicate why one thing was not art and the other thing suddenly is art. (Interview Grond 1, translated)

Grond also expresses reluctance about tapping into the kind of resources that might become available by presenting sonification as an art project, as this often "has a very, very decorative function, that is strongly geared towards infotainment and actually providing a justification for all the money being spent on these [large-scale research] projects" (interview Grond 1, translated). With these reservations, Grond quite explicitly distances himself from the kind of sonification projects that I have described in chapter 2 as examples of sonification as a source of the auditory sublime.

Several interviewees reinforce the boundary between science and art, stating that ICAD is not unreservedly open to artistic contributions: "if it's purely art, or purely music, then it belongs in a different conference" (interview Walker). "People might still benefit from it; as a matter of fact in all likelihood would, if it's interesting stuff. But you wouldn't just take it in if it's a good piece of music, and say it should be at ICAD." (Interview Kramer) One interviewee emphasises that sonification, like visualisation, allows some aesthetic freedom, but is "actually a technical procedure (...), it's rule-bound, and a visualisation is not yet a painting. And likewise, a sonification cannot automatically be compared to a musical composition." (Interview Dombois, translated) Quotes like these show that the sonification researchers do not want to displace the boundary between science and art altogether; rather, they want to slip through the fence as they see fit. In order to do so, they occasionally drill or patch up holes in the fence.

\subsection{Conclusions}

In this chapter, I have scrutinised the emergence and professionalisation of an academic field dedicated to sonification. This has meant focusing on the historical narratives which are generated within this field, and in turn help to shape the contours of the community; the various conference traditions and components that are created to foster a sense of community and identity; the efforts to develop a stringent definition of sonification, and their implications for who may or may not speak for sonification; the attempts to find applications of sonification that would attest to its usefulness 
beyond this core community in a broader scientific, artistic, commercial or popular sphere; and finally, the negotiation and balancing of an identity between science and art. These episodes add up to a story of how an academic community that breaks with certain conventions of scientific data display attempts to establish the legitimacy of its activities.

One of my interviewees has remarked that "the niche for [sonification] doesn't exist at all, not yet" (Interview Baier 2, translated). In order to create a niche in which sonification can be regarded as an acceptable way of analysing and representing scientific data, much work needs to be done: transforming data into sound, making it sound good, developing and relaying listening skills, familiarising oneself with different scientific specialisations from which the data are taken, building up and defining a field. The creation of such a niche can be seen as an instance of 'boundary work'. According to Thomas Gieryn, such boundary work is part and parcel of any scientific field, as science "acquires its authority precisely from and through episodic negotiations of its flexible and contextually contingent borders and territories" (Gieryn 1995: 405).

This chapter has looked at such negotiations of flexible and contextually contingent borders, but in a field that sets out to cross boundaries as much as it draws them; it creates, maintains, reinforces, adjusts, transgresses, negates and breaks down boundaries, often all in one move. What is at stake is not only where the precise boundaries of sonification lie, but also what the nature of the thing being bounded actually is: a scientific discipline, an artistic practice, a cutting-edge hybrid between science and art, a scientific methodology, a tool, an application, a mass medium. How sonification is framed is itself part of the repertoire of boundary work, from which its practitioners selectively draw from in order to position and legitimise their approach.

In the introduction to this chapter, I mentioned Zolberg and Woon's study of immigration discourse, in which they distinguish between three types of boundary work: boundary crossing, boundary blurring, and boundary shifting. If an individual crosses boundaries, the boundaries themselves remained unchanged; if boundaries become blurred, they remain more or less in the same place but become less distinct, and multiple memberships become possible; and finally, a boundary shift refers to a deep structural change, in which the group identity is fundamentally redefined. I have suggested scrutinising the boundary work of sonification not only in terms of the strategies involved, but also in terms of whether they involve such a fundamental redefinition of the boundary between science and art. In the course of this chapter, it has become clear that such a transformation does not occur in the context of sonification; while plenty of boundary crossing and boundary blurring takes place, the rheto- 
ric of the community does not point at a fundamental displacement of the boundary between science and art. At the same time, it would be missing the point to characterise it only as boundary crossing and blurring: shifts are indeed happening, but they are shifts back and forth. As I have suggested, they are better understood not as removing, but as slipping through the fence - which can involve meddling with the fence. The boundary work of sonification may be best described not as crossing, blurring or shifting - nor as expulsion, expansion or protection, as Gieryn (1999) puts it - but as boundary slipping.

Perhaps the most salient characteristic of the boundary work of sonification, then, is one that has been disregarded in previous studies of boundary work: the practitioners not only demarcate and erase boundaries, but at times are quite ready to submit to existing categorisations, even if they may not agree with them, if it is convenient for them - only to distance themselves again and question those categorisations at the next opportunity. For example, they may accept the label of 'music' or 'sound art' in order to acquire funding or reach an audience, even if they consider this a misrepresentation of their work; only to then reject the categorisation again and insist that sonification is not music after all. Existing cultural attributions are thus simultaneously embraced and subverted; sonification both assimilates to and undermines existing conventions of scientific representation. There is no widespread consensus within the community about how far sonification should go in its strategies of assimilation or subversion, and the individual researchers flexibly navigate between the two strategies.

Sonification is thus sometimes positioned in conformity with scientific conventions such as objectivity and reliability; at other times, it is emphasised to be more cutting-edge and avant-garde than boring old disciplinary science. Which qualities of sonification are stressed and which are disregarded may vary from one context to another, as a result of negotiations that both the field as a whole and the individual practitioners deal with. It can be a matter of strategic choice, but also of disciplinary identity and professional "jurisdictional control" (Abbott 1988: 3). It has implications for the self-perception, the composition, the contours and the size of the community: who may speak for sonification, and who may not? If the goal is to establish sonification and gain acceptance, is it best to ensure its publicity and popularity, e.g. by being open to artistic contributions, or to appear as a small, but highly professional community of experts?

As Olga Amsterdamska (2005: 20) has indicated, "the establishment of [boundaries between disciplines] creates the need to emphasise both the distinctiveness of a field of research and, simultaneously, its conformity with the prevailing, though 
changeable, standards or markers of scientificity". Such a pattern is certainly visible for sonification, which is positioned as both distinctive from and compatible with notions of scientificity. Studies of emerging disciplines have shown how these have struggled with defining their objects, facts and methods, and how they have differentiated themselves from or associated themselves with public health (Amsterdamska 2005), amateur science (de Wilde 1992), religion (Evans 2009) or common sense (Derksen 1997a). Cooper and Bowers, in their work on the emergence of the field of $\mathrm{HCI}$, discuss a discipline which has to position itself in relation not to one, but a number of different disciplines; they argue that the field therefore has to manage "a multiplicity of discursive dilemmas as the claims of different disciplines are invoked, managed, and played off against one another. Skepticism of the foundations of HCI could come, then, from any of a multiplicity of sources." (Cooper and Bowers 1995: 61) For sonification, a comparable reference point could be its positioning vis-à-vis music, but also visualisation. At the same time, what is specific for sonification is that it not only takes on one or a few disciplines as competitors, but challenges fundamental conventions about scientific analysis and data display. Since sonification is in principle applicable to data from any scientific discipline and its claims therefore potentially affect all of these fields, its boundary work, too, reaches out in many different directions.

As this analysis has shown, the sonification community walks a rocky path on its way to have listening to data accepted as a legitimate scientific activity. It takes on many different fields simultaneously, and has to face scepticism from as many sides. One of my interviewees has remarked that scientists from other fields do not necessarily dismiss the possibility of interesting sonification applications; in classic "Not In My Backyard" fashion, they just tend to rule them out for their own field. Thus, physicists might be ready to concede the potential of sonification in neurology, but not in physics (interview Vogt). However, the success of sonification will depend on its ability to convince specialists of the promise of sonification for their own turf. In most scientific fields, gaining academy legitimacy requires the practitioners of other disciplines and science policy makers to accept that the field offers scientific approaches or knowledge that can co-exist with the approaches and knowledge generated by other scientific fields; for the legitimacy of sonification, however, this is not quite enough. In order to reach scientific acceptance, the field not only has to flourish as its own independent academic field, but its techniques and approaches have to be taken up by other scientific disciplines and leave their marks there. The practitioners of sonification are well aware of this issue, which is why there is such a widespread concern that the field should not only develop its own facts, objects and methods, but 
also come up with killer applications: it is the successful application of sonification techniques in scientific disciplines other than sonification itself that the acceptance of sonification will ultimately depend on.

At the same time, for the survival of the ICAD community, a community which many of its members are clearly attached to, it is not enough that people start using sonification: they also have to accept the community as possessing exceptional authority to produce and judge sonifications. Some respondents have expressed concern, for example, that sonifications are being used more widely by scientific visualisation groups or artists, but that this does not add up to a thorough engagement with the epistemic possibilities of sonification, and to some extent even has the effect of pulling the rug from under the feet of the dedicated sonification community (Bielefeld fieldnotes 2009). To counter such developments, the community has to establish itself as an 'obligatory passage point' (Callon 1986; Cooper and Bowers 1995) for sonification. In this chapter, some of the strategies with which the community tries to accomplish this have been mentioned. For example, a historiographical narrative that takes 1992 (the organisation of the first ICAD conference) as the starting point of systematic sonification research reinforces the position of ICAD. ${ }^{51}$ Recent attempts to redefine sonification in a more stringent manner have the effect of excluding examples of auditory display from outside of the community - but also, as critics of these attempts argue, many that are, or should be, part of the field - from the status of sonification work.

In this chapter, I have studied the boundary work of the sonification community in terms of its struggle for acceptance. One of the things being negotiated in this struggle is whose acceptance it is that is being sought, and what sonification should be accepted as. Should sonification seek acceptance as a scientific method, as an artistic practice, as a technological application, or as a popular movement? If sonification is framed in terms of art or broad popular appeal, that may mean a stronger alignment between the community described in this chapter and the kind of sonification work described in chapter 2 . On the other hand, if sonification primarily seeks scientific legitimacy, it may distance itself from such projects. Such a scientific framing, however, invariably means that sonification will have to face the question: where's the

\footnotetext{
${ }^{51}$ The significance of choosing such birth years has been pointed out by Ulfried Geuter with an example from the history of psychology: "The celebration of the year 1879 as the birth year of scientific psychology (...) points to a certain concept of what is thought to be scientific in psychology." (Geuter 1983: 194) 1879 is the year in which Wilhelm Wundt founded his laboratory for experimental psychology in Leipzig; counting it as the birth of psychology therefore implicitly frames psychology as an empirical, experimental science at its very core.
} 
objectivity in that? I will explore how the sonification community deals with this question in the next chapter. 


\section{Chapter 4}

\section{Trained Ears and Correlation Coefficients: Notions of Objectivity and Scientific Quality in Sonification}

A scene not entirely untypical for a presentation at the annual ICAD conference: during the short time allocated for discussion and questions at the end of the talk, an audience member asks how the sonification that had just been heard was made. How were the data mapped to sound, and what kinds of decisions were made in the process? The speaker adopts a somewhat defensive tone in his reply: yes, some decisions about how to map and process the sounds had indeed been made, "just like you do in visualisation", but the mapping itself was very precise and reproducible (ICAD fieldnotes 2010).

Discussions like these are part of an ongoing process in which notions of objectivity are negotiated within the sonification community. In this chapter, my goal is to retrace these constructions of objectivity. ${ }^{52} \mathrm{My}$ goal in doing so, however, is not to determine whether a particular practice is or is not objective, nor to find immutable and universal criteria to distinguish objective science from non-objective pseudoscience. Indeed, STS scholars in the last decades have moved away from considering objectivity as something that can be identified with the help of a checklist. Instead, they have argued that objectivity itself is a historically constructed and mutable concept; a concept that cannot be nailed down to one fixed meaning, but which is always in flux and is negotiated in relation to specific practices and representations. The precise meaning of objectivity is therefore not only subject to historical changes (Daston and Galison 1992, 2007), but also to ongoing negotiations that lead to divergent meanings and standards of objectivity in different disciplines (Boumans and Beaulieu 2004; Huutoniemi 2010; Lamont 2009). My aim, therefore, is to explore how the meanings of objectivity take shape in the context of sonification research.

Most often within historical and sociological studies of science, practices of objectivity have been studied in connection with images and visual practices (Alac 2004; Beaulieu 2001, 2002; Borck 2008; Daston and Galison 1992, 2007; de Rijcke 2010; de

\footnotetext{
${ }^{52}$ A shorter, German version of the material presented in this chapter is currently in print (Supper forthcoming).
} 
Rijcke and Beaulieu 2007; Joyce 2005); only very rarely have they also considered the importance of the auditory sense (Bruyninckx 2012; Rice 2008). Lorraine Daston and Peter Galison, in particular, have done much to show not only how the meanings of objectivity have shifted over time, but how closely these shifts have been aligned with changes in imaging practices. Drawing upon examples from the genre of scientific atlases in a variety of scientific disciplines, Daston and Galison (1992, 2007; Galison 1998) trace the profound changes that the 'epistemic virtues' of science have undergone in the course of several centuries. They concentrate their attention on three such epistemic virtues (truth-to-nature, mechanical objectivity and trained judgement), which emerged at different historical moments in time, but without ever driving away the predecessors completely: "New epistemic virtues come into being; old ones do not necessarily pass away." (Daston and Galison 2007: 41) According to Daston and Galison, up until the second half of the nineteenth century, the ideal of 'truth-to-nature' reigned in science: in this regime of representation, scientific atlasmarkers sought to abstract from the individual idiosyncrasies that exist in nature, in favour of a higher plane of perfection. For instance, when depicting a plant, an image-maker was never to depict an individual specimen, with its blemishes and imperfections, but rather to derive from a number of individual specimens the ideal characteristics of the underlying type, and so represent what the plant would look like if stripped of all of its irregularities and variations. Such scientific depiction rested upon a careful distinction between the typical and the accidental and required the judgement and skills of a sage.

In the second half of the nineteenth century, the ideal of mechanical objectivity emerged, stealing much of the ground that had previously been occupied by truth-tonature. Daston and Galison $(1992,2007)$ show that mechanical objectivity claimed to "let nature speak for itself"; in this regime of depiction, intervention by human beings to show an idealised archetype was very much frowned upon as anseemly activity and contaminating influence; instead, the actual specimens, with all their peculiarities and irregularities now moved to the front-stage, and their individual blemishes came to be seen as markers of authenticity. With the help of various mechanical devices different graphical techniques, but especially the camera, were at centre of this development - the presence of the observer could (supposedly) be eliminated entirely. Non-intervention was now the highest ideal that a scientist could aspire to.

Daston and Galison (2007; Galison 1998) also discuss a third regime of representation, which emerged in the twentieth century: trained judgement. Within this regime, interpretation and intervention became permissible again. However, now intervention was not to be the act of a genius or sage (as was the case in truth-to- 
nature), but of a trained expert, with a "professional, practiced eye" (Galison 1998: 336). "The expert (unlike the Genius) can be trained: and (unlike the machine) the expert is expected to learn - to read, to interpret, to draw salient, significant structures from the morass of uninteresting artifact and background" (Galison 1998: 337). Unlike in truth-to-nature, the goal is not the idealisation of nature, but the distinction of relevant from irrelevant information and detection of patterns and structures in the data. While the geniuses of the seventeenth and eighteenth centuries sought to idealise nature, and the scientists of mechanical objectivity practiced (or at least preached) absolute self-restraint, the regime of trained judgement marks "a newfound confidence among scientists in the twentieth century" (Daston and Galison 2007: 313). It is this third regime of depiction, trained judgement, that will be most relevant for the purposes of understanding sonification; the putative promise of sonification, after all, lies precisely in its ability to detect structures and salient patterns among a large amount of data - and to do so by a type of intervention, of making audible something that had not previously been audible. As we will see in this chapter, sonification researchers routinely draw upon elements of the discourse described by Daston and Galison in order to justify their activities.

It is worth noting that the word 'objectivity' does not appear in the terms 'truthto-nature' or 'trained judgement'; for Daston and Galison, these are not types of objectivity, but alternatives to it: "However dominant objectivity may have become in the sciences since circa 1860, it never had, and still does not have, the epistemological field to itself. Before objectivity, there was truth-to-nature; after the advent of objectivity came trained judgment." (Daston and Galison 2007: 27f.)

However, there are various moments where Daston and Galison acknowledge that trained judgement is better considered a supplement rather than the diametrical opposite of objectivity. For instance, they point out that "scientists invoking judgment to form their atlas images in the twentieth century had already taken on board or worked through mechanical objectivity" (Daston and Galison 2007: 318), and what's more, that these scientists did not reject the instruments of objectivity: "they embraced instruments, along with shareable data and images, as the infrastructure on which judgment would rest" (Daston and Galison 2007: 329). Indeed, Daston and Galison conclude: "By the mid-twentieth century, objectivity and subjectivity no longer appeared like opposite poles; rather, like strands of DNA, they executed the complementary pairing that underlay understanding of the working objects of science." (Daston and Galison 2007: 361) In all of these examples, however, trained judgement is described as coexisting with (mechanical) objectivity, rather than as being itself a new form of objectivity. 
In my reading of the sonification discourse on objectivity, it makes more sense to think of trained judgement - or rather, 'trained ears', the term I will use for the specific form that the epistemic virtue of trained judgement takes in the context of sonification - as a new conception of objectivity: one that defines itself not in opposition to subjectivity, but instead embraces elements of subjective intervention and interpretation, but without giving up all claims of objectivity. These researchers insist that sonification can be both subjective and objective. Like in the anecdote that started this chapter, they often draw upon the more established authority of visualisation in order to do so.

This recurrence on visualisation is unsurprising, as historical studies show that even disciplines that study sound have often turned to visualisation in order to render their object of study 'objective'. For instance, graphical techniques such as the spectrograph have come to play an important role for the study of birdsong, as many ornithologists distrusted an approach based entirely on listening, which they considered to offer only a "subjective and individual experience" (Bruyninckx 2012: 142). Various graphical techniques have also played an important role in the development of acoustics as a scientific discipline. For instance, in his study of the nineteenth century acoustician and instrument maker Rudolph Koenig, David Pantalony provides a detailed description of one specific episode in the history of acoustics in which visual techniques were used "in a conscious move away from too much reliance on the 'expert ear"' (Pantalony 2004: 433). Douglas Kahn argues that graphical techniques especially helped to differentiate the new discipline of acoustics from music:

Beginning in the late eighteenth century and pervading the nineteenth century, three new inscriptive practices as applied to sound - graphical techniques in general, visible sound techniques, and automatic recording instruments as represented by the phonograph and phonography contributed to a loosening up of the reliance of acoustics upon music. A plethora of lines made sound tangible and textual by making the invisible visible and holding the time of sound still. (Kahn 2002: 180)

Hankins and Silverman (1995) provide a thorough historical study of the importance of graphical instruments for the development of acoustics in the nineteenth century. Their conclusion is quite similar to Douglas Kahn's, and makes explicit how these graphical techniques were linked to a new conception of objectivity that emerged at the same time: 
Acoustics became recognized as a part of experimental physics - distinct from its origins in music or harmonics - when a battery of new instruments was developed to analyze sound and to record it pictorially. With the graphical trace, a complex sound wave could be described in terms of precise physical quantities, rather than by the subjective evaluation of the human ear. (Hankins and Silverman 1995: 221f.)

Here, the resemblance to what Daston and Galison call mechanical objectivity is obvious: with the help of machines that mechanically record the properties of sounds, the necessity of a subjective evaluation of acoustic characteristics was reduced and the sounds were thus both visualised and objectivised in the same move - or such was the hope, in any case, of the proponents of these graphical methods.

There is thus a long historical tradition of using visualisation in order to objectively study the properties of sound. Sonification, of course, attempts a different strategy, as listening itself is now being presented as a scientific strategy, and the expert ear is re-introduced as a scientific authority. This goes against the grain of scientific developments of the last one and a half centuries, and so it should come as no surprise that many scientists express doubts about listening as a strategy of scientific research. In the next section, I will establish that objectivity, or rather the perceived lack thereof, is a problem for sonification, as many scientists are sceptical about whether sonification can be an objective scientific approach.

In the remaining two sections of this chapter, I will explore the response of the sonification community to this accusation that listening cannot be objective. As I will show, the sonification researchers have developed different discourses of objectivity in response to such scepticism, and these discourses have to be understood in the context of different research interests and disciplinary perspectives that exist within the sonification community. In section two, I will therefore trace the constructions of 'objectivity' and 'scientific quality' as they are being debated and negotiated in the ICAD community. In the third section, I will then probe further into the origins and motivations behind these constructions: how can they be understood in terms of different research interests, different conceptions of the users of sonification, and different disciplinary perspectives?

\subsection{Sonification vs. “the Hard Science”: Amusing, Trivial and Marginally Relevant}

In chapter 2, I have shown that sonification is becoming an increasingly popular tool for public outreach and popularisation activities; a tool which is praised because it 
offers a new kind of sensory experience, a new type of intuitive access to the data. This framing of sonification implicitly casts it as something that is useful only for the purposes of communicating with the general public, but that would be rather less effective in helping scientific experts understand the data that they study or communicate it to their specialist peers. After all, intuitive sensory experiences are not regarded as essential to objective and reliable scientific knowledge by most scientists; Anne Beaulieu summarises this attitude as: "the intuitive is not scientific and therefore dangerous" (Beaulieu 2002: 75). In order to figure out just how accepted sonification is as a scientific method and whether it faces scepticism in the scientific domain, I have asked these researchers how they use sonification and how their academic peers tend to react to it. Their responses show that they mostly conceive of it as a gimmick that may be useful in attracting interest by the masses, but useless as a tool for scientific analysis

Some researchers restrict the playing of these sounds entirely to public talks for a general audience, while others use them more widely. One astrophysicist, who plays the sounds of the universe just after the big bang in public lectures, categorically rejects the idea of playing these sounds for an audience of scientists: "I would not do it, no. I would feel ashamed. (...) It's too trivial." (Interview Heise) In contrast, the astero-seismologists Conny Aerts and Donald Kurtz describe how they use sonifications of stellar oscillations:

Yes, I take that to scientific conferences as an introduction if it's not a conference in my own field. So you have general conferences sometimes, where people work in cosmology or in planets, and they have nothing to do with this field. (...) I also do it with my classes. (...) [But for talks with specialist peers] we wouldn't use them, no. No. We use the frequency diagrams. (Interview Aerts)

I gave a professional talk at Warwick University on Wednesday (...), and that was to graduate students, post-docs and staff. And even though it was purely technical, there were a couple of places during the talk where I played some audible sounds for their amusement too. (...) They understand that we don't do science on that, but they too are amused by these things and interested and, sure, I use it even for professional talks. (...) Whenever you're giving a talk, you don't want to just go on and on hammering about hard stuff, you got to kind of let up and be light occasionally to keep the flow and to keep people from losing mental energy, and these are very useful for that. They're 
marginally relevant, but they're an amusement that kind of lifts the level of the talk up to the superficial level briefly, to let you get a mental breather before you dive back into the hard stuff again. (Interview Kurtz)

Aerts and Kurtz draw the line at playing the sound files in front of an audience of specialist peers, but they both acknowledge that distinguishing only between a general and a specialist scientific audience is not sufficient: there are categories that fall in between, such as those of amateur scientists, ${ }^{53}$ scientists-in-training or peoplewho-are-also-scientists-but-not-immediate-colleagues. Kurtz' considerations also show that it is not only a question of whether or not sounds are being played at all, but one of how much room they take. Whereas he professes to use his sound examples "veeerry sparingly for a professional talk", his talks for a general audience will be "much more on the sound, much easier on the hard science" (Interview Kurtz). Amateur scientists, who are "not the general public, they actually do know some astronomy", will get "some hard stuff" (interview Kurtz) along with some sounds. The implication is clear: the more ignorant of the 'proper science' an audience can be expected to be, the more sonification examples they will get to hear at Kurtz' talks.

Some of my interviewees report that the sonifications are better-received among the general public than among their peers. In preparation of a public talk, John Heise exchanged notes with another professor who was going to speak in the same lecture series. When Heise informed him of his plans of using sound, "I knew from his reaction that he didn't approve that at all" (interview Heise). Similarly, Chris Hayward mentions giving a lecture that attracted both a general audience and colleagues from seismology. "And for the general audience, who, you know, weren't seismologists, it was kind of neat, and from the seismologists, it was, 'well you didn't set up the experiment correctly, because, you know, of all of these details'." (Interview Hayward) Hayward concedes that there were seismological shortcomings in their demonstration, and he soon stopped trying to use sonification in specialist contexts because the promise simply didn't match the effort of doing it properly. He continues to make use of sonification examples for general audiences or students, but does not bring them to specialist talks anymore.

However, some scientists do play their sonification examples at talks for specialist audiences. For example, the astrophysicist Zoltan Kolláth says he always brings sounds; while his specialist peers might not need the sounds in order to understand what he is talking about, "usually they enjoy it. At least you can wake up the guys."

\footnotetext{
${ }^{53}$ Indeed, amateurs have a particularly prominent tradition in the field of astronomy (Schaffer 1988; McCray 2008), and continue to play a role in astronomy today (Messeri 2010).
} 
(Interview Kolláth) Milton A. Garçes also reports that he brings his audified infrasounds of volcanoes to scientific conferences all the time - and resents my question of whether he even plays in front of an audience of fellow infrasound specialists:

Oh, especially! (...) Usually, it comes as a relief, because people say, "oh, I can understand that!" So it's almost like a comic relief or hiatus in intense scientific discussion. So usually these sounds are accompanied by very solid scientific work. And so, if you put it, "listen, just for fun, let's put this on!", then people welcome that. It's almost like telling a joke in the middle of my talk. It breaks the tension, it makes it more accessible, and it's something that you can walk away with, you know. It's a different kind of memory. (Interview Garçes)

These quotes show that practices of how and for which audience the sounds are being played differ between different scientists working with sonification examples. Some use them exclusively for popular science talks in front of a general audience, others also draw upon them when talking to students, amateur scientists or professional scientists from a different discipline or specialisation, and others again also declare playing them for their scientific peers. It is worth remarking that Garçes and Kolláth, who both passionately talk about playing sound examples at scientific talks, have actually produced these sounds themselves, and have invested considerable creative and aesthetic energy - in the case of Kolláth, also in collaboration with the composer Jenõ Keuler - into making them. Some of the other scientists mentioned above, who rule out using the sounds for conference talks, such as John Heise and Donald Kurtz, have not; they make use of existing sound files that circulate on the internet or among their peers. Kolláth and Garçes' decision to play these sounds for their peers might be related to the enthusiasm and the sense of pride of the amateur musician (for they both talk about their sounds as music) who has invested a lot of energy of making something and wants to share it with the world.

But perhaps it's more than just a matter of artistic pride. The scientists who transformed the signals into sounds themselves also know them more intimately than those who came across them somewhere. Or rather, they know not only the sound, but also the source signal and the process of transformation that resulted in the eventual sound. Those who merely play sounds created by others, on the other hand, often do not possess this kind of knowledge: they understand the crude principle which was applied in order to shift the data into the audible domain, but not necessarily the specifics of it. Sometimes, they still remember who made the sounds that 
they are using (interviews Aerts, Kurtz). They profess to vaguely understand the kind of software being used - although they cannot say what that software was, exactly (interviews Heise, Kurtz). They aren't necessarily sure that the different sounds they use to demonstrate the properties of different stars have actually been transformed in the same way, and therefore cannot guarantee that they really allow for comparative listening; in other words, the stars may not be "playing in the same key" (interview Kurtz). These kinds of details are often deliberately ignored as irrelevant, and some researchers even resent it if their audience engages too much with the details of the sounds (interview Heise). Overall, then, many of these scientists don't necessarily know or care about the specifics of the transformation, unless they were the ones making the transformation in the first place. This might indeed be a significant difference. As Peter Galison (1997: 427) points out in his discussion of the bubble chamber in particle physics - drawing upon earlier work by Hacking (1983) on microscopes - the belief in the reliability of scientific instruments has much to do with both the ability to intervene and with an understanding of the physical and technical principles of the apparatus. The apparatus for sonification, of course, is the software used to transform the data into sound, and those who know their instrumentation do indeed seem to have more trust in the resulting sounds.

Yet this difference should not be overemphasised; at the core, despite the different practices of making sonifications and playing them for various kinds of publics that have been sketched above, sonification seems to be framed in a remarkably similar way by these scientists. These examples all show that the scientists think of the sonification as not quite properly scientific. Even those who play the sounds for their specialist peers describe them as welcome elements of diversion or entertainment that can help to liven up an otherwise dry and difficult academic presentation, rather than as accurate and objective representations of scientific data that can help scientific understanding of the phenomena under study. A fairly clear dividing line is drawn between the sounds as entertainment and the transmission of what Kurtz has referred to as "the hard science". The sonifications entertain, give some room to breathe, maybe convince the uninitiated that this is fascinating stuff, but they don't add anything to scientific understanding; they are made to look epistemologically inconsequential. But that they are indeed so inconsequential does not go without saying. The way that sound has been produced for otherwise soundless and abstract phenomena such as stellar oscillations or seismic waves seems to show us something quite fundamental about how these phenomena are thought of and approached by the scientists; the example of thinking of volcanoes as working just like organ pipes or stellar oscillations just like trumpets have already been mentioned in chapter 2 . Such models 
are not entirely innocent, they can tell us something about the way that the phenomena being modelled are perceived by the scientists. Indeed, even if the sonifications are comparable to a joke being told in the middle of a talk, mere elements of light entertainment, that does not make them inconsequential, as humour and lighthearted diversions can be quite integral aspects of scientific practice (Mulkay and Gilbert 1982). The claim that the representations used to discuss scientific results are of no cognitive or epistemological importance whatsoever is quite an easy way out.

Yet many of the interviewed scientists do claim that the sounds aren't really related to their scientific work. After all, they tell me, when it comes to analysing data or communicating important information to scientific peers, they rely on different methods of representation: "But we don't use it in the analysis, we use it to give popular talks." (Interview Aerts) "But we don't do science that way, we do that for amusement." (Interview Kurtz)

The proper scientific way of doing it, according to these scientists, would be to visualise rather than sonify the data. In the most extreme cases, the effort that goes into visualising data is black-boxed entirely, e.g. when John Heise says that "I do the analysis on the computer, of course, so there's no sound produced", and that "the analysis is done by computer, and the computer doesn't interpret sounds, so there is a graph in the computer" (interview Heise). Here, it appears completely self-evident that a computer produces graphs yet no sound - as though the fact that the computer was programmed to produce graphs and no sound wasn't based on certain assumptions about what constitutes a useful display method in scientific analysis. When asked whether he would make use of it if the computer did routinely produce sounds, Heise answers in the negative: "No, it wouldn't add anything useful. Because it's the number that counts." (Interview Heise) For Donald Kurtz, too, the proper scientific way of working has nothing to do with sound, as scientists - unlike the general public - approach science through graphs:

Our way of looking at things is not the way of the general public. And so we've taken this information that we've received from the sounds in the stars, causing the stars to vibrate. We then use mathematical processing to extract the information about the sounds, and then we use that to model what's happening inside the stars. (...) And the tools that we use to do that and talk to each other are graphs. (...) So we're plotting lots of scientific graphs, which to you just looks like incredibly arcane lines drawn through points. But we've learned to see that, and with that as the information coming into our minds, 
we are building up a picture and actually seeing the inside of a star. (Interview Kurtz)

Visualisation is also mentioned as an essential element by Conny Aerts: "First of all, we visualise it. Because a data analyst who does his job properly should do that. We look at the data." (Interview Aerts) So, visualising is part of the routines of what 'a data analyst who does his job properly' should do, but sonifying it is not. Frequency diagrams - the specific type of visualisation that Aerts is talking about - simply match "how we think. It's more precise, and that's the way we think" (interview Aerts).

Interestingly, however, the visualisations that seem to be the epitome of scientific analysis are not exactly regarded as images here; what these scientists emphasise are the numbers behind the graphs and diagrams. As John Heise has remarked, "it's the number that counts" (interview Heise). The number, not the image. The number just happens to take the form of an image in the process of scientific analysis. This is a well-known trope among STS scholars studying pictorial practices in science, many of whom have second-guessed whether the visual form is merely coincidental and indeed has no bearing on the contents of scientific knowledge. For instance, Kwa et al. (2009) have investigated the role of images in geography and landscape ecology and have concluded that the scientists' insistence that these images are merely pretty pictures with no further significance should not be taken at face value: the pictures help to define their object of research, and indeed the process of fine-tuning models of ecotopes is mostly carried out by eye. In a study about digital brain mapping, Anne Beaulieu has coined the term of 'iconoclastic imagers' for scientists who create images as a central aspect of their research practice, yet downplay the epistemic significance of these images, insisting that "these 'pretty pictures' are at best useful visual aids when giving talks" (Beaulieu 2002: 54), and that the images aren't really images but statistical maps anyway. But Beaulieu concludes that "in spite of the distancing from imaging contexts and from the visual (...), the arguments and claims of functional imagers rely to a great extent on aspects of these traditions. It appears that while an epistemic role is often denied to representations, their use does contribute to the study of the brain specific to functional imaging through reliance on the spatiality of the data." (Beaulieu 2002: 74) Beaulieu traces this paradox back to a traditional hierarchy of scientific evidence in which knowledge that appeals to cold reason is considered more valuable than that which appeals to the senses.

With their emphasis on diagrams as numbers, the scientists studied in this section could also be regarded as 'iconoclastic imagers' who create and use images but 
deny their significance. Yet if they are iconoclastic about the images they employ, then they are even more sonoclastic about their sounds. After all, the images are at least granted a role in the process of scientific analysis, while the sounds are relegated entirely to the realm of popular talks, or to the status of jokes when they are used in professional talks.

The decision to frame sonification in this way is not necessarily always born out of conviction that sonification is not sufficiently credible to be used as a scientific technique; it can also be a pragmatic decision related to career perspectives - which are all the more telling about how these scientists perceive the general scientific opinion on sonification. For instance, physicist Lily Asquith positions her sonification work mostly as a science popularisation activity, and it is indeed through public outreach funding that the project is financed. Asquith's ambition, however, is to make the sonifications useful for her own research:

I want it to be useful for me. (...) And it's probably the most exciting part of it for me, but it's a case of finding enough hours in the day to actually try and implement it, to make some kind of proof of it having any use. And then of course to get anyone to take it seriously will be, ah, [laughs] a huge task, because physicists - you do things the way you do them, as everyone does. You have methods of doing science, and why on Earth would you want to listen to it, you know? It's not something I want to be making a big fuss about, because I want people to take me seriously as a physicist. [Laughs.] I'm at the beginning of my career, and I don't want to be famous for being mad. [Laughs.] But it's something I'm quietly working on. (Interview Asquith)

Asquith is well aware of her fragile status as a young physicist: when the sonification project started, she was in the final stages of her $\mathrm{PhD}$ project, and work on it continued while she was looking for a job. By the time I interviewed her, she had just moved to a new continent in order to start working as a PostDoc, and sonification became "very much something that I'm trying to fit in around my job" (interview Asquith) even the interview with me took place on a Sunday, before taking a friend on a boating trip.

Not only is it difficult to build a career upon sonification, but even as something that's done in the spare time, sonification is a potential threat to the career of a young scientist. And careers of young scientists are increasingly marked by fragility and uncertainties anyway, as a growing amount of scientific research is based on externally funded, short-term research projects, while prospects of stable, permanent posi- 
tions are getting dimmer (Allen Collinson 2003; Araújo 2009; Hakala 2009) - developments which are arguably especially disadvantageous for female researchers (de Cheveigné 2009: 131). Especially for young (and even more especially, young female) scientists, who have yet to build a lasting reputation, getting too involved in sonification work can therefore be a threat for one's career prospects. Sophia Roosth points out that when Jim Gimzewski started listening to yeast cells, he already was "a celebrity in the nanotech world" (Roosth 2009: 334) who had won numerous prestigious awards, and in doing so, Roosth implicitly hints that he could get away with a little bit of craziness. For a less established scientist, however, the stakes are high. Asquith's way of dealing with this problem is to downplay her interest in sonification as a scientific tool to some extent, and to instead put more emphasis on its usefulness as a means of public engagement. When prodded whether that means that she is trying to sneak sonification into scientific research practice through the backdoor of science popularisation, Asquith concurs:

I mean, I've been honest about this from the beginning that I think there's something in this, I think we can use this as a technique. But I'm very aware that I need to be careful with that. (...) It's very much useful as an outreach project, and I really enjoy doing communication work, so that's - it's not a pretence, it's true that it's an outreach project, but it, yeah, you're right, it's a nice way to try and sneak it in quietly. (Interview Asquith)

Sonification, it appears, has a long way to go before it can be considered an established scientific technique, something that does not need to sneak in through the backdoor. Of course, the strategy of the ICAD community - which was first introduced in chapter 3 and which will also be the focus of the remainder of this chapteris to march in through the front door, anyway: many researchers within ICAD actively try to establish sonification as a legitimate scientific activity, not merely a nice publicity gag to be used during public talks. However, they, too, face criticism and scepticism in the wider scientific community. One ICAD board member describes that he was the first to establish sonification as a research theme within his university department of neuroinformatics. In doing so, he had the support of the head of the department, but was also confronted with "very sceptical looks from colleagues who said, 'well, will that really be of any use', 'this could also be visualised instead', 'listening is very subjective' - and all these arguments that were voiced against listening" (interview Hermann 1, translated). Another ICAD member recalls approaching a professor in financial science about a possible collaboration: 
And of course I went to talk to him and he thought I was crazy - "what are you talking about, turning the market into sound?" They can sort of visualise things, you know, most people are so visually oriented that they understand what a graph is, but the idea that you'd listen to this, it sounds slightly off the wall, really. And that is a pressure in this whole game, you know, in this whole field, people are quite suspicious. Suspicious is maybe not the right word quite sceptical, I would say. They need to be convinced, in a way. (Interview Worrall)

Such scepticism is often a problem in the process of peer review, where the reviewers are usually domain specialists without any sonification experience. Several of the interviewed scientists report that project proposals were rejected because of a reviewer very polemically arguing against the scientificity of the proposed approach or even, simply, because the reviewers failed to understand what was being proposed (interviews Grond 2, Hermann 2, de Campo). Here, too, the situation is particularly problematic for young researchers. For example, Florian Dombois relates that when he first started transforming data into sound 15 years earlier, his geophysics professor at the time was "quite disappointed and actually also shocked". After all, the professor was convinced, "that's not objective“ (interview Dombois, translated).

According to Dombois, the situation isn't quite as severe as it was 15 years ago, and his peers have become "much more pragmatic and open" (interview Dombois, translated). That is probably true - although it might also be true that Dombois' own perspective, and the perspective of others upon his activities, has shifted to some extent because most of his recent work has been situated in artistic or art-as-research contexts rather than in 'purely' scientific ones. In any case, young sonification researchers today do still seem to face a certain amount of scepticism from their (nonICAD) 'home' disciplines. For instance, when Katharina Vogt started working on the sonification of physical data (as part of the SonEnvir project, an Austrian interdisciplinary and interuniversity project that ran between 2005 and 2007), she was a PhD student at the department for theoretical physics in Graz. Yet this environment proved not particularly welcoming towards sonification work, or more generally, towards young female researchers with an unconventional research topic (interview Vogt). As a result, she switched to become a member of the department for electronic music instead, and kept ties with the physics department mostly through her secondary supervisor. A year before finishing her $\mathrm{PhD}$, she had all but given up hope of convincing the physicists at her former department of the usefulness of sonification: 
Well, I don't believe that it's really possible to convince them to switch [to using sonification], I don't believe it. They will, even if I have a great sonification that works great, they will say, 'yes, that's cute' (...), but they would not change their methodology because of that. I don't think they would. Especially theoretical physics is far too abstractly oriented for that and too far away, somehow, from the idea that things can be regarded as being relative. It's all about absolute truth, that's just how it is, and that's a number that's just written somewhere. That's not exactly what I believe, but that's the attitude I come across. (Interview Vogt, translated)

In a different $\mathrm{PhD}$ thesis emerging out of the SonEnvir project, Alberto de Campo summarises the reactions of the physicists who tried out the sonifications: "The main point of criticism was the idea of a qualitative rather than quantifiable approach towards physics, which is seen as a possible didactics tool but "not hard science." (de Campo 2009: 120) In other words, the physicists were open to the idea of using the sounds in outreach activities, but sceptical of the ambitions of the SonEnvir team to integrate sound into the toolkit of standard scientific analysis techniques.

So far in this chapter, I have shown the contested status of sonification in science: sonification has to struggle with the perception of not delivering objective representations of data, and therefore being useless as a tool for 'real' scientific analysis and communication. In the remainder of the chapter, I will show how researchers within ICAD attempt to frame the debate around the objectivity of sonification in a different way in their efforts to establish it as a scientifically legitimate procedure.

\subsection{Evaluating Ourselves to Death or Doing Show-and-Tell}

"Bam-bam-bam-bam-bam." Over the phone, Bruce Walker sings me an auditory graph with rising pitch. I have asked him to name an example he likes to draw upon in order to convince his fellow psychologists of the value of sonification-related research. Walker's example is more than just the auditory graph itself. After letting them hear the graph and explaining that the sound represents money, he would ask his colleagues whether he was getting richer or poorer. Almost all of them would answer that, as the pitch goes up, the money increases. Walker would then tell them about a study in which hundreds of people, both blind and sighted, were asked this question. While the sighted respondents shared the interpretation of Walker's colleagues, the blind respondents thought the opposite. Walker concluded that blind and sighted respondents worked with different mental models; while for most sighted 
respondents, high pitch equalled high amounts of money, the blind respondents worked with a different logic:

If I took a coin and I dropped on a table it would go 'clink'. If I took a roll of coins and dropped them on the table it would go 'clonk'. And if I took a bag of coins and I dropped it on the table it would go 'thud'. And for [the blind people], more coins, more money (...) makes a lower pitch sound. (Interview Walker)

Walker uses this anecdote to demonstrate to his psychologist colleagues that research on auditory perception yields interesting and unexpected results - and can be backed up, of course, by correlation coefficients. ${ }^{54}$

However, what interests me in this chapter is the way that debates about the usefulness of the kind of evaluation of auditory displays described by Walker shape the ICAD community itself, and not just its relations to other fields, such as psychology. Specifically, I will argue that the self-conception of ICAD as a community which produces objective and credible scientific research is very much entangled with a discourse about user testing and evaluations. However, different disciplinary orientations make it difficult for the community to reach consensus on whether, when and what kind of testing is required. I will therefore sketch out an alternative conception of the objectivity of sonification that co-exists next to the user-testing paradigm. I will refer to these two conceptions as the correlation coefficients and the trained ears approaches.

The issue in these debates is not so much that anyone denies that evaluations of sonification mappings can be of value; however, what is at stake is whether such research should be included with every sonification publication. Traditionally, this has not been the case. After the first ICAD conference, Gregory Kramer summed up:

Auditory display is a young field. As in any field, it takes time to establish a solid foundation of rigorous research. (...) Few of the papers at ICAD included the actual running of subjects along with the experimental design necessary for a more rigorous proof of display effectiveness. (Kramer 1994b: XXIX f.)

\footnotetext{
${ }^{54}$ The results of this study, and the accompanying correlation coefficients, can be found in Walker and Lane (2001).
} 
Recent literature studies of ICAD proceedings - which are congruent with my own readings in the field - indicate that "there has been a trend toward increasing usage of [user or participant data] testing" (Bonebright and Miner 2005: 518). In Frauenberger's (2009) survey of the publications in the proceedings of ICAD 2007, ${ }^{55}$ all but four out of 23 papers included some sort of evaluation of the designs - but that includes subjective evaluation by the author or pilot studies promising further research as well as the 'experimental design' that Kramer had hoped for. In a recent publication, David Worrall expresses a desire for an integration of sonification tools with tools for evaluation, which would allow the conduction of experiments and analysis of results in a single framework and thus "promote the independent evaluation of empirical experimentation necessary for scientific validation" (Worrall et al. 2007: 451). In an interview, a long-standing ICAD board member explains why he considers quantitative user tests to be essential:

You need some way to measure what you actually achieve when you're using sonification. It's not enough that you say this, listen, this really sounds better than yesterday. That's not the result. But if you can show that when you have 10 people doing this task they do things $10 \%$ better when they're using the auditory display than when they're not using the auditory display - that's a result. (Interview Gröhn)

A result, it would appear, is only a result if it can be expressed as a percent value and preferably be assigned with a level of statistical significance. 'Trust in numbers' (Porter 1995) is the name of the game. Another interviewee takes a similar line when he refers to such work as having 'research components,' as opposed to doing 'show and tell':

I always encourage papers at the conference that have evaluation components, that have research components, that are introspective or self-reflective. They look at what they've done and they try to assess it and evaluate it and figure out, place it within some theoretical context. As opposed to the kind of papers where people are basically doing show and tell. (...) There will always be plenty of applications, but I think we always need to push for more of the science and evaluations. (Interview Walker)

\footnotetext{
${ }^{55} \mathrm{He}$ took into account all 11 papers and 12 posters that presented a design for an auditory application, ranging from sonifications of scientific data to auditory games. "Papers describing purely artistic projects" were excluded, since they follow a different rationale, where the issue of evaluation is posed differently (Frauenberger 2009: 59).
} 
It's interesting to see what counts as a 'research component' here; it has to do with placing one's work in a theoretical cadre and relating it to the work of others, but is also strongly associated with evaluation and experimental set-ups. An important part of this is the existence of a control group against which the results are measured. For instance, Paul Vickers talks about a study on program sonification by one of his peers, criticising the lack of a proper experimental design: "he didn't really have a control group, so he didn't compare his program sonification against people who weren't using it. So you couldn't actually draw any firm conclusions from it, other than, I think $68 \%$ of people found bugs using his system, but...as opposed to what, is the question." (Interview Vickers)

Thomas Hermann also mentions the scientific necessity of doing user tests:

Journals are usually bent on having new contributions secured by evaluations, by user tests. (...) And, uh, that's time-consuming and laborious and sometimes blocks the process of actually bringing our methods to the people. But it just has to be done, that's how science works. (Interview Hermann 2, translated)

However, compared to the interviewees quoted above, Hermann seems less enthusiastic about this need for user testing; it is required if you want to publish your work in a renowned scientific journal, but it also slows down the development of new techniques and the process of making these available to the public. He goes on to suggest that ICAD should not adopt the requirement of user testing from the scientific journals, and instead put more emphasis on exchanging inspiring ideas and techniques:

Where the scope of possibilities to represent data via sound is concerned, we are still at the beginning. I think that there are still procedures, techniques and approaches that nobody has even thought of before, and that one should dare to methodically penetrate into unknown territory as well. And personally, I really welcome it, because it inspires me a lot, if things can be heard at ICAD conferences that have never been sonified in this way before and that nobody has heard before, and that is valuable in itself, because it fosters creativity. And in this context, it is a pity if these, occasionally very interesting, novel, innovative approaches are not accepted as a paper because they lack an evaluation. (Interview Hermann 2, translated) 
Hermann does not question that evaluations make up "the scientific value in terms of traditional criteria of assessment", but he does suggest that this is not the only thing that should dictate the process of peer review at ICAD. While such traditional scientific standards may be appropriate for academic journals, they would be inappropriate at ICAD, as many conference attendants would be disappointed if they "heard presentations where they just see a few statistics with levels of significance, but don't hear a single sound" (interview Hermann 2, translated). He therefore suggests that inspiration of the community should be an important factor next to the traditional scientific criteria in accepting papers; not only the confirmation of knowledge and evaluation of methods should be considered as valuable contributions, but so should the presentation of new techniques. This is important, he argues, precisely the full range of possibilities of transforming data into sound has not yet been explored - an argument that roughly corresponds to the concern of Florian Grond that the community displays a tendency of "evaluating oneself to death", as an evaluation might have the result that "a plant is killed, so to speak, before it is even fully grown" (interview Grond 1, translated).

The objections to user testing, however, are not limited to the putative danger of premature evaluation of an as-yet-fragile research field. Another concern is that, while user tests surely measure something - and even express the results in neat numbers, endowed with measures of significance - it's not always clear that what's being measured really addresses the potentially most useful aspects of the sonification. According to Alberto de Campo, user testing often involves developing "rather trivial tasks" and then measuring how well or how quickly they are performed by the test users. This style of measuring, says de Campo, does not match the openness and complexity of scientific practice. So if the sonification is intended to afford new possibilities of exploration and interaction, then such a style of evaluating "measures something that's easily measurable, but something you're not actually interested in" (interview de Campo, translated). Florian Grond expresses very similar concerns when he points out that evaluation is always about well-defined tasks, but that actual scientific practice often involves problems for which no solution has been found yet, and where immediate revelations cannot be expected from any method of data analysis - a mere measurement of performance in terms of the efficiency of problemsolving is therefore not necessarily appropriate, because "this defined task has nothing to do with whether the tool is really useful in the end" (interview Grond 1, translated).

Despite some of these critical remarks about the destructive effects or the false sense of verification provided by user tests, it appears that peer review practices at 
ICAD do tend to favour papers that have included evaluations. While the standard peer review form for ICAD submissions does not explicitly ask whether user tests or other forms of empirical validation have taken place, ${ }^{56}$ some of my interviewees profess to exert (gentle) pressure for such 'research components' when writing peer reviews for conference papers (interviews Gröhn, Walker). This approach is contested; for instance, Florian Dombois complained about the peer review practices at a previous ICAD conference:

Many of the best sonification examples were curated out, peer reviewed away. (...) There is a central stream and poster sessions, and [many] good things were sent into the poster sessions. Because [the reviewers] had abstruse ideas about evaluability and intersubjectivity. So they said, if somebody makes a sound and did not make a series of user tests with 17 - at least, I don't know, 17, 20 - test persons, then we cannot accept this, because that's not scientific. It's as if you would not have a graph printed if someone cannot prove that he let 17 people look at the graph to make sure they can see something in the graph. That is, I think, that's absurd. (Interview Dombois, translated)

Interestingly, here the authority of visualisation is invoked in order to justify why sonification shouldn't require mandatory user testing. Florian Grond makes a similar case, also drawing upon a comparison to visualisation:

The first visualisations of molecules were not evaluated, they were just made. And they were extremely functional. Certainly, there was some thought behind it and not just daubing something on paper, sure, but that's what I mean: something was done, it was extremely functional, it is - I'm not sure if the medial representation, if you can call this a scientific method, but it is at

\footnotetext{
${ }^{56}$ If anything, the ICAD peer review even explicitly acknowledges the possibility of valuable contributions outside of the realm of empirical testing. Reviewers are asked about the "Overall Value Added to the Field", and can check as many as appropriate out of the following options: New information; Valuable confirmation of present knowledge; Clarity to present understanding; New perspective, issue, or problem definition; Not much; Other. Of course, this list of options contains no indication of which kinds of contributions are more valuable than others; presumably, "valuable confirmation of present knowledge" weighs more than "not much", but is it worth more or less than a "new perspective, issue, or problem definition"? The blank review form doesn't say, so to the extent that this criterion is used to select papers for the conference, it is up to the paper chair - who makes the ultimate decision, on the basis of the peer reviews, to accept or reject a paper - to make this call. (This discussion is based on the blank review form employed in the peer review process for ICAD 2009, passed on to the author by a member of the ICAD board and regular peer reviewer.)
} 
the very least a valid scientific tool, without having gone through an evaluation process. (Interview Grond 1, translated)

Grond argues here that something does not need to have been evaluated in order to be accepted as a valid scientific tool, and uses the historical example of the first molecular visualisations as an instance that underlines his argument. Indeed, visualisation is drawn upon extensively in order to legitimise sonification practices. For instance, it is used to justify the sometimes subjective nature of sonification work, such as when presenters are asked after a conference talk why they chose to do something in a particular way. A frequent response is to point out that taking this kind of decision is also part and parcel of working with visualisation methods, and therefore, there is nothing illegitimate about it. The more accepted status of visualisation is thus employed as an ally to defend the subjectivity of sonification, and to maintain that sonification can be objective and scientific despite the necessity of making subjective decisions. Thomas Hermann also refers to visualisation to strengthen his argument for a definition of sonification as an objective scientific method (see chapter 3): "sonification is an accurate scientific method which leads to reproducible results, addressing the ear rather then [sic] the eye (as visualization does)" (Hermann 2008b: 3).

What can be noticed in this discourse about the relationship between sonification and visualisation is that the sonification researchers simultaneously destabilise and stabilise visualisation. On the one hand, sonification practitioners tend to be quick to point out the subjective and even aesthetic decisions that are involved in making visualisations - and in that sense, they destabilise the notion that visualisations are merely innocent depictions of nature. The idea of visualisations as 'mechanically objective' (Daston and Galison 1992, 2007), representing nature as it really is without any elements of human intervention, is thus thoroughly deconstructed. Yet at the same time, a message is delivered that "there's nothing wrong with that" - it's okay to make certain decisions and interventions in data visualisation, but if we can accept those decisions in visualisation, then we have to be ready to accept them in sonification, too.

This discourse of objectivity, then, links up (albeit implicitly) to what Daston and Galison refer to as 'trained judgement': a regime of objectivity in which human intervention and interpretation, and therefore a certain measure of subjectivity, is accepted. It is accepted under the condition that it is carried out by trained experts who highlight and make visible certain characteristics in the data, and who "with a trained eye" (Daston and Galison 2007: 328) are able to perceive patterns in the data that would otherwise go unnoticed. It is the status of the auditory equivalent - the 'trained 
ear' - that these sonification researchers seem to aspire to. This 'trained ear' is pitted against the requirement of user testing as a way to establish the objectivity of sonification. Accordingly, a paper given by Florian Dombois and colleagues at ICAD 2008 argues that sonification should seek to "involve more experts in each research topic" (Dombois et al. 2008: 3) instead of relying on user tests with amateurs. Once the expert opinions of domain scientists have been involved in this way, Dombois argues, "there will be good reason to trust not only the judgment of a visualization expert about a picture, but also a judgment of a sonification expert about a sound" (Dombois et al. 2008: 3).

In a paper at ICAD 2004, Andy Hunt and Thomas Hermann very explicitly embrace subjectivity, bemoaning its decreasing importance due to various technical inventions, such as the widespread use of computers, which have led to an "increased objectivity of measurement". Counter to this development, Hunt and Hermann propose "a countertrend which moves towards subjective methods, which will allow greater qualitative understanding of the system under examination" (Hunt and Hermann 2004: 3).

Considering such strong appeals for subjectivity and against objectivity, does it even make sense to regard what I have termed as the 'trained ear' approach as a conception of objectivity at all? I think it does; for while the sonification researchers at times very much emphasise the subjectivity of their approach, they can also be quite insistent that that does not mean that sonification is not objective. One of the authors cited above, Thomas Hermann, is after all the same person who proposed a redefinition of sonification as a scientific method, stating criteria such as objectivity and reproducibility (Hermann 2008b). And for other sonification researchers, too, it's often a matter of pride that sonifications are not tampered with after the fact: you can play with all sorts of parameters in the stage of sound synthesis, you can experiment with different mappings of the data to sound, but actually changing the resulting sounds themselves is often frowned upon. Indeed, Thomas Hermann argues that it is the combination of different subjective views that can add up to an objective sonification:

The reader may have the impression that such sonifications are so strongly tuned to the subjective preferences of the user that they may not be particularly 'objective' to communicate structural features in the data. However, sonification is actually always the result of strongly subjective tuning of parameters. Furthermore, each mapping is equally valid as true representation of the data. Only the combination of different (sonic) 'views' 
may yield a more 'objective' overall impression of structures in the data. (Hermann, Bunte, and Ritter 2007: 467)

In this quote, the trained ear meets with 'aperspectival objectivity' (Daston 1992), in which many different views from somewhere together add up the 'view from nowhere'. However, unlike in aperspectival objectivity, different points of view are not achieved by multiplying the number of observers (intersubjectivity), but rather by multiplying the number of sonic representations of the same dataset. It is through listening to many, many different sonifications (and possibly glancing at visualisations at the same time) that the researcher fully begins to understand the overall structure and patterns that are contained in the data; in other words, she has to lend her trained ear to the data.

It is this invocation of the trained ear that can be considered the main rival of quantitative user tests when it comes to establishing the objectivity and scientificity of sonification work. A number of sonification researchers within ICAD repeatedly stress that user testing should not be a requirement, because the community should be self-confident enough to trust that their methods work, and instead focus on developing useful techniques and applications that can then show their value by being taken up by scientific experts. The assumption is that they can prove their usefulness by providing methods that scientific experts are actually willing to put to use and are able to work with. If there is any need for a formal evaluation at all, then it should be a context-specific, not necessarily quantitative evaluation.

Several members of the ICAD community have started developing such alternative techniques of evaluation, often based on qualitative methods. Barrass' work towards a 'sonification design meshodology' (not a methodology, but 'a mesh of methods') is an example, as is recent work by Brazil and Fernström (2009), applying ethnographic methods to test an auditory display in its context of usage (interview Fernström). In some cases, qualitative evaluations are also combined with quantitative tests (interview Brewster).

It is not always easy to figure out how to best evaluate sonification. One problem is that it's not even necessarily self-evident what the appropriate evaluation criteria are. At the Science by Ear 2 workshop taking place in Graz in February 2010, the participating sonification specialists, programmers and physicists first went through a deliberative process in which the relevant evaluation criteria and their relative importance was decided, before each of them filled in an evaluation sheet giving a quantitative judgement of the various sonification approaches that had been developed by the interdisciplinary teams. While the team managed to find a consensus on the rela- 
tive importance of the different criteria, the process did show that the question of what the appropriate criteria for evaluation should be was not entirely obvious.

This workshop, Science by Ear 2, was held in the context of a research project on sonification in theoretical physics, QCD-Audio. The project was a follow-up of sorts to an earlier Austrian sonification project, the SonEnvir project - and indeed, the heritage to SonEnvir is made explicit in naming the workshop Science by Ear 2, as the first Science by Ear workshop was held in the course of SonEnvir. While QCD-Audio was dedicated entirely to sonifying data from theoretical physics (and specifically, quantum chromodynamics), SonEnvir involved data from different scientific disciplines. Besides theoretical physics, the involved domain sciences were signal processing, neurology and sociology, and the project was coordinated at the Institute for Electronic Music. It is due to this multidisciplinary set-up that SonEnvir is a particularly complex and meaningful case showing the struggle to find an appropriate evaluation methodology. The stated purpose of the project was the development of a sonification framework that would be useful for a broad variety of different scientific fields. Alberto de Campo explains the idea behind this interdisciplinary framework:

The reasoning behind this was that are actually many people who always build new stuff from scratch for a specific application, for a specific domain, and that surely there must be potential for synergy effects here, with things that are solved in a similar way each time anyway. Or where there may be five different ways and where it would be good if these standard cases would be more readily available and easier to adapt for new things. (Interview de Campo, translated)

Yet at the same time, the general framework is developed on the basis of the research problems brought to the table by a small number of academics from a few specific disciplinary backgrounds, so a certain tension emerges: "is it supposed to be about having a great framework in the end, or is it about having done interesting things for the specific domain sciences. Should be both, of course, in the best case." In fact, they aren't even necessarily in contradiction: "Well, in order to write a good framework, one actually needs interesting, difficult questions." (Interview de Campo, translated) The sociologist in the team, Christian Dayé, explains this tension in terms of a shift while the idea of a general framework acted as a starting point, the emphasis shifted more towards developing specific applications for specific contexts of usage:

At first the goal of the project was to build a generic platform for sonification, which would be somehow useful for, and could be used by, all disciplines. And 
that was somehow modified, to the effect that we said, well, that doesn't make sense, because we kind of obstruct the potential of sonification; it would be better to make case-oriented sonifications with the full range and try to think afresh about each of them. (Interview Dayé, translated)

But as a result, the question of what should be evaluated becomes less clear, because it becomes an issue of evaluating several specific collaborations rather than answering the more general question of whether this is "a platform that is useful to each of the domain sciences" (interview Dayé, translated). The evaluation thus shifted away from a general evaluation of the sonification framework, and split up into several different components: a sociological evaluation of the interdisciplinary working process (interviews de Campo, Dayé), and also, "wherever that was reasonably sensible" (interview de Campo, translated) an evaluation of some of the specific tools that had been developed.

The latter indeed had to be developed and considered for each discipline with an eye to the specific application context at hand. The sociological evaluation, because of the aforementioned concerns and because it appealed to the research interests of the sociologist performing the evaluation (interview Dayé), became an evaluation of the interdisciplinary working process, rather than of the usefulness of the sonifications for a sociological research context. For other disciplines, such specific evaluations were carried out, but the limitations were set by the nature of the research questions and of the available users to test the applications. For instance, for medicine, there was a user test, yet the number of scientists involved in it was too small to really allow a quantitative evaluation: "While we tested with the complete potential user group at our partner institution, a test group is rather small $(n=4)$; thus we consider the tests (and especially the open question/personal interviews section) more qualitative than quantitative data." (de Campo et al. 2007: 540) In physics, the idea of a quantitative evaluation was also abandoned: "A hearing test with statistical analysis was not appropriate as there are not enough subjects familiar with researching spin models." (Vogt et al. 2007: 264)

The previous paragraphs introduced some of the evaluation procedures that have been proposed and implemented in sonification projects as alternatives to classical, quantitative user tests. And they are indeed formulated as alternatives; standardised user tests serve as the reference point to which they are compared, as is obvious when the various SonEnvir sub-projects have go out of their way to justify why a more quantitative approach had not been possible. As Trudy Dehue has described the status quo in psychology, "comparative experimentation with randomly composed 
control and experimental groups is the standard against which all other research designs are measured" (Dehue 1997: 653). But why has this particular standard become so dominant in the interdisciplinary field of sonification? And furthermore, if it has become such a clear reference point, why does it remain so controversial, as the heated debates about the necessity of user testing, the competing conception of the 'trained ear' and the various alternative approaches of evaluation have shown? Why is it so hard for the sonification community to agree upon on a proper standard of good scholarship?

\subsection{Interdisciplinary Frictions}

The debates sketched out above show that there is little consensus within the ICAD community about what a proper standard for a 'good' or even 'objective' sonification should be. They also show that the ability to define such standards is something that the community strives for; as ICAD is becoming more standardised and professionalised (see chapter 3), such standards are becoming more prominent. At stake are the criteria by which a specific paper or research project is judged as a valuable or dispensable contribution to the field of auditory display; but at the same time, so is the standing of the field as a whole. In this sense, we can understand these debates as showcasing different strategies of establishing the legitimacy of sonification. This becomes most explicit when Florian Dombois argues that the privileging of user testing not only debases papers which include no such evaluations, but undermines the accomplishments of the community on the whole: "It's like giving up something you have just achieved, which is saying: listening is an authority." (Interview Dombois, translated) In this view, the insistence on evaluations has destructive effects precisely because it second-guesses the usefulness and appropriateness of sonification in every step. The approach favouring user tests, too, is involved with a quest for scientific credibility: listening is an authority, and we're not just going to claim it, we're going to prove it. Especially with its emphasis on quantitative testing, it links up to common strategies of quantification as a means of establishing objectivity and overcoming distrust (Porter 1995). Both approaches are thus concerned with different ways of establishing the scientific legitimacy of sonification.

However, the debates are not just of interest because we can see different types of boundary work at play. They reveal something quite fundamental about different quality standards, different ideas of what constitutes research, different conceptions of objectivity - and with that, they show something about the challenges of doing interdisciplinary research. My goal in this section of the chapter, therefore, is to un- 
derstand where the different views and perspectives come from. I will do so by taking on three different (but very much interlaced) aspects that have a bearing on the positions taken in the debates traced above: the different research interests that various ICAD members bring to sonification, the different users they have in mind for their sonifications, and the different disciplinary backgrounds they stem from.

ICAD is a small but diverse community of scholars, hardly a uniform group of researchers who all flock to the conferences because they are interested in the exact same issues and investigate them from the exact same perspective. Certainly, the community shares an interest in using sound to represent information, but the form that this takes varies considerably. While some in the field are more interested in aesthetic issues, others might emphasise informational requirements; while some are interested in investigating general capabilities and limitations of the human auditory system and exploiting this knowledge by designing applications according to these features, others might be more interested in using sonification as a tool for the analysis of complex data; while some use sonification to build audio interfaces for particular devices (such as a specific model of mobile phone or mp3 player), others concentrate their efforts on exploring particular datasets (such as EEG data or seismic waves) via sound.

These different research interests also entail different requirements of empirical verification, and therefore rub off on what the researchers consider appropriate standards of valid scientific research. For researchers who are interested in auditory perception - such as Bruce Walker, who describes his work as "psychological research and understanding those processes, and how people understand what they hear and how to design sonification to take advantage of the abilities of the human auditory system" (interview Walker) - it is essential to find out general features of the auditory system, and it is therefore plausible to involve relatively large numbers of subjects when putting a sonification to the test, as the perception of human subjects is precisely what's of interest. Walker names Thomas Hermann as a counter-example to his own interest:

I don't go and look for people who, uh, try to sonify their data. You know, someone like Thomas Hermann, in Germany - he creates sonifications, and he works with doctors and physicists and stuff, and his area of interest is new ways of sonifying data. (...) But he doesn't do the psychological research to figure whether his way is better than the previous or a different way. (Interview Walker) 
Thomas Hermann explains that what attracted him to sonification in the first place was the possibility of combining a life-long passion for music and listening with an interest in understanding and mining complex data (interview Hermann 1). As described in the previous section, Hermann does not reject user tests categorically; he considers them an essential element of getting papers published in high-standing academic journals. However, he does think of ICAD as a forum for the exchange of new ideas, techniques and approaches, and warns that the insistence on evaluations might put a damper on this exchange. Whereas for Walker, the user tests are an essential component of the research itself, for Hermann, they are a nice extra. This is quite understandable considering their main research interests: while Walker's research is primarily concerned with the hearing subjects, Hermann's is much more concerned with the data and with the techniques through which they are made audible. It stands to figure that actually involving a large number of listeners in the research is of more concern for the former than for the latter.

Already implicit in these different research interests are different intended users for the sonifications. Walker, who in a quote cited above mentioned that he does not seek out contact with specialists looking to sonify their data, professes to adhere to a "universal design perspective and try to design (...) to help as many people as we can" (interview Walker). This specifically refers to the equal inclusion of blind and sighted users, but also hints that the underlying user conception is a fairly generic one - the formulation by Oudshoorn, Rommes and Stienstra (2004) of the "user as everybody" springs to mind. While sometimes specific applications are developed for specific groups of users, Walker describes the overall principle as follows:

We understand that sometimes you have to make decisions and design something for sighted people that's not going to work for blind or vice versa, but our attempt is always, at least in the research, to understand what is necessary for all of those different groups. (Interview Walker)

This predilection has also shaped the tools built in Walker's Sonification Lab; with the 'Sonification Sandbox' (a name that already emphasises its playful, easy-to-use nature), a tool has been developed that caters to the 'average user'. This becomes apparent in a paper introducing the Sandbox to the ICAD community, in which the authors argue that, among other shortcomings, previous sonification toolkits have suffered from being "built for the expert sonification designer, and not the schoolteacher, student, or average researcher" (Walker and Cothran 2003: 161). This is in stark contrast, again, to someone like Thomas Hermann, who seeks out sustained 
collaboration with scientists specialised in a particular domain. He describes the ideal of such collaboration:

I am very versed in the development of methods and in the actual design of sonification, and of course I can't have the domain knowledge in all of these areas in which I have collaborations. (...) So it's great if you really have a team, of someone who brings this domain knowledge and the interest and openness for sonification, and someone who understands the methodical points and is able to efficiently and quickly transform these data into sound, and then together you can listen to these data. (Interview Hermann 1, translated)

The ideal user of the sonification here is far from a 'user as everybody'; it is a highly specialised researcher who is intimately familiar with the phenomena and data that are being explored by sound, and who can employ her expert judgement to appraise the sonification. Indeed, she has a specialised sonification researcher by her side, so that the two domains of expertise can complement each other, which makes the sonification more robust. This goes back to the 'trained ears' approach discussed above, but acknowledges that very few researchers would really be able to combine all of the necessary skills and knowledge that are required to exercise 'trained judgement' in sonification research; therefore, the expertise is shared between different members of a research team. ${ }^{57}$ Having said that, a sustained collaboration is not necessarily always desired. For instance, Florian Grond, who is doing his $\mathrm{PhD}$ with Hermann in Bielefeld, works on a sonification plug-in for a piece of software commonly employed by chemists to visualise molecular structures; the idea (although Grond himself expresses some reservations) is that the researchers might able to produce sonifications more or less independently (interview Grond 1). But here, too, the group of potential users is far more circumscribed than a generic 'user as everybody', as the tool is developed for application by chemists, integrated into the specialised software that they already work with.

The question of how the users are configured, however, has strong implications for the kind of evaluation being required; if the user is supposed to be 'everybody', then it makes sense to involve 'everybody' in testing the sonification. In practice, that often means involving relatively large numbers of subjects, for instance psychology students participating in the research for course credit (Smith and Walker 2002; Walker and Mauney 2004; Zhao et al. 2005), and letting this subsection of the popu-

\footnotetext{
${ }^{57}$ Dombois too mentions that sonification requires the expertise of "sound experts and scientists, who sometimes will all be the same person, but sometimes not” (Dombois et al. 2008: 1).
} 
lation stand in for the broader population of potential users. This, in fact, chimes with the conception of the 'user as everybody' as formulated by Oudshoorn, Rommes and Stienstra (2004), who have shown that when designers talk about 'everybody', they tend to have a narrow subsection of the population in mind. The participants in these user tests tend to be relatively inexperienced; even when tests explicitly take into account learning curves, they tend to do so only on a relatively short-term and limited basis, because "it is difficult to recruit motivated participants for extended periods" (Flowers 2005: 3).

On the other hand, if the goal is to develop tools for expert users, the question of how well a hundred college-age kids perform in using the auditory display does not even enter the picture, as it is the usefulness of the display of the domain expert that really counts, and the best way of making sure that a small number of specialists can work with a sonification might simply be to collaborate closely and develop the technique together. As the examples from the SonEnvir project earlier in this chapter have shown, statistically significant evaluations are often not feasible with such a research set-up. Florian Grond suggests that the formal evaluation is not the most important thing, and if anything should be done at the very end of the process; what is more important, and should happen from the start, is to simply ask people in the domain areas whether they would be interested in using something like this (interview Grond 1).

The problem, according to Grond, is that these domain scientists are usually not present in the ICAD community ${ }^{58}$ - and to compensate the lack of involvement by domain scientists, the community develops a peculiar habitus of displaying its own scientificity. The ubiquity of user tests and evaluations is part of the ICAD community's efforts "to be really critical, in order to make itself relevant" (interview Grond 1, translated). However, says Grond, these tests tend to evaluate performance in very narrow tasks which may not be an adequate measure for the potential usefulness of the tool in research practice. The best empirical evidence of the usefulness of sonification for scientific specialists in the end would not be an auditory perception test - it would be a discovery of a new scientific insight by means of listening to a sonification which could then be empirically substantiated by other methods and theoretical advances. In other words, it would be the development of a killer application, as described in chapter 3 .

\footnotetext{
58 The importance of intensive collaboration with specialists in the domains from which data is being sonified (interviews Brazil, Hermann 1), and the difficulties of finding such specialists who are willing to cooperate (interviews Dombois, Kramer) is a recurring theme in my interviews.
} 
So far, I have given an account of the different research interests and target users of sonification, drawing on only a few ICAD members as standing in for broader paradigms within the community - a slightly oversimplified way of looking at things, to be sure, but a useful way of succinctly highlighting some of these differences. In doing so, my account has also treated the different research interests and user conceptions as though they emerged out of a vacuum and are merely expressions of the idiosyncratically different predilections of these individuals. But far from emerging out of a vacuum, these different stances are related to differences in disciplinary background.

Of course, the different research interests and user conceptions themselves spring forth from certain disciplinary perspectives. But different disciplines not only bring different research questions to the table; they also have their own, not necessarily compatible, quality standards and conceptions of objectivity (Huutoniemi 2010; Lamont 2009). Within sonification, we can find scientists from any number of scientific disciplines, including some that show multiple allegiances. To name a few researchers mentioned in this chapter: Vickers is a computer scientist; Walker is associated with the psychology as well the computer science department; Hermann studied physics before doing a $\mathrm{PhD}$ in computer science and now heads an ambient intelligence research unit; Grond studied chemistry and is now doing his $\mathrm{PhD}$ within Hermann's research group; Vogt studied environmental systems science before joining a department of theoretical physics when she started working on a sonification project, but later switched over to an electronic music department; Dombois studied geophysics but now leads a department for transdisciplinary research with a strong artistic bent. The list could be continued.

The type of quantitative evaluation that has given so much food for discussion within the community primarily originates from a tradition of psychological research, and as such can be placed in a historical context of the professionalisation of psychology. Historical work on the rise of psychology shows how psychologists have drawn upon strategies of standardised testing and quantitative measurement in an effort to demarcate their discipline from the muddy waters of the humanities and common sense and to establish its cultural authority by a closer alignment with the well-respected professions of medicine and engineering (Brown 1992; Derksen 1997b, 2001; Zupan 1976). The reliance on quantification here was linked, argues JoAnne Brown, to a broader political culture of progressivism in the United States, in which numbers came to be seen as the solution for social problems (Brown 1992: 40) - a thesis that nicely supports Theodore Porter's (1995) account of the power of quantitative methods in modern science and public life. But it was also an effort to 
juggle the tension "between methodological demands presumed to have been derived from the 'exact' physical and biological sciences and a subject matter extending uneasily into the social and human sciences" (Ash 1992: 193) that has led experimental psychologists to stake their "claim to the status of a science by emphasizing its methodological inheritance from the natural sciences" (Dehue 1997: 669) - even if it meant suggesting that techniques that in fact were developed within psychology had originated from the natural sciences (Dehue 1997). Mitchell Ash diagnoses psychology with a tendency of "exaggerating certain scientific preferences, in particular by (...) reifying certain conventions of method and measurement in a 'cult of empiricism"' (Ash 1992: 194). In this view, psychology's reliance on quantification could almost be regarded as a compensation strategy for the disputed scientific nature of its subject matter. In any case, these studies show that the self-conception of psychology as a scientific discipline is strongly based on a historically grown - although not inevitable, as the existence of alternative methodological traditions within psychology shows (Dehue 1995) - reliance on quantification and measurement.

It is this historically grown standard of what constitutes good (psychological) research that also comes into play in the debates about user testing among sonification researchers. With the insistence on testing, the established quality standards of one scientific discipline - psychology - that makes up the interdisciplinary matrix of sonification is stipulated as a marker of quality for the field as a whole.

That said, the focus on user tests is not exclusive to psychology. Another discipline with a strong foothold within sonification is the field of human-computer interaction (HCI), itself a field that emerged at the intersection of various more traditional disciplines, notably computer science and cognitive psychology (Cooper and Bowers 1995: 50). Cooper and Bowers argue that HCI has derived much of its legitimacy "from its claimed knowledge of the cognitive user" (1995: 52), and that "the discourse of cognitive psychology is typically conferred privileged access to and understanding of" (1995: 50) the user. It is hardly surprising, then, that user tests are common in $\mathrm{HCI}$, and therefore also in the sonification community, in which HCI research plays an important role. One interviewee explains: "A big part of HCI is all about involving your users, and so we always try and do the right things." (Interview Brewster) Another one makes the lineage between HCI experiments and those in psychology explicit when he asserts that "human-computer interaction (...) is strongly influenced by the psychology way of doing things, and psychologists do experiments" (interview Vickers). When this interviewee started his $\mathrm{PhD}$ project on a sonification of computer programming code, it therefore went without saying for him that an evaluative study would be part of the research: 
I'd been kind of trained in the way, from the viewpoint that you always have to do evaluations, otherwise you can't state whether you've given a contribution or not. You need some way of evaluating your work. And in a science and engineering paradigm, where I came from, that usually revolved around - in engineering, you kind of, you do some benchmarking. Or in the HCI community, you tend to do some kind of experiments with subjects, to see how they use the tool. So I always had in mind that I was going to do that, but it became clear from reading the prior work that had been published on program sonification that nobody else had. That being, several people had built systems and then had said, "look at this!", and that's it. (...) So that just made it clearer for me that I did have to do a proper comparative study. (Interview Vickers)

It is thus primarily through the disciplinary perspectives of psychology, computer science and human-computer interaction - fields that are quite influential within the ICAD community - that we can understand the emphasis on user testing and quantitative evaluation. In the previous section, I have pitted this approach against an alternative conception of objectivity in sonification research, which I have termed the 'trained ears' approach. It is more difficult to associate this approach with any particular type of evaluation practice; after all, one of its tenets holds that a systematic evaluation might not be necessary as the involved researchers should trust their own expert judgement. Where close collaboration between sonification researchers and domain specialists is sought, the quality standards of the involved domain science (be that neurology, seismology, sociology or chemistry) might be as relevant as whatever standards the ICAD community can come up with; this is especially true when a publication in an academic journal in the data domain is aspired. It is therefore no surprise that some researchers within ICAD are more reluctant about favouring the quality standards of any particular scientific field.

This is not meant to suggest that the debates about the need for evaluations within the sonification community run neatly along disciplinary lines; it is meant to suggest, however, that the difficulties of finding agreement on the appropriate quality standards is rooted in a scientific culture in which different research interests and disciplinary backgrounds meet, and in which no consensus has been established about what the standards for good scientific work could be.

The situation is further complicated by the fact that sonification research goes beyond the traditional boundaries of academic science. Huutoniemi points out: "Whenever research crosses boundaries between disciplines, the problem arises that 
each discipline carries specific and sometimes conflicting assumptions about quality. If research also integrates expertise outside of academia, the dilemma of multiple standards is even more challenging." (Huutoniemi 2010: 309) This is true for sonification, where - besides the aforementioned differences in perspectives on what it means to be scientific - not everyone even aspires to the status of doing science to the same extent:

In my view, sonification is a field of applied science and design. Design is a problem-solving process rather than a theory-proving process. It is multifaceted and specifically situated. It recognizes multiple solutions to the same problem and that the designer, context and audience are critical elements. It is iterative and requires evaluations at incremental decision points. (...) Rather than a scientific experiment with large numbers of subjects, the designer needs to rapidly test alternatives with just a few subjects. (Stephen Barrass, personal e-mail correspondence on July 10th, 2009)

This interviewee works in a design department, so it is no surprise that he favours practices that align with the design way of doing things. He also, however, acknowledges that for those with a more scientific background, "testable hypotheses with repeatable results that can be generalised" (Barrass, personal e-mail correspondence on July 10th, 2009) are required. This kind of methodological pluralism is not so unusual within the ICAD community, which takes pride in its interdisciplinary character. The computer scientist Paul Vickers, who was socialised into a paradigm of quantitative evaluation, also acknowledges that "sonification isn't scientific. It can be used scientifically." (Interview Vickers) According to Vickers, interdisciplinarity need not be a problem for the community as long as everyone remains aware of these disciplinary differences and the ensuing different quality standards. Talking about peer review and the potential problems of interdisciplinarity, he states that it is necessary to make sure that the work goes out to the right reviewers, so that psychologists review psychological work, computer scientists review computer science work, and artists review artistic pieces: “So I don't actually think it's a problem so much, because you will find people who can read it for you." (Interview Vickers)

\subsection{Conclusions}

In this chapter, I have explored notions of objectivity in sonification research. I have done so in three parts. In the first section, I have shown that objectivity is a problem 
for sonification; even those researchers who make use of sonification in their talks tend to be sonoclastic about their sounds. That is to say, they tend to talk of sonification as a nice gimmick for science popularisation or a little bit of light entertainment during an otherwise dry academic talk, but not as a legitimate tool of scientific analysis and representation. Sonification is thus framed as something that is devoid of objectivity. In the second and third section, I have turned to the researchers within the ICAD community who seek to frame sonification in different terms - and do so particularly in the context of ongoing and sometimes quite heated debates about the objectivity of sonification and ways of establishing scientific quality within the community. Some of the different positions taken in these debates were introduced in the second section, while the third section sought to explore more thoroughly where these different positions come from.

I have concentrated on two different conceptions of objectivity and scientific quality in my analysis. On the one hand - in an approach that is alluded to in the title of this chapter as correlation coefficients - some researchers attempt to make their sonifications robust by exposing them to thorough quantitative testing and evaluations. By making a large number of respondents listen to the sonifications and registering their results, they adopt a strategy of dealing with the charge that sonification is 'merely subjective'. Even if auditory perception might be an individual and subjective phenomenon, this approach promises, there is a way of dealing with that: subjectivity can be averaged out if a large enough number of test subjects can be taken into account, so that overall patterns and regularities remain. This closely resembles the way in which the discipline of psychology has established its scientific and cultural authority despite the "seeming impossibility of a science of subjectivity" (Ash 1992: 194). Like in Linda Derksen's study on the estimation of measurement errors in DNA profiling, objectivity is achieved as "as the outcome of a variety of practices and interactions, most of which have the intent of removing subjectivity, but actually have the function of making subjectivity invisible by accounting for its effects on the final measurement." (Derksen 2000: 829)

This approach dominates much of the debates within the ICAD community about objectivity and scientific quality, but it is also hotly contested. Not everyone who stresses the importance of evaluation for sonification insists on large-scale quantitative studies - indeed, as I have shown, various different, often qualitative approaches to evaluation have been developed within the community. And some researchers even postulate that sonification should be able to stand on its own without necessarily requiring evaluation, and that subjectivity is something that should be accepted or even embraced rather than averaged out. With a nod to Daston and Gali- 
son, I have termed this the trained ears approach, and shown that some researchers within ICAD take a view of sonification as trained judgement: sonification requires judgement and manipulation of data, and only the subjective intervention of the expert researcher can help to detect patterns in large amounts of data. Subjectivity is thus posed as central to the functioning of sonification, not a threat that needs to be managed; instead of engaging in user tests, the researchers should focus on expert discourse, and trust their own expertise rather than second-guessing it with quantitative tests.

My analysis has highlighted that these approaches and strategies are strongly shaped by different disciplinary backgrounds, different motivations and research questions that led to an interest in sonification, and different conceptions of who the users of sonification are and ought to be. In principle, these could coexist within the community, and it has indeed been argued that they should. However, as already seen in chapter 3 , there is tension in the field about whether sonification needs to be a discipline with its own markers of scientific quality, or a loose interdisciplinary conglomerate of different fields in which different markers can co-exist. This higher-level tension about the nature and future of the community play into and further complicate the debates about objectivity, scientific quality and modes of evaluation.

Yet I want to avoid the impression that I am describing here two different camps of sonification research, and that the field is neatly divided between them. The field is far messier and less predictable than that. Not everyone could be assigned to one of those positions; and even those who, on the basis of my analysis, seem to fall squarely into one camp in fact often display a remarkable diversity in their approaches, exploring different research interests, engaging with different users and employing different evaluation techniques in different projects. Rather than conceptualising this is a split into different camps within the sonification community, I want to posit that these are different strategies of establishing the objectivity of sonification, and such strategies can be handled flexibly by the researchers. Which strategy is adopted depends, for instance, on the purpose and usage for which the concrete sonification is being developed.

One important aspect of the trained ears approach has been left out in my discussion of it so far: trained ears, as the name already implies, require training. Indeed, Daston and Galison argue that the regime of trained judgement puts unprecedented strain on the viewers of images:

The reasoned image is authoritative because it depicts an otherwise hidden truth, and the objective image is authoritative because it 'speaks for itself (or 
for nature). But the interpreted image demands more from its recipient, explicitly so. The oft-repeated refrain that one needs to learn to read the image actively (with all the complexity that reading implies) also transformed an assumed spectator into an assumed reader. (Daston and Galison 2007: 360)

Like viewing images, listening to sonifications requires training, practice, and skill. Indeed, this is true not only for sonifications that operate within the logic of trained ears. Within the correlation coefficients tradition, it is up to the makers of a sonification to design it in such a way that an average listener will be able to hear the relevant information in the sonification - but even then, user tests rarely evaluate only the first attempts to work with a particular sonification, but try to take into account the learning curves associated with using it. I will turn to these skills involved in designing as well as listening to sonifications in the next chapter. 



\section{Listening with the Red Button within Reach: Professional Audition in the Gadget Community of Sonification}

A big red button, located on top of a computer desk on wheels in the CUBE, the performance space of the Institute of Electronic Music in Graz: when the interdisciplinary workshop Science by Ear 2 started, I did not know what purpose this object would serve. Neither, it seemed, did many of the workshop participants. Midway through the three-day workshop on the sonification of physical data, however, everyone had come to appreciate its functionality. When the red button was pushed, all sounds going through the multi-channel soundboard would be turned off immediately. This could come in quite handy when the small teams presented the fruits of their sonification design processes, as there was always a risk that a sonification suddenly sounded different when presented in the plenary session than it did when the team worked on it half an hour earlier, or that the frantic last-minute changes implemented by the programmers had slightly different results than anticipated. The causes of the unexpected sounds could be manifold, ranging from a mistuned sound parameter in the audio synthesis programming language to an error in the sequence in which the lines of codes were executed. While these mistakes were of a rather simple nature - nothing that can't be amended by fixing a line of code, changing a single number, or simply hitting enter a few times in the correct order - the resulting sounds could be quite jarring and painful to the ears indeed. The best way to fix them before any participants had to suffer throbbing headaches or hearing damage was to hit the red emergency button first and then attempt to identify and rectify the problem. It helped if someone already held their hand on the trigger in anticipation of painful sounds before the sonification even started playing.

The red emergency button, as one of the tools that are used in sonification practice, is an example of the kind of object that I want to discuss here. It also illustrates some of the skills that are needed to work with sonification: anticipating how things might go wrong, being quick on the trigger when it comes to stopping unwanted sounds, identifying and fixing errors in the sonification design. Such skills and tools of sonification practice will concern me in this chapter. These skills and tools, or 
more generally the actual work that goes on when sonifications are made and used, have been largely black-boxed in this dissertation so far. This is quite an inexcusable state of affairs, especially in the light of some of the essential work done within STS and history of science showing how important instruments (Galison 1997; Hankins and Silverman 1995; Lenoir 1988; Rothbart 2007; van Helden and Hankins 1994), research materials and models (de Chadarevian 2004; Kohler 1999), skilled workers (Goodwin 1994; Shapin 1989), and tacit and embodied skills (Collins 2001; Delamont and Atkinson 2001; Myers 2008) are to the functioning of science.

It can be useful to think of the skills involved in sonification work as a kind of professional audition. This term has been used by Thomas Porcello to describe the professional expertise displayed by audio engineers, which is rooted in "the ability (and the sanction) to speak authoritatively as an expert" (Porcello 2004: 734) about sound. As I will discuss in section three of this chapter, Porcello uses this notion to analyse the linguistic repertoires used by audio engineers in talking about sound. Porcello has adapted the term from Charles Goodwin, who developed the notion of professional vision to describe the "socially situated activity accomplished through the deployment of a range of historically constituted discursive practices" (Goodwin 1994: 606) in two professional domains, those of archaeological field excavation and legal argumentation. Professional vision, Goodwin argues, involves techniques such as coding, highlighting, and constructing and articulating graphic and material representations. Goodwin thus focuses on how professionals engage with the visual and material phenomena that they study, how they order them, direct attention to certain aspects of these phenomena, and make sense of them. Compared to this, Porcello's focus in his discussion of professional audition is somewhat narrower, as he is primarily concerned with linguistic practices, with how audio professionals speak about sound. This is not to say, of course, that he claims that being a professional sound engineer is exclusively a matter of language; he acknowledges skills such as the ability to operate the control room equipment, to select and place microphones for the purposes of recording, or to understand enough musical theory and practice to follow the discussions of performers, arrangers and producers.

Yet, curiously, one activity is black-boxed in Porcello's discussion of professional audition: that of listening. While Porcello mentions that the education of aspiring sound engineers involves sessions of "intensive listening" (Porcello 2004: 755), he does not discuss what they actually do when they listen and whether they employ different strategies of listening. Sound studies scholars have pointed out that different modes of listening exist that are available to listeners, whether it is in the context of listening to the radio (Douglas 1999; Goodman 2010), to music (Plourde 2008; Stock- 
felt 2008), in everyday situations (Truax 2001 [1984]), or as a more general theory of different types of listening in different contexts (Pinch and Bijsterveld 2012). Building upon such work, I will argue that the professional audition of sonification is a matter of different styles of designing, listening and communicating about sound; and importantly, it engages not only the ear, but the whole body of the sonification practitioner and listener.

Professional audition is closely linked to the tools and instruments that are part of every stage of sonification work, from the usually computer-assisted transformation of data into sound to the playback systems used to listen to a finished sonification. As I will argue, the sonification community is one that is very much centred on such tools, and I am interested in how these tools shape the community. In his work on the commercialisation of probe microscopy, Cyrus Mody has coined the term of an instrumental community to describe how a community, consisting of a group of people and institutions who build, develop, use, sell and popularise a research technology, "coalesces around a technology" (Mody 2006: 59). In this chapter, I apply this notion to sonification, but my analysis diverges from Mody's in two points. The first point of difference is that, unlike Mody who focuses on the interplay between academic and corporate actors, I concentrate on inter- and transdisciplinary exchange. The claim that sonification is an inherently interdisciplinary endeavour has been a recurring theme in the previous chapters, but here I ask how this actually gets enacted in practice, and how the tool-orientation of the community helps or hinders interdisciplinary collaboration.

The second modification of Mody's concept is that I adapt the term of an instrumental community and instead describe sonification as a gadget community. Sonification is not an instrument in the strict sense, but rather an umbrella term that describes a variety of different techniques for turning data into sound, as well as for the sounds that result from these techniques. ${ }^{59}$ Sonification does, however, rely on a plethora of tools and instruments, and I will show that the sonification community has focused much of its energies on developing and adapting such tools. In doing so, the purpose of the sonification and the meaning of the data being sonified may sometimes be overshadowed by the efforts put into the development of the tools themselves. The term 'gadget' seems to capture this element; while the term 'instrumental community' can be taken to imply that its instruments are instrumental for enabling a particular type of scientific research - for instance, probe microscopy was "instru-

\footnotetext{
${ }^{59}$ That said, the instrumental community described by Mody also does not group itself around one single instrument, but rather around a group of microscopy techniques which are collectively referred to as probe microscopy (Mody 2006).
} 
mental in orienting various disciplines to new sets of questions" (Mody 2011: 25) - a gadget community may develop tools for the sake of the tools themselves, and is sustained by the fascination and sense of novelty afforded by them. A gadget community continually searches for new and better tools for the job - or, indeed, takes the tool as a starting point and goes searching for new jobs for the tool (see the search for a killer application, as described in chapter 3).

A certain amount of gadgetry is common in many scientific disciplines. Karin Knorr has suggested that tinkering with local contingencies is a normal part of successful scientific work; this tinkering is not limited to, but certainly includes creatively using scientific instruments in unanticipated ways (Knorr 1979: 368). In his ethnographic work in a marine field research lab, Frank Nutch has studied a particular type of scientist, the 'gadget-scientist': "For gadget-scientists, tinkering within the research project is an intrinsically rewarding experience. They perceive themselves as having a degree of control over local conditions and achieve a sense of personal accomplishment by doing hands-on, practical work - work that will usually serve to circumvent temporal and economic constraints." (Nutch 1996: 218f.) Nutch emphasises the advantages that these tinkerers have in dealing with unforeseen problems, which allows them to go through with their research where non-tinkering scientists might be forced to abandon a project.

During long stretches of its history, even the field of probe microscopy may quite accurately be described as a gadget community in the sense I have sketched out above, ${ }^{60}$ as researchers "had yet to find suitable applications for these tools" (Mody 2006: 66). As a result, academics primarily taught their students to build rather than use microscopes, and students tended "to test microscopes on readily available materials rather than on scientifically disciplined specimens: leaves of houseplants, polaroids, bone from rib-eye steaks, ice, and the electrochemistry of Coke versus Pepsi, to name a few" (Mody 2006: 66). Especially during its early existence, the probe microscopy community was inhabited by a large population of gadget-scientists and tinkerers. Indeed, compared to some of the adventurous designs of early tunnelling microscopes, where items such as "pencil leads" and "brushes made from [the researchers'] own eyebrow hairs" (Mody 2006: 66) were used in the construction of instruments, the sonification designs described in this chapter appear downright conservative. Moreover, these items are the result of tinkering in the literal sense of

\footnotetext{
${ }^{60}$ In suggesting that Mody's instrumental community may (at least during its early history) be considered as a gadget community, I do not mean to imply that Mody had it wrong with his characterisation of probe microscopy. The term gadget community is not used in contrast to, but rather as a specification of, a particular type of instrumental community.
} 
the word, while my discussion of sonification will extend the category to refer not only to tinkering with hardware, but also to tinkering with software and programming code.

In referring to sonification as a gadget community, I do not intend to chastise the community for a lack of scientific substance or to imply that it is doomed forever to the status of providing some 'gadgets' - as I have shown above, an emphasis on gadgets is common in many scientific disciplines, and even the community for which the term 'instrumental community' was coined in fact started out as what I will refer to here as a gadget community. However, I do want to show that during its current status of development, sonification is best characterised as a gadget community, both because of its unusually high concentration of gadget-scientists and for its relative dearth of concrete, sustained applications for the tools developed in the field.

In order to study the tools and skills of sonification, and thus understand sonification as a gadget community that possesses a particular kind of professional audition, I will follow the lifecycle of sonification through different contexts and stages. ${ }^{61}$ The chapter is therefore organised according to a distinction between five stages of sonification work: learning to make sonification, choosing or building sonification tools, designing sonifications, integrating them into work practices and routines of scientists (i.e. listening), and finally, presenting sonification in public.

\subsection{Learning Sonification}

When I started my empirical research, one of my first interview partners asked me, "But Alexandra, if you're going to study sonification, shouldn't you learn how to sonify?" I had to concede that I probably should, and so, in June 2008, I headed to Bielefeld for two weeks, where I was provided with a workspace in the iLab (short for Interaction Lab, an infrastructure that has since given way to the Ambient Intelligence Lab), and Thomas Hermann took me under his wing to teach me the basics of working with his sonification framework of choice, the audio synthesis programming language SuperCollider (sC).

As a novice not only to the world of audio synthesis and sonification design, but to any kind of computer programming, these two weeks were quite instructional for me indeed. The goal for my stay was to develop a simple but versatile sonification of descriptive statistical data, an auditory equivalent of a box plot graph: a graph that

\footnotetext{
${ }^{61}$ While the resulting division of stages is different, I owe the idea of making such a classification in the first place to Steven Shapin's distinction between the trying of an experiment, its showing, and the discoursing upon it in seventeenth century England (Shapin 1988).
} 
contains information on the minimum and maximum values in a dataset, as well as on its median value and the lower and upper quartile. We started out by brainstorming what such a sonification might sound like, a process that involved visual as well as auditory sketching. We jotted down notes, drew graphs, and used our voices to express and communicate expectations. This, I was informed when I was reluctant to employ my own vocal cords for the purpose, was an important step in the making of any sonification.

In the course of my stay, I would be acquainted with a number of additional skills. An important one was simply - to paraphrase Rodgers and Moraga (2011) the skill of "learning to think like SuperCollider", that is, understanding the structure, particularities and assumptions built into it. This included the fact that starting sC did not automatically start its sound server; the importance of the comment function, where lines preceded by a "//", although ignored by the programming language, are nonetheless essential to help the programmer keep track of what they are doing; and the fact that $\mathrm{sC}$, as Hermann put it, "cannot calculate", or in any case does not know the rules for order of operations: according to $\mathrm{sC}, 4+5^{\star} 2$ equals 18 , rather than 14 .

I started my learning process with simple code for sound synthesis, learning how to change audio parameters such as pitch and sharpness. In theory, this was easy enough, as I only had to define these sound parameters and change their values according to my own preferences. The difficult part for someone with no audio synthesis background was to figure out what numbers to use in defining these parameters. A 'wrong' choice here could lead to instant ear-ringing and headaches. I was reminded of skiing lessons, where the first (and in my case, only) thing we learned was braking: the line of code that allowed me to stop the sound seemed to be the most important thing I had learned so far.

The next step was to drive the sound by variables in a dataset. I was given a few standard datasets that were often used in teaching, and started using them as the basis of my sonification. Little by little, new variables and parameters were added. By the end of week two, we had a sonification that contained clicks for each value in the data set; sound events for $0 \%, 10 \%, 25 \%, 50 \%, 75 \%, 90 \%$ and $100 \%$ percentiles; a buzzing sound indicating the density curve of the data; a hissing sound that would start one standard deviation before the mean, building up in intensity up to the point of the mean, and gradually swell down until it stopped one standard deviation after the mean; and a panning function that would allow listening to different sub-sets of a dataset in the left and right audio channel. We also built a simple graphical user interface for the sonification so that certain parameters could be changed without having to change the code, as well as a small tutorial for comparative listening: in order 
to make sense of these sonifications, it helped to know what certain other distributions (such as a normal distribution or a uniform distribution) would sound like in comparison.

I learned how to optimise code to run more efficiently, and how to make sense of error messages. The trickier thing was how to figure out if something was wrong in the absence of error messages. Strategies for doing so involved comparing the output to one's expectations and figuring out why it didn't sound as one might be led to expect; trying the code with different datasets, as a mistake that was hardly noticeable while listening to one dataset might be more obvious in another; or looking at graphic representations of the data, which might indicate that the data were not parsed correctly.

Another thing I had to learn was not to pay too much attention to the meaning of the data, and to focus on whether the sonification provided an accurate representation of the dataset, not what that representation could tell us about the real world. I am not claiming this as a universal characteristic of sonification: there are certainly applications where sonification is used to explore datasets in order to draw conclusions about the phenomena that these data represent. However, this only becomes feasible once one can be reasonably sure that the sonification indeed provides an accurate representation; otherwise, it would be impossible to tell whether what can be heard is a characteristic of these data, or an artefact of the way in which the data have been mapped onto sound. This is why I was given what my hosts called the 'standard' datasets, which were well-understood already, and therefore allowed focusing on the sonification, not on the data.

Being "well-understood", however, meant something different than I had expected. A good example is the Iris dataset, which was first introduced in the 1930s (Fisher 1936) and has since become a classic example for discriminatory data analysis, well-known not only (or even primarily) in the sonification field. It has been used to experiment with auditory displays since at least the early 1980s, when Sarah Bly used the dataset in her doctoral dissertation (Frysinger 2005). The dataset contains four different variables (sepal length, sepal width, petal length and petal width) that describe specimens of three different species of the Iris flower. But when I started asking questions about the meanings of theses categories, it soon became clear to me that these were not the same questions that were brought to the data by the computer scientists and data analysts. For instance, most members of the research group knew that the variables described the petals and sepals of the Iris flower, but they did not know which part of the flower these words corresponded to (the dataset was marked in English, while their biology education had taken place in German), or they knew 
that the petal referred to the 'flowery' part and therefore assumed that the sepal must be the stem. When I mentioned that the sepal referred not to the stem, but to the green leaves that usually lie underneath the colourful petals, this revelation was received with a mixture of surprise and polite indifference. My point is not that these computer scientists are ignorant of botany, or at least of English botanical vocabulary - I had to look up the words, too. My point is that it wasn't important enough for them to give any thought to, let alone look it up. Indeed, one of the students at the department was even surprised when I mentioned the word "flower" in relation to Iris - "you mean the famous Iris dataset is not about the iris of the eye?"

And yet it is true that this dataset is suitable for sonification because it is wellunderstood: in terms of its data structure, it is well-understood, and easily understandable even for beginners. And this is the quality that really matters for learning sonification: it's the simplicity of structure, not of meaning, that counts. During an interview, Thomas Hermann explained that the data he likes to give to beginners are "well-understood data, sometimes even synthetic data, where the structure at hand is entirely clear" (interview Hermann 1, translated). With this kind of data, initial successes can be achieved easily. At the same time, he explained, it is also important to give beginners an idea of the potential of sonification and its possible applications, which means showing them examples of meaningful sonifications with more complex datasets, "where you only share the sound examples and their explanation" while black-boxing the programming code that is needed to create the sonifications (interview Hermann 1, translated). The transition from normal brain activity to an epileptic seizure in an EEG is one such example for him: very suitable for demonstrative purposes, but too complex for a novice in terms of code.

Of course, it is not unusual that sonification is usually taught with standard datasets; in many fields, ranging from experimental to field sciences, students first learn about doing research in the context of routine experiments or studies that contain none of the uncertainties and complexities that more experienced researchers have to do deal with in their scientific practice (Delamont and Atkinson 2001). Indeed, as Daston and Galison note: "Aspiring scientists first honed their skills by repeating exercises that were already part of the repertoire of the discipline. Fledgling chemists were set to synthesizing known compounds; young physicists replicated wellestablished results and re-solved old problems; stripling zoologists practiced classification on models and specimens of known species." (Daston and Galison 2007: 326) Novice sonification researchers, it may be added, rehearsed sonification design on well-understood standard datasets. 
I have described my own learning experience of sonification in some detail here, but I am not claiming that it is representative of learning to work with sonification on the whole. A trajectory of never having done any computer programming work until age 25, and then immediately taking on SuperCollider is rather unusual: compared to various other sound synthesis tools that are used to create sonifications, $\mathrm{sC}$ does not have the reputation of being the most accessible option for programming novices. My own experience was also unusual in that I was interested in learning sonification primarily in order to learn about sonification, whereas most researchers would be more likely to learn it in order to apply it on a particular project or dataset. Nonetheless, the discussion of my experience indicates the variety of skills that make up the professional audition of sonification, ranging from programming skills to listening skills, from being able to anticipate what something might sound like to being able to meaningfully talk about sound. In the remainder of this section, I will discuss how my interviewees have described their own or typical learning processes in sonification research.

For instance, Thomas Hermann had a head start on me when he started working with sonification. Having played the electronic organ since his early childhood, he became interested in music programming on the computer as a teenager. When he had the idea of turning data into sound years later during a data mining lecture, "I think I already had a very extensive idea of the technical possibilities, and a good pursuit of this interface between computer and music, or sound and computer" (interview Hermann 1, translated). But even then, learning sonification provided some challenges, as he had to work through the existing literature on his own in a field in which no canon existed (interview Hermann 1), and which was highly interdisciplinary:

But still I think this is something which, if you start being interested in this as a computer scientist, presents a roadblock, because sonification is, if it is one thing, it is highly interdisciplinary: signal processing, algorithmics or computer programming, acoustics - that's physics; then you need an understanding of auditory physiology, of psycho-acoustical issues, of design issues and even aesthetics, and even psychology in order to set up experiments. That's a whole mingle-mangle of different fields of which you need at least a basic understanding. And that might make it difficult for many to really enter this field properly. (Interview Hermann 1, translated) 
Other researchers also talk about this hurdle. For instance, Eoin Brazil says he spent the first two years of working with sonification "just trying to catch up", learning concepts from music, physics and psychoacoustics, as well as keeping track of developments in his own field of computer science and interaction design (interview Brazil).

Not only does working with audio require understanding of scientific concepts from many fields; it also involves hardware skills. During my own crash course in sonification design, I did not try my hands at this, but I did observe some tinkering with various gadgets and hardware pieces. The occasional need for such tinkering was also mentioned during my interviews. Mikael Fernström explains: "I still use whatever it takes to achieve the result. It doesn't matter if it's writing code, building electronics, or whatever it takes." (Interview Fernström) In order to be able to do so, of course, one needs skills in building electronics or tinkering with hardware. The sonification researcher Katharina Vogt acknowledges that she lacks these skills; compared to many of her (mostly male) colleagues at the Institute of Electronic Music in Graz, Vogt says she understands relatively little of the underlying hardware technology used in sonification. While Vogt is able to make do with her own skills for the most part, she often finds herself needing the help of her (mostly male) colleagues in order to work in the CUBE (the aforementioned performance space, featuring the red emergency buttons) with its rather complex technological set-up: "And I do regard this as a shortcoming, I would really have to know a lot about this, and this is such a generation of tinkerers, who have been soldering with electronics all their lives, that's something I never did." (Interview Vogt, translated) Vogt points out the gendered nature of this imbalance by putting emphasis on the masculine ending when talking about her colleagues in this context (in German: Kollegen; the female equivalent would be Kolleginnen).

This gender difference is not coincidental: historical studies show that tinkering with audio hardware (and specifically, with radio technology) has become gendered as a 'masculine' activity (Douglas 1987, 1999; Haring 2007), and these gender roles can be difficult to change. Indeed, Dunbar-Hester's ethnographic study of contemporary radio activism shows that even among technical enthusiasts and self-described 'geeks' who are active in a group "which is founded on, and genuinely committed to, equality and diversity" (Dunbar-Hester 2008: 212), hardware tinkering tends to remain a predominantly masculine activity. While the women studied by DunbarHester possessed significant technical skills, especially when it came to computer programming or radio production, they generally lacked the skills or the confidence to tinker with hardware. Their male peers had acquired these skills "in high school or 
earlier, which enabled them to bring a great degree of seemingly native competence to the group" (Dunbar-Hester 2008: 214). This matches Vogt's experience: while she came to work with sonification without relevant software or hardware skills (interview Vogt), the software skills were easier to acquire 'on the job', while the lack of hardware tinkering background was harder to compensate, precisely because her male colleagues could look back on relevant experience starting in their childhood. As has been pointed out by historians of science, the childhood toys that scientists played with early on in their life, the hobbies that they practiced during their youth, can resonate in their later research (Wachelder 2007).

Skills developed before the practitioners started working with sonification can come in useful not just where hardware tinkering is concerned, but also in relation to musical experience. Most of my interviewees assert that having prior experience working with sound and music helps when it comes to learning sonification, and does so in several different ways: it can help with understanding musical parameters and concepts, with being able to listen for structures, and with opening up perspectives on what can be done with sound. On the first point, Tony Stockman argues that "the jargon can't be underestimated, and, you know, just the meaning of pitch and amplitude. Phenomena such as masking, you know, what types of sound, and the fact that normally lower sounds mask higher sounds. Phenomena such as beats." (Interview Stockman)

Gerold Baier emphasises how helpful a musical background can be for listening to sonifications. His concern is not so much with the experience of playing an instrument, but of analytically listening to complex musical pieces. Those who possess such experience, especially composers, he argues, "are always looking for structures (...), always actively searching with the ear" (Interview Baier 2, translated). While Baier talks about the listening experience of the end-user of a sonification here, others have pointed out the importance of listening "like composers, sound designers, and recording engineers" (Vickers 2006: 215) especially for sonification designers. Similarly, Alberto de Campo stresses that having an artistic background can help to open up design perspectives because it broadens the space of imagination, "just because you have experienced more different types of possible sounds" (interview de Campo, translated).

Yet Baier and de Campo argue that the nature of one's musical background makes a difference, as some types of music provide a more thorough foundation for sonification than others. For Baier, traditional classical music with its harmonic concepts might be too constrained for sonification, whereas modern, experimental music is more open to exploratory listening and experimenting with sound material (inter- 
view Baier 2). Alberto de Campo draws a similar conclusion: traditional musical training can be constraining, while composers such as John Cage and Alvin Lucier are good stepping stones for doing sonification (interview de Campo).

In this section, I have tried to give an impression of some of the tools that need to be mastered and skills that need to be learned in order to design and work with sonification. In many cases, a number of skills that the sonification researchers have learned long before they 'discovered' sonification can be carried over into this new domain: skills such as tinkering with hardware, making music or programming can come in helpful for doing sonification, and can become problematic if they are lacking. Skills such as these make up the professional audition of sonification.

\subsection{Choosing and Building Sonification Tools}

In June 2010, at the 16th ICAD in Washington, a one-day "Sonification Hack Day" took place on the day before the start of the main conference. Some twenty participants came together, planning to "gather informally and share ideas, share code, write new code, and invent new projects together", as the announcement explained. There was no set schedule; the day started with a round of introductions in which the participants could talk about their interests and concrete projects they wanted to work on. After collecting ideas on the blackboard, a number of teams would be formed which would then discuss these issues during two-hour sessions.

It turned out, however, that few participants had arrived with concrete ideas for problems or projects to work on. Although a few groups working on different topics - such as brainstorming ideas for a sonification of network packages, or discussing the usage of instrumental samples - were formed in the afternoon, all morning was spent in a plenary discussion instead. Rather than working on concrete projects, the overwhelming interest was in exchanging opinions on and experiences with sonification tools.

This episode shows how much concern is given within the community to finding the right tools for the sonification job. Much of the ensuing discussion was dedicated to getting an overview of existing tools and their advantages and drawbacks. When someone asked what the best tool for sonification was, no clear answer was given, as it was agreed that it depended on the concrete goal, as well as on the user's previous experience and skills. While some general preferences were given for open-source over paid software - a recurring theme also during my interviews (interviews Barrass, Fernström, Harris, Kolláth) - the main drift seemed to be that it is often best to try to stick with the tools one already knows because it saves time and allows to, as one 
interviewee put it, "reuse and recycle" one's previous work (interview Fernström). In cases where learning something new was unavoidable, it was recommended to go with software that matches one's own style and preferences of working.

One day earlier, at the ICAD Think Tank (a forum for graduate students to present and discuss their projects before a panel of experienced ICAD members), a student also asked what the best tool for sonification was, and the ensuing discussion made explicit what such different 'styles of programming' may entail. In phrasing his query, the student mentioned his previous experience with the programming language $\mathrm{C}$. Based on this information, the panel members made two suggestions: the programming languages SuperCollider ("if you love programming, you'll love SuperCollider") or Csound ("Csound is pretty much C"). In making these recommendations, the panellists hinted at a basic split between two types of programming languages: those in which the programmer codes by typing text, and those where most of the work is done through graphical interfaces. Csound and $\mathrm{sC}$ are both examples of the former approach, and were recommended for people who like this style of work. Notable examples of the latter paradigm are Max/MSP and Pure Data, both of which rely on a graphical approach towards programming: rather than typing letters into a text editor, the user produces sound by creating visual objects on the screen and drawing connections between them. As one of the panellists remarked, these tools are best avoided "if you prefer code".

Despite the rather different programming styles of graphical and text-based coding alluded to above, in the grand scheme of things, the aforementioned programming languages are quite similar. All of them were developed for the purposes of music programming, and at a time when real-time programming was already possible; the first electronic compositions, by contrast, were developed in a process of "offline programming, submitting batch jobs, waiting for audio to generate, and transferring to persistent media for playback or preservation" (Wang 2007: 63). ${ }^{62}$ In order to transform these computer music tools into tools for sonification, they often had to be extended; for instance, the SonEnvir project (see chapter 4) involved the creation of extensions for SuperCollider in order to create a sonification environment. Such adaptations of electronic music tools are very widespread in the sonification community; however, other tools also exist that were developed especially for the purposes of sonification. Some sonification researchers present building their own tools as a matter of principle and professional pride. For instance, Paul Vickers reports that in his $\mathrm{PhD}$ work on program sonification for computer scientists, "I did

\footnotetext{
${ }^{62}$ The first versions of CSound were in fact developed for offline programming; later versions, however, did include real-time capabilities (de Campo 2009: 19ff.).
} 
what all good engineers do, and I built a system. (Laughs.) Every engineer builds something, don't they?" (Interview Vickers) Fellow computer scientist Stephen Brewester explains a very similar line of thought:

Yeah, we mostly roll our own [software]. We've written lots of different applications to generate different types of audio feedback, mostly using MIDI and things like that. We use other tools as well, Sonification Sandbox and other things, by Bruce Walker. But we mostly just write our own, because there aren't very many standard things around, and we're a computer science department, and most of our projects, you know, the students want to use their computer science skills to make things, so we tend to do it ourselves. (Interview Brewster)

For Brewster, the main problem with standard tools is that they do not provide for an easy integration of audio and haptic displays, which is an important focus for his research group. Some of the other tools in development within the sonification community - such as the Sonification Sandbox developed at the Sonification Lab of Bruce Walker (Walker and Cothran 2003), as well as the sonifYer software developed by Florian Dombois and his colleagues (Dombois et al. 2008) - focus on beginnerfriendliness and ease of use, so that even users without extensive programming skills and access to excessive computing power are able to make their own sonifications without much fuss. While the Sonification Sandbox is developed primarily for the purposes of creating auditory graphs, sonifYer has been developed mostly with audifications in mind. SonifYer has only been around for a few years and has so far, to my knowledge, only been used in sonification projects of the team that developed the software (although it is available for free download for anyone using the Mac operating system ${ }^{63}$ ); the Sonification Sandbox, on the other hand, is more widely used. ${ }^{64}$ As discussions during the Sonification Hack Day showed, it is popular in the sonification community as a teaching tool to introduce undergraduate students to auditory display, and also as a tool to create "quick and dirty sonifications". In his dissertation, Alberto de Campo describes the Sandbox as serving an "intentionally limited range, but it covers that range well" (de Campo 2009: 19) - for instance, it is "useful for learning basic concepts of parameter mapping sonification with simple data, and it may be sufficient for many auditory graph applications" (de Campo 2009: 20).

\footnotetext{
${ }^{63}$ See http://www.sonifyer.org/ (last access on November $14^{\text {th }}, 2011$ ).

${ }^{64}$ See http://sonify.psych.gatech.edu/research/sonification_sandbox/ (last access on November $14^{\text {th }}$, 2011).
} 
Another recent effort to create new tools for sonification is the SoniPy framework initiated by David Worrall. Worrall explains that he had originally set out to do his dissertation on a sonification of stock market data, "but in the process of doing all that, I realised how inadequate the tools were." (Interview Worrall) Worrall therefore focused his PhD thesis on the development of tools, introducing SoniPy, a "heterogeneous software framework for data sonification" (Worrall 2009: 5-5), written in the programming language Python. SoniPy “integrates various existing independent components such as those for data acquisition, storage and analysis, cognitive and perceptual mappings as well as sound synthesis and control" (Worrall 2009: 5-5). It can be regarded as a reaction to what Worrall describes as the "tool problem" of the sonification community:

Most of the tools for sonification come historically out of computer music. (...) People come along and they go, "right, well, I'd like to turn some data into sound, so I need some sound software, what sound software is there out there?" And they go: "Oh, there's this whole computer music community out there and they've got amazing tools, I'll use that!" (Interview Worrall)

In doing so, argues Worrall, they often run into problems because the computer music software was designed to generate music based on algorithms, not to handle data, let alone large complex datasets that have to be processed in real time. In order to solve this problem, data-handling facilities have to be added to the sound synthesis software. And this is where, says Worrall, "you hit a brick wall (...). You put a call out to the computer music community and everyone goes 'nah, I haven't done that', 'nah, you could write it though, you could write it!', they say, 'you could write it!'” (Interview Worrall)

But Worrall chose a different route than adding these data-handling facilities to existing computer music software; a route he also wanted to avoid because he was not keen to become known as the guy who writes data processing features for SuperCollider, therefore taking on responsibility to maintain the tools: "Because all that has to happen is that the operating system has to change underneath it, or you get on a different computer, and it stops working. So you've got to stop everything you do (...) and fix the tools." (Interview Worrall). Instead, he opted for a solution where the existing computer music tools meet the existing data processing tools. After all, these tools - "amazing tools for doing exactly that" - are out there already, "out in the outside world, in the scientific world" (interview Worrall). Building proper tools for sonification for Worrall therefore means not so much deciding on the best tools for 
making sound, but rather creating interfaces between the tools developed by the computer music community for making sound and those developed by the scientific community for handling complex datasets.

In this rationale, Worrall puts a lot of emphasis on how limiting the reliance on computer music tools is for the sonification community. His reservations are convincing, but at the same time, one might wonder whether the electronic music tools also enable sonification work, or in other words: whether there is a good reason to use these tools, despite their limitations in handling large and complex data. Apart from the ability to make fancy sounds, what do these music tools $d o$ for the sonification community?

Quite a lot, I would argue: they create a sense of continuity between the world of computer music and the world of sonification, and with that, they enable much of the collaboration that takes place within the community. Many of my interviewees have mentioned that they saw sonification as a possibility to combine their scientific interests with a long-standing passion for making music. In the previous section, I have quoted Thomas Hermann as saying that, when he started turning data into sound, he could build upon his past in composing computer music - something that was possible precisely by making use of computer music tools and the related programming skills for the purposes of transforming data into sound. David Worrall was active as a composer of computer music for decades before starting to work with data; in his own words, since "before PCs were around, really. So my early work in computer music was with punch cards, which dates me, I'm sure." (Interview Worrall)

Of course, Worrall did not immediately jump from punch cards to sonification; in the intervening decades, he built up relevant expertise in computer music programming. Alberto de Campo, the initiator of the SonEnvir project, had also been working in electronic music and media art for years before working with sonification; indeed, he first became involved in sonification when looking for a project that would combine his musical activities with his wife's academic work in sociology (interview de Campo). For him, too, the usage of music tools provided continuity between his work as an artist and as a sonification researcher. Years later, de Campo collaborated with the musician Marcus Schmickler for the piece Bonner Durchmusterung. Much of the work for this composition was done in SuperCollider; a programming language that Schmickler, although a sonification novice, had already worked with in previous musical pieces (interview Schmickler). Even for the asterophysicists Zoltan Kolláth, working with CSound provided a way of building upon previously developed skills, as he had already been playing around with electronic sounds before turning his star data into music (interview Kolláth). Indeed, for some people working on the devel- 
opment of music technologies, sonification is of interest not so much because of the specific data being sonified, but rather because it provides a way of "confront[ing] our technologies" (interview Warusfel) and exploring new technological directions.

These are just a few examples of how the usage of tools from electronic music helped in creating a smooth transition between previous work in creating electronic music and new experiments in sonifying data; they enabled these researchers to 'shift' between the boundaries of computer music and sonification. The concept of 'boundary shifters' has been used by Bijsterveld and Schulp to explain that innovation in the design of classical musical instruments has generally been driven by people who "found themselves at the crossroads of professions" (Bijsterveld and Schulp 2004: 667), for instance between composition, performance and instrument making, rather than those who inhabit only one of those worlds. ${ }^{65}$ In a similar way, many sonification practitioners have been known to shift between scientific research and computer music. I have argued that, whatever limitations these music tools may have in dealing with complex datasets, they facilitate such boundary shifting and therefore help to strengthen the interdisciplinary gadget community of sonification. People with relevant musical expertise - and, as I have shown in the previous section, hardware tinkering skills - can easily transfer their skills over to sonification and become valuable members of the sonification community. At the same time, this is an advantage only for people who already possess such musical, programming and hardware skills. It therefore favours the integration of people with computer programming, hardware tinkering, and musical experience (especially with experimental and computer music), but may provide an obstacle for people who are not in the possession of such skills. Computer scientists and artists are more likely to bring these skills to the table than domain scientists are. Since the increased integration of domain scientists is a professed goal of many in the ICAD community, this may present a problem - but it doesn't have to, if the collaboration can be organised in such a way that computer programmers and musicians are responsible for building and operating the tools, but domain scientists can be fully integrated in later phases of the research process, such as contributing their expertise to the design of concrete sonification applications, and using these applications to listen to their data. It is these stages of the sonification cycle that I will turn to in the next sections.

\footnotetext{
${ }^{65}$ Trevor Pinch and Frank Trocco (2002) introduce a very similar concept, the 'go-between', to explain innovation in another musical instrument, the synthesiser.
} 


\subsection{Designing Sonification}

In the design of concrete sonification applications, many decisions have to be made: about the variables in the dataset that will be expressed via sonification, about the technique (e.g. audification, parameter mapping or model-based sonification), and about the sound parameters (e.g. frequency, duration or sharpness) to be driven by the data.

During one of my stints of participant observation, I had the chance to observe a design situation in which most of these decisions had already been made. The basic outline for the sonification (using a dataset with information about sunspots) had already been developed, and so had a visual display to go along with the sonification. The goal was to develop an audio-visual installation that could be showcased at an official laboratory opening; it was, therefore, a sonification developed primarily for the purposes of technical demonstration rather than scientific understanding. During my stay, the activity mainly involved adapting the basic sonification to work well on the multi-speaker system of the lab, as well as some aesthetic fine-tuning. This process started with a series of rather jarring sounds (which evoked protest from uninvolved lab members), featured a lot of experimentation on the way (prefaced by warnings of "beware, a sound is coming!", so that the lab-mates could steel themselves and cover their ears), and finally resulted in a much more pleasant-sounding sonification - as the sonification researcher pointed out to me with a grin, a "random discovery". However, once he had randomly found a design that worked, by experimenting with different synthesis oscillators and different numerical values, he was not content to leave it at that. When further tweaks turned out to have different results than anticipated, he went back to the drawing board to figure out the source of the problem, rather than simply reverting to the previous calibration. The moment where the sonification was deemed finished was not when it sounded good, but when it did so "in a controlled way" (Bielefeld fieldnotes 2009).

But how do you determine that something "sounds good", anyway? It's impossible to pinpoint universal criteria for a sonification that sounds good, but on that day in the lab, consensus was reached easily; by the end of the design session, even the lab-mate who had at first been most critical of the sounds apologised for his harsh words, as the sonification now sounded "very relaxing". The director of the lab, who joined towards the end of the work session, stated that it sounded like minor thirds. This prompted the researcher to do some adjustments, and to finally remark that he had succeeded in "tuning it away from the thirds". Both of them agreed that it sounded better now; better, and "less musical". Rather than sounding like a piece of 
harmonic music, the sonification was now described as sounding "like water that drips onto an out-of-tune harp". The consensus seemed to be that a good sonification should sound aesthetic, but without sounding too obviously musical.

Agreement on what sounds good was less easily reached within the interdisciplinary working groups at the aforementioned Science by Ear 2 workshop. Each of these working groups consisted of four to seven participants, some of whom were experts in the scientific field from which data were sonified, some were experienced sonification designers, and some were programmers in charge of implementing the proposed sonification designs. Within these groups, disagreement on aesthetic matters was relatively common, and the aesthetic preferences were linked to the different roles within the group: while the domain scientists mostly preferred traditional musical sounds, the sonification experts and programmers (who usually had thorough musical backgrounds) tended to prefer abstract ones. ${ }^{66}$ For instance, one participating physicist expressed a preference for the sound of a piano. When the first attempts at sonifications were heard and sounded nothing like a piano, he protested:

Physicist 1: But that's not a piano!

Physicist 2: No.

Programmer 1: Nope, not a piano. I forgot, [Types.] I still meant to have a waiting time in between them. (Science by Ear 2 transcripts, translated)

This was a continuing pattern throughout the session: the physicist repeatedly voiced his preference, which was repeatedly brushed off or taken purely as a joke. For instance, when the physicist remarked that he hoped the piano was already implemented, the programmer chuckled and assured him that it was (it was not, nor would it be in the remainder of the session). Now, to some extent the remarks were probably indeed jocular; but the serious remarks by the same physicist showed that in his imagination, the data were indeed represented by the sounds of musical instruments,

\footnotetext{
${ }^{66}$ Disagreements between scientists and musicians about whether or not to use conventional musical instruments seem to be quite common. For instance, the physicist Lily Asquith reports that in the LHC sonification project (see chapter 2), similar discussions have taken place between her and the musicians she worked with: Whereas she wanted to hear the physical particles represented as "real instruments", her collaborators insist that the data were "their own sounds" and should not be represented by existing musical instruments (interview Asquith). Somewhat similarly, Tony Stockman has described bringing two different types of sonification - one very musically sounding in a traditional sense, the other very abstract - to a presentation for a group of blind professionals. It turned out that those participants with no musical training tended to prefer the more musical sonifications because they found them more aesthetically pleasing, while the musicians found the musical flourishes distracting, because it invited them to search for musical structures instead of structures in the data (interview Stockman).
} 
for instance when he talked about a sonification in which one particle sounded like a piano, another one like a viola, and so on. This was in marked contrast to how the programming and sonification experts tended to express their expectations of what something should sound like. One popular strategy for doing so (and one that I will talk about in more detail in the final section of this chapter, on the presentation of finished sonifications) was to sing what a dataset might sound like; this strategy was also shared by some of the physicists present. In one instance, a sonification expert was singing his idea of what a sonification of lead-lead collisions in a CERN experiment might sound like:

Sonification Expert 1: If I walk around here now, it's going diung diung diung diung diung diung diung diung diung [gesticulates]. Of course they also change, because they have a different angle, if the coordinate axis is here and I have an angle here, and an angle here, and I'm in the centre, then it will go Shepard. Now I have to sing Shepard: diung diung diung diung diung diung diung diung. [Sings with rising and falling pitch.] And to be honest, it actually goes diung ding di diung di diung $d u d u$ du diung dooong diuooong, because here I have, because there was the coordinate axis here, I have reduced the frequency vibrato. (Science by Ear 2 transcripts, translated)

Along with the vocalisation of a sonification idea, this quote also contains a different strategy of talking about sound. When the sonification expert talks about a "frequency vibrato", he uses a fairly technical audio term. This strategy was not used by the scientific domain experts, but was a common resource for the sonification veterans:

Programmer 2: It would be quite funny if you could just recognise these things quickly. Acoustically it is, it could simply be a frequency modulation, where you can hear the roughness as an exciter, and the modulation. (Science by Ear 2 transcripts, translated)

Sonification Expert 1: If the same particle is higher in the $\mathrm{z}$-coordinate, then I make a band-pass, so that the high Shepard tones are audible, and if they are lower in the z-coordinate, I make a band-pass so that the lower ones are audible. In principle, they are all playing all the time. Whether I can hear them depends on how I close I am and on how they function. I can do the zcoordinate with the band-pass of the Shepard tones, I can do the radius, ah, 
the angle with the pitch, with the basic frequency of the Shepard tone. (Science by Ear 2 transcripts, translated)

Many of these terms, such as "exciter" or "band-pass [filter]" put emphasis on the physical causes of a sound rather than describing what something sounds like to the listener. These technical terms were invoked quite casually by the participants with extensive sonification knowledge throughout Science by Ear 2, and generally not used by those who came to the workshop without prior sonification experience. Indeed, it is questionable whether the precise meaning of these terms really carried over to the sonification novices at all. This was implicitly acknowledged when the sonification expert quoted in the last quote above decided to explain what Shepard tones are ${ }^{67}-$ an explanation that came, however, five minutes after the above quote. Occasionally, and generally while speaking softly to each other, apparently not expecting the other participants to understand, the sonification and programming experts engaged in very brief conversations that were held entirely in technical shorthand, e.g. when announcing that they would be using a 'ringz'. Ringz is the name of a specific type of audio filter employed in SuperCollider; in other words, to someone with SuperCollider knowledge, 'ringz' stands for a set of very specific audio characteristics, but to someone without that knowledge, it is a completely meaningless expression.

The exchanges discussed above bear a striking resemblance to those analysed by Thomas Porcello (2004) in his study of sound engineers' repertoires for talking about sound. Porcello contrasts two types of conversations: one between a studio veteran and a first-year student of sound engineering; and one between two veteran professionals. The strategies they use to talk about sound include the usage of metaphor, of vocables (a strategy I mentioned above: singing the desired sounds with one's own voice), of association (looking for shared frame of referents in the form of the sound of particular bands or recordings using), or of talking in technical shorthand about sound, "not in terms that are descriptive of their acoustic features (as vocables and metaphors both are), but by naming the technologies that generate them" (Porcello 2004: 748). Porcello shows that the search for musical associations, such as particular bands or recordings, is one that is often favoured by recording novices, but rejected by the seasoned professionals. On the other hand, conversations between professionals may consist entirely of technical shorthand. Again, this is the same pattern that

\footnotetext{
${ }^{67}$ Shepard tones are a sequence of tones in which every tone sounds higher than the one that came before it, yet overall the pitch appears to remain the same. It therefore sounds like the pitch is continually rising, without actually ever getting any higher. For the visually inclined reader, it might help to think of it as the acoustic counterpart to the never-ending staircase in M.C. Escher's Ascending and Descending lithograph.
} 
has transpired in my analysis of exchanges during the Science by Ear 2 workshop, where the experienced sonification practitioners resort to talking about band-pass filters, while the novices are more likely to think about sounds in terms of musical reference points, such as the piano. Porcello points out the advantages of the very technical conversations between studio professionals (they are able to converse about the desired sound in an extremely precise and efficient manner), but he also shows that these conversations can have an exclusionary effect:

Whereas association is a way of talking about musical sounds that allows knowledgeable fans or consumers to participate fully in such talk, no one without production experience could participate authoratively, or even remotely equally, in this second conversation. (Porcello 2004: 752)

It is rather unlikely that the sonification practitioners deliberately set out to exclude the scientific domain experts from the conversation; more likely, their (at least occasional) failure to communicate in an inclusive manner had more to do with obliviousness to the fact that their terminology was hard to understand for novices and, perhaps most pressingly, with time constraints imposed by the set-up of the workshop. The interdisciplinary teams had about two hours to reach a shared understanding of the scientific data, to come up with a useful sonification design, and to actually implement it - a rather demanding task, especially for those in charge of the programming work. In this context, it is understandable that at times more priority was put on efficiently communicating ideas to at least a sub-section of the participants (those with sonification experience), at the expense of taking time to make sure that everyone in the room understood exactly what was proposed. The domain scientists themselves were often all too happy to be left out of certain decisions, anyway, as the following exchange shows:

Physicist 3: I don't know it, the sonifying is your business, I don't know.

Programmer 2: No no, that's not how it is in such a group.

Physicist 3: Yes, it is.

Programmer 2: Actually, it is all of our business. (Science by Ear 2 transcripts, translated)

The imbalance was not completely one-sided. While those with sonification expertise made efforts to understand the structure and meaning of the physical data, their understanding, especially considering the short time-frame of each collaboration, was 
also necessarily incomplete, and it often transpired throughout the session that not all participants were fully able to understand exactly what was being sonified. While those who had experience with sonification (but not physics) struggled to understand some of the physical concepts at hand, those who had domain expertise (but none in sonification) pointed out their difficulties with actually picking up information through listening - including simply being able to say whether the pitch was going up or down.

Most participants seemed to consider the workshop a success because it allowed a group of interdisciplinary researchers to get together and do concentrated work on sonification ideas and design - as one participant with extensive sonification background pointed out during the workshop, this is exactly the kind of activity that the sonification community does not engage in nearly enough. The evaluations of the concrete sonification designs (which across the board were judged more positively by the sonification experts than by the domain scientists) also showed that participants thought the workshop provided some interesting sonification prototypes and designs.

At the same time, the collaboration was not considered an unqualified success, as some of my after-workshop conversations with participants showed. Many of them thought that, as a result of the time pressure and the lack of moderation within the small groups, it could not be ensured that everyone was able to follow what went on in each conversation. Nor could agreement on what the purpose of the workshop actually was be ensured: while some of the physicists explicitly referred to it as coming together to see whether sonification might have the potential to be a useful tool for physical research, the sonification researchers tended to have already made up their mind about this question, and saw it as an opportunity to collaborate in order to actualise this potential. Also, the above analysis of the different ways of talking about sound shows that the participants did not quite succeed in finding a shared language to communicate about sonification.

This is not particularly surprising; the sonification researchers I interviewed tended to acknowledge that interdisciplinary collaboration on a sonification project is necessarily a long-term and ongoing process, not something that can be worked out once and for all in the course of a few days. For instance, Thomas Hermann explains that collaboration must consist of more than just the delivery of a dataset:

You also have to understand the semantics, what the data mean and what is interesting about them in first place, and that requires an exchange beyond the delivery of these data as a file on a disk or on a USB stick. It requires a creation of understanding, on the side of the domain scientist of what sonification can 
deliver in the first place, and on the side of the sonifiers of what is interesting about this, how to prepare these data by sound. And I think that that is the most important thing about this interdisciplinary collaboration, that you foster and bring further this type of exchange. (Interview Hermann 1, translated)

Eoin Brazil also talks about the need to "involve everyone (...) in every stage" (interview Brazil) of the design process in a planned sonification project (which ended up not getting funding) involving scientists from different disciplines:

Because I am not an earthquake scientist, or I am not a specialist in marine analysis of the particular data, nor do I know very much about fluid dynamics, so our role is more to provide the environment, show some of the possibilities based on existing sonifications, and work with them to try and see if we can develop some sort of sound language, a sonification that will allow them to explore their data in a more meaningful way. But obviously, it's a partnership. It's an equal partnership, because we're only really - I don't even want to call it an equal partnership, but I would nearly put them ahead in that partnership, because they are the ones who are the experts, we are really only facilitating this. (Interview Brazil)

Indeed, some sonification researchers have made sustained efforts to engage with the scientific fields from which they take the data to be sonified, and have built up considerable expertise in these domains, as well as sustaining institutional links into these scientific disciplines. For sonification to move beyond the status of gadget community, and to instead become a community in which gadget-scientists and other types of researchers exist next to each other on more equal footing, these links are essential and need to be strengthened; after all, once a sonification has been designed, no matter how well, it still has to be worked with. And more than anything, that means that scientists have to be ready to actually approach their datasets and domains of study by listening to sonifications - not just once out of curiosity about what something might sound like, but extensively in their everyday research practices. 


\subsection{Listening to Sonification}

The Austrian SonEnvir project is often held up as a rare positive example of sustained interdisciplinary collaboration between sonification researchers and scientists from a number of different scientific fields. Yet all three of the SonEnvir team members I have interviewed have pointed out to me that "a huge amount of time for listening was not available, not even in this project" (interview Dayé, translated). The initiator of the project, Alberto de Campo, concludes that "if I did the project all over again [laughs], I'd know now that I would have to demand much more persistently that the scientific partners try out the things, listen to them, learn to play around much more" (interview de Campo, translated). Much of that potential had gotten lost in the shuffle of project deadlines, new prototypes that had to be developed and presented, and administrative responsibilities (interviews Dayé, de Campo). Time constraints are not the only thing holding scientists back from listening to sonifications. The sociologist in the SonEnvir project reports that his dissertation adviser had announced from the very start that he would not be getting involved in listening to sonifications, on account of having "the ears of a pig" (in German: Schweinsohren, interview Dayé). While the sonification researchers emphasise that listening is a learned skill, quotes like these show that some domain scientists are fundamentally unwilling to even attempt to acquire this skill.

In the course of SonEnvir, the team of researchers set steps to ensure that the project would not dissolve in bureaucratic exercises, for instance with the introduction of research meetings devoted entirely to the contents of the project rather than administrative issues (interviews Dayé, de Campo), or with the organisation of the Science by Ear workshop - although the emphasis in the latter was on the development and implementation of new sonification techniques rather than on sustained listening.

The lack of sustained listening is a problem that is often discussed within the sonification community. For instance, at the aforementioned Sonification Hack Day, one participant raised an issue that most participants seemed to recognise: the problem of how to stop people from turning off the sonification. The first (and not entirely serious) suggestion he received was to remove the 'off button from the sonification interface. Another recommendation was to simply "make the sonification better". Indeed, annoyance at the constant auditory exposure is a reason given by scientists against spending too much time listening to sonifications, as they "will drive you crazy" (interview Garçes), while working with graphic displays is "less stressful" (interview Hayward). This has been described as "the major problem of 
sonification" (interview Warusfel). It is for this reason that aesthetics and good sound design are of so much importance when it comes to making sonifications: it may make all the difference not just between a nice-sounding and an even more nicesounding sonification, but between a tolerable one and an intolerable one - and as such, it may make the difference between one which is actually used and one which isn't. As one of the participants at the Science by Ear 2 workshop pointed out during a discussion of the appropriate criteria for evaluating sonifications, what was originally suggested as a criterion of 'aesthetics' might in fact be an issue of 'ergonomics' instead. In the end, the participants agreed to re-name the criterion 'agreeableness' (in German: Annehmlichkeit).

One participant, however, pointed out that this criterion very much depended on the purpose of the sonification task: aesthetic issues pose themselves differently in monitory versus exploratory listening. Interestingly, this distinction overlaps with the categories that were recently proposed by STS scholars Trevor Pinch and Karin Bijsterveld (2012: 14f.), who distinguish between monitory, diagnostic, exploratory and synthetic listening. In this classification, monitory listening refers to an auditory surveillance employed to check the proper functioning of instruments, machines and patients' bodies; diagnostic listening is about checking what is wrong rather than if something is wrong (as monitory listening does); exploratory listening is listening to discover new phenomena; and finally, synthetic listening "is focused on the understanding of polyphonic patterns of sound" (Pinch and Bijsterveld 2012: 14).

Pinch and Bijsterveld mention the sonification of scientific data as their only example of synthetic listening; and indeed, sonification often involves listening to complex, polyphonic patterns of sound. At the same time, the categories and examples are somewhat misleading, for two reasons: firstly, the categories are not mutually exclusive, as one can engage in synthetic listening according to Pinch and Bijsterveld's definition for the purposes of either monitoring, diagnosis or exploration; and secondly, because my research shows that all of the modes discussed by Pinch and Bijsterveld in fact play a role for the making of and listening to sonifications.

One example of the usage of sonification for monitory listening is the work done by the SonEnvir team on the sonification of EEG data. They describe a clinical setting in which an assistant watches over a patient from an adjacent room, keeping track of the patient's state both by watching him on a video recording and by monitoring the real-time EEG recording on a different screen. However, atypical EEG activity does not necessarily go hand in hand with atypical physical behaviour, so there is a risk that peculiarities in the EEG might not be noticed immediately because the assistant is focusing on the video rather than the EEG screen: 
Here, sonification is potentially very useful, because it can alleviate constant attention demands: One can easily habituate to a background soundscape, which is known to represent 'everything is normal'. When changes in brain activity occur, the soundscape changes (in most cases, activity is increased, which increases both volume and brightness), and this change in the acoustic environment automatically draws attention. (de Campo et al. 2007: 536)

The tradition of diagnostic listening in sonification reaches back to a time before the term sonification was even commonly used; after all, Speeth's (1961) study on the auditory discrimination between earthquakes and nuclear blasts provides a textbook example of diagnostic listening. Diagnostic listening also plays a role in the process of designing sonifications, such as when errors in the sonification design (or even in the dataset itself) are found because something sounds different than anticipated. Along with other techniques (e.g. the inspection of the program code), listening and relistening to the sonification is an important technique for finding out not only that something is wrong with the sonification design, but also what is wrong with it exactly.

Finally, exploratory listening also plays a prominent role in sonification activities. The usage of sonification for exploratory data analysis has been treated in detail in Thomas Hermann's (2002) PhD thesis, which set out to "provide researchers with a toolbox of methods to render sonifications for new, non-analyzed datasets in order to enhance their understanding and insight into the data, to assist the choice of models to explain or characterize the data" (Hermann 2002: 3) The thesis concludes with a range of practical applications, from the sonification of psychotherapeutic protocols to the sonification of multi-channel scientific images.

The differentiation between monitory, diagnostic and exploratory listening is one between different purposes of listening: is it to find out if something is wrong, or to find out what is wrong, or to find new phenomena or aspects in a dataset. They tell us very little about how we actually listen. On the other hand, synthetic listening - the fourth mode of listening mentioned by Pinch and Bijsterveld - says less about the purpose (what is it that we want to understand about the polyphonic patterns of sound?) than it does about how we do so: by intensely concentrating on the detection of overall patterns among multiple sound streams.

The skill of synthetic listening is indeed important in sonification research, but I will show that it is not the only one that plays a role, and will therefore complement it with the strategies of interactive listening and immersive listening. None of these three listening strategies is unequivocally linked with one of the purposes of listening 
(monitory, diagnostic or exploratory listening) discussed above. My aim in distinguishing these strategies is not so much the development of an exhaustive categorisation scheme as it is to show the diversity of the listening skills that are involved in sonification.

To begin with, Christian Dayé and Alberto de Campo describe the skill of synthetic listening with the help of musical analogies:

The ear can follow highly complex properties of sound, and trace multiple streams of auditory events. Thus, it can be used to explore high-dimensional data structures or to monitor multiple processes simultaneously. An example from music may help clarify this: Imagine listening to a piece of chamber music, say a string quartet. Given some musical training, a listener should be able to discriminate between the different instruments, and to follow their paths through the piece. Translated into more scientific language, this means that the ear is able to filter a complex stream of sound events to identify single constituent streams and trace their development over time. (Dayé and de Campo 2006: 350)

David Worrall's work on stock market sonification is an example of synthetic listening:

So the stock market's a resonant system, it goes up and down, right? (...) And the ear's a superb analyser of resonators, (...) the hearing system is essentially a Fourier analysis machine. And so the fact that you can hear two people speaking at the same time, or, you know, you can listen to an orchestra and listen to the second oboe while all the other stuff is going on is an example of how attention and the ear itself has an amazing ability to be able to differentiate structures, aural structures that you can't possibly see. (Interview Worrall)

Worrall explains that he made extensive use of his of his stock market sonifications while making his own stock trading decisions. The sonification allowed him to hear pressure building in the market in a way that the visual representations could not, because the visuals emphasise the extremes of ups and downs: "If a mood swings high, then the chart goes up high. But it might only go up high very weakly, but you can't see that, because you don't get a sense of when it goes up high or how strong the high is. Whereas if you do it in sound, you can actually, you can get a better sense of that." (Interview Worrall) 
The analogies to listening to orchestras and string quartets shows an assumption of listening to one stable sonification that unfolds in time: when a music aficionado listens to a piece of classical music, she generally listens to the whole thing in sequence, rather than turning off the second oboe halfway through or replacing it by didgeridoo in order to see how that affects the piece on the whole. However, that is not necessarily true where sonification is concerned; indeed, some sonification researchers focus precisely on the design of sonifications that lend themselves to interactive listening.

In these sonifications, "the user is dynamically involved in the generation of the sound" (Pauletto and Hunt 2009: 923), which is thought to increase the usability of a sonification. This approach addresses doubts about the assumption that "submitting the entire contents [of] 'dense and complex' datasets to sonification" (Flowers 2005: 2) will prompt interesting information to simply 'pop out' in the sonification. After questioning such over-optimism and noting that in thirteen years of working with sonification, he had "yet to see this 'work" (Flowers 2005: 2), John Flowers suggests that more room for interactive listening may help: "If our data sonification tools permit the user to interact with complex data to select subsets of variables and to select mappings (...), and to change selections quickly and easily to gain multiple auditory viewpoints, I believe our ears can indeed help us gain insight into complex data" (Flowers 2005: 4).

In the last years, the design of interactive sonifications has become increasingly popular, and a series of workshops dedicated to Interactive Sonification, organised by Andy Hunt and Thomas Hermann, has resulted from (and added to) its proliferation. Hunt and Hermann argue that interactive sonification takes advantage of the everyday listening skills, as interaction is "one of the basic methods we use in order to make sense of our environment" (Hunt and Hermann 2004: 1). Hermann's method of model-based sonification is interactive by design. Whereas parameter mapping sonification works by a mapping of characteristics in the data onto certain parameters of sound (e.g. pitch, duration, timbre), model-based sonification instead consists of a dynamical system that remains silent until the user interacts with it. According to the proponents of this technique, it has two advantages: on the one hand, it corresponds to everyday listening practice and the skills and expertise we have built up in this domain (a table makes no sound, but we can glean something about its material constitution when we put down a glass on its surface; even a guitar makes no sound unless its strings are plucked); and on the other hand, it allows for a more rounded auditory perception of the data because the model can quickly be adapted to produce different auditory views. Thomas Hermann explains this advantage with a visual 
analogy: if you look at a cup from one angle, it might look like a rectangle; from another angle, it looks like a circle; but if you combine multiple views, you end up with a representation of what the cup looks like. Each of these views corresponds to a single mapping of data to sound, but if you listen to different mappings and put them into relation to each other, you end up with a fuller perception of what is actually contained in the data. ${ }^{68}$

Interactive listening is an interesting case in point to illustrate, but also attenuate, my earlier claim that there is no intrinsic link between the strategies and the purposes of listening that I have identified. The rationale for interactive listening outlined above is directed at a purpose of explorative listening: through interactive listening, it is argued, we gain a fuller understanding of a dataset, and we may find interesting information or patterns in the data. But interactive listening can also be relevant for the purpose of diagnosis. For instance, in the aforementioned example of diagnostic listening during the design process of a sonification, the programmer tries to diagnose and correct errors in the sonification design through a strategy of interactive listening, that is, through alternately adjusting settings and listening to the results until the desired outcome has been reached. However, the strategy of interactive listening will usually not be adopted in relation to monitoring applications; after all, the very idea behind monitory listening is that the listener is able to tune out the sounds unless something happens in the data that explicitly demands her attention; therefore, a strategy involving constant engagement and interaction with the sounds will not be particularly useful in the cases where monitoring is the sole purpose.

Finally, immersive listening is a type of listening that is less widespread in the ICAD community, but links up most closely with sonifications from the world of popular science that have been discussed in chapter 2 and their promise of sublime, immersive experiences. Robert Alexander discusses that he chose this approach in his sonification of solar wind data, which he designed in such a way that scientists would be able to listen to it for extended periods of time in order to sub-consciously get a better grip on their data:

With that version of the sonification, I was intending for it to be absorbing of a long period of time. (...) I thought that if there's any chance for new knowledge to be gleaned from the experience of listening to the sonification, it would most likely begin on a sub-conscious level with, you know, turning off the conscious mind and soaking in large amounts of the solar wind data and

\footnotetext{
${ }^{68}$ E-mail correspondence with Thomas Hermann, March $3{ }^{\text {rd }} 2011$.
} 
just absorbing it, and then maybe starting to notice some underlying tendencies, that, you know, at first might be too subtle to notice in the sonification, um, but, you know, after some close listening would become more apparent. (Interview Alexander)

Unlike in synthetic or immersive listening, understanding here is posed to kick in on a sub-conscious rather than a conscious level. Nonetheless, the emphasis on absorption implies that immersive listening is not the same as what Truax (2001 [1984]) refers to as 'background listening' or what radio historians call 'distracted listening' (Douglas 1999; Goodman 2010). While understanding is assumed to begin subconsciously, the activity of listening itself is not one of passive or unconscious hearing: the absorbed listener is actively engaged with the sound. It would be wrong to interpret the different listening strategies I have described here as merely as differences in the "attention level" (Truax 2001 [1984]: 21) of the listener; they are differences in kind rather than in intensity. If anything, they are differences not in the amount of attention paid by the listener, but in the extent to which he or she has control over the data. While immersive listening plays with associations of a listener being submerged in a sea of sound and therefore not in control, synthetic listening poses a more controlled listening subject: while the listener does not have control over the sounds being heard, he is able to filter these sounds and find his own paths through them. Interactive listening, finally, affords even more control to the listener, as she is constantly able to intervene in the sounds she hears.

Of course, this distinction between different levels of control assumes a division of labour between the designer and the listener of a sonification; after all, the person designing a sonification is by definition to a large extent in control of what the data sound like. In this section, I have not only distinguished between some of the different purposes that listening to data can be directed at and between some of the different strategies of listening; I have also shown that such a division of labour between the creators and the end-users of sonification cannot currently be assumed as the norm. So far, there are very few cases where sonification has been integrated into the everyday research practices and routine data analysis methods of scientists; much more emphasis in the field of sonification is put on developing tools and designing sonifications than it is on really working with finished sonifications over extended periods of time. The listeners of sonification are usually either the creators themselves (or their direct colleagues), or test subjects who try out a sonification in the short term, but not scientists who have integrated sonification into their routine toolbox for data analysis. Precisely because so much more emphasis is currently being put on 
tool-building, tool-adapting and sonification design, rather than on sustained application and concentrated listening, it makes sense to think of sonification as a gadget community.

\subsection{Demonstrating Sonification}

The speaker plays a sound file, explains to the audience what they had just heard, then states "I will do it a second time". It's silent for a second while he clicks on the symbol on his slides that should trigger the sound. No sound can be heard. "It doesn't want to do it a second time." The speaker moves on with his talk, and on to his next slide.

Another speaker plays a sound, then mimics what the audience just heard with his own voice. Recreating particular elements of the sound heard, he points out what characteristics the audience should attend to. Then he plays the same sound again.

Another speaker begins by singing his sonification, explaining what we are about to hear. Then he plays the sonification.

Another speaker also begins by singing before playing. While the sonification plays, he moves his hands up and down along with the pitch, as though he was conducting a piece of music.

Another speaker announces: “This is where I'm going to play a little sound for you", and clicks on a loudspeaker symbol on his slides. No sound emerges. The speaker blames the Microsoft corporation, checks whether the sound is enabled on his computer, and tries to access the sound file through the file manager instead of the presentation slides. It still doesn't work. One of the conference organisers gets up to check the sound system of the lecture hall, turns up the volume knob, and the sound can be heard.

Another speaker explains how he made a sonification, shows a graphical representation of it, discusses a scatter plot diagram, but does not let the audience hear the sonification itself: "It doesn't sound very good."

Another speaker plays a few sounds, with some breaks in between. He explains how the different sounds differ: "You wouldn't be able to tell in this environment, but ...". “As I said, you can't hear it here, but they are distinguishable".

Another speaker apologises for presenting his quantitative results as bar graphs, but not providing a sonification of them.

These are a few instances I observed during the three ICAD conferences I attended in the course of my research: 2008 in Paris, 2009 in Copenhagen, and 2010 in Washington DC. They give an insight into the various techniques that exist for mak- 
ing sounds understandable, the technical mishaps that can happen in presenting sounds, and the decisions that have to be made about whether or not to play any sound at all. In this section, I want to throw light on some of these different decisions and techniques.

Most of the examples above describe how speakers integrate sonifications into their talks; some of them, however, feature researchers making excuses for not having brought any sounds. Some ICAD presentations employ no sound beyond the sound of human speech; they may describe a sonification verbally, show its physical waveform as a graph, but not play the sound of the sonification itself. The results of statistical tests are commonly shown as bar graphs or pie charts, but not often heard as auditory graphs. Many community members are concerned about this scarcity of sound at the conferences.

In chapter three, we have already encountered some of the institutional measures that are being taken in order to stimulate people to make more use of sound in their presentations, such as the introduction of aural submissions or of awards for the best sonification presented at the conference. There are other methods to stimulate the usage of sound files as well. For instance, the 2010 Call for Papers included the following note, in which the authority of visualisation is once again deployed:

Authors are strongly encouraged to incorporate auditory display into the presentation of their papers by including examples of the sounds used in their work and/or by sonifying their results. Just as it would be unusual for presentations of papers on graphics not to include visual artefacts, it should be the norm that ICAD paper presentations employ sound in addition to the voice of the speaker. ${ }^{69}$

On a more individual level, members of the ICAD community also try to encourage others to make use of sounds more often. For instance, I have overheard veteran ICAD participants encouraging newer community members to always bring sounds to the conference. The request for more auditory examples is also often made during the open mic session, where community members can make short announcements about new publications or projects, requests for collaborations, or whatever else they might have to say to the community. One recurring theme is the complaint that not enough sounds can be heard during the conference. For instance, during the open mic at ICAD 2010, one speaker told the audience that he had enjoyed the conference

\footnotetext{
${ }^{69}$ See http://www.icad.org/icad2010/ under 'Submissions Information' (last accessed on November $14^{\text {th }}$, 2011).
} 
immensely, but that "we have one problem, many of you have this problem": throughout the conference, he had seen all kinds of different graphs, but not heard a whole lot of sonifications. At the very least, people should be making use of some of the simple tools that are available for a basic conversion of data into sound - his students are all capable of doing this, because he forces them to, so there should be no reason for the ICAD community not to do the same. Doing so should be a minimum requirement in one's effort of quality control. The speaker concluded with an emotional appeal: "Please do that, you'll make me so happy!"

Perhaps the most radical proposal to stimulate the playing of sounds at ICAD conferences has been discussed half-jokingly during conference breaks and open mic sessions: banning the use of visuals and of slideshows, or at least of graphs and pie charts. While there currently seem to be no plans of implementing this proposal, even the suggestion shows that visual displays are cast as competitors and potential threats for sonification, and that the lack of sound at ICAD conferences is seen as undermining the authority of sonification. As one participant has remarked during a coffee break, "we need to use our own tools" - if even the ICAD community does not systematically employ sonification, how should it be expected to take on in the rest of the world?

Of course, the examples at the beginning of this section show that there can be pragmatic reasons not to rely too heavily on the usage of sounds: the technology can fail, or things can sound different in the conference room than in the laboratory or office for which the sonification was designed. Some ICAD conferences have taken place in halls with better sound displays and better room acoustics than others - for instance, the Espace du Projection of IRCAM in Paris (a concert hall optimised for the performance of electro-acoustic music) allows for more acoustical control than the ceremonial room in the Museum of Copenhagen. But even in a room with the best acoustics and the fanciest speaker system, sonifications designed for headphones will not sound at their best.

So there are limitations to the usage of auditory displays even at conferences dedicated to Auditory Display. However, the anecdotes at the beginning of this section show that many speakers do in fact come to ICAD conferences armed with sound files; in fact, one of my respondents has mentioned that optimising the sounds for conference presentation, under the supervision of colleagues and $\mathrm{PhD}$ advisors, is an important part of the conference preparation routine.

Just bringing the sounds to the conference is not enough, however, and presenting sonification requires more than just auditory skills. In the words of Jens Lachmund, the presentation of sonification is not a purely auditory phenomenon, but 
"an auditory [one] that, at least partly, [is] being shaped through the visual" (Lachmund 1999: 428). ${ }^{70}$ For each of the presentations mentioned, the laptop screen of the presenter was hooked up to a projector, and in each case, it was used for more than just presenting text on the screen. Usually integrated into prepared Powerpoint slides, the presentations come with any number of different images: clip-art symbols adorning the sides of the slides; schematic diagrams showing the technical set-up of a system; screenshots or even live demos of the software employed in making the sonifications; photos of the tools in use; dynamic, graphic representations that run in parallel with the sound; or even graphical waveforms of the sonifications themselves that are shown instead of playing the sounds. All of these visual methods have a place in rendering sonification presentable in front of an audience.

Apart from the images shown on their computer screens, the presenters employ visual techniques in order to point out particularly salient aspects of the sonified data: by pointing at the screen while playing a sound, by drawing graphs on the blackboard while explaining something, or by gesticulating along with the sound in order to emphasise changes in pitch. These activities direct the attention of the listener; as Tim Ingold points out, the addition of visual elements helps to orient the sense of hearing and "transforms passive hearing into active listening" (Ingold 2000: 277). However, activities such as pointing, gesticulating or even writing on a blackboard might in fact be considered as not entirely visual phenomena, but ones that at the same time hint at elements of tactility and embodiment - they refer to "the haptic dimension of visuality" (Mayer 2011: 32) and make up the corporal knowledge and 'body-work' (Myers 2008) of sonification. Like the crystallographic modelers studied by Myers, these researchers involve their own bodies in understanding and communicating about their data ${ }^{71}$ - and like in Myers' study, this appears to be especially true for more experienced researchers.

Another important corporeal technique has been mentioned in the episodes above: a practice sometimes jokingly referred to as "data karaoke" by sonification researchers, in which a human being mimics the sound of a sonification. This skill has already been mentioned earlier in this chapter: while designing sonifications, it is important to develop concrete expectations of how the data should be mapped and what they should sound like; making an auditory sketch is an effective way of making

\footnotetext{
${ }^{70}$ Lachmund made this observation in the context of his study of medical auscultation (Lachmund 1999), in which he shows that the auditory skills involved in auscultation were not independent from visual skills, as visual imagery and visualisations also played a role.

${ }^{71}$ Morana Alac makes a similar observation in her ethnographic study of fMRI practitioners, for whom brain scans become visible "not only through visual perception, but also through the involvement of hands" (Alac 2008: 484).
} 
these expectations more tangible and of communicating with collaborators. Importantly, the resulting sounds can not only be heard, but also felt in the body of the person engaging in data karaoke. While pointing and grasping are examples of the tactility of vision, data karaoke is an instance of "the tactility of sound" (Connor 2004: 157). Like molecular biologists and protein crystallographers build and physically handle models as a way of gaining a more intimate understanding of structures (de Chadarevian 2004; Myers 2008), sonification researchers who use data karaoke may strengthen their relationship to the data by engaging in body-work of their own, by giving voice to the data and feeling them in their own body.

As the examples above show, the skill of data karaoke is also important in presenting finished sonifications to an audience. In order to point out the different components or the salient characteristics of a sound, the presenter's voice can be used to underline what is interesting about the sound. Clearly, data karaoke is very much an auditory skill, drawing on the capacities of the human voice and ear; but at the same time, it also very much a case of tactility and body-work. Presenting and listening to sonification concerns not only the ear; it also engages the senses of seeing and touching. The professional audition of sonification is not a purely auditory phenomenon.

\subsection{Conclusions}

In this chapter, I have explored the tools and skills of sonification research and followed them through five different contexts: the learning stage, the choice or creation of tools for sonification, the design of concrete sonifications of particular scientific datasets, the working with and listening to those sonifications once they have been designed, and finally, the presenting of more-or-less finished sonifications in front of a scientific public. I have tried to give a thick description of some of the work that goes on in each of these stages; at the expense, perhaps, of mentioning every single aspect that plays a role. For instance, more could have been said about the choice of the concrete audio parameters and the mappings between data and sound in the section about designing sonification, and the section about presenting sonification could have included discussion of printed publications as well as oral presentations. In the end, the intention of describing some relevant aspects in detail won over the desire for encyclopaedic completeness.

This way of structuring the chapter allowed me to distinguish between different types of work going on in sonification. However, it may have given a false sense of linearity between the stages, as later stages often feed back into or overlap with earlier ones. For instance, the choice of tools does not necessarily chronologically come 
between learning and designing; it is entirely possible to start out by trying out some sonification designs (stage 3), before deciding that a different tool might be better suited to the job (stage 2), and therefore learning to work with this new tool (stage 1). Designing sonifications is also frequently hard to fully separate from listening to already designed sonifications; this is especially true because most of those currently listening to sonifications are directly involved in dedicated sonification projects, while cases of uninvolved scientists (who are divorced from the context of sonification design) integrating existing sonification techniques into their work practices are very rare indeed.

My discussion of these contexts of sonification work has allowed me to develop two notions that I have raised in the introduction to this chapter; on the one hand, the notion of professional audition as a set of skills that are shared within the sonification community and that every competent member of the community has to possess; and on the other hand, the notion of a gadget community, which is more focused on the development of the tools than on their application. I will be using the remainder of this chapter to elaborate on these concepts.

The notion of professional audition may be a strong term for a community which itself is still in flux; referring to the skills described in this chapter as a stable set of "professional perceptual standards" (Goodwin 1994: 615) may be a slight overstatement. Perhaps it is better to think of it as a professional audition which is still in the making; its contours are already visible, but some of the skills it encompasses haven't been fully developed yet. For instance, the need for finding ways to express expectations for a sonification and to communicate about sound, and to do so across disciplinary boundaries, has become obvious; this does not mean, however, that the community has already developed these competencies to the necessary extent. The very fact that interdisciplinary workshops such as Science by Ear 2 exist shows the willingness of community members to develop such competencies, but the concrete experiences of this workshop also demonstrate that there is still work left to do.

Nonetheless, the elements of the sonification-specific professional audition can already be made out on the basis of my analysis here. In short, professional audition refers to a set of practices that allow practitioners to design, listen to, and communicate about sonifications. This includes hardware tinkering as well as programming skills; the competence to imagine and anticipate what something might sound like, to express these expectations and translate them into a concrete sonification design; the ability to meaningfully talk about sound, and to do so in the way that is understandable to peers and collaborators; the skill of listening closely and carefully, and of engaging in different types of listening activities; and various strategies of presenting 
sonification work to an audience. It is important to keep in mind that these skills are not exclusively auditory skills. For instance, sketching a sonification design before it is implemented or presenting it to an audience once it is finished involves strategies of pointing, gesticulating, drawing, humming and singing; that is, it involves skills that are auditory, visual and tactile.

The cultivation of such a sense of professional audition has an important function in holding together the scientific community and in establishing the authority of sonification by accentuating the expertise it requires: it helps to define sonification as "a community of competent practitioners" (Goodwin 1994: 615). As such, it functions to legitimise the scientific community dedicated to sonification, and helps to draw the boundaries between insiders (who possess the skills that make up the professional audition of sonification) and outsiders (who do not). For example, the ability to engage in technical discourse about sound, to tinker with hardware, or to do computer programming are markers of the expertise of sonification researchers, from which they draw their authority to create auditory scientific representations; but they also create potential exclusions, as individuals who do not possess these skills may not be able to make a significant contribution to the community.

In this chapter I have argued that the sonification community can currently best be understood as a gadget community; that is, as a community which is more enthralled by the tools themselves than the scientific substance of what can be found out with the help of these tools, and which is more concerned with finding or developing the right tools than with actually listening to the results of concrete sonification examples. The choice of the right tools is considered extremely important, and the practice of building and developing your own tools functions almost as a status symbol. This tool-centricity of sonification may not be entirely unproblematic; in the course of my research, a number of people have expressed - often off the record uncertainty about whether the ICAD was indeed the right community for them (without, however, indicating another community that would be a better outlet for sonification research), as discussions there tended to focus very much on tools and techniques. Talking about the scientific background and significance of the data being sonified, they felt, was either actively (e.g. in the peer review process) or tacitly discouraged; or, when an interest was shown in the scientific background of a project, the qualification to really engage in an informed discussion of these scientific issues was often missing. Indeed, one of the scientists who had participated in the first ICAD conferences (a domain scientist who created sonifications of the data he was working with) later fell out of touch with the community, because "it was highly 
technical, (...) tool-building, and I could see that, you know, it was moving away from me. There wasn't a lot I could do to contribute to it." (Interview Hayward)

As I have shown, the focus on the tools of sonification does facilitate certain kinds of collaboration. Specifically, it provides an easy way into the community for people who already possess certain skills specified in the professional audition of sonification, which they can carry over into their work in sonification, for instance skills in electronic composition or in tinkering with hardware. On the other hand, precisely because the sonification field - and the ICAD as its most prominent institutional embodiment - is so focused on tools and techniques, researchers who are less interested in the technical details of sonification work and more interested in the scientific significance of the data and phenomena being sonified might feel less welcome in the community, or less equipped to or interested in contributing to it. The gadget-oriented character of sonification thus both enables and limits certain kinds of interdisciplinary collaboration.

Characterising sonification as a gadget community does not imply that the community is doomed to live on the fascination of technological gadgets forever and ever; it may well be a transitory phase in the development of sonification. However, in the current stage of development, this tools-focus may present an obstacle in the community's struggle for scientific acceptance. As I have argued, the professional audition of sonification helps to establish the authority of sonification experts; at the same time, however, it seems to limit or marginalise contributions by those whose acceptance the sonification community seeks the most: scientific domain experts.

When I introduced my research questions at the beginning of this dissertation, I argued that understanding how the practitioners of sonification try to establish the legitimacy of sonification also means studying the obstacles that they face in doing so. My analysis of the gadget community of sonification is thus an important step in reaching such an understanding. It is now time to return to these larger research questions. 



\section{Chapter 6 \\ Conclusions}

In this dissertation, I have studied the sonification of scientific data at a peculiar and particularly interesting stage of its development: at a moment where its future is still wide open and the question of its scientific acceptance has not been settled. This has allowed me to address the two questions that I have posed at the beginning of this book, and that I want to return to now: why the sonification of scientific data has attracted considerable interest in the last few years, and how the practitioners of sonification try to establish its scientific legitimacy. I will begin by addressing the second question.

A scientific community explicitly dedicated to sonification has developed over the last twenty years (although a few scattered applications existed earlier), and has just reached the point where a small group of researchers regard this field as their primary or default scientific community. The community is setting first steps of professionalisation and of establishing a firm disciplinary identity, rather than viewing the field as an eclectic and temporary mingling of disciplines. At the same time, critical voices within the field have started to express concerns - often off the record that the field is starting to stagnate and has not developed as far as expected. I have coined the notion of a gadget community in chapter 5 to characterise a community which is so focused on technological development for its own sake that concrete work with these tools is sometimes neglected.

A particular challenge has been to convince domain scientists (who apply sonification to concrete research problems) to become involved and make enduring use of sonification techniques in their scientific analyses (see chapters 4 and 5). To the extent that such researchers are willing to work with sonification at all, they usually only do so in contexts that are framed as amusing diversions or as popular outreach to laypeople, but not as part of their actual research routines (see chapters 2 and 4). In order to attain scientific acceptance, many sonification researchers hope for the development of a 'killer application', a specific sonification example that will prove so successful that some of its glory will rub off on the field as a whole (see chapter 3 ). At the same time, the standards by which a successful sonification should be judged are also intensely negotiated within the community (see chapter 4). Nor is it entirely clear whether the community should seek acceptance exclusively within the domain of specialised academic science, or whether it should position itself more in relation 
to art, music or public outreach (see chapters 2 and 3). In this dissertation, I have analysed how the practitioners of sonification navigate this cragged terrain.

My interest in the strategies used by members of the sonification community in their struggle for scientific acceptance became most explicit in my analysis of the boundary work of the sonification community in chapter 3. In this chapter, I showed that the practitioners of sonification are not so much busy moving the boundary between art and science in one direction or the other, but rather constantly slipping through the fence between the two terrains: the boundary work of sonification does not aim at a fundamental redefinition of what doing science means, but rather flexibly moves between existing cultural attributions. I have referred to this mechanism as boundary slipping. However, other chapters also contributed to the understanding of the community's struggle for academic legitimacy, for instance by analysing the discourses about objectivity that are aimed at establishing sonification as an objective scientific method (see chapter 4), or the cultivation of professional audition, a set of skills that distinguishes competent practitioners of sonification (see chapter 5).

Precisely because sonification is such a young and still unsettled field, some of the tensions and fundamental decisions the sonification community has to face are particularly palpable and amenable for study. The sonification community currently has to balance two such "essential tensions" 72 that I want to discuss in these conclusions. The first tension - which is at play within the community's struggle for scientific acceptance - concerns the extent to which sonification is made to either break away from or link up to established scientific practice. The practitioners of sonification often quite self-consciously break with norms of scientific representation and present their approach as an antidote to a science traditionally dominated and constricted by the sense of vision. At the same time, the sonification community is eager to fit in with the structures of science and to gain scientific acceptance. Thus, the community struggles with a tension between compliance with the science system and non-conformity.

The second tension, on the other hand, is one of deciding between striving for scientific legitimacy, or going after something else entirely: a sense of public fascination. As such, it is a tension between the two phenomena that make up the subtitle of this book. My claim is not that the two are necessarily incompatible - they may even reinforce each other in certain contexts. In the context of the contemporary sonifica-

\footnotetext{
${ }^{72}$ This term has been used by Edward Hackett (2005) - with a nod to Thomas Kuhn's (1977) classic treatise on the essential tension between tradition and innovation in normal science - to describe the various tensions that a research group has to face, for instance in balancing autonomy and control, inquiry and education, or openness and secrecy.
} 
tion community, however, they do not go together quite so easily, as the strategies that are successful in establishing public interest in sonification do not automatically lead to its increased scientific acceptance. Practitioners of sonification have to strike a balance between striving either for public fascination or for scientific legitimacy - or juggling the two in such a way that they become compatible.

This tension, then, leads back to the other research question of this dissertation, which asked what the recent public fascination with sonification was based on. In order to answer this question, I have proposed the concept of the auditory sublime (see chapter 2). I have coined this term to describe the specific kind of experience of science that sonification is thought to offer, an intimate experience of the awe and wonder of science which the audience is allowed to partake in. The concept of the auditory sublime does not yet explain, however, why this fascination with sonification is such a recent phenomenon. Why do musical pieces, public talks, newspaper articles and blog posts about sonification proliferate in the early twenty-first century, and why haven't they been a constant in the media landscape in the decades and centuries before? On the following pages, I discuss two current developments within science that are related to the recently increased prominence of sonification projects and initiatives: changing constellations of science and society, and the emergence of digital technologies in scientific research and artistic practice. In short, my argument is that sonification, with its promise to tap into the auditory sublime, can offer a remedy in the perceived crisis in the relations between science and society, where new strategies are urgently sought to convince the public of the need to support scientific research. At the same time, the practice of sonification is also linked to the existence of digital technologies, such as electronic sound synthesis or mp3s allowing for the easy dissemination of sound files.

Both of these developments - the changing relation between science and society, and the emergence of digital technologies - also have implications for the scientific legitimacy of sonification. The quest for scientific acceptance, too, is linked to developments in the realm of digital technologies, where methods of electronic publishing and new visualisation techniques have changed the landscape fundamentally. It is also related to the changing relationship between science and the public - although much more ambiguously than the public fascination with sonification is. The tensions between framings of sonification that are primarily directed at public reception, and those that are primarily directed at scientific credibility, become most explicit in the context of the relations between science and society. Below, I will sketch out how the practice of sonification is interlinked with these broader developments within science that go beyond the scope of sonification itself. 


\subsection{Digital Sounds and Images}

Throughout this dissertation, a plethora of digital technologies that play a role in sonification work have made an appearance. From the examples of sonification in the public sphere (chapter 2) to the ethnographic descriptions of sonification in action (chapter 5), the vast majority of the sonification work described in this book has been enabled by the possibilities of digital technologies, and in particular, the sound synthesis capabilities of modern computers. One could easily imagine a statement about the relationship between sonification and digital technologies that simply reads: digital technologies are the technical condition for the existence of sonification. Or even more simply: the computer has brought about sonification.

As a self-respecting STS scholar, steeled against the dangerous temptations of technological determinism (Smith and Marx 1994; Wyatt 2008) - or cyberbole, as Steve Woolgar (2002) has named the specific kind of technological determinism that often crops up in debates about information and communication technologies - I will not be making this particular argument. Instead, I want to retrace the rather more complex interrelationship between sonification and digital technologies, and specifically three different types of digital technology: digital images, digital audio, and digital publications. As I will show in this section, these technologies play a role for sonification not merely as a technical condition for the proliferation of sonification, but also as factors in the community's struggle for scientific acceptance. At the same time, the technologies do not have a unidirectional and unstoppable impact on the practice of sonification; rather, it is within the scientific community that the way in which these technologies are taken up and appropriated into contexts of use is negotiated.

The idea that digital images play a role for sonification, which is all about displaying data by auditory means, might be surprising - at least to someone who has not read this dissertation. In the light of the preceding chapters, it is not very surprising at all. After all, the relationship between sonification and visual practices has been a recurring theme throughout the book, and I have argued that it makes no sense to study the different senses in isolation from each other. To underline this point, I will briefly reflect on the interrelationship between sound and vision in sonification research, before returning to the implications of digital images for sonification.

Visualisation practices have often been used as a point of reference for sonification, for example when sonification was defined in relation to visualisation (see chapter 3), or when subjective decisions that have to be made in the making of sonifications were justified by pointing out that similar decisions are also part and parcel of 
the making of visualisation, and accepted as such (see chapter 4). Indeed, images themselves play a practical role for sonification: they are ubiquitous as graphical user interfaces for sonification tools, as printed graphs and diagrams in publications, or as powerpoint slides during presentations (see chapter 5), and their presence or absence contributes to the creation of engaging and immersive listening experiences (see chapter 2). Some sonification researchers have found scientists who are experienced at working with visualisation to be more open-minded about the potential of sonification because they know from experience that different representations of the same dataset are possible and that it can be useful to experiment with alternatives (see chapter 3). And in any case, many in the field believe that it is necessary to link up sonification with existing tools and skills in order to lower inhibitions, for instance by adding sonification functionalities to existing frameworks for scientific visualisation (see chapter 3 ).

However, these examples might make the relationship between sonification and visualisation appear more harmonious than it actually is. Just as often as it is framed as a role model for sonification, visualisation is regarded as its competitor. Its predominance is blamed for the marginalisation of sonification (see chapters 1 and 3 ), in part because the scepticism that sonification researchers often face from peer reviewers seems driven by the argument that visual displays would be better suited for dealing with scientific data (see chapter 4). Because of concerns about the privileging of images at the expense of sounds, the use of visual techniques for presentation purposes is contested within the community, giving rise to talk about banning slideshows and graphical representations from conferences (see chapter 5). The relationship between sonification and visualisation is thus a complex one, and it rests upon the same tension that has been a central theme of my dissertation: the extent to which sonification should either try to fit in with existing (usually visual) practices, or instead try to liberate itself from their perceived constraints and limitations, and thus break away from them as radically as possible.

The above also hints at the result of the idea of sonification as a breaching experiment, which I have proposed in the introduction: can sonification, by breaching the conventions of scientific representation, teach us something not only about the status of sound, but also of vision, in science? Indeed, the relationship between sonification and visualisation seems to show that the visual is so firmly entrenched in science that it has become more or less inescapable; even for a practice like sonification, which sets out to provide an alternative to the visual sense, a recurrence on vision has become unavoidable. 
In the light of this complex relationship between sound and vision, then, it is no surprise that developments in the domain of digital imaging technologies would influence, however ambiguously, sonification. Since visualisation is often used as a point of reference for legitimising sonification, changes within imaging practices also make available new ways in which sonification can be made to link up to visualisation. An important development here is the introduction of digital images, which according to some commentators have given rise to an entirely new visual culture. For instance, Jonathan Crary talks about a radical transformation of visuality in the twentieth century:

The formalization and diffusion of computer-generated imagery heralds the ubiquitous implantation of fabricated visual "spaces" radically different from the mimetic capacities of film, photography, and television. These latter three, at least until the mid-1970s, were generally forms of analog media that still corresponded to the optical wavelengths of the spectrum and to a point of view, static or mobile, located in real space. Computer-aided design, synthetic holography, flight simulators, computer animation, virtual environment helmets, magnetic resonance imaging, and multispectral sensors are only a few of the techniques that are relocating vision to a plane severed from a human observer. (...) Most of the historically important functions of the human eye are being supplanted by practices in which visual images no longer have any reference to the position of an observer in a "real," optically perceived world. If these images can be said to refer to anything, it is to millions of bits of electronic mathematical data. (Crary 1990: 1f.)

One of Crary's examples is the medical imaging technology of magnetic resonance imaging (MRI). Many scholars of visual cultures and STS have studied MRIs, trying to answer whether and how they differ from previous medical images. Crary's observation that the images correspond only to numbers in a dataset and not to an observable visual reality is an important starting point for such considerations. Kelly Joyce explains the status of these images by comparing them to X-rays:

MRI, despite its current construction as a visualizing technique, does not produce anatomical images in a straightforward fashion, nor does it use X-ray techniques to create pictures of the internal body. Instead, it is used to numerically measure how hydrogen nuclei absorb and release energy in response to particular frequencies. Each numerical value is then coded and 
transformed via computer software into a component of an image. (Joyce 2006: 5)

As a result of this process, there are very few restrictions to what the resulting images might look like - after all, the numbers can be transformed into images in many different ways, much more so than would be the case with an imaging technology where the starting point is already a visible signal. During its early history, the question of what kind of images should be produced by MRI was intensely negotiated indeed, what was at stake was whether any images should be produced at all, or whether the output should take a purely numerical form (Joyce 2006). These decisions were intimately connected with questions of professional competences and responsibilities; questions of who would operate the machines, who would be considered competent to interpret the output, and even where the machines should be located (Burri 2008a, 2008b; Joyce 2006).

Not only did the digital images become wrapped up in debates about labour relations and professional competencies; they have also sparked debates about the nature of objectivity in the age of digitality (Beaulieu 2001; Prasad 2005). Amit Prasad's detailed account of the making and interpretation of MRI images shows how the practitioners create these images and how they establish their trustworthiness. Each image is based on multiple parameters of numerical measurements. There is no single "correct" mapping between data and image; instead, the technologists adjust the images based on their own judgement in a process of "dynamic interaction" (Prasad 2005: 299), and build up large networks of images (different MRIs as well as other types of images) for the purpose of comparison and cross-referencing. The medical gaze afforded by MRI is therefore "not constituted by a single act of 'seeing' and its representation in a single exemplary image of the body" (Prasad 2005: 309); instead, the credibility of MRI rests upon the accumulation of and comparison between these different images. In Prasad's account of MRI, this task of comparison rests with a human observer who has to detect patterns in the various images and to make a judgement about what the salient characteristics are. Although Prasad uses the term "cyborg visuality" to refer to this regime of representation, it links up very well to what Daston and Galison have described as "trained judgement" (see chapter 4). Indeed, it is probably no coincidence that most of the concrete examples Daston and Galison show and discuss as examples of trained judgements are in fact digitally created images.

In chapter 4, I already showed that parts of the sonification community have started to link up to a discourse of trained judgement in order to justify the objectiv- 
ity and scientific legitimacy of sonification. Much like Prasad has shown for MRIs, sonifications are usually created by mapping multiple characteristics of numerical data into sound; and much like for MRIs, making sonifications often means not so much searching for the one perfect representation of a dataset, but interactively trying out different settings to find patterns - a strategy I have referred to as interactive listening in chapter 5. Compared to ideals of mechanical objectivity, it seems easier for sonification to be shown to correspond to trained judgement. To the extent that developments in the domain of digital images may further strengthen the discourse of trained judgement, then, they might also help along the scientific acceptance of sonification.

The practice of sonification is intimately intertwined not only with developments related to digital images, but also with the possibilities of digital audio. This is not to say, however, that digital audio is a technical requirement for sonification - it is perfectly possible to represent data as sound by playing notes on a piano, by tapping a rhythm on a table, or by humming a tune. Conserve such sound via recording has been possible since the late nineteenth century (Chanan 1995; Morton 2000; Sterne 2003). And yet it is no coincidence that the potential of sonification started being explored systematically only in the digital age. Digital audio makes it more convenient to transform data into sound, an advantage especially when it comes to dealing with large and complex datasets. It allows mapping the same dataset, or different datasets, onto different characteristics of the resulting sound. Even in the simple sonification that I designed as a complete novice (with help from the sonification researcher Thomas Hermann) during my two weeks of learning audio programming, a multitude of different sonic characteristics were driven by parameters in the dataset, ranging from the sharpness of the tone to its pitch, from its timbre to the panning effect, i.e. its position in the stereo field. As Hermann remarked, thanks to developments in audio computing, the type of tasks that would have filled an entire diploma thesis when he entered the field in the late 1990s nowadays could be assembled within a week (interview Hermann 1). Without the possibilities afforded by digital audio and the widespread availability of personal computers with audio capabilities, the sonification field would be a very different one indeed.

Not only do developments in digital audio facilitate the creation of sonifications, but they also make it much easier to share and distribute the sounds. When Karl Steinbrugger (1974) published his catalogue of earthquake-related sounds in the bulletin of the Seismological Society of America in 1974, the accompanying sound examples were pressed on a thin vinyl disc - a so-called flexi disc - that had to be pressed for the occasion (Dombois 2008). When the first ICAD proceedings were 
published in print twenty years later (Kramer 1994b), the sound recordings could be presented in a different format: on CD. Compared to flexi-discs, CDs can hold much more data and are cheaper and easier to produce, especially on a non-commercial scale (just about anyone has access to CD-burning facilities, while flexi discs, even at the height of their popularity, required equipment that was only available via professional channels). Since then, another technology has become available that makes the sharing of sound files even easier, cheaper, and less prone to degradation, as the sounds can now be put online as digital files, for example in the mp3 format. The mp3 is a technology that was developed and is cherished precisely for affording portability (Sterne 2006). ${ }^{73}$

Technical developments in digital audio therefore make life easier for the practitioners of sonification. This is not just a matter of convenience, as the possibility to easily circulate recordings of sonifications may help to establish their credibility. The ability to be circulated, shared and integrated with written text, after all, is considered an important advantage of visualisations and graphical representations (Latour 1986, 1990; Lynch 2006). Portable audio formats such as the mp3, especially if embedded into electronic publications, may thus help sonification to catch up to visualisation in terms of scientific acceptance - they could, in a nutshell, allow sound to function as what Latour $(1986,1990)$ has referred to as 'inscriptions', and thus to serve as credible scientific evidence. As one of my interviewees has pointed out, "a sound has to be published in order to count as an academic argument" (interview Dombois, translated).

This also means, however, that the future of sonification is linked to that of publication practices in the sciences more generally. For example, if a broader development toward electronic publications takes place, this might make life easier for the practitioners of sonification, as audio or multimedia content could be more easily integrated into digital than into printed publications. Much research is being done at

\footnotetext{
${ }^{73}$ A word of caution should be added here: As always, the technology itself does not dictate how it will be put to use, which depends on a wider social and cultural context. While the mp3 was developed with the goal of portability, concerns about copyright and file-sharing have led to the development of files with 'digital rights management' (DRM) capabilities, which are designed to restrict the circulation of electronic files. While DRM has mostly been applied in the music and movie industry in the name of fighting against piracy, some experiments with DRM also exist in academic publishing, where some publishing houses are trying to limit the circulation of offprints of articles by their authors (Striphas 2010). I know of no cases of DRM being used to restrict circulation of audio examples of sonification, and the widespread tenor in the field is that these examples should be circulated more rather than less. Nonetheless, while a development towards sonification examples with DRM restrictions seems highly unlikely, it is a technical possibility. That said, a more common limitation to the circulation of $\mathrm{mp} 3 \mathrm{~s}$ is the existence of 'dead links'. For instance, if a researcher uploads mp3s to her university's webspace, these often become unavailable if the university homepage undergoes restructuring.
} 
the moment on the future of scientific publishing in the age of digital media, but it is still unclear to what extent these possibilities will be taken up. Indeed, research so far suggests that initial expectations of substantive transformations of the content and form of scientific publications have not been met. Advocates of electronic publishing have pointed out its many advantages, such as the ability to integrate multimedia contents and datasets, to work with hyperlinking and to increase user involvement and interaction (MacKenzie Owen 2005: 10f.), but most electronic journals so far have made little use of these capabilities. Instead, they usually are "little more than mirror-images of print journals" (Jankowski 2009: 16). This especially applies to journals that exist in paper-based as well as electronic versions, but is often also true for electronic-only journals. Even when journals explicitly offer such options, authors only rarely make use of them (MacKenzie Owen 2005: 230). MacKenzie Owen concludes that digitalisation has so far mostly affected the process of scientific publication - e.g. submission and review procedures or how people find and read articles rather than its substance (MacKenzie Owen 2005: 232). If this trend persists, the potential benefits of digital publications for sonification will continue to be mostly theoretical.

Based on the potential advantages of electronic publishing for audio and multimedia content, one might expect that the sonification community would latch onto these new technologies for scientific communication and bid farewell to the more restrictive format of printed pages. However, this is not the case, or at least not unequivocally so. The president of ICAD, Bruce Walker, describes the ambitions for a journal dedicated to sonification as follows:

My view is that the journal needs to be a modern journal that includes an optional paper or printed copy, but that also has an extensive website to handle the electronic files related to audio and video. (...) We don't want this to be just an online or an e-journal, electronic journal. Because there's something in terms of prestige that comes with print. (Interview Walker)

Here, the advantages of an electronic journal are made explicit, and indeed, Walker goes on to refer to the digital version as "the best version, and the print version would be less desirable, because it wouldn't have access to all of the audio files" (interview Walker). Yet despite its shortcomings, the printed version is nonetheless considered to be indispensible. These contemplations acknowledge that a journal publication serves a double function: on the one hand, it is a means of formal communication of scientific results, and on the other hand, it is a status symbol and sign of academic 
prestige. For the former function, the electronic version is more convenient, but for the latter, the existence of a printed version is regarded as essential. ${ }^{74}$ And the latter aspect seems to dominate when it comes to the plans of a journal dedicated to sonification. In the conversations I had with ICAD board members about the idea of founding a journal, its practical value of distributing scientific results was scarcely mentioned at all - for this, the current channels of self-published, publicly available conference proceedings seems to be considered as sufficient. Instead, the journal is intended to demonstrate a process of disciplinary maturing (interview Hermann 2), to raise the profile of the community (interview Brewster) and to acquire academic status (interview Worrall). Between these goals and the belief in the status-enhancing effects of having a print journal, it is no surprise that the sonification community is determined to have one.

Of course, the community could make a different choice and decide to ignore the traditional markers of scientific authority and instead focus their energies on the development of publication outlets that best suit their own pragmatic needs. The fact that the practitioners of sonification choose not to do so is a sign of their willingness to play according to the established rules of science, to acquire academic credibility in the old-fashioned way. On the one hand, the community is willing to embrace the possibilities of digital media, but on the other hand, it is not ready to depart from traditional means of publishing and the traditional signifiers of academic authority that come along with them. This example further underlines an argument Hine (2008) makes in her study of digital technologies in biological systematics. Such technologies are never just autonomous agents of change, but are in fact shaped by the extent and way to which they are put to use. The mere existence of a particular type of technology is not enough to ensure that it will be used, let alone that it will do away with older traditions and technologies. Therefore, it is not possible to straightforwardly predict how the existence of digital technologies will influence the practice and standing of sonification; instead, it is within the academic community of sonification that these technologies take on their identity, and it is up to the practitioners to reflexively decide how to use them. The way in which they currently use and think about them emphasises the community's struggle with a tension between innovation and conservation, between compliance and non-conformity.

\footnotetext{
${ }^{74}$ Kristrún Gunnarsdóttir (2005) has made very similar observations in her study of the use of electronic preprint archives in high-energy physics: while electronic preprints have more 'use value' to the physicists, the journal publications take on great significance for their 'token value' as signs of academic status.
} 


\subsection{Science and Society}

One thing that has become clear in the course of this dissertation is that the very meaning of 'sonification' is contested and subject to negotiation. This has become apparent not only in relation to the explicit debates about how the term should be defined (see chapter 3), but also in the more subtle different ways in which sonification is framed. In chapter 2, I have sketched one of these framings: as a source of spectacular experiences, an auditory sublime. As I have argued in chapter 4, this framing of sonification goes hand in hand with a sonoclastic attitude of many of the scientists who work with sonification as part of their popularisation activities: while these scientists happily use sonification examples as components of their talks or media appearances, they generally disavow them as objective scientific representations, and regard them merely as amusing and marginally relevant gimmicks.

Chapter 4 has also introduced two very different framings that are available to sonification, which I have referred to as the correlation coefficients and the trained ears approaches. While the former is concerned with creating credibility for sonification through strategies of quantitative testing and measuring what average users can hear when listening to a specific sonification, the latter seeks to establish the legitimacy of sonification by creating a discourse of expert judgement, in which subjective interventions are considered to be permissible. It is important to remember that these different framings do not just emerge out of thin air, but are intimately linked with different disciplinary perspectives and research foci, as well as with different conceptions of the users of sonification. In contrast to the framing of the auditory sublime, however, both of them seek to establish the legitimacy of sonification on (relatively) firm scientific ground; while sonification as a source of the auditory sublime is heralded for its musical innovations, artistic spectacles, or for its potential in 'bringing science to the masses', these approaches are concerned with legitimacy in the context of academic research and in the eyes of specialised scientists.

Sonification, framed as a source of the auditory sublime, has received considerable media attention in the last few years; sonification concerts, musical talks, public talks and magazine articles have been flourishing. On the other hand, the attempts to frame sonification as a methodological approach for scientific specialists have met some resistance. While a community of scientists (and some artists) dedicated to pushing the agenda of sonification has emerged since the early 1990s, they have often found it difficult to convince peer reviewers, funding agencies and 'domain scientists' that listening to data can be a fruitful approach in scientific research. In other words, the 'auditory sublime' framing of sonification currently seems to be more successful 
than those that frame sonification as a tool for scientific researchers. In these conclusions, I will provide an explanation for this imbalance. In chapter 2, I have argued that the idea of sonification as an auditory sublime is so forceful because it plays into a long-standing cultural tradition of thinking of sound as being good at creating intimate, emotional and enveloping experiences; on the other hand, as a source of abstract information - which is what the more 'scientific' framings of sonification emphasise - it is usually disavowed. The point I want to make now is that the success of this framing of sonification also has to do with broader changes in the scientific system, and in particular, with the changing importance and nature of 'public understanding of science' initiatives.

It has been pointed out that the relationship between science and its publics has become especially challenging in the last few decades. As Ulrike Felt argues, at a time when the costs of scientific research run high while governments are becoming more concerned with whittling down expense, the idea that "the pursuit and acquisition of knowledge [was] valuable enough in itself to justify pouring money into basic research" (Felt 2000: 7) has lost much of the self-evidence that it once possessed. Considerable public scepticism about the benefits brought forth by scientific and technological progress has been heard since the advent of science-critical social movements in the 1960s (Lewenstein 1992; Macdonald 1998a) and more recently in relation to scandals such as the late 90 s outbreak of 'mad-cow disease'. These developments have given rise to "a sense of widespread crisis of public mistrust of science" (Wynne 2006: 211) in science and policy circles. Although it has been argued that this discourse tends to overestimate the amount of trust people had in science before the most recent developments (Wynne 2006), it is nonetheless widely agreed that the relation between science and society has taken on a new urgency in the recent past.

Not only the relationship between science and society has changed over time, but so has the policy response to it. For a long time, it was assumed that if the public does not support science, this can only be the fault of the public. The public acceptance and support of science were equated with knowledge about science, and the terms "public understanding" and "public appreciation" used quite interchangeably (Lewenstein 1992; Wynne 1995). If such understanding and appreciation was lacking, then the public had to be educated so that they could improve their ways. This view has been called into question in the last few decades, beginning with constructivist studies of public understanding of science which problematised not only 'the public', but also the meaning of the term 'understanding', and, importantly, the 'science' part of the equation (Wynne 1995). A similar rhetoric, often influenced by the language of STS (Irwin 2006; Joly and Kaufmann 2008), has made its way into policy circles, 
where "it has become a mainstream international commitment by scientific and policy institutions using science to encourage and cultivate two-way 'public engagement with science' as a means of alleviating this crisis of public mistrust" (Wynne 2006: 212). Wynne argues that this commitment is often quite superficial, and that the old "primitive one-way assumption about educating an ignorant public into '(scientifically) proper attitudes"” still lives on, despite the lip service to two-way engagement (Wynne 2006: 213).

Still, even if some of the changes in thinking about science/society relations were superficial, the change in rhetoric nonetheless entailed different strategies of actually reaching the public. In particular, one strategy to deal with the perceived crisis in the relationship between science and the public has been a new emphasis on initiatives that purport to engage laypeople not as mere passive recipients of (popularised) scientific knowledge, but as active participants. A notable example of this development is the sprouting of so-called interactive exhibits in science museums and science centres (Barry 1998; Heath and Vom Lehn 2008; Macdonald 1998b). These usually computer-based interactives have been critically examined, for their neoliberal underpinnings of conceiving of museum visitors as consumers (Barry 1998; Macdonald 1998b), as well as for focusing too much on the interaction between an individual visitor and a computer, at the expense of the arguably more important interaction between different museum visitors (Heath and Vom Lehn 2008). Nonetheless, their very existence does point towards a commitment to offering museum visitors a more active and hands-on engagement with the science on display. Insofar as these displays are judged by their ability to spark broad upstream debates about scientific developments, they often fall flat; but the claims they are based on are often more modest anyway, instead promising that a more active approach might lead visitors to build up more personal and therefore more memorable connections to what is on display. Despite the hopes attached to them as a solution to the crisis of relations between science and the public, their underlying rationale is not so much that they stimulate more far-reaching and democratic debates about science, but rather that they would be able to get individuals more interested in - and, so the assumption goes, therefore more supportive of - science by offering unique experiences. Sharon Macdonald concludes that these exhibits take knowledge "into the non-transferable realms of the individual, it becomes fetishized into experience" (Macdonald 1998b: 131; original emphasis). Rather than "providing visitors with a set of facts or principles which they can take away and apply elsewhere", they "provide a sense of the sensory self, an individualized experience” (Macdonald 1998b: 131). 
Another strategy of getting laypeople interested in science has been the support of initiatives that bridge the gap between science and art. By "enlisting artists to foster the public's relationship with science" (Born and Barry 2010: 108), it was hoped that new audiences of people who would otherwise be uninterested in science could be reached. It was thought that art-science projects "would make it possible to manage the ways in which the public might develop not only cognitive, but interactive and affective involvements with science. In this view, in place of a mistrustful, disengaged and anxious population, art-science would assist by assembling a public that was not only ready to participate in debate about the risks raised by scientific research, but excited and entranced by science." (Born and Barry 2010: 109)

It is in this context that the approach of sonification as an auditory sublime has to be understood, for it contains the same promises as interactive museum exhibits: allowing non-scientists to share in some of the fascination of doing science, and connecting science with art. Based on the long-standing cultural beliefs (see chapter 1) about vision as a sense that creates distance and detachment, while hearing allows for involvement and intimacy, the promise of sonification as auditory sublime rests precisely on its ability to turn detached spectators into engaged listeners, who are expected to take home an individualised experience from listening to scientific data.

My argument here is not that the mixture of science and spectacle which is being offered here is an entirely new historical development; historical studies of 'wonder shows' and science-infused magic performances in the nineteenth century are evidence to the contrary (Lachapelle 2009; Nadis 2005). I do want to argue, however, that such a mixture takes on a particular urgency in the current social and political context, in which scientists and policy-makers alike worry about dwindling public support for science. In this situation, the promise of science as a source of spectacular experiences takes on a new importance in acquiring support for science in general, or for particular scientific research fields or projects in particular.

It is in this changing societal context that sonification, with its promise of sublime experiences, has gained prominence, and will very likely continue to do so. As I have shown in chapter 2 , sonification often comes with a promise to allow the general public to share in some of the fascination of scientific research. It does so not by relying on an explanation of scientific facts, provided by a specialist for an ignorant public (although such explanations may be components of sonification examples, too), but instead by allowing access to a sensory experience that demonstrates the wonder of science. Many scientists explicitly frame this as sharing the excitement and awe that they experience in their own research. In a time where scientific knowledge is said to be increasingly complex and incomprehensible, and where efforts to explain 
science to a general public are increasingly scrutinised as condescending top-down approaches, such sublime experiences are a possible solution to the quandary of how to get the general public interested in and engaged with science. ${ }^{75}$ It must be stressed that I am not claiming here that sonification projects by definition offer more democratic, less top-down engagements with science; indeed, as I have shown in chapter 2 and 4 , many of those scientists who use sonification for the purposes of public outreach are not at all interested in flattening the hierarchy between scientific specialists and laypeople, let alone in deconstructing the difference between 'real science' and 'popular science'. The promise of sonification, then, is not so much that of a more democratic, two-way, bottom-up engagement with science, but rather of a more individualised, personal experience of it.

The above can explain why sonification has become popular in the last years as the basis for music performances and recordings, of popular science talks or of articles in the science pages of newspapers. But how are the changing relations between science, art and their publics related to the legitimacy of sonification in the world of specialised scientific research and in the eyes of scientific experts? The answer to this question is far more ambiguous and less clear-cut.

Within the scientific community dedicated to sonification, as I have shown in chapter 3, there is disagreement about the extent to which sonification work that is driven primarily by artistic ambitions or by motivations of public outreach should be integrated into the community. On the one hand, the inclusion of such work is thought to have advantages: it may create additional public visibility for sonification, it may open up funding possibilities, it may bring in new aesthetic sensibilities or new technical approaches, and even the fact of enlarging the community may be a value in its own right. On the other hand, there are also concerns that some of this work is not sufficiently rigid and may thus harm the community's claims to sonification as a methodologically sound scientific technique, or that the framing sonification too

\footnotetext{
${ }^{75}$ Incidentally - as I have hinted in chapter 2 - it is at the same time also a possible solution for a problem in the field of contemporary classical music, a genre which itself is often described as suffering a crisis of public interest: "Twentieth-century classical composition (...) sounds like noise to many. (...) While the splattered abstractions of Jackson Pollock sell on the art market for a hundred million dollars or more, and while experimental works by Matthew Barney or David Lynch are analyzed in college dorms across the land, the equivalent in music still sends ripples of unease through concert audiences and makes little perceptible impact on the outside world." (Ross 2007: xvi) The analysis of the relationship between contemporary classical music and the music-listening public has not been my goal in this dissertation. Nonetheless, it is worth remarking that crossover projects between science and contemporary music may not only reach an audience for science that had previously only been interested in art, but may similarly create new listeners for contemporary art music among audiences traditionally more interested in science, technology or experimentation.
} 
much in terms of artistry or of amusement may undermine its claims to scientificity by sending a mixed message to domain scientists. This does not mean that the dedicated sonification community rejects the framing of the auditory sublime entirely; indeed, they often embrace it, for instance by inviting artists or researchers who have created sonifications that have gotten public exposure to attend the annual ICAD conferences, or by engaging in artistic performances of their own. However, they do struggle with tensions about the extent to which they should frame their own research in those terms, and they navigate this terrain carefully - without, however, sidestepping it entirely. Rather, dealing with it becomes a delicate balancing act. For instance, in chapter 3 I have reported an anecdote of two sonification researchers who were able to present their findings at a conference of specialists in the domain of their sonification application only by agreeing to put their work in a musical context, evoking a crossover between science and art - although the researchers were then careful to point out that this was not their actual intention. Similarly, some of my interviewees have remarked that making promises about interdisciplinary collaboration, about collaborations between scientists and artists, or about including elements of public outreach increases the chances for getting monetary support - an important point in a field in which it is notoriously difficult to acquire funding through the traditional funding channels of disciplinary science.

These examples show that the changing constellation of science and society is seen as bringing benefits for the academic legitimacy of sonification - but only to a certain extent. The framing of sonification as an auditory sublime, as a measure for public outreach or as a new type of artistic initiative, can link up to these developments far more easily than a more traditionally scientific framing in terms of legitimacy in the eyes of scientific specialists can. As a result, those striving for the academic legitimacy of sonification do try to link up and seek contact with the sonification as an auditory sublime, but not without restrictions. For all the promises that this framing entails, it also brings the dangers of viewing sonification merely as a nice artistic experiment or some fun diversion from the real science - an impression that those who want to establish sonification as a real science in its own right want to avoid at all costs. Accordingly, they quite flexibly shift between the different framings of sonification and try to strike a balance between the popular appeal and the scientific legitimacy of sonification. At times, they make use of the repertoires of sonification as an auditory sublime, as a source of wonder and spectacle, in order to reach an audience or obtain funding; yet at other times, they emphasise the detached and rational character of sonification and position it as an objective scientific technique, because they think that a different framing might jeopardise the scientific legitimacy 
of sonification in the eyes of scientific experts. The balancing of this tension between fascination and legitimacy has been the central theme of this dissertation. 


\section{Appendix A \\ Participant Observation}

Unless indicated otherwise, the analysis is based on fieldnotes taken during or immediately after the event.

\section{Workshop and Conferences}

Sonic Interaction Design (SID) Training School on Biomedical Data Sonification in Bielefeld, Germany, February 2008

$14^{\text {th }}$ International Conference on Auditory Display in Paris, France, June 2008

- and pre-conference workshop: Recycling Auditory Displays

$15^{\text {th }}$ International Conference on Auditory Display in Copenhagen, Denmark, May 2009

Science by Ear 2 workshop in Graz, Austria, February 2010 (analysis based on fieldnotes and transcriptions of audio recordings)

$16^{\text {th }}$ International Conference on Auditory Display in Washington, DC, June 2010

- and pre-conference workshop: Graduate ThinkTank

- and pre-conference workshop: Sonification Hack Day

\section{Concerts and Talks}

Navigating the Space of the Future. Presentations given by the media artists Yolande Harris, David Dunn and Atau Tanaka at the Nederlands Instituut voor Mediakunst / Netherlands Media Art Institute in Amsterdam, the Netherlands, April 2008

Musik \& Gehirn I (Music \& the Brain I). Presentation given by the neuropsychologist Lutz Jäncke, and a performance by the sonification researchers Gerold Baier and Thomas Hermann, featuring pre-recorded sonifications as well as a live EEG sonification of the brainwaves of composer Alvin Lucier. At the Wien Modern festival in Vienna, Austria, November 2008

Musik \& Gehirn III (Music \& the Brain III). Presentation given by sonification researchers Gerold Baier and Thomas Hermann, and performance of several pieces - among them Music for Solo Performer - by composer Alvin Lucier. At the Wien Modern festival in Vienna, Austria, November 2008

Het geluid van de oerknal (The Sound of the Big Bang). Studium Generale popular science lecture by the astrophysicist John Heise in Maastricht, the Netherlands, February 2009

Wie klingt der Himmel? (What Does the Sky Sound Like?) Popular Science lecture by the amateur astronomer Paul Hombach in Bonn, Germany, March 2009

Sternenrest: sterren maken geen muziek (Sternenrest: Stars Don't Make Music). Concert by the composer Willem Boogman, with an introductory conversation between Boogman and the ethicist Chris Bremmers in Brugge, Belgium, April 2009 
Bonner Durchmusterung. Concert by Marcus Schmickler (with Carsten Goertz and Alberto de Campo), introduced by the astronomer Michael Geffert in Bonn, Germany, May 2009

Bonner Durchmusterung. Concert by Marcus Schmickler (with Carsten Goertz and Alberto de Campo) in Graz, Austria (at the Science by Ear 2 workshop), February 2010

Stellar Music. Performance by Iris van der Ende in Heerlen, April 2010

Asteroseismology. Introductory lecture for graduate students by the astronomer Conny Aerts in Leuven, October 2010

\section{Short-Term Research Stays}

Two-week stay of learning to do sonification in Bielefeld, Germany (at the iLab of the Neuroinformatics Department), June 2008

Four-day follow-up visit in Bielefeld, Germany (now within the 'Ambient Intelligence' group at the Cognitive Interaction Technologies Centre of Excellence), October 2009 


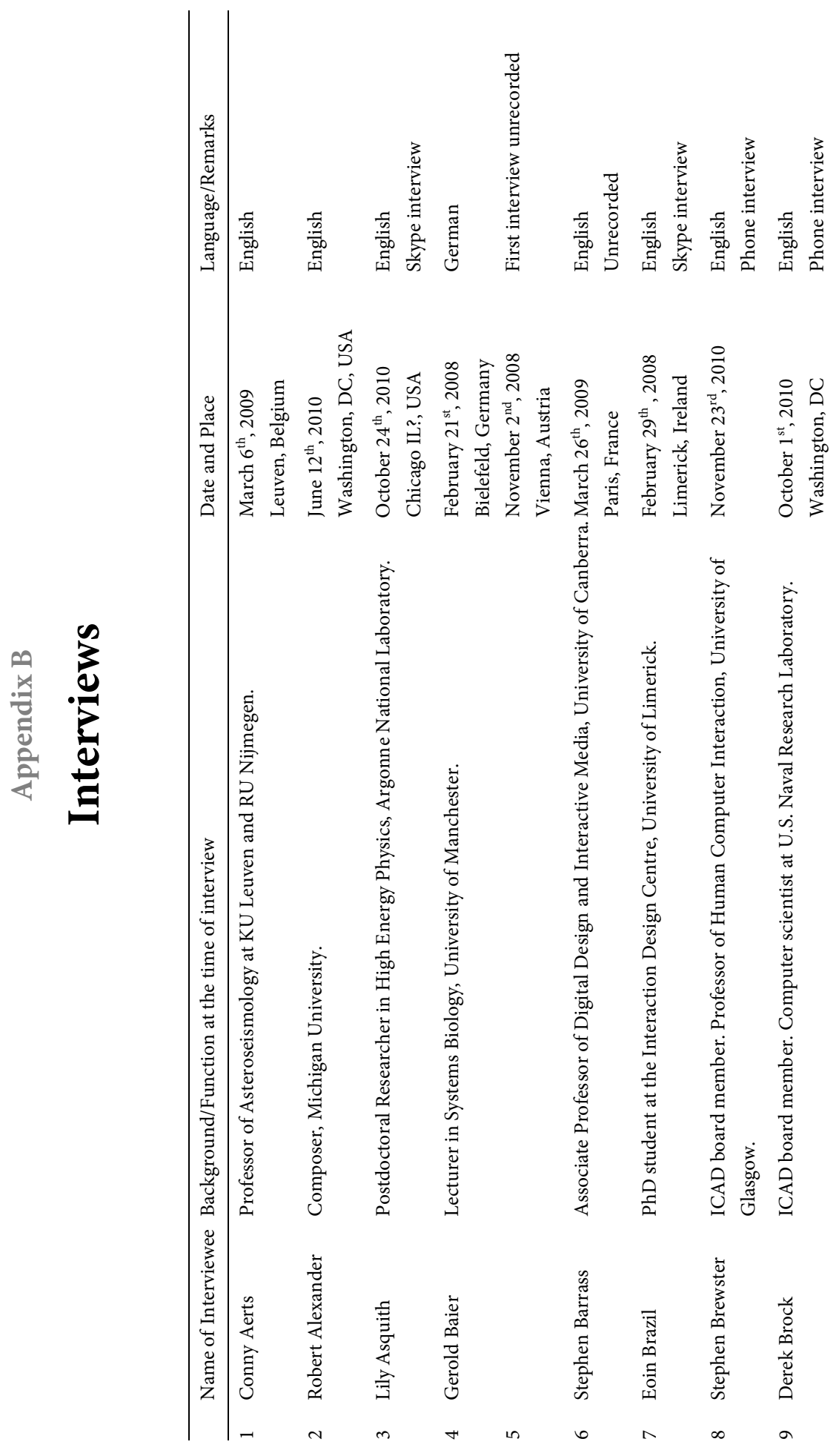




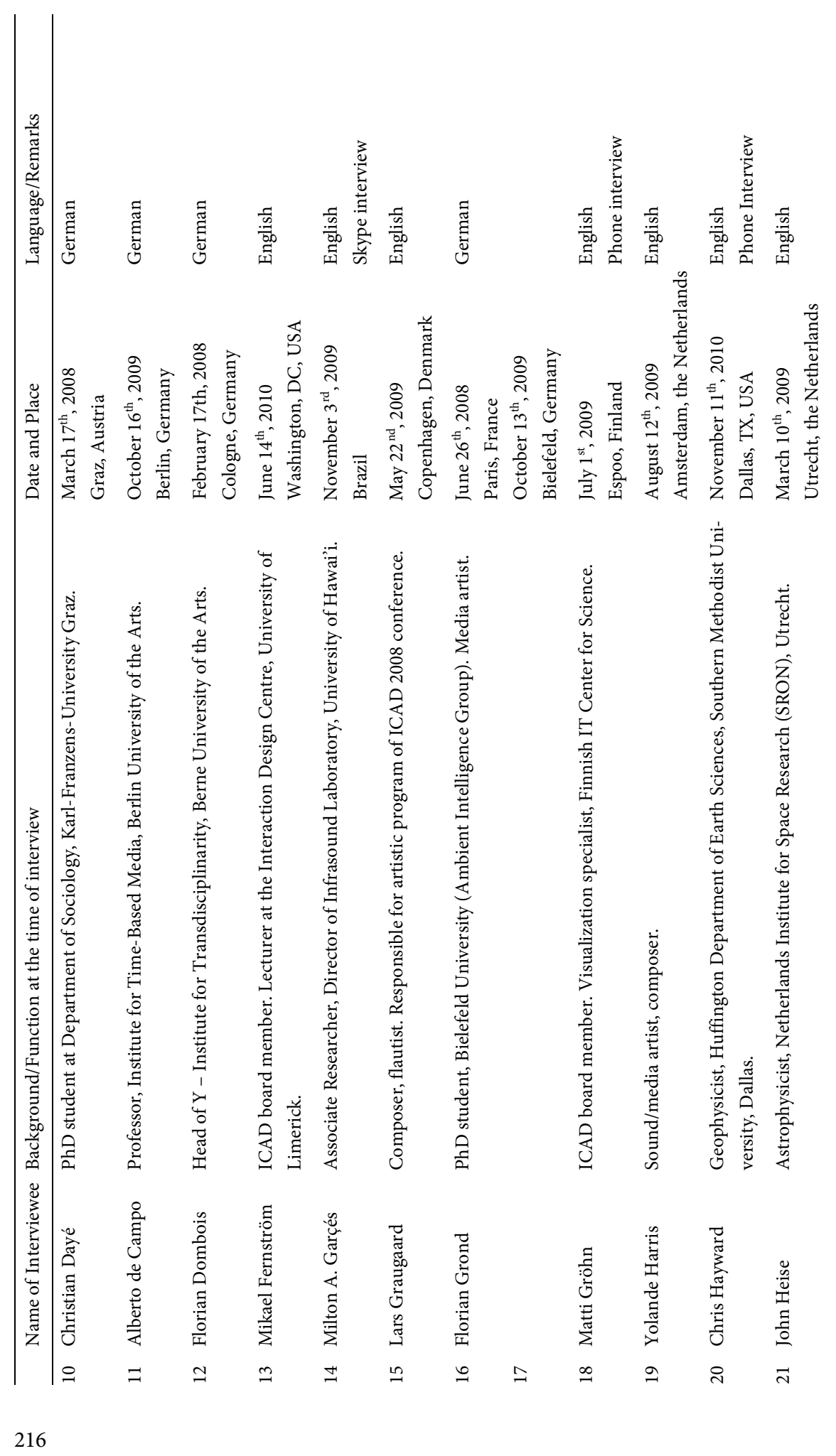




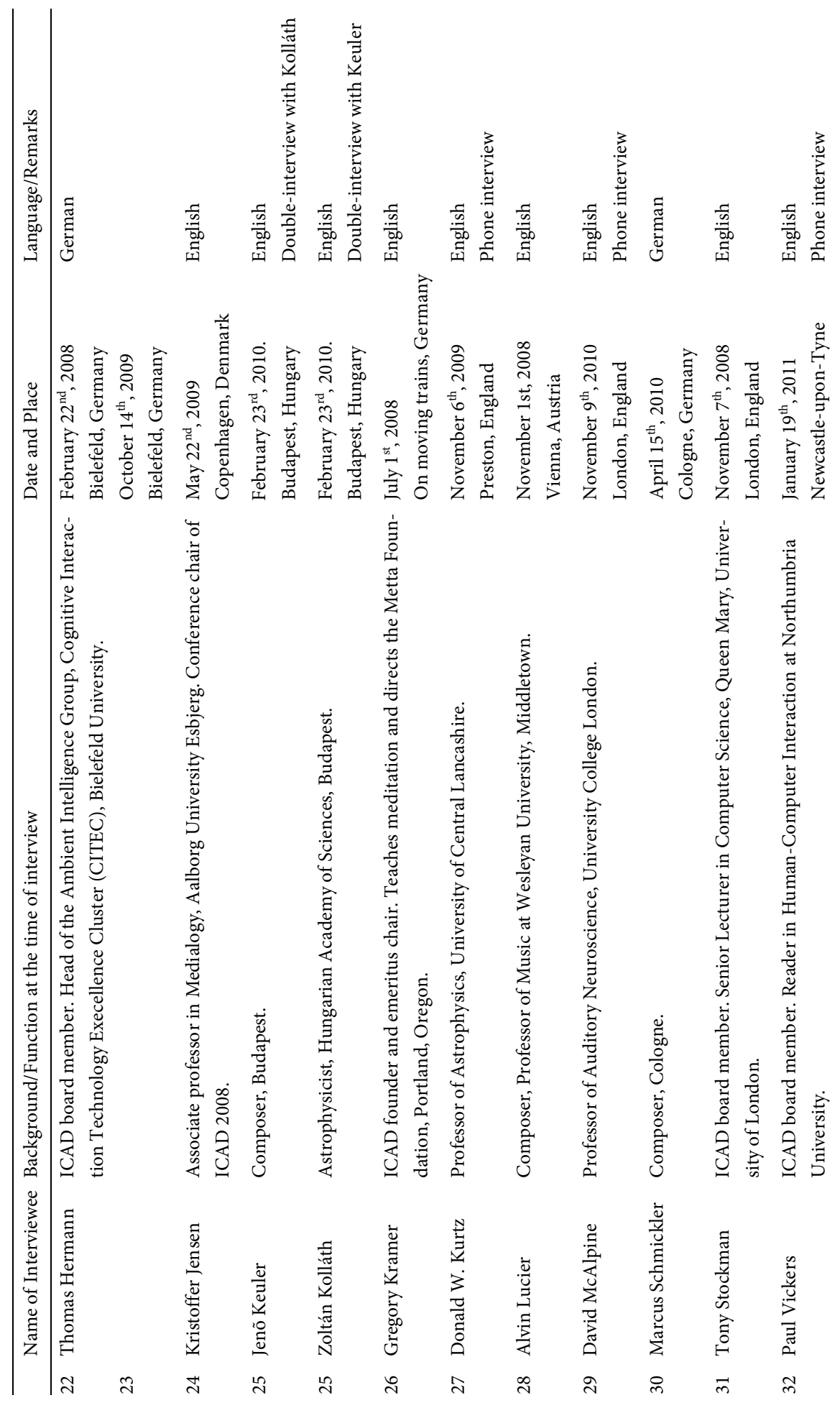




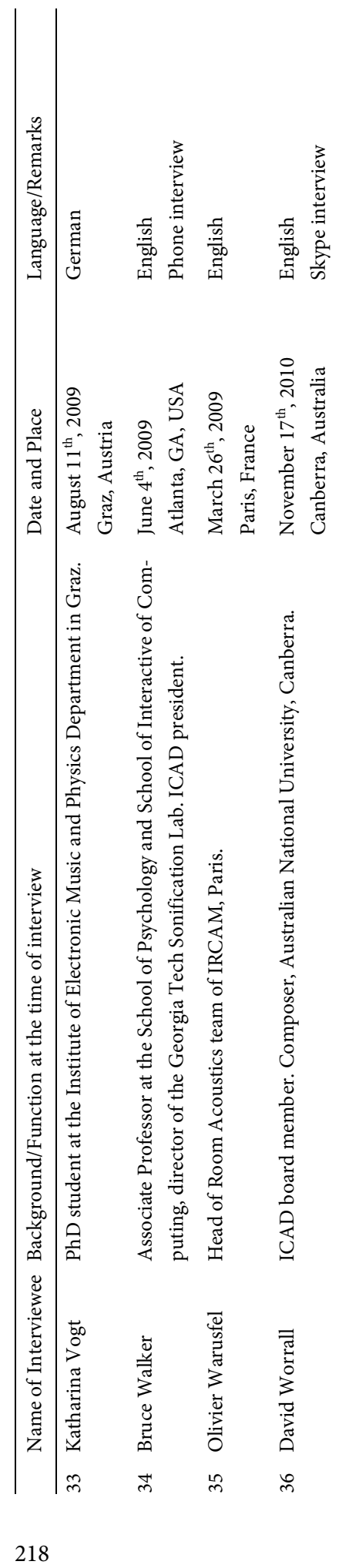




\section{Appendix C \\ Original Quotes of Translated Material}

This appendix collects the original quotes of material that has been included in translation, by order of appearance. All quotes were translated by Alexandra Supper.

\section{Chapter 1: Introduction}

p.9: "Kaltes klares Licht von der Kuppel machte jede Einzelheit deutlich, die Pulte, an denen die fünfhundert Physiker saßen, das Podium mit der Schaltanlage für Umrechner und der großen Leuchttafel, die Publikumstribüne an der einen Längsseite, die Kabinen mit den elektronischen Einrichtungen für die Berichterstatter und den Simultanübersetzer-Computern gegenüber. (...) Der nächste, der das Podium betrat, war ein kleiner alter Mann mit Glatze und Spitzbart, im viel zu weiten, ihn umschlotternden schwarzen Anzug. Er sprach ein paar Worte in weichem Singsang und mit den typischen Knacklauten der dänischen Sprache, fügte, mit Hilfe seines Gebisses, noch ein paar Zisch- und Pfeiflaute hinzu und verband die Schaltanlage mit seinem akustischen Umrechner. Ein fernöstlich klingendes monotones Stück Musik begann. Zugleich erschienen auf der Leuchttafel Ziffern und Formeln in verschiedenen Farben. Sie veränderten sich mit der Musik, häuften sich, verschwanden, kehrten wieder." (Hey 1982: 77ff.)

p.9f.: "haben wir uns daran gewöhnt, Kongresse von Physikern auch als Musikereignisse zu verstehen" (Hey 1982: 32)

p.16: "ein Riesenfortschritt (...) eine der angesehensten neurophysiologischen oder neurologischen Zeitschriften, hat einen hohen Impact, wird von allen gelesen, also auch wirklich breit wahrgenommen" (interview Baier 2)

p.16: "haben noch nicht begriffen, was für eine Bedeutung das hat, dass das einmal jetzt so akzeptiert ist, und dass man da auch aufbauen kann. Dass man sich darauf beziehen kann und sagen kann, also, selbst wenn euch das nicht gefällt und wenn ihr das für anstrengend haltet, trotzdem ist es so, dass es machbar ist, und es kann so gemacht werden." (interview Baier 2)

\section{Chapter 2: Sublime Frequencies: The Public Life of Sonification}

p.37: "Des Kaisers Garten lag an einem großen See. Ein Stück weit im Wasser draußen aber war eine schöne kleine Insel mit Bäumen und Blumen und mit einem niedlichen Gartenhaus. Vom Ufer zu der Insel hinüber führte aber eine schmale Brücke. Keine gewöhnliche Brücke, o nein! In einem einzigen großen Bogen life sie hinüber zur Insel und war aus lauter nebeneinandergelegten Goldplatten gemacht, die fingen an zu klingen, wenn jemand darüberlief. Bei jedem Menschen, der darüberging, tönten sie anders. Bei einem taten sie wie Blech - klirr, klirr, klirr, - bei dem andern gaben sie wohl dann und wann einen Ton, dazwischen schepperten sie wieder wie Glasscherben, und bei noch einem anderen fingen sie gar an zu singen, leise und eintönig, aber doch schön. Wenn aber der Kaiser darüberging, klangen sie wie das Geläut einer großen Kirche. Aus den Tönen, die die Brücke von sich gab, wenn einer darauf trat, konnte aber der Kaiser hören, was es für ein Mensch war, der darüberging - ein guter oder rein schlechter, denn schöne Töne gab sie nur, wenn ein guter Menscher darüberging." (Kayssler-Beblo 1952: 5) 
p.59f.: "Das war mir relativ wichtig, dass man sozusagen in dem Bereich dann ziemlich straightforward bleibt, also dass es da keine wirklichen Manipulationen gibt.“ (Interview Schmickler)

p.61: "mir ist so eine Art Form von Arbeitsweise nicht so fremd, also dadurch dass ich viel so mit algorithmischen Verfahren gearbeitet hab und sozusagen das auch gewohnt, dass eine Dramaturgie aus einem Algorithmus entsteht." (Interview Schmickler)

p.61: “Also, mir ging's ja auch ein bisschen darum, sozusagen ein populärwissenschaftliches Thema darzubieten, oder das populärwissenschaftlich aufzubereiten. Also mir ging's jetzt eben dann auch darum, dass sozusagen Leute, die nicht Experten auf dem Gebiet sind, so ein bisschen nachvollziehen können, was da eigentlich passiert." (Interview Schmickler)

p.63: "freier oder assoziativer mit den Sujets umgehen soll“ (interview Schmickler)

\section{Chapter 3: Jam Sessions and Killer Applications: Disciplines and Boundaries of Sonification}

p.75: "das Ohr hat irgendwie eine schlechte Lobby gehabt ganz lang." (Interview Dombois)

p.75: "Wenn ich einen Klang gehört habe und ich nicht wieder anhören konnte, das ist ja keine Instanz. Wenn ich ein Bild anschaue und ich kann es wieder anschauen, wird es eine Instanz." (Interview Dombois)

p.85: "Das erstaunliche an dieser ICAD-Community ist, dass die Leute, die da mitspielen in den Hauptrollen, sind Avantgarde genug und denken, dass sie da keine Berührungsängste [zwischen Wissenschaft und Kunst] haben. (...) Das ist eine skurrile Truppe.“ (Interview Dombois)

p.100: "Und mit dem Sonification Handbook hatte ich eigentlich die Vision, es mal zu schaffen, einen Kanon zusammenzutun, der den kompletten Bogen spannt von der Seite der Daten - Statistik, Data Mining - über die Verfahrensseite - Sonifikationstechniken - bis hin zur Klangsynthese-Seite und auch der Evaluations-Seite den ganzen Bogen zu spannen und als ein homogenes Gesamtwerk, auch als Lehrmaterial, darzustellen." (Interview Hermann 2)

p.100: "selbst 10 Jahre nach Kramers Buch, oder 15 Jahre mittlerweile, die Community noch nicht so konsolidiert ist, dass diese Kohärenz darstellbar ist" (interview Hermann 2)

p.100: "Im Endeffekt haben wir dann den Standpunkt entwickelt, dass es vielleicht auch einfach grundsätzlich besser ist für die Community, wenn wir das ein bisschen umdefinieren als so eine Art Zusammenstellung von unterschiedlichen Perspektiven auf Sonifikation, die dann per se heterogener sein können und auch einfach sind. Das ist einfach die Realität in Sonification Research 2009. (...) ich glaube, man kriegt keine kohärente Nomenklatur hin." (Interview Hermann 2)

p.102: "Das ist auch ganz klar - weil die haben eben Expertise sich erworben damit und wenn man jetzt sagt, 'ab morgen nur noch hören und nicht mehr schauen', dann werfen die ja damit die Expertise weg, die sie über viele Jahre erworben haben. Würd ich auch nicht einsehen, wieso ich das tun soll." (Interview Grond 1)

p.103: "mit etablierten visuellen Repräsentationsmodi einhergeht, weil das auch der einzige Weg ist, um, denk ich mal, Sonifikation bekannt und beliebt zu machen.“ (Interview Grond 2)

p.103: "Ich glaub, das war vielleicht ein Fehler, oder ist auf jeden Fall - nicht auf jeden Fall, aber möglicherweise ein Irrweg, den man aber leicht im Schwung der Begeisterung begeht. Dass man der Sonifikation zu viel Gewicht gibt, als ob es nichts anderes gäbe. (...) Oder man will die Sonifikation jetzt entwickeln als Ersatz von allem anderen. Und ich glaube, das ist nicht zielführend. (...) Und ich glaube nur dass im gesunden Kanon aller Sinnesmodalitäten man die beste Lösung finden wird.“ (Interview Hermann 2) 
p.104: "sehr offen in dem, wie sie ihre Methode suchen. Also, die haben Probleme und sehen, dass es nicht nur eine Art gibt, die zu lösen“ (interview Vogt)

p.104: “Also, die Beispiele wo's offenkundig um dynamische Vorgänge geht, wie Seismologie und Neurologie, sind relativ unmittelbar einleuchtend, weil da die Daten ja im Prinzip schon ganz nah an physikalischen Klängen dran sind. Oder zumindest - gut, Neurologie wäre ja elektrische Schwingungen, aber immerhin schon Schwingungen, schon Vorgänge in der Zeit. Ähm, das ist relativ einleuchtend für die meisten Leute.“ (Interview Alberto de Campo)

p.104: "Prototyp der dynamischen Krankheit" (interview Baier 2)

p.105: "die einzige Art, es durchzusetzen, wird sein, ein Prototyp oder ein überzeugendes Beispiel herauszuarbeiten und an einer Krankheit, an einem Symptom, an einer kleinen Ecke das aufzuhängen, wo man Fachleute überzeugen kann.” (Interview Baier 2)

p.110: "sehr vorsichtig” (interview Grond 1)

p.111: "wenn man mit der Sonifikation in der Chemie auf Chemiker zugeht, dann glauben die eigentlich immer als erstes, dass das (...) sowieso Kunst ist, und es dauert lang, sie zu überzeugen, dass das einen wissenschaftlichen Mehrwert haben könnte. Und dann ist es natürlich kontraproduktiv, wenn man es dann erst wieder als Kunst verwendet. Weil es dann einfach schwer zu kommunizieren ist, warum das eine jetzt nicht Kunst war und das andere jetzt plötzlich Kunst ist.“ (interview Grond 1)

p.111: "aber das hat dann leider eine ganz ganz dekorative Funktion, nämlich das ist ganz stark auf der Ebene des Infotainment und eigentlich der Rechtfertigung dafür, wieso man so viele Gelder für solche speziellen Projekte ausgibt“ (interview Grond 1)

p.111: "eigentlich ein technisches Verfahren, (...) das ist ja etwas Regelhaftes, und eine Visualisierung ist auch noch keine Malerei. Und so ähnlich ist auch eine Sonifikation noch nicht automatisch mit einer musikalischen Komposition vergleichbar.“ (Interview Dombois)

p.112: "Die Nische existiert gar nicht [für Sonifikation], noch nicht." (Interview Baier 2)

\section{Chapter 4: Trained Ears and Correlation Coefficients: Notions of Objectivity and Scientific Quality in Sonification}

p.129: 'sehr skeptischen Blicken von den Kollegen, die sagten, 'naja, bringt das denn was', 'das kann man doch auch visualisieren', 'das Hören ist doch sehr subjektiv', und alle diese Argumente, die gegen das Hören dann natürlich vorgebracht wurden“ (Interview Hermann 1)

p.130: "Als ich damals damit angefangen habe, mein damaliger, mein alter Geophysik-Professor, (...) war ziemlich enttäuscht und eigentlich auch erschrocken, was ich damit will und warum ich das tue, weil er nicht verstanden hat, der meinte, ja aber das ist ja nicht objektiv.“ (Interview Dombois)

p.130: “viel pragmatischer und offener“ (interview Dombois)

p.131: “Also, ich glaub nicht, dass man die wirklich überzeugen kann umzusatteln, das glaub ich nicht. Die werden, also auch wenn ich eine super Sonifikation hab die super funktioniert, dann werden sie sagen, 'ja das ist nett' (...), aber sie würden deshalb nicht ihre Methodik verändern. Das glaub ich nicht. Dafür ist gerade theoretische Physik zu abstrakt unterwegs und zu weit weg von, irgendwie, auch davon dass man Dinge auch relativ sehen kann. Es ist alles eine objektive Wahrheit, das ist halt einfach so, und das ist eine Zahl die da einfach steht. Das ist nicht unbedingt was ich glaub, aber das ist so die Einstellung, die ich da seh." (Interview Vogt) 
p.134: "Und Journals, äh, in der Regel sind darauf versessen, dass man, wenn man was Neues beiträgt, das durch Evaluationen, durch User-Tests sichert. (...) Und, äh, das ist zeitintensiv und aufwendig und blockiert manchmal den Prozess, unsere Methoden wirklich jetzt unters Volk zu bringen. Aber das muss man halt machen, so funktioniert die Wissenschaft.“ (Interview Hermann 2)

p.134: "Was den Möglichkeitenraum angeht, Daten klanglich zu repräsentieren, sind wir erst am Anfang. Ich glaube, dass es da noch Verfahren, Techniken und Ansätze gibt, an die einfach noch niemand gedacht hat, und dass man es ein bisschen wagen sollte, auch in unbekanntes Terrain methodisch vorzudringen. Und ich begrüße es selber sehr, weil's mich sehr inspiriert, wenn auf ICAD-Konferenzen, äh, Dinge zu hören sind, die in so einer Weise nie verklanglicht wurden und nie ein Mensch zuvor gehört hat, und das an sich ist schon ein großer Wert, weil das die Kreativität fördert. Und in dem Zusammenhang finde ich es dann schade, wenn solche, mitunter sehr interessanten, neuartigen, innovativen Ansätze, vielleicht deswegen nicht als Paper durchkommen, weil ihnen eine Auswertung fehlt." (Interview Hermann 2)

p.135: "den wissenschaftlichen Wert im Sinne von traditionellen Bewertungsmaßstäben“ (Interview Hermann 2)

p.135: "sie dann Vorträge hören, in denen sie nur ein paar Statistiken sehen mit Signifikanz-Niveaus, und nicht einen Sound hören" (interview Hermann 2)

p.135: "weil man sich zum Beispiel vielleicht zu Tode evaluiert (...), dass man ein Pflänzchen sozusagen killt bevor es noch überhaupt stark ausgewachsen ist” (interview Grond 1)

p.135: "recht triviale Aufgaben” (interview de Campo)

p.135: "misst man zwar etwas, was sich leicht messen lässt, aber etwas, was einen eigentlich nicht interessiert" (interview de Campo)

p.135: "diese definierte Aufgabe hat nicht etwas damit zu tun, ob das Tool dann letztlich nützlich ist" (interview Grond 1)

p.136: "Da hatten die ganz viel - die ganzen guten Sonifikationsbeispiele selber rauskuratiert, rausgepeerreviewed (...). Es gibt da so einen Central Stream und Poster Sessions, und die ganzen guten Sachen sind in die Poster Sessions geschickt worden. Weil man abstruse Vorstellungen von Evaluierbarkeit und Intersubjektivität hatte, und da hieß es dann, wenn jemand einen Klang macht und er hat nicht eine Reihe mit User-Tests gemacht mit 17, mindestens was weiß ich, 17, 20 Testpersonen, dann nehmen wir das nicht rein, weil das ist nicht wissenschaftlich. Das ist so, also wenn ich eine Graphik nicht abdrucken würde, wenn nicht jemand nachweisen kann, dass er 17 Leute auf die Graphik hat kucken lassen, ob sie was sehen auf der Graphik. Das ist, finde ich, das ist dann absurd.“ (Interview Dombois)

p.136f.: "Die ersten Visualisierungen von Molekülen sind nicht evaluiert worden, die sind einfach gemacht worden. Und sie waren hochgradig funktional. Natürlich hat man sich was dabei gedacht und nichts hingekleckst, ja, aber das ist das, was ich mein: man hat was gemacht, es war hochgradig funktional, es ist ich weiß nicht ob die mediale Repräsentation, ob man dazu wissenschaftliche Methode sagen kann aber es ist zumindest ein valides wissenschaftliches Tool, ohne durch einen wissenschaftlichen Evaluierungsprozess gegangen zu sein.“ (Interview Grond 1)

p.140: "Die Überlegung dafür war, dass es eigentlich ganz viele Leute gibt, die jeweils immer von Grund auf neuen Kram bauen für eine bestimmte Anwendung, für ein bestimmtes Gebiet, und dass es da ganz sicher Synergie-Effekte geben kann eigentlich, von den Dingen, die man eh jedes Mal auf eine ähnliche Weise wieder löst. Oder wo's meinetwegen fünf verschiedene Weisen gibt, wo’s gut wäre, wenn quasi dann diese Standardfälle leichter verfügbar und leichter adaptierbar für neue Sachen sind.“ (Interview de Campo) 
p.140: "geht's jetzt darum, nachher ein tolles Framework zu haben, oder geht's darum, interessante Dinge für die einzelnen Anwendungswissenschaften gemacht zu haben. Sollte natürlich beides sein, im besten Fall.“ (Interview de Campo)

p.140: “Also, um ein gutes Framework zu schreiben, braucht man eigentlich interessante, schwierige Fragen." (Interview de Campo)

p.140f.: “Anfänglich war der Projektplan der, eine generische Softwareplattform zu bauen, die für alle Disziplinen irgendwie sinnvoll ist, und genutzt werden kann. Und das wurde dann irgendwie abgeändert, nämlich dahingehend, dass wir gesagt haben, na, das macht keinen Sinn, weil wir verstellen uns sozusagen Potenzial von Sonifikation, es ist besser, man macht sozusagen fallorientierte Sonifikationen mit dem ganzen Spektrum und versucht jedes wirklich von Neuem zu denken.“ (Interview Dayé)

p.141: “eine Plattform, wo alle Zielwissenschaften was damit anfangen können” (interview Dayé)

p.141: “wo das einigermaßen vernünftig ging” (interview de Campo)

p.142: "Das ist wie selber wieder sich das abgewöhnen, was man gerade erobert hat, nämlich zu sagen: das Hören ist eine Instanz. “ (Interview Dombois)

p.145: "Ich bin ja sehr stark an der Methodenentwicklung und an der wirklichen Ausführung von Sonifikation versiert, und kann natürlich in all diesen Bereichen, in denen ich dann Zusammenarbeit habe, auch das Domänenwissen besitzen. (...) Da ist es einfach toll, wenn man wirklich ein Team hat, jemanden der dieses Domänenwissen mitbringt und das Interesse und die Offenheit für die Sonifikation und jemanden, der das Methodische versteht und effizient, schnell diese Daten klanglich verwandeln kann, und gemeinsam hört man dann in diese Daten rein.“ (Interview Hermann 1)

p.146: “total kritisch zu sein, um sich selbst relevant zu machen” (interview Grond 1)

\section{Chapter 5: Listening with the Red Button within Reach: Professional Audition in the Gadget Community of Sonification}

p.162: "gut verstandene Daten, sogar zum Teil synthetische Daten, bei denen ganz klar ist, was für eine Strukturierung vorliegt“ (interview Hermann 1)

p.162: "wo man also eigentlich nur die Klangbeispiele plus die Erklärung dazu bereitstellt" (interview Hermann 1)

p.163: "hatte ich glaube ich schon einen sehr breiten Eindruck von den technischen Möglichkeiten, und eine gute Verfolgung dieses Schnittbereichs Computer und Musik, also Klang und Computer“ (interview Hermann 1)

p.163: "Aber sicherlich ist das glaub ich etwas was, wenn man jetzt, sagen wir als Computerwissenschaftler anfängt sich für sowas zu interessieren, eine Hürde darstellt, denn Sonifikation ist, wenn es etwas ist, dann ist es hochgradig interdisziplinär: Signalverarbeitung, Algorithmik, also Programmierung von Computern, Akustik, das ist Physik; dann braucht man Verständnis von der Hörphysiologie, von psychoakustischen Dingen, von gestalterischen Dingen bis hin zur Ästhetik, und bis hin zur Psychologie um Experimente zu machen. Das ist ein ganzes Sammelsurium von Fachbereichen, von denen man zumindest ein grundlegendes Verständnis in allen haben muss. Und das macht es vielleicht für viele schwierig, so richtig schön da einzusteigen.“ (Interview Hermann 1)

p.164: "Und das seh ich auch als Manko, da müsste ich mich auch sehr gut auskennen, und das ist halt so eine Bastler-Generation, die halt eh immer schon mit Elektronik herumgelötet haben, das hab ich nie gemacht." (Interview Vogt) 
p.165: "nach Strukturen suchen, die ganze Zeit (...), dieses aktive Reinsuchen mit dem Ohr" (interview Baier 2)

p.165: "einfach weil wenn man mehr unterschiedliche Arten von möglichen Klängen erlebt hat" (interview de Campo)

p. 173: Physicist 1: Das ist aber kein Klavier.

Physicist 2: Nein.

Programmer 1: Nee, ist kein Klavier. [Tippt.] Ich hab vergessen, ich wollte da noch eine Wartezeit zwischen denen drinnen haben. (Science by Ear 2 transcripts)

p. 174: “Wenn ich jetzt da herumgeh macht's diung diung diung diung diung diung diung diung diung [angeregte Handbwegegungen]. Natürlich ändern sie sich auch, weil sie einen unterschiedlichen Winkel haben, wenn da der Koordinatenachse ist und ich hab hier einen Winkel, und hier einen Winkel, und ich bin in der Mitte, dann geht das - Shepard. Jetzt muss ich Shepard singen: diung diung diung diung diung diung diung diung. [Singt höher und tiefer werdend.] Und ehrlicherweise geht's diung ding di diung di diung du du du diung dooong diuooong, weil ich hab da, weil da die Koordinatenachse war, hab ich hier das Frequenzvibrato geringer gemacht." (Science by Ear 2 transcripts)

p.174: "Es wär ja schon lustig, wenn man einfach diese Sachen schnell erkennen kann, akustisch ist es ja, könnte ja einfach eine Frequenzmodulation sein, das die Rauheit - ein Filter, wo man die Rauheit hört als Exciter, und die Modulation." (Science by Ear 2 transcripts)

p.174f.: "Wenn das gleiche Teilchen in der z-Koordinate weiter oben ist, dann mach ich einen Bandpass, dass die hohen Shepard-Töne hörbar sind, wenn sie unten sind in der z-Koordinate, mach ich einen Bandpass dass die unteren hörbar sind. Die spielen im Prinzip immer alle. Ob ich sie höre, hängt davon ab, wie nahe ich dran bin und wie sie funktionieren. Ich kann also, mit z-Koordinate den Bandpass der ShepardTöne machen, ich kann den Radius, ah den Winkel mit der Tönhöhe, mit der Grundfrequenz des ShepardTons machen." (Science by Ear 2 transcripts)

p.176: Physicist 3: Ich weiß es nicht, das Sonifizieren ist eure Sache, ich weiß nicht.

Programmer 2: Neinnein, so ist das nicht in so einer Gruppe.

Physicist 3: Doch.

Programmer 2: Es ist schon unser aller Sache. (Science by Ear 2 transcripts)

p.177f.: "Man muss dazu auch die Semantik verstehen, was die Daten bedeuten und was überhaupt interessant ist, und das erfordert eben über die reine Lieferung dieser Daten als Datei auf einer Diskette oder USB-Stick hinaus einen inhaltlichen Austausch, ein Herbeistellen von Verständnis, von Seiten der Domänwissenschaftler, was kann überhaupt die Sonifikation liefern, und von Seiten der Sonifikatoren heraus, was ist überhaupt jetzt interessant, in welche Richtung diese Daten klanglich aufzubereiten. Und ich glaube, das ist das hauptsächlich Notwendige bei dieser interdisziplinären Zusammenarbeit, dass man diesen Autausch pflegt und voranbringt." (Interview Hermann 1)

p.179: "so richtig viel Zeit zum Hören war nicht einmal in diesem Projekt” (interview Dayé)

p.179: "Wenn ich das Projekt noch mal machen würde [lacht], wüsste ich jetzt, dass man von den wissenschaftlichen Partnern viel stärker einfordern muss, dass die die Sachen viel mehr ausprobieren, anhören, spielen lernen." (Interview de Campo)

\section{Chapter 6: Conclusions}

p.203: "damit ein Klang ein wissenschaftliches Argument ist, muss er publiziert sein" (interview Dombois) 


\section{Bibliography}

Abbott, Andrew (1988), The System of Professions: An Essay on the Division of Expert Labor. Chicago/London: The University of Chicago Press.

Adams, Douglas (1988), Dirk Gently's Holistic Detective Agency. London: Pan Books.

Adams, John Luther (2004), Winter Music. Middletown: Wesleyan University Press.

- - (2009), The Place Where You Go to Listen: In Search of an Ecology of Music. Middletown: Wesleyan University Press.

Adrian, E.D., and B.H.C. Matthews (1934), The Berger Rhythm: Potential Changes from the Occipital Lobes in Man. Brain 57, 355-385.

Aerts, Conny, Jørgen Christensen-Dalsgaard, and Donald W. Kurtz (2010), Asteroseismology. Dordrecht/Heidelberg/London/New York: Springer.

Akst, Jef (2009), A Cancerous Melody. In The Scientist. Retrieved on October 122010 from http://www.the-scientist.com/blog/display/55998/.

Alac, Morana (2004), Negotiating Pictures of Numbers. Social Epistemology 18 (2-3), 199-214.

_-_ (2008), Working with Brain Scans: Digital Images and Gestural Interaction in fMRI Laboratory. Social Studies of Science 38 (4), 483-508.

Amsterdamska, Olga (2005), Demarcating Epidemiology. Science, Technology, \& Human Values 30 (1), $17-51$.

Anderson, Benedict (2006 [1983]), Imagined Communities. New ed. London/New York: Verso.

Appelrouth, Scott (2011), Boundaries and Early Jazz: Defining a New Music. Cultural Sociology 5 (2), 225242.

Applegate, Celia, and Pamela Potter (2002), Music and German National Identity. Chicago/London: The University of Chicago Press.

Ash, Mitchell G. (1983), The Self-Presentation of a Discipline: History of Psychology in the United States Between Pedagogy and Scholarship. In Functions and Uses of Disciplinary Histories, edited by L. Graham, W. Lepenies and P. Weingart. Dordrecht: D. Reidel Publishing Company, 143-189.

___ (1992), Historicizing Mind Science: Discourse, Practice, Subjectivity. Science in Context 5 (2), 193207.

Asquith, Lily (2010a), Listening to the Atlas Detector. Retrieved on October 122010 from http://lhcsound.wordpress.com/2010/04/27/listening-to-the-atlas-detector/.

_-_ (2010b), What Does an Electron Sound Like? Retrieved on October 122010 from http://lhcsound.wordpress.com/2010/02/19/what-does-an-electron-sound-like/.

Baier, Gerold (2001), Rhythmus: Tanz in Körper und Gehirn. Reinbek: Rowohlt Taschenbuch Verlag.

Baier, Gerold, and Thomas Hermann (2004), The Sonification of Rhythms in Human Electroencephalogram. In Proceedings of the 10th International Conference on Auditory Display. Sydney, Australia.

Baier, Gerold, Thomas Hermann, and Ulrich Stephani (2007a), Event-based Sonification of EEG Rhythms in Real Time. Clinical Neurophysiology 118 (6), 1377-1386.

- - - (2007b), Multi-Channel Sonification of Human EEG. In Proceedings of the 13th International Conference on Auditory Display. Montréal, Canada.

Ballora, Mark (2000), Data Analysis through Auditory Display: Applications in Heart Rate Variability. PhD Thesis, Faculty of Music, McGill University, Montréal.

Barrass, Stephen (1997), Auditory Information Design. PhD Thesis, Australian National University, Canberra. 
- (2011), The Aesthetic Turn in Sonification towards a Social and Cultural Medium. AI \& Society OnlineFirst, doi: 10.1007/s00146-011-0335-5 (August 30, 2011), 1-5.

Barrass, Stephen, and Gregory Kramer (1999), Using Sonification. Multimedia Systems 7 (1), 23-31.

Barrass, Stephen, Mitchell Whitelaw, and Freya Bailes (2006), Listening to the Mind Listening: An Analysis of Sonification Reviews, Designs and Correspondences. Leonardo Music Journal 16, 13-19.

Barry, Andrew (1998), On Interactivity: Consumers, Citizens and Culture. In The Politics of Display: Museums, Science, Culture, edited by S. Macdonald. London/New York: Routledge, 98-117.

Barry, Eric D. (2010), High-Fidelity Sound as Spectacle and Sublime, 1950-1961. In Sound in the Age of Mechanical Reproduction, edited by D. Suisman and S. Strasser. Philadelphia: University of Pennsylvania Press, 115-138.

Beaulieu, Anne (2001), Voxels in the Brain: Neuroscience, Informatics and Changing Notions of Objectivity. Social Studies of Science 31 (5), 635-680.

- - (2002), Images Are Not the (Only) Truth: Brain Mapping, Visual Knowledge, and Iconoclasm. Science, Technology, \& Human Values 27 (1), 53-86.

Bell, Emma, and Daniel King (2010), The Elephant in the Room: Critical Management Studies Conferences as a Site of Body Pedagogics. Management Learning 41 (4), 429-442.

Bensaude-Vincent, Bernadette (1983), A Founder Myth in the History of Sciences? The Lavoisier Case. In Functions and Uses of Disciplinary Histories, edited by L. Graham, W. Lepenies and P. Weingart. Dordrecht: D. Reidel Publishing Company, 53-78.

Bijsterveld, Karin (2004), 'What Do I Do with My Tape Recorder...?': Sound Hunting and the Sounds of Everyday Dutch Life in the 1950s and 1960s. Historical Journal of Film, Radio and Television 24 (4), 613-634.

-_- (2008), Mechanical Sound. Technology, Culture, and Public Problems of Noise in the Twentieth Century. Cambridge/London: The MIT Press.

Bijsterveld, Karin, and Marten Schulp (2004), Breaking into a World of Perfection: Innovation in Today's Classical Musical Instruments. Social Studies of Science 34 (5), 649-674.

Bonebright, Terry L., and Nadine Miner (2005), Evaluation of Auditory Displays: Comments on Bonebright et al., ICAD 1998. ACM Transactions on Applied Perception 2 (4), 517-520.

Boogman, Willem (n.d.), Sternenrest: 'Stars Don't Make Music'. Retrieved on October 122010 from http://www.sternenrest.nl/files/music_English.htm.

Borck, Cornelius (2005), Hirnströme. Eine Kulturgeschichte der Elektroenzephalographie. Göttingen: Wallstein Verlag.

_- (2006), Between Local Cultures and National Styles: Units of Analysis in the History of Electroencephalography. Comptes Rendus Biologies 329 (5-6), 450-459.

- - (2008), Recording the Brain at Work: The Visible, the Readable, and the Invisible in Electroencephalography. Journal of the History of the Neurosciences 17 (3), 367-379.

Born, Georgina (1995), Rationalizing Culture: IRCAM, Boulez, and the Institutionalization of the Musical Avant-Garde. Berkeley/Los Angeles/London: University of California Press.

Born, Georgina, and Andrew Barry (2010), Art-Science: From Public Understanding to Public Experiment. Journal of Cultural Economy 3 (1), 103-119.

Bourdieu, Pierre (1975), The Specificity of the Scientific Field and the Social Conditions of the Progress of Reason. Social Science Information 14 (6), 19-47.

Bovermann, Till (2010), Tangible Auditory Interfaces: Combining Auditory Displays and Tangible Interfaces. PhD Thesis, Technische Fakultät, Bielefeld University, Bielefeld.

Boyle, Alan (2007), Music of the Genes. In Cosmic Log on msnbc.com. Retrieved on October 122010 from http://cosmiclog.msnbc.msn.com/_news/2007/05/04/4350049-music-of-the-genes. 
Brain, Robert M. (2002), Representation on the Line: Graphic Recording Instruments and Scientific Modernism. In From Energy to Information: Representation in Science and Technology, Art, and Literature, edited by B. H. Clarke, Linda Dalrymple. Stanford: Stanford University Press, 155-177.

Branton, Lorna (2006), Scientists Tell Us to Tune in to Songs of the Stars. In Innovations Report. Retrieved on October 122010 from http://www.innovations-report.com/html/reports/physics_astronomy/ report-68749.html.

Braun-Thürmann, Holger (2006), Ethnografische Perspektiven: Technische Artefakte in ihrer symbolischkommunikativen und praktisch-materiellen Dimension. In Technografie: Zur Mikrosoziologie der Technik, edited by W. Rammert and C. Schubert. Frankfurt/New York: Campus Verlag, 199-221.

Brazil, Eoin, and Mikael Fernström (2009), Subjective Experience Methods for Early Conceptual Design of Auditory Displays. In Proceedings of the 15th International Conference on Auditory Display. Copenhagen, Denmark.

Brindle, Reginald Smith (1987 [1975]), The New Music: The Avant-garde Since 1945. Second ed. Oxford/New York: Oxford University Press.

Brown, JoAnne (1992), The Definition of a Profession: The Authority of Metaphor in the History of Intelligence Testing, 1890-1930. Princeton: Princeton University Press.

Brown, Theodore L. (2003), Making Truth: Metaphor in Science. Urbana/Chicago: University of Illinois Press.

Bruyninckx, Joeri (2012), Sound Sterile: Making Scientific Field Recordings in Ornithology. In The Oxford Handbook of Sound Studies, edited by T. Pinch and K. Bijsterveld. Oxford/New York: Oxford University Press, 127-150.

Bucchi, Massimiano (1996), When Scientists Turn to the Public: Alternative Routes in Science Communication. Public Understanding of Science 5 (4), 375-394.

_-_ (1998), Science and the Media: Alternative Routes in Scientific Communication. London/New York: Routledge.

Buchler, J.R., P.A. Yecko, and Z. Kolláth (1997), The Nature of Strange Modes in Classical Variable Stars. Astronomy and Astrophysics 326, 669-681.

Bull, Michael, and Les Back, eds (2003), The Auditory Culture Reader. Oxford/New York: Berg.

Bunders, Joske, and Richard Whitley (1985), Popularisation Within the Sciences: The Purposes and Consequences of Inter-Specialist Communication. In Expository Science: Forms and Functions of Popularisation, edited by T. Shinn and R. Whitley. Dordrecht: D. Reidel Publishing Company, 61-77.

Burke, Edmund (2008 [1757]), A Philosophical Enquiry into the Origins of our Ideas of the Sublime and Beautiful. Edited by A. Phillips. Oxford/New York: Oxford University Press.

Burri, Regula Valérie (2008a), Doing Distinctions: Boundary Work and Symbolic Capital in Radiology. Social Studies of Science 38 (1), 35-62.

_-_ (2008b), Doing Images: Zur Praxis medizinischer Bilder. Bielefeld: transcript.

Burri, Regula Valérie, and Joseph Dumit (2008), Social Studies of Scientific Imaging and Visualization. In The Handbook of Science and Technology Studies, Third Edition, edited by E. J. Hackett, O. Amsterdamska, M. Lynch and J. Wajcman. Cambridge/London: The MIT Press, 297-317.

Burri, Regula Valérie, Cornelius Schubert, and Jörg Strübing (2011), Introduction: The Five Senses of Science. Making Sense of Senses. Science, Technology \& Innovation Studies 7 (1), 3-7.

Cage, John (1961), Silence. Lectures and Writings by John Cage. Middletown: Wesleyan University Press.

-_- (1963), A Year From Monday. New Lectures and Writings by John Cage. Middletown: Wesleyan University Press. 
Callon, Michel (1986), Some Elements of a Sociology of Translation: Domestication of the Scallops and the Fisherman of St. Brieuc Bay. In Power, Action and Belief: A New Sociology of Knowledge, edited by J. Law. London/New York: Routledge, 196-233.

Cassidy, Angela (2006), Evolutionary Psychology as Public Science and Boundary Work. Public Understanding of Science 15 (2), 175-205.

Cerulo, Karen A. (1989), Sociopolitical Control and the Structure of National Symbols: An Empirical Analysis of National Anthems. Social Forces 68 (1), 76-99.

Chanan, Michael (1995), Repeated Takes: A Short History of Recording and Its Effects on Music. London/New York: Verso.

Chandler, David L. (2004), Universe Started With Hiss, Not Bang. In New Scientist. Retrieved on October 12, 2010 from http://www.newscientist.com/article/ dn5092-universe-started-with-hiss-not-bang. html.

Childs, Edward (2005), International Conference on Auditory Display 2004: Listening to the Mind Listening. Computer Music Journal 29 (1), 86-89.

Chouet, Bernard (1985), Excitation of a Buried Magmatic Pipe: A Seismic Source Model for Volcanic Tremor. Journal of Geophysical Research 90 (B2), 1881-1893.

Chu, Jennifer (2007), A Prelude in Protein. In Technology Review. Retrieved on October 122010 from http://www.technologyreview.com/biomedicine/18708/.

_-_ (2008), A Musical Score for Disease. In Technology Review. Retrieved on October 122010 from http://www.technologyreview.com/biomedicine/21094/?a=f.

Clark, Stuart (2007), Vanities of the Eye: Vision in Early Modern European Culture. Oxford/New York: Oxford University Press.

Classen, Constance (1993), Worlds of Sense: Exploring the Senses in History and Across Cultures. London/New York: Routledge.

(1997), Foundations for an Anthropology of the Senses. International Social Science Journal 49 (153), 401-412.

Colin McEnroe Show (2010), CMS: Eavesdropping on the Brain: Connecticut Public Broadcasting Network. Radio program, aired on February 172010.

Condit, Celeste M., Benjamin R. Bates, Ryan Galloway, Sonja Brown Givens, Caroline K. Haynie, John W. Jordan, Gordon Stables, and Hollis Marshall West (2002), Recipes or Blueprints for Our Genes? How Contexts Selectively Activate the Multiple Meanings of Metaphors. Quarterly Journal of Speech 88 (3), 303-325.

Connor, Steven (2004), Edison's Teeth: Touching Hearing. In Hearing Cultures: Essays on Sound, Listening and Modernity, edited by V. Erlmann. Oxford/New York: Berg, 153-172.

Cooper, Geoff, and John Bowers (1995), Representing the User: Notes on the Disciplinary Rhetoric of Human-Computer Interaction. In The Social and Interactional Dimensions of Human-Computer Interfaces, edited by P. J. Thomas. Cambridge: Cambridge University Press, 48-66.

Courtland, Rachel (2010), What Does the Hottest Matter Ever Made Sound Like? In New Scientist. Retrieved on October 122010 from http://www.newscientist.com/article/dn18998.

Crary, Jonathan (1990), Techniques of the Observer: On Vision and Modernity in the Nineteenth Century. Cambridge/London: The MIT Press.

Daston, Lorraine (1992), Objectivity and the Escape From Perspective. Social Studies of Science 22 (4), 597618.

_-_ (2001), Scientific Objectivity with and without Words. In Little Tools of Knowledge: Historical Essays on Academic and Bureaucratic Practices, edited by P. Becker and W. Clark. Ann Arbor: The University of Michigan Press, 259-284. 
Daston, Lorraine, and Peter Galison (1992), The Image of Objectivity. Representations 40, 81-128.

- - (2007), Objectivity. New York: Zone Books.

Daughtry, J. Martin (2003), Russia's New Anthem and the Negotiation of National Identity. Ethnomusicology $47(1), 42-67$.

Dayé, Christian, and Alberto de Campo (2006), Sounds Sequential: Sonification in the Social Sciences. Interdisciplinary Science Reviews 31 (4), 349-364.

de Campo, Alberto (2009), Science By Ear. An Interdisciplinary Approach to Sonifying Scientific Data. PhD Thesis, Institute of Electronic Music and Acoustics, University for Music and Dramatic Arts Graz, Graz.

de Campo, Alberto, Robert Hoeldrich, Gerhard Eckel, and Annette Wallisch (2007), New Sonification Tools for EEG Data Screening and Monitoring. In Proceedings of the 13th International Conference on Auditory Display. Montréal, Canada.

de Chadarevian, Soraya (2004), Models and the Making of Molecular Biology. In Models: The Third Dimension of Science, edited by S. de Chadarevian and N. Hopwood. Stanford: Stanford University Press, 339-368.

de Cheveigné, Suzanne (2009), The Career Paths of Women (and Men) in French Research. Social Studies of Science 39 (1), 113-136.

de Rijcke, Sarah (2010), Regarding the Brain: Practices of Objectivity in Cerebral Imagining. 17th Century Present. PhD Thesis, Gedrags- en Maatschappijwetenschappen, Rijksuniversiteit Groningen, Groningen.

de Rijcke, Sarah, and Anne Beaulieu (2007), Taking a Good Look at Why Scientific Images Don't Speak for Themselves. Theory \& Psychology 17 (5), 733-742.

de Wilde, Rein (1992), Discipline en Legende: De Identiteit van de Sociologie in Duitsland en de Verenigde Staten 1870-1930. Amsterdam: Van Gennep.

Dehue, Trudy (1995), Changing the Rules: Psychology in the Netherlands, 1900-1985. Cambridge: Cambridge University Press.

-__ (1997), Deception, Efficiency, and Random Groups: Psychology and the Gradual Origination of the Random Group Design. Isis 88 (4), 653-673.

Delamont, Sara, and Paul Atkinson (2001), Doctoring Uncertainty: Mastering Craft Knowledge. Social Studies of Science 31 (1), 87-107.

DeNora, Tia (2000), Music in Everyday Life. Cambridge: Cambridge University Press.

Derksen, Linda (2000), Towards a Sociology of Measurement: The Meaning of Measurement Error in the Case of DNA Profiling. Social Studies of Science 30 (6), 803-845.

Derksen, Maarten (1997a), Are We Not Experimenting Then? The Rhetorical Demarcation of Psychology and Common Sense. Theory \& Psychology 7 (4), 435-456.

- (1997b), Wij Psychologen: Retorica en demarcatie in de geschiedenis van de Nederlandse psychologie. PhD Thesis, Rijksuniversiteit Groningen, Groningen.

- - (2001), Discipline, Subjectivity and Personality: An Analysis of the Manuals of Four Psychological Tests. History of the Human Sciences 14 (1), 25-47.

Dombois, Florian (2001), Using Sonification in Planetary Seismology. In Proceedings of the 7th International Conference on Auditory Display. Espoo, Finland.

- _- (2008), Sonifikation. Ein Plädoyer, dem naturwissenschaftlichen Verfahren eine kulturhistorische Einschätzung zukommen zu lassen. In Acoustic Turn, edited by P. M. Meyer. Munich: Fink, 91-100.

Dombois, Florian, Oliver Brodwolf, Oliver Friedli, Iris Rennert, and Thomas Koenig (2008), SONIFYER. A Concept, a Software, a Platform. In Proceedings of the 14th International Conference on Auditory Display. Paris, France. 
Douglas, Susan J. (1987), Inventing American Broadcasting: 1899-1922. Baltimore: John Hopkins University Press.

-__ (1999), Listening In: Radio and the American Imagination, from Amos ' $n$ 'Andy and Edward R. Murrow to Wolfman Jack and Howard Stern. New York: Times Books.

Downey, Gary Lee, Joseph Dumit, and Sharon Traweek (1997), Corridor Talk. In Cyborgs \& Citadels: Anthropological Interventions in Emerging Sciences and Technologies, edited by G. L. Downey and J. Dumit. Santa Fe: School of American Research Press, 245-263.

Dunbar-Hester, Christina (2008), Geeks, Meta-Geeks, and Gender Trouble: Activism, Identity, and Lowpower FM Radio. Social Studies of Science 38 (2), 201-232.

Dunn, John, and Mary Anne Clark (1999), Life Music: The Sonification of Proteins. Leonardo 32 (1), $25-$ 32.

Dyson, Frances (2009), Sounding New Media: Immersion and Embodiment in the Arts and Culture. Berkeley/Los Angeles/London: University of California Press.

Edford, Rachel (2007), The Elegance of The Elegant Universe: Unity, Beauty, and Harmony in Brian Green's Popularization of Superstring Theory. Public Understanding of Science 16 (4), 441-454.

Erlmann, Veit (2004), But What of the Ethnographic Ear? Anthropology, Sound, and the Senses. In Hearing Cultures: Essays on Sound, Listening and Modernity, edited by V. Erlmann. Oxford/New York: Berg, 1-20.

Essl, Karlheinz (2007), Algorithmic Composition. In The Cambridge Companion to Electronic Music, edited by N. Collins and J. d'Escriván. Cambridge: Cambridge University Press, 107-125.

Evans, Bob (2010), Music of the Spheres? Stand by for the Boson Sonata. In Geneva Lunch. Retrieved on October 122010 from http://genevalunch.com/blog/2010/07/09/music-of-the-spheres-stand-by-forthe-boson-sonata/\#.

Evans, Michael S. (2009), Defining the Public, Defining Sociology: Hybrid Science-Public Relations and Boundary-Work in Early American Sociology. Public Understanding of Science 18 (1), 5-22.

Felt, Ulrike (2000), Why Should the Public "Understand" Science? A Historical Perspective on Aspects of the Public Understanding of Science. In Between Understanding and Trust: The Public, Science and Technology, edited by M. Dierkes and C. v. Grote. Amsterdam: Harwood Academic Publishers, 7-38.

Fildes, Jonathan (2006), Volcanic Eruptions Score Melodies. In BBC News. Retrieved on October 122010 from http://news.bbc.co.uk/2/hi/science/nature/4777565.stm.

Fisher, R.A. (1936), The Use of Multiple Measurements in Taxonomic Problems. Annals of Eugenics 7 (2), $179-188$.

Flowers, John (2005), Thirteen Years of Reflection on Auditory Graphing: Promises, Pitfalls, and Potential New Directions. In Proceedings of the First Symposium on Auditory Graphs. Limerick, Ireland.

Forsey, Martin Gerard (2010), Ethnography as Participant Listening. Ethnography 11 (4), 558-572.

Frauenberger, Christopher (2009), Auditory Display Design: An Investigation of a Design Pattern Approach. PhD Thesis, Interaction, Media \& Communication, Queen Mary - University of London, London.

Friese, Heidrun (2001), Thresholds in the Ambit of Discourse: On the Establishment of Authority at Academic Conferences. In Little Tools of Knowledge: Historical Essays on Academic and Bureaucratic Practices, edited by P. Becker and W. Clark. Ann Arbor: The University of Michigan Press, 285-312.

Frith, Simon (1996), Music and Identity. In Questions of Cultural Identity, edited by S. Hall and P. du Gray. London/Thousand Oaks/New Delhi: SAGE Publications, 108-127.

Frysinger, Steven P. (2005), A Brief History of Auditory Data Representation to the 1980s. In Proceedings of the First Symposium on Auditory Graphs. Limerick, Ireland.

Galison, Peter (1997), Image \& Logic: A Material Culture of Microphysics. Chicago/London: The University of Chicago Press. 
- (1998), Judgment Against Objectivity. In Picturing Science, Producing Art, edited by C. A. Jones and

P. Galison. London/New York: Routledge, 327-359.

Gann, Kyle (2006), Fairbanks: A Long Ride in A Slow Machine. In NewMusicBox. Retrieved on October 12 2010 from http://www.newmusicbox.org/article.nmbx?id=4573.

Garfinkel, Harold (1967), Studies in Ethnomethodology. Englewood Cliffs: Prentice Hall.

GEANT2 (2006), Singing Volcanoes: Scientists Translate Volcanic Behavior into Sound Waves. In Science-

Daily. Retrieved on October 122010 from http://www.sciencedaily.com/releases/2006/08/ 060810084743.htm.

Gee, Brian (1989), Amusement Chests and Portable Laboratories: Practical Alternatives to the Regular Laboratory. In The Development of the Laboratory: Essays on the Place of Experiment in Industrial Civilization, edited by F. A. J. L. James. Basingstoke: Macmillan, 37-59.

Gefter, Amanda (2010), LHCsound: Listening to the God Particle. In New Scientist CultureLab Blog. Retrieved on October 122010 from http://www.newscientist.com/blogs/culturelab/2010/05/listening-tothe-god-particle.html.

Gena, Peter, and Charles Strom (1995), Musical Synthesis of DNA Sequences. In Proceedings of XI Colloquio di Informatica Musicale. Bologna, Italy.

-_- (2001), A Physiological Approach to DNA Music. In Proceedings of CADE 2001.

Gergen, Kenneth J. (1994), The Mechanical Self and the Rhetoric of Objectivity. In Rethinking Objectivity, edited by A. Megill. Durham/London: Duke University Press, 265-287.

Geuter, Ulfried (1983), The Uses of History for the Shaping a Field: Observations on German Psychology. In Functions and Uses of Disciplinary Histories, edited by L. Graham, W. Lepenies and P. Weingart. Dordrecht: D. Reidel Publishing Company, 191-228.

Ghosh, Pallab (2010), God Particle Signal is Simulated as Sound. In BBC News. Retrieved on October 12 2010 from http://www.bbc.co.uk/news/10385675.

Gieryn, Thomas F. (1983), Boundary-Work and the Demarcation of Science from Non-Science: Strains and Interests in Professional Ideologies of Scientists. American Sociological Review 48, 781-795

- - (1995), Boundaries of Science. In Handbook of Science and Technology Studies, edited by S. Jasanoff, G. E. Markle, J. C. Petersen and T. J. Pinch. London/Thousand Oaks/New Delhi: SAGE Publications, 393-443.

--_ (1999), Cultural Boundaries of Science: Credibility on the Line. Chicago/London: The University of Chicago Press.

Goodman, David (2010), Distracted Listening: On Not Making Sound Choices in the 1930s. In Sound in the Age of Mechanical Reproduction, edited by D. Suisman and S. Strasser. Philadelphia: University of Pennsylvania Press, 15-46.

Goodwin, Charles (1994), Professional Vision. American Anthropologist 96 (3), 606-633.

Graham, Loren, Wolf Lepenies, and Peter Weingart, eds (1983), Functions and Uses of Disciplinary Histories. Dordrecht: D. Reidel Publishing Company.

Gramling (2007), Singing Songs of Volcanoes. In Geotimes. Retrieved on October 122010 from http://www.geotimes.org/apr07/article.html?id=trends.html.

Grau, Oliver (2003), Virtual Art: From Illusion to Immersion. Cambridge/London: The MIT Press.

Gregory, Jane, and Steve Miller (1998), Science in Public: Communication, Culture, and Credibility. New York: Plenum Trade.

Gresham-Lancaster, Scot (2011), Relationships of Sonification to Music and Sound Art. AI \& Society OnlineFirst, doi: 10.1007/s00146-011-0337-3 (August 27, 2011), 1-6. 
Grimshaw, Mark (2012), Sound and Player Immersion in Digital Games. In The Oxford Handbook of Sound Studies, edited by T. Pinch and K. Bijsterveld. Oxford/New York: Oxford University Press, 347366.

Grond, Florian, Stefan Janssen, Stefanie Schirmer, and Thomas Hermann (2010), Browsing RNA structures by Interactive Sonification. In Proceedings of the 3rd Interactive Sonification Workshop (ISon 2010). Stockholm, Sweden.

Guice, Jon (1999), Designing the Future: The Culture of New Trends in Science and Technology. Research Policy 28 (1), 81-98.

Gunnarsdóttir, Kristrún (2005), Scientific Journal Publications: On the Role of Electronic Preprint Exchange in the Distribution of Scientific Literature. Social Studies of Science 35 (4), 549-579.

Hackett, Edward J. (2005), Essential Tensions: Identity, Control, and Risk in Research. Social Studies of Science 35 (5), 787-826.

Hacking, Ian (1983), Representing and Intervening: Introductory Topics in the Philosophy of Natural Science. Cambridge: Cambridge University Press.

Hagerty, M.T., S.Y. Schwartz, M.A. Garcés, and M. Protti (2000), Analysis of Seismic and Acoustic Observations at Arenal Volcano, Costa Rica, 1995-1997. Journal of Volcanology and Geothermal Research 101, 27-65.

Halffman, Willem (2003), Boundaries of Regulatory Science: Eco/toxicology and Aquatic Hazards of Chemicals in the US, England and the Netherlands. PhD thesis, Science Dynamics, University of Amsterdam, Amsterdam.

Hankins, Thomas L., and Robert J. Silverman (1995), Instruments and the Imagination. Princeton: Princeton University Press.

Haring, Kristen (2007), Ham Radio's Technical Culture. Cambridge/London: The MIT Press.

Hayward, Chris (1994), Listening to the Earth Sing. In Auditory Display. Sonification, Audification, and Auditory Interfaces, edited by G. Kramer. Reading: Addison-Wesley Publishing Company, 369-404.

Heath, Christian, and Dirk Vom Lehn (2008), Configuring 'Interactivity': Enhancing Engagement in Science Centres and Museums. Social Studies of Science 38 (1), 63-91.

Hedgecoe, Adam M., and Paul Martin (2003), The Drugs Don't Work: Expectations and the Shaping of Pharmacogenomics. Social Studies of Science 33 (3), 327-364.

Hellsten, Ina (2002), The Politics of Metaphor: Biotechnology and Biodiversity in the Media. PhD Thesis, Department of Journalism and Mass Communication, Tampere University, Tampere.

Hermann, Thomas (2002), Sonification for Exploratory Data Analysis. PhD Thesis, Technische Fakultät, Bielefeld University, Bielefeld.

- - (2008a), Daten Hören. In Sound Studies: Traditionen - Methoden - Desiderate, edited by H. Schulze. Bielefeld: transcript, 209-228.

- - (2008b), Taxonomy and Definitions for Sonification and Auditory Display. In Proceedings of the 14th International Conference on Auditory Display. Paris, France.

Hermann, Thomas, Gerold Baier, Ulrich Stephani, and Helge Ritter (2006), Vocal Sonification of Pathologic EEG Features. In Proceedings of the 12th International Conference on Auditory Display. London, England.

Hermann, Thomas, Kerstin Bunte, and Helge Ritter (2007), Relevance-Based Interactive Optimization of Sonification. In Proceedings of the 13th International Conference on Auditory Display. Montréal, Canada.

Hermann, Thomas, and Andy Hunt (2005), An Introduction to Interactive Sonification. IEEE Multimedia $12(2), 20-24$. 
Hermann, Thomas, and Helge Ritter (2005), Model-Based Sonification Revisited: Authors' Comments on Hermann and Ritter, ICAD 2002. ACM Transactions of Applied Perception 2 (4), 559-563.

Hey, Richard (1982), Im Jahr 95 nach Hiroshima. Munich: Heyne Verlag.

Hilgartner, Stephen (1990), The Dominant View of Popularization: Conceptual Problems, Political Uses. Social Studies of Science 20 (3), 519-539.

Hine, Christine (2007), Multi-sited Ethnography as a Middle Range Methodology for Contemporary STS. Science, Technology, \& Human Values 32 (6), 652-671.

-_- (2008), Systematics as Cyberscience: Computers, Change, and Continuity in Science. Cambridge/London: The MIT Press.

Hofstadter, Douglas R. (1980 [1979]), Gödel, Escher, Bach: An Eternal Golden Braid. Reprint ed. New York: Vintage Books.

Howes, David, ed. (1991), The Varieties of Sensory Experience: A Sourcebook in the Anthropology of the Senses. Toronto/Buffalo/London: University of Toronto Press.

Hugill, Andrew (2007), The Origins of Electronic Music. In The Cambridge Companion to Electronic Music, edited by N. Collins and J. d'Escriván. Cambridge: Cambridge University Press, 7-23.

Humphreys, Michael (2005), Getting Personal: Reflexivity and Autoethnographic Vignettes. Qualitative Inquiry 11 (6), 840-860.

Hunt, Andy, and Thomas Hermann (2004), The Importance of Interaction in Sonification. In Proceedings of the 10th International Conference on Auditory Display. Sydney, Australia.

Huutoniemi, Katri (2010), Evaluating Interdisciplinary Research. In The Oxford Handbook of Interdisciplinarity, edited by R. Frodemann, J. T. Klein and C. Mitcham. Oxford/New York: Oxford University Press, 309-320.

Ihde, Don (2007 [1976]), Listening and Voice: Phenomenologies of Sound. 2nd Edition ed. Albany: State University of New York Press.

Ingold, Tim (2000), Stop, Look and Listen! Vision, Hearing and Human Movement. In The Perception of the Environment: Essays on Livelihood, Dwelling and Skill. London/New York: Routledge, 243-287.

Irwin, Alan (2006), The Politics of Talk: Coming to Terms with the 'New' Scientific Governance. Social Studies of Science 36 (2), 299-322.

Jackson, Myles W. (2003), Harmonious Investigators of Nature: Music and the Persona of the German Naturforscher in the Nineteenth Century. Science in Context 16 (1/2), 121-145.

James, Jamie (1993), The Music of the Spheres: Music, Science, and the Natural Order of the Universe. New York: Grove Press.

Jankowski, Nicholas (2009), The Contours and Challenges of E-Research. In E-Research: Transformations in Scholarly Practice, edited by N. Jankowski. London/New York: Routledge, 3-31.

Jay, Martin (1993), Downcast Eyes: The Denigration of Vision in Twentieth-Century French Thought. Berkeley/Los Angeles/London: University of California Press.

Joly, Pierre-Benoit, and Alain Kaufmann (2008), Lost in Translation? The Need for 'Upstream Engagement' with Nanotechnology on Trial. Science as Culture 17 (3), 225-247.

Jones, Robert Alun (1983), On Merton's "History" and “Systematics” of Sociological Theory. In Functions and Uses of Disciplinary Histories, edited by L. Graham, W. Lepenies and P. Weingart. Dordrecht: D. Reidel Publishing Company, 121-142.

Joyce, Kelly (2005), Appealing Images: Magnetic Resonance Imaging and the Production of Authoritative Knowledge. Social Studies of Science 35 (3), 437-462.

Joyce, Kelly A. (2006), From Numbers to Pictures: The Development of Magnetic Resonance Imaging and the Visual Turn in Medicine. Science as Culture 15 (1), 1-22. 
Juolo, Patrick (2008), Killer Applications in Digital Humanities. Literary and Linguistic Computing 23 (1), 73-83.

Jütte, Robert (2005), A History of the Senses: From Antiquity to Cyberspace. Cambridge: Polity Press.

Kahn, Douglas (1999), Noise, Water, Meat: A History of Sound in the Arts. Cambridge/London: The MIT Press.

- - (2002), Concerning the Line: Music, Noise, and Phonography. In From Energy to Information: Representation in Science and Technology, Art, and Literature, edited by B. Clarke and L. D. Henderson. Stanford: Stanford University Press, 178-194.

- - (2010), Alvin Lucier, Edmond Dewand und Music for Solo Performer. In Klangmaschinen zwischen Experiment und Medientechnik, edited by D. Gethmann. Bielefeld: transcript, 211-229.

Kayssler-Beblo, Anne (1952), Die Klangbrücke. Stuttgart: K. Thienemanns Verlag.

Keating, Peter, Alberto Cambrosio, and Michael Mackenzie (1992), The Tools of the Discipline: Standards, Models, and Measures in the Affinity/Avidity Controversy in Immunology. In The Right Tools for the Job: At Work in Twentieth-Century Life Sciences, edited by A. E. Clarke and J. H. Fujimura. Princeton: Princeton University Press, 312-354.

Klein, Julie Thompson (1996), Crossing Boundaries: Knowledge, Disciplinarities and Interdisciplinarities. Charlottesville/London: University Press of Virginia.

Knorr Cetina, Karin (1995), Laboratory Studies: The Cultural Approach to the Study of Science. In Handbook of Science and Technology Studies, edited by S. Jasanoff, G. E. Markle, J. C. Petersen and T. J. Pinch. London/Thousand Oaks/New Delhi: SAGE Publications, 140-166.

Knorr, Karin D. (1979), Tinkering Toward Sucess: Prelude to a Theory of Scientific Practice. Theory and Society 8 (3), 347-376.

Knudsen, Susanne (2003), Scientific Metaphors Going Public. Journal of Pragmatics 35 (8), 1247-1263.

(2005), Communicating Novel and Conventional Scientific Metaphors: A Study of the Development of the Metaphor of Genetic Code. Public Understanding of Science 14 (4), 373-392.

Kohler, Robert E. (1999), Moral Economy, Material Culture, and Community in Drosphila Genetics. In The Science Studies Reader, edited by M. Biagioli. London/New York: Routledge, 243-257.

Kolláth, Z. (2006), Public Outreach in Asteroseismology. In Astrophysics of Variable Stars, edited by C. Sterken and C. Aerts. San Francisco: Astronomical Society of the Pacific, 421-433.

Kramer, Gregory (1994a), An Introduction to Auditory Display. In Auditory Display. Sonification, Audification, and Auditory Interfaces, edited by G. Kramer. Reading: Addison-Wesley Publishing Company, 1-77.

——- ed. (1994b), Auditory Display. Sonification, Audification, and Auditory Interfaces. Reading: Addison-Wesley Publishing Company.

Kramer, Gregory, Bruce Walker, Terry Bonebright, Perry Cook, John Flowers, Nadine Miner, and John Neuhoff et al. (1997), Sonification Report: Status of the Field and Research Agenda. Report prepared for the National Science Foundation. Santa Fe: International Community for Auditory Display.

Kramer, Gregory, and Bruce N. Walker (2004), Sound Science: Marking Ten International Conferences on Auditory Display. ACM Transactions of Applied Perception 2 (4), 383-388.

Kuhn, Thomas (1977), The Essential Tension: Selected Studies in Scientific Tradition and Change. Chicago/London: The University of Chicago Press.

Kursell, Julia (2008), Sounds of Science - Schall im Labor (1800-1930). Berlin: Max Planck Institute for the History of Science. 
Kwa, Chunglin, Mieke van Hemert, and Lieuwe van der Weij (2009), Visualising Landscapes: Do Pictures Represent Theory or Data?. In Geospatial Technology and the Role of Location within Science, edited by H. J. Scholten, R. van de Velde and N. van Manen. Dordrecht/Heidelberg/London/New York: Springer, $47-58$.

Lachapelle, Sofie (2009), Science on Stage: Amusing Physics and Scientific Wonder at the NineteenthCentury French Theatre. History of Science 47 (3), 297-315.

Lachmund, Jens (1998), Between Scrutiny and Treatment: Physical Diagnosis and the Restructuring of 19th Century Medical Practice. Sociology of Health \& Illness 20 (6), 779-801.

- - (1999), Making Sense of Sound: Auscultation and Lung Sound Codification in Nineteenth-Century French and German Medicine. Science, Technology, \& Human Values 24 (4), 419-450.

Lakoff, George, and Mark Johnson (2003 [1980]), Metaphors We Live By. New ed. Chicago/London: The University of Chicago Press.

Lamont-Doherty Earth Observatory (2005), The Sound of a Distant Rumble: Researchers Track Underwater Noise Generated by December 26 Earthquake. Retrieved on October 122010 from http://www. ldeo.columbia.edu/news/2005/07_20_05.htm.

Lamont, Michèle (2009), How Professors Think: Inside the Curious World of Academic Judgment. Cambridge/London: Harvard University Press.

Lamont, Michèle, and Virág Molnár (2002), The Study of Boundaries in the Social Sciences. Annual Review of Sociology 28, 167-195.

Latour, Bruno (1986), Visualization and Cognition: Thinking With Eyes and Hands. Knowledge and Society: Studies in the Sociology of Culture Past and Present 6 (1), 1-40.

-_- (1990), Drawing Things Together. In Representation in Scientific Practice, edited by M. Lynch and S. Woolgar. Cambridge/London: The MIT Press, 19-68.

Latour, Bruno, and Steve Woolgar (1986 [1979]), Laboratory Life. The Construction of Scientific Facts. Second ed. Princeton: Princeton University Press.

Leach, James (2003), Creative Land: Place and Procreation on the Rai Coast of Papua New Guinea. New York: Berghahn Books.

Learmonth, Mark, and Michael Humphreys (2011), Autoethnography and Academic Identity: Glimpsing Business School Doppelgängers. Organization OnlineFirst, doi: 10.1177/1350508411398056 (April 7, 2011), 1-19.

Lederman, Leon, and Dick Teresi (1993), The God Particle: If the Universe Is the Answer, What Is the Question? Boston: Houghton Mifflin Company.

Lenoir, Timothy (1988), Practice, Reason, Context: The Dialogue Between Theory and Experiment. Science in Context 2 (1), 3-22.

-_- (1997), Instituting Science: The Cultural Production of Scientific Disciplines. Stanford: Stanford University Press.

Lewenstein, Bruce V. (1992), The Meaning of 'Public Understanding of Science' in the United States after World War II. Public Understanding of Science 1 (1), 45-68.

Living on Earth (2006), Listening to Alaska: NPR. Radio program, aired in the week of April 21, 2006.

López, José Julián (2007), Notes on Metaphors, Notes as Metaphors. Science Communication 29 (1), 7-34.

Lucier, Alvin (2005 [1995]), Reflections: Interviews, Scores, Writings 1965-1994 / Reflexionen: Interviews, Notationen, Texte 1965-1994. 2nd, revised ed. Cologne: MusikTexte.

Lynch, Michael (2006), The Production of Scientific Images: Vision and Re-Vision in the History, Philosophy, and Sociology of Science. In Visual Cultures of Science: Rethinking Representational Practices in Scientific Knowledge Building and Science Communication, edited by L. Pauwels. Hanover/London: Dartmouth College Press, 26-40. 
Macdonald, Sharon (1998a), Exhibitions of Power and Powers of Exhibition: An Introduction to the Politics of Display. In The Politics of Display: Museums, Science, Culture, edited by S. Macdonald. London/New York: Routledge, 1-24.

(1998b), Supermarket Science? Consumers and the 'Public Understanding of Science'. In The Politics of Display: Museums, Science, Culture, edited by S. Macdonald. London/New York: Routledge, 118-138.

MacKenzie Owen, J.S. (2005), The Scientific Article in the Age of Digitization. PhD Thesis, Faculty of Humanities, University of Amsterdam, Amsterdam.

Marcus, George E. (1995), Ethnography in/of the World System: The Emergence of Multi-Sited Ethnography. Annual Review of Anthropology 24, 95-117.

Mayer, Katja (2011), Scientific Images? How Touching! Science, Technology \& Innovation Studies 7 (1), 29-45.

Mayne, Eleanor (2006), Fed up with Pop Music? Then Listen to Some Real Stars... Right Here. In MailOnline. Retrieved on October 122010 from http://www.mailonsunday.co.uk/news/article-400289/Fedpop-music-Then-listen-real-stars--right-here.html.

McCray, W. Patrick (2000), Large Telescopes and the Moral Economy of Recent Astronomy. Social Studies of Science 30 (5), 685-711.

- - (2008), Keep Watching the Skies! The Story of Operation Moonwatch \& the Dawn of the Space Age. Princeton/Oxford: Princeton University Press.

McGourty, Christine (2003), Listening to 'Singing Volcanoes'. In BBC News. Retrieved on October 122010 from http://news.bbc.co.uk/2/hi/in_depth/sci_tech/2003/denver_2003/2763657.stm.

McLuhan, Marshall (1962), The Gutenberg Galaxy. London: Routledge \& Kegan Paul.

McNutt, S.R. (1986), Observations and Analysis of B-type Earthquakes, Explosions, and Volcanic Tremor at Pavlof Volcano, Alaska Bulletin of the Seismological Society of America 76 (1), 153-175.

Meinel, Christoph (2004), Molecules and Croquet Balls. In Models: The Third Dimension of Science, edited by S. de Chadarevian and N. Hopwood. Stanford: Stanford University Press, 242-275.

Mellor, Felicity (2003), Between Fact and Fiction: Demarcating Science from Non-Science in Popular Physics Books. Social Studies of Science 33 (4), 509-538.

Messeri, Lisa R. (2010), The Problem with Pluto: Conflicting Cosmologies and the Classification of Planets. Social Studies of Science 40 (2), 187-214.

Meyer, Petra Maria, ed. (2008), Acoustic Turn. Munich: Fink.

Miner, Carol, and Paula Della Villa (1997), DNA Music: Reverse Translating Proteins Yields Microbiological Melodies. The Science Teacher (May Issue), 19-21.

Mitchell, Stuart (2010), Ludwig's Last Song - in D \& A. In Token Rock. Retrieved on October 122010 from http://www.tokenrock.com/inspiration/article/Stuart-Mitchell/166/.

Mitman, Gregg (1996), When Nature Is the Zoo: Vision and Power in the Art and Science of Natural History. Osiris 11, 117-143.

Mócsy, Ágnes, Paul Sorensen, and Alexander Doig (n.d.), The Sound of the Little Bang. Retrieved on October 122010 from http://soundofthelittlebang.com/.

Mody, Cyrus C.M. (2005), The Sounds of Science: Listening to Laboratory Practice. Science, Technology, \& Human Values 30 (2), 175-198.

- - (2006), Corporations, Universities, and Instrumental Communities: Commercializing Probe Microscopy, 1981-1996. Technology and Culture 47 (1), 56-80.

-_- (2011), Instrumental Community: Probe Microscopy and the Path to Nanotechnology. Cambridge/London: The MIT Press. 
Morgan, Robert P. (1998), The Twentieth Century - Introduction. In Source Readings in Music History, edited by O. Strunk and L. Treitler. New York/London: W.W. Norton \& Company, 1271-1279.

Morton, David (2000), Off the Record: The Technology and Culture of Sound Recording in America. New Brunswick/London: Rutgers University Press.

Morus, Iwan Rhys (2010), Worlds of Wonder: Sensation and the Victorian Scientific Performance. Isis 101 (4), 806-816.

Mössinger, Juliane (2005), The Music of Life. Nature 435 (19 May 2005), 280.

Mulkay, Michael, and G. Nigel Gilbert (1982), Joking Apart: Some Recommendations Concerning the Analysis of Scientific Culture. Social Studies of Science 12 (4), 585-613.

Mumma, Gordon (2011), Alvin Lucier's Music for Solo Performer 1965. In Source. Music of the Avantgarde, 1966-1973, edited by L. Austin and D. Kahn. Berkeley/Los Angeles/London: University of California Press, 79-81.

Myers, Greg (2003), Discourse Studies of Scientific Popularization: Questioning the Boundaries. Discourse Studies 5 (2), 265-279.

Myers, Natasha (2007), Modeling Proteins, Making Scientists: An Ethnography of Pedagogy and Visual Cultures in Contemporary Structural Biology. PhD thesis, Massachusetts Institute of Technology.

- - (2008), Molecular Embodiments and the Body-work of Modeling in Protein Crystallography. Social Studies of Science 38 (2), 163-199.

Nadai, Eva, and Christoph Maeder (2005), Fuzzy Fields. Multi-Sited Ethnography in Sociological Research. In Forum Qualitative Social Research 6 (3). Retrieved on July 5, 2011 from http://nbnresolving.de/urn:nbn:de:0114-fqs0503288.

Nadis, Fred (2005), Wonder Shows: Performing Science, Magic, and Religion in America. New Brunswick/London: Rutgers University Press.

Nelkin, Dorothy (1994 [1987]), Selling Science: How the Press Covers Science and Technology. 2nd revised ed. New York: Freeman.

- - (2001), Molecular Metaphors: The Gene in Popular Discourse. Nature Reviews Genetics 2 (7), 555 559.

Nelkin, Dorothy, and M. Susan Lindee (1995), The DNA Mystique: The Gene as a Cultural Icon. New York: Freeman.

Nicolson, Malcolm (1993), The Introduction of Percussion and Stethoscopy to Early Nineteenth-Century Edinburgh. In Medicine and the Five Senses, edited by W. F. Bynum and R. Porter. Cambridge: Cambridge University Press, 134-153.

Noble, Denis (2006), The Music of Life: Biology Beyond the Genome. Oxford/New York: Oxford University Press.

Ntarangwi, Mwenda (2010), Reversed Gaze: An African Ethnography of American Anthropology. Urbana/Chicago/Springfield: University of Illinois Press.

Nutch, Frank (1996), Gadgets, Gizmos, and Instruments: Science for the Tinkering. Science, Technology, \& Human Values 21 (2), 214-228.

Nye, David E. (1994), American Technological Sublime. Cambridge/London: The MIT Press.

Ohno, S. (1988), On Periodicities Governing the Construction of Genes and Proteins. Animal Genetics 19 (4), 305-316.

Ohno, Susumu, and Midori Ohno (1986), The All Pervasive Principle of Repetitious Recurrence Governs Not only Coding Sequence Construction But Also Human Endeavor in Musical Composition. Immunogenetics 24 (2), 71-78. 
Oliver, Myrna (2000), Susumu Ohno; Geneticist Wrote Music Based on DNA. In Los Angeles Times, January 19, 2000. Retrieved on October 122010 from http://articles.latimes.com/2000/jan/19/ news/mn-55406.

Ong, Walter J. (1991), The Shifting Sensorium. In The Varieties of Sensory Experience: A Sourcebook in the Anthropology of the Senses, edited by D. Howes. Toronto/Buffalo/London: University of Toronto Press, 25-30.

Oudshoorn, Nelly, Els Rommes, and Marcelle Stienstra (2004), Configuring the User as Everybody: Gender and Design Cultures in Information and Communication Technologies. Science, Technology, \& Human Values 29 (1), 30-63.

Pantalony, David (2004), Seeing a Voice: Rudolph Koenig's Instruments for Studying Vowel Sounds. The American Journal of Psychology 117 (3), 425-442.

Pasveer, Bernike (2006), Representing or Mediating: A History and Philosophy of X-ray Images in Medicine. In Visual Cultures of Science: Rethinking Representational Practices in Scientific Knowledge Building and Science Communication, edited by L. Pauwels. Hanover/London: Dartmouth College Press, 41-62.

Pauletto, Sandra, and Andy Hunt (2009), Interactive Sonification of Complex Data. International Journal of Human-Computer Studies 67 (11), 923-933.

Pendick, Daniel (1999), What's This Volcano Trying to Tell Us? New Scientist 2174 (20 February, 1999), 26-30.

Perkins, Tim (1995), Review of Gregory Kramer, Editor: Auditory Display: Sonification, Audification, and Auditory Interfaces. Computer Music Journal 19 (2), 110.

Pestre, Dominique (1999), Commemorative Practices at CERN: Between Physicists' Memories and Historians' Narratives. Osiris 14, 203-216.

PhysOrg (2009), Technology and Art Unite to Create Dance Show Based on Volcanic Sounds of the Earth. Retrieved on October 122010 from http://www.physorg.com/news157308512.html.

-_- (2010), Scientists Listen to the Sun in New Sonification Project. Retrieved on October 122010 from http://www.physorg.com/news186418364.html.

Piekut, Benjamin (2011), When Orchestras Attack! John Cage Meets the New York Philharmonic. In Experimentalism Otherwise: The New York Avant-Garde and Its Limits. Berkeley/Los Angeles/London: University of California Press, 20-64.

Pinch, Trevor, and Karin Bijsterveld (2012), New Keys to the World of Sound. In The Oxford Handbook of Sound Studies, edited by T. Pinch and K. Bijsterveld. Oxford/New York: Oxford University Press, 335 .

Pinch, Trevor J., and Karin Bijsterveld (2003), "Should One Applaud?" Breaches and Boundaries in the Reception of New Technology in Music. Technology \& Culture 44 (3), 536-559.

Pinch, Trevor, and Frank Trocco (2002), Analog Days: The Invention and Impact of the Moog Synthesizer. Cambridge/London: Harvard University Press.

Pink, Sarah (2009), Doing Sensory Ethnography. London/Thousand Oaks/New Delhi: SAGE Publications.

Plourde, Lorraine (2008), Disciplined Listening in Tokyo: Onkyo and Non-Intentional Sounds. Ethnomusicology 52 (2), 270-295.

Polli, Andrea (2004), Modelling Storms in Sound: the Atmospherics/Weather Works Project. Organised Sound 9 (2), 175-180.

- - (2005), Atmospherics/Weather Works: A Spatialized Meteorological Data Sonification Project. Leonardo 38 (1), 31-36.

Porcello, Thomas (2004), Speaking of Sound: Language and the Professionalization of Sound-Recording Engineers. Social Studies of Science 34 (5), 733-758. 
Porta, Miquel (2003), The Genome Sequence Is a Jazz Score. International Journal of Epidemiology 32 (1), 29-31.

Porter, Roy (1993), The Rise of Physical Examination. In Medicine and the Five Senses, edited by W. F. Bynum and R. Porter. Cambridge: Cambridge University Press, 179-197.

Porter, Theodore M. (1995), Trust in Numbers: The Pursuit of Objectivity in Science and Public Life. Princeton: Princeton University Press.

Powers, Richard (1992), Gold Bug Variations. New York: Harper Perennial.

Prasad, Amit (2005), Making Images/Making Bodies: Visibilizing and Disciplining through Magnetic Resonance Imaging (MRI). Science, Technology, \& Human Values 30 (2), 291-316.

Rammert, Werner, and Cornelius Schubert, eds (2006), Technografie: Zur Mikrosoziologie der Technik. Frankfurt/New York: Campus Verlag.

Rapp, Rayna (1997), Real-Time Fetus: The Role of the Sonogram in the Age of Monitored Reproduction. In Cyborgs \& Citadels: Anthropological Interventions in Emerging Sciences and Technologies, edited by G. L. Downey and J. Dumit. Santa Fe: School of American Research Press, 31-48.

Ray, Gene (2004), Reading the Lisbon Earthquake: Adorno, Lyotard, and the Contemporary Sublime. The Yale Journal of Criticism 17 (1), 1-18.

Regier, Alexander (2010), Foundational Ruins: The Lisbon Earthquake and the Sublime. In Ruins of Modernity, edited by A. Schönle and J. Hell. Durham/London: Duke University Press, 357-374.

Rice, Tom (2008), "Beautiful Murmurs": Stethoscopic Listening and Acoustic Objectification. Senses \& Society 3 (3), 293-306.

- - (2010), 'The Hallmark of a Doctor': the Stethoscope and the Making of Medical Identity. Journal of Material Culture 15 (3), 287-301.

- - (2012), Sounding Bodies: Medical Studies and the Acquisition of Stethoscopic Perspectives. In The Oxford Handbook of Sound Studies, edited by T. Pinch and K. Bijsterveld. Oxford/New York: Oxford University Press, 298-319.

Ricks, Delthia (1986), Scientist Discovers Genetic Formula for Music. In Los Angeles Times. Retrieved on October 122010 from http://articles.latimes.com/1986-04-27/local/me-24131_1.

Roberts, Lissa (1995), The Death of the Sensuous Chemist: The 'New' Chemistry and the Transformation of Sensuous Technology. Studies in History and Philosophy of Science 26 (4), 503-526.

Rodgers, Diane M., and Reinaldo J. Moraga (2011), The Trouble With Thinking Like Arena: Learning to Use Simulation Software. Bulletin of Science, Technology \& Society 31 (2), 144-152.

Roosth, Sophia (2009), Screaming Yeast: Sonocytology, Cytoplascmic Milieus, and Cellular Subjectivities. Critical Inquiry 35 (2), 332-350.

Rosenboom, David (1990), The Performing Brain. Computer Music Journal 14 (1), 48-66.

Ross, Alex (2007), The Rest Is Noise: Listening to the Twentieth Century. New York: Picador.

Rothbart, Daniel (2007), Philosophical Instruments: Minds and Tools at Work. Urbana: University of Illinois Press.

Ryan, Marie-Laure (2001), Narrative as Virtual Reality: Immersion and Interactivity in Literature and Electronic Media. Baltimore/London: The John Hopkins University Press.

Scaletti, Carla (1994), Sound Synthesis Algorithms for Auditory Data Representations. In Auditory Display. Sonification, Audification, and Auditory Interfaces, edited by G. Kramer. Reading: Addison-Wesley Publishing Company, 223-251.

Schaffer, Simon (1988), Astronomers Mark Time: Discipline and the Personal Equation. Science in Context 2 (1), 115-145. 
Schmidgen, Henning (2008), Silence in the Laboratory: The History of Soundproof Rooms. In Sounds of Science - Schall im Labor (1800-1930), edited by J. Kursell. Berlin: Max Planck Institute for the History of Science, 47-61.

Schoon, Andi, and Florian Dombois (2009), Sonification in Music. In Proceedings of the 15th International Conference on Auditory Display. Copenhagen, Denmark.

Schubert-Minski, Theresa (2009), Hören nach Zahlen: Sonifikation, Forschung zwischen Wissenschaft und Kunst: Bayrischer Rundfunk. Radio program.

Schulze, Holger, ed. (2008), Sound Studies: Traditionen - Methoden - Desiderate. Bielefeld: transcript.

Secord, Anne (2002), Botany on a Plate: Pleasure and the Power of Pictures in Promoting Early Nineteenth-Century Scientific Knowledge. Isis 93 (1), 28-57.

Sever, Megan (2004), The Infrasound Renaissance. In Geotimes. Retrieved on October 122010 from http://www.geotimes.org/june04/technology.html.

Shapin, Steven (1988), The House of Experiment in Seventeenth-Century England. Isis 79 (3), 373-404.

- - (1989), The Invisible Technician. American Scientist 77 (6), 554-563.

- (1992), Discipline and Bounding: The History and Sociology of Science As Seen Through the Externalism-Internalism Debate. History of Science 30, 333-369.

Shinn, Terry, and Richard Whitley, eds (1985), Expository Science: Forms and Functions of Popularisation. Dordrecht: D. Reidel Publishing Company.

Smith, Daniel R., and Bruce N. Walker (2002), Tick-Marks, Axes and Labels: The Effects of Adding Context to Auditory Graphs. In Proceedings of the 10th International Conference on Auditory Display. Kyoto, Japan.

Smith, Jonathan (2010), Brain Music. In Viceland Today. Retrieved on October 122010 from http://www.viceland.com/blogs/en/2010/04/27/brain-music/.

Smith, Merritt Roe, and Leo Marx, eds (1994), Does Technology Drive History? The Dilemma of Technological Determinism. Cambridge/London: The MIT Press.

Speeth, Sheridan Dauster (1961), Seismometer Sounds. Journal of the Acoustical Society of America 33 (7), 909-916.

Steinbrugge, Karl V. (1974), A Catalog of Earthquake Related Sounds. Bulletin of the Seismological Society of America 64 (5), 1409-1417.

Stephenson, Bruce (1994), The Music of the Heavens: Kepler's Harmonic Astronomy. Princeton: Princeton University Press.

Sterne, Jonathan (2001), Mediate Auscultation, the Stethoscope and the 'Autopsy of the Living': Medicine's Acoustic Culture. Journal of Medical Humanities 22 (2). 115-136.

-_- (2003), The Audible Past: Cultural Origins of Sound Reproduction. Durham/London: Duke University Press.

- - (2006), The MP3 as Cultural Artifact. New Media \& Society 8 (5), 825-842.

Stockfelt, Ola (2008), Adequate Modes of Listening. In Audio Culture: Readings in Modern Music, edited by C. Cox and D. Warner. New York/London: Continuum, 88-93.

Stoller, Paul (1989), The Taste of Ethnographic Things: The Senses in Anthropology. Philadelphia: University of Pennsylvania Press.

Striphas, Ted (2010), Acknowledged Goods: Cultural Studies and the Politics of Academic Journal Publishing. Communication and Critical/Cultural Studies 7 (1), 3-25.

Sturm, Bob L. (2001), Composing for an Ensemble of Atoms: The Metamorphosis of Scientific Experiment into Music. Organised Sound 6 (2), 131-145. 
Supper, Alexandra (2012), The Search for the "Killer Application": Drawing the Boundaries around the Sonification of Scientific Data. In The Oxford Handbook of Sound Studies, edited by T. Pinch and K. Bijsterveld. Oxford/New York: Oxford University Press, 249-270.

- - (forthcoming), Wie objektiv sind Sonifikationen? Das Ringen um wissenschaftliche Legitimität im gegenwärtigen Diskurs der ICAD. In Das geschulte Ohr: Eine Kulturgeschichte der Sonifikation, edited by A. Schoon and A. Volmar. Bielefeld: transcript.

Taruskin, Richard (2005), The Oxford History of Western Music. Volume 5: The Late Twentieth Century. Oxford/New York: Oxford University Press.

Taylor, Jerome (2010), What Does the 'God Particle' Sound Like? In The Independent. Retrieved on October 122010 from http://www.independent.co.uk/news/science/what-does-the-god-particle-soundlike-2008811.html.

Thieberger, Ed M. (1995), An Interview with Charles Dodge. Computer Music Journal 19 (1), 11-24.

Tiryakian, Edward A. (1979), The Significance of Schools in the Development of Sociology. In Contemporary Issues in Theory and Research. A Metasociological Perspective, edited by W. Lepenies. London: Alwych Press, 211-233.

Truax, Barry (2001 [1984]), Acoustic Communication. Second ed. Westport: Greenwood.

Turney, Jon (2004a), The Abstract Sublime: Life as Information Waiting to Be Written. Science as Culture $13(1), 89-103$.

-- (2004b), Accounting for Explanation in Popular Science Texts--An Analysis of Popularized Accounts of Superstring Theory. Public Understanding of Science 13 (4), 331-346.

van Dijck, José (1998), Imagenation: Popular Images of Genetics. Houndmills: Macmillan Press.

-_- (2005), The Transparent Body: A Cultural Analysis of Medical Images. Seattle/London: University of Washington Press.

van Helden, Albert, and Thomas L. Hankins, eds (1994), Instruments. Vol. 9 of Osiris.

van Lente, Harro (1993), Promising Technology: The Dynamics of Expectations in Technological Developments. PhD Thesis, University of Twente, Enschede.

Verbeek, Peter-Paul (2005), What Things Do: Philosophical Reflections on Technology, Agency, and Design. University Park: The Pennsylvania State University Press.

- - (2008), Obstretric Ultrasound and the Technological Mediation of Morality: A Postphenomenological Analysis. Human Studies 31 (1), 11-26.

Vickers, Paul (1999), CAITLIN: Implementation of a Musical Program Auralisation System to Study the Effects on Debugging Tasks as Performed by Novice Pascal Programmers. PhD Thesis, Loughborough University, Loughborough.

- - - (2006), Sonification Abstraite/Sonification Concrète: An 'Aesthetic Perspective Space' for Classifying Auditory Displays in the Ars Musica Domain. In Proceedings of the 12th International Conference on Auditory Display. London, England.

Vogt, Katharina (2010), Sonification of Simulations in Computational Physics. PhD Thesis, Institute of Electronic Music and Acoustics / Institute for Physics, University for Music and Dramatic Arts Graz / University of Graz, Graz.

Vogt, Katharina, Fritz Plessas, Alberto de Campo, Christopher Frauenberger, and Gerhard Eckel (2007), Sonification of Spin Models: Listening to Phase Transitions in the Ising and Pott Model. In Proceedings of the 13th International Conference on Auditory Display. Montréal, Canada.

Volcano's Deadly Warning (2002), Volcanoes Talking. PBS Nova. Retrieved on October 122010 from http://www.pbs.org/wgbh/nova/volcano/chouet.html.

Wachelder, Joseph (2007), Toys as Mediators. Icon: Journal of the International Committee for the History of Technology 13, 134-169. 
Walker, Bruce N. (2000), Magnitude Estimation of Conceptual Data Dimensions for Use in Sonification. PhD Thesis, Rice University, Houston.

Walker, Bruce N., and Joshua T. Cothran (2003), Sonification Sandbox: A Graphical Toolkit for Auditory Graphs. In Proceedings of the 9th International Conference on Auditory Display. Boston, MA, USA.

Walker, Bruce N., and David M. Lane (2001), Psychophysical Scaling of Sonification Mappings: A Comparison of Visually impaired and Sighted Listeners. In Proceedings of the 7th International Conference on Auditory Display. Espoo, Finland.

Walker, Bruce N., and Lisa M. Mauney (2004), Individual Differences, Cognitive Abilities, and the Interpretation of Auditory Graphs. In Proceedings of the 10th International Conference on Auditory Display. Sydney, Australia.

Wang, Ge (2007), A History of Programming and Music. In The Cambridge Companion to Electronic Music, edited by N. Collins and J. d'Escriván. Cambridge: Cambridge University Press, 55-71.

Waterman, Christopher A. (1990), "Our Tradition is a Very Modern Tradition": Popular Music and the Construction of Pan-Yoruba Identity. Ethnomusicology 34 (3), 367-379.

Weinberg, Gil, and Travis Thatcher (2006), Interactive Sonification: Aesthetics, Functionality and Performance. Leonardo Music Journal 16, 9-12.

Whittle, Mark (2004), Primordial Sounds: Big Bang Acoustics. Retrieved on October 122010 from http://www.astro.virginia.edu/ dmw8f/sounds/aas/press_release.pdf

Willcock, Ian (2006), Composing Without Composers? Creation, Control, and Individuality in Computerbased Algorithmic Composition. In Electronics in New Music, edited by C.-S. Mahnkopf, F. Cox and W. Schurig. Hofheim: Wolke Verlag, 221-235.

Williams, Rosalind (1990), Notes on the Underground: An Essay on Technology, Society, and the Imagination. Cambridge/London: The MIT Press.

Wittgenstein, Ludwig (1969 [1953]), Philosophische Untersuchungen/Philosophical Investigations. Third ed. New York: The Macmillan Company.

Woolgar, Steve (2002), Five Rules of Virtuality. In Virtual Society? Technology, Cyberbole, Reality, edited by S. Woolgar. Oxford/New York: Oxford University Press, 1-22.

Worrall, David (2009), Sonification and Information: Concepts, Instruments and Techniques. PhD Thesis, University of Canberra, Canberra.

_-_ (2010), Parameter Mapping Sonic Articulation and the Perceiving Body. In Proceedings of the 16th International Conference on Auditory Display. Washington, DC.

Worrall, David, Michael Bylstra, Stephen Barrass, and Roger Dean (2007), SoniPy: The Design of an Extendable Software Framework for Sonification Research and Auditory Display. In Proceedings of the 13th International Conference on Auditory Display. Montréal, Canada.

Wyatt, Sally (2004), Danger! Metaphors at Work in Economics, Geophysiology, and the Internet. Science, Technology, \& Human Values 29 (2), 242-261.

_-_ (2008), Technological Determinism Is Dead; Long Live Technological Determinism. In The Handbook of Science and Technology Studies, Third Edition, edited by E. J. Hackett, O. Amsterdamska, M. Lynch and J. Wajcman. Cambridge/London: The MIT Press, 165-180.

Wynne, Brian (1995), Public Understanding of Science. In Handbook of Science and Technology Studies, edited by S. Jasanoff, G. E. Markle, J. C. Petersen and T. J. Pinch. London/Thousand Oaks/New Delhi: SAGE Publications, 361-388.

-_- (2006), Public Engagement as a Means of Restoring Public Trust in Science - Hitting the Notes, but Missing the Music? Community Genetics 9 (3), 211-220.

Your DNA Song (2009). Retrieved on October 122010 from http://www.yourdnasong.com/. 
Zhao, Haixa, Benjamin K. Smith, Kent Norman, Catherine Plaisant, and Ben Shneiderman (2005), Interactive Sonification of Choropleth Maps. IEEE Multimedia 12 (2), 26-35.

Zimmerman, Brett (2003), Nineteenth-Century American Astronomy and the Sublime. Journal of the Royal Astronomical Society of Canada 97 (3), 120-123.

Zolberg, Aristide Z., and Long Litt Woon (1999), Why Islam Is Like Spanish: Cultural Incorporation in Europe and the United States. Politics \& Society 27 (1), 5-38.

Zupan, M.L. (1976), The Conceptual Development of Quantification in Experimental Psychology. Journal of the History of the Behavioral Sciences 12 (2), 145-158. 


\section{Discography}

This is not a general reference list for musical pieces based on sonification, but a discography listing recorded works that were explicitly mentioned in the text. The dates behind brackets always refer to the date of the recording, not of the composition or first performance. Performance pieces or installations that do not exist in recorded form are not mentioned here.

John Cage (1986), "Atlas Eclipticalis", on: Atlas Eclipticalis with Winter Music, Mode Records, mode 3/6. John Cage (1992), Atlas Eclipticalis for Three Flutes, hat hut, hat ART CD 6111.

Charles Dodge (1970), Earth's Magnetic Field, Nonesuch, H-71250. Re-released on Various Artists, Columbia-Princeton Electronic Music Center 1961-1973 (1998), New World Records, 80521-2.

Florian Dombois (1999), Earthquake Sounds. Volume 1: Kobe 16.1.1995, 20:46 ut, self-released CD-R, no catalogue number.

Felix Hess (2001), Air Pressure Fluctuations, Stadtgalerie Saarbrücken, ed.RZ 10014.

Jacob Kirkegaard (2005), Eldfjall, Touch, T33 20.

Christina Kubisch (2007), Five Electrical Works, Important Records, IMPREC167.

Alvin Lucier (1982), Music for Solo Performer, Lovely Music, VR 1014.

Mickey Newbury (1973), "Cortelia Clark", on: Heaven Help the Child Elektra, EKS-75055. Now available on Heaven Help the Child (2011), Drag City Records, DC-476.

Andrea Polli (2009), Sonic Antarctica, Gruenrekorder, Gruen 064.

David Rosenboom (1977), “On Being Invisible, Part I" and "On Being Invisible, Part II", on: On Being Invisible, Music Gallery Editions, \#MGE-4. Re-released on Invisible Gold (2000), Pogus Productions, 21022-2.

David Rosenboom (2000), "On Being Invisible II (Hypatia Speaks to Jefferson in a Dream)", available on: Various Artists, Transmigration Music, Centaur Records, CRC 2490: CDCM Computer Music Series Volume 30 .

Sc.Art (2009), A Jól Temperált Univerzum, SzemTanú Produkció, SZT005. Digital version under the English title The Well-Tempered Universe released in 2010.

Bob L. Sturm (2002), Music from the Ocean, Composerscientistrecordings, no catalogue number. 


\section{Samenvatting}

In dit proefschrift bestudeer ik de sonificatie van wetenschappelijke data - de omzetting van data in geluid - en in het bijzonder de (soms gespannen) verhouding tussen de publieke fascinatie voor en de wetenschappelijke legitimatie van sonificatie. Mijn analyse richt zich op de wetenschappelijke gemeenschap die rond deze representatietechniek is ontstaan. Daarbij gaat het zowel om de alledaagse praktijk van het sonificatiewerk als om de disciplinaire contexten en publieke debatten waarin dit werk zich situeert. Twee centrale vragen worden in dit proefschrift behandeld. Ten eerste, waarom geniet sonificatie de laatste jaren - en pas de laatste jaren - toenemende populariteit? En ten tweede, op welke manieren proberen de beoefenaars van sonificatie de wetenschappelijke legitimiteit van hun activiteiten te bewerkstellingen?

Sonificatie wordt soms beschreven als de auditieve pendant van data-visualisatie - zij het een minder bekende en minder geaccepteerde pendant. Toch is deze beschrijving van de relatie tussen sonificatie en visualisatie te kort door de bocht. Sonificatie wordt niet alleen als een alternatief voor, maar ook als een aanvulling op visualisatie gezien. En in pogingen om sonificatie geaccepteerd te krijgen, wordt visualisatie als rivaal én als bondgenoot ingezet, als lichtend voorbeeld, maar ook als voorbeeld van hoe het niet moet.

Deze complexe verhouding tussen sonificatie en visualisatie duikt in discussies binnen de sonificatie-gemeenschap steeds opnieuw op. Men is het er niet over eens of sonificatie het meest kans maakt op wetenschappelijke legitimiteit en acceptatie wanneer deze praktijk zich aan zou passen aan de bestaande conventies van wetenschappelijke representatie en verbeelding (die vrijwel altijd visueel georiënteerd zijn), of wanneer ze zich daar juist van zou afwenden. Hoe moet de sonificatie-gemeenschap bij voorbeeld omgaan met de wijdverbreide opvatting dat geluid geheel en al ongeschikt is voor het representeren van wetenschappelijke inhoud, omdat luisteren niet objectief en niet exact is? Door deze opvatting luid tegen te spreken; door een combinatie van sonificatie en visualisatie aan te bieden die het gemakkelijk maakt om snel tussen visuele en auditieve representaties om te schakelen; of door helemaal geen pretenties van objectiviteit of nauwkeurigheid te formuleren?

Niet alle beoefenaars van sonificatie zijn echter geïnteresseerd in sonificatie als wetenschappelijke en objectieve methode. Voor sommigen van hen is sonificatie gewoon een leuk en bruikbaar instrument om de aandacht van leken voor wetenschappelijke thema's te trekken. Het argument dat sonificatie niet objectief is omdat 
luisteren te emotioneel en subjectief van karakter zou zijn, doet hen dus niets. Voor hen gaat het niet om de academische acceptatie van sonificatie maar om het opwekken van fascinatie bij het publiek. Maar, zoals gezegd, er zijn ook beoefenaars die juist wel de acceptatie van sonificatie als wetenschappelijke methode nastreven, en die dus - zoals de titel van dit boek aangeeft - aan lobbywerk voor het oor doen.

Mijn proefschrift analyseert dit streven naar legitimatie - maar ook de alternatieve benadering van sonificatie als object van publieke fascinatie - vanuit een constructivistisch perspectief, dat beïnloed is door benaderingen uit het veld van wetenschaps- en technologiestudies (STS). Op de volgende pagina's bespreek ik mijn argumentatielijn in deze analyse nog eens per hoofdstuk.

In hoofdstuk 1 introduceer ik de praktijk van sonificatie, maar ook mijn eigen onderzoeksperspectief daarop. Naast een korte beschrijving van sonificatie en van mijn methodologische benadering (een kwalitatieve analyse van interviews, etnografische aantekeningen en primaire teksten) bestaat het voornaamste deel van dit hoofdstuk uit een bespreking van het debat over de "hiërarchie van de zintuigen" een hiërarchie waarin het zien een vaste plek aan de top inneemt - en wat dit voor sonificatie betekent. Ik bied een kritisch perspectief op werk in disciplines als mediastudies en de antropologie van de zintuigen dat de dominantie van het visuele ter discussie stelt en de rol van andere zintuigen benadrukt. Want, zo beargumenteer ik, deze bijdragen schetsen vaak een te simpel beeld, zowel van het visuele als van andere zintuigen. Deze studies bestendigen, nolens volens, de traditionele hiërarchie van de zintuigen door bepaalde kenmerken aan bepaalde zintuigen toe te schrijven. Net als in de traditionele hiërarchie van de zintuigen wordt het visuele met neutraliteit en afstandelijkheid geassocieerd, terwijl het auditieve met onderdompeling en emotie in verband wordt gebracht - het enige dat verandert is de relatieve waardering van deze eigenschappen. Historische studies tonen daarentegen aan dat dit problematisch is, omdat ook de status van het visuele aan de top van de hiërarchie soms betwist werd, en voorts omdat het auditieve ook als een bron van rationaliteit, neutraliteit en afstandelijkheid is beschouwd, net zoals visie emotionele en onderdompelende ervaringen kan voortbrengen.

Voorgenoemde literatuurstudie vormt de basis voor mijn benadering van sonificatie, waarbij ik stel dat er geen natuurlijke verband bestaat tussen geluid en onderdompeling of visie en rationaliteit, maar dat deze connotaties juist in een historischcultureel proces worden geconstrueerd. Academische bijdragen over de rol van de zintuigen in de wetenschap dienen de processen waarin deze connotaties gemaakt, versterkt, betwist of genegeerd worden, juist nauwkeurig te volgen. Bovendien beargumenteer ik in dit hoofdstuk dat het niet voldoende is om een zintuig in afzonde- 
ring van andere zintuigen te bestuderen, maar dat juist de wisselwerkingen tussen bijvoorbeeld kijken, luisteren en betasten van belang zijn.

Hoofdstuk 2, het eerste van de vier empirische hoofdstukken, gaat verder in op de eigenschappen die met horen en zien in verband worden gebracht. In dit hoofdstuk bestudeer ik het "publieke leven" van sonificatie, dat wil zeggen, haar bestaan en verspreiding in concertzalen, op muziekopnames, in geluidskunst-galerieën, maar ook in collegezalen voor populair-wetenschappelijke lezingen of in kranten. Ik begin door voorbeelden van sonificatie uit vijf verschillende disciplines te geven: geowetenschap, astrofysica, hoge-energiefysica, neurologie en genetica. In deze vijf velden concentreer ik me op voorbeelden en projecten die primair gericht zijn op een publiek van leken en kunstliefhebbers en niet op wetenschappelijke experts. De leidende vraag van dit hoofdstuk is waarom er, zowel onder populariseerders van wetenschap en journalisten als onder kunstenaars en componisten, de laatste jaren een toenemende fascinatie voor sonificatie ontstaan is. Mijn antwoord hierop is dat het succes gebaseerd is op de belofte dat sonificatie een ervaring kan teweegbrengen die ik het auditief sublieme noem. Deze evaring van ontzag en verschrikking, betovering en overweldiging, wordt gecreëerd door het inzetten van verschillende retorische, muzikale en technologische middelen. Daarbij gaat het bij voorbeeld om het gebruik van metaforen die impliceren dat het geluid rechtstreeks uit het gesonificeerde fenomeen voortkomt (en daardoor verhullen dat het eigenlijk de uitkomst is van een aantal menselijke en technologische interventies), of om een technische opzet die het publiek in het midden van de sonificatie plaatst en hen uitnodigt om zich te verbeelden dat zij zich in het centrum van een ster of een vulkaan bevinden. De invocaties van het sublieme zijn dan ook opvallend gelijkvormig, zowel bij projecten in de wetenschapspopularisering als in de muziek. Ze zijn bedoeld om fascinatie voor wetenschappelijk onderzoek te creëren bij een breed publiek, dat daarmee zijn eigen, geïndividualiseerde ervaringen van wetenschap mee naar huis neemt. De verspreiding van sonificatie in de publieke sfeer hangt dus zowel samen met haar geschiktheid aan te sluiten bij een bestaand cultureel discours over geluid als een omhullend, emotioneel medium (dat ik in hoofdstuk 2 kritisch onder de loep nam), als met de toenemende behoefte aan projecten met expliciete en ruime aandacht voor wetenschapspopularisering en publieke participatie.

Hoofdstuk 3 richt zich op een gespecialiseerde wetenschappelijke gemeenschap gewijd aan sonificatie: de International Community for Auditory Display (ICAD). Het hoofdstuk begint met een verkenning van de geschiedenis en historiografie van dit veld, met als startpunt de eerste ICAD conferentie in 1992. Doel van deze historische benadering is niet zozeer een reconstructie van de geschiedenis van deze ge- 
meenschap, maar een begrip van de wijze waarop haar (auto)biografie de gemeenschap helpt om continuïteit en identiteit te construeren. De overige paragrafen van dit hoofdstuk richten zich op de vraag hoe disciplinaire identiteit en de grenzen van de gemeenschap worden uitonderhandeld en geconstrueerd in bepaalde sociale praktijken (zoals het samen maken en beluisteren van muziek tijdens de jaarlijkse conferenties), in verschillende definities van sonificatie, en via de toekomstverwachtingen van haar leden. De relatie tussen wetenschap en kunst, die vooral in de laatste paragraaf van het hoofdstuk aan bod komt, speelt hierbij een belangrijke rol.

Het conceptuele raamwerk voor dit hoofdstuk start met het concept boundary work ('grenswerk'), waarbij ik de vraag stel hoe de grenzen van de sonificatiegemeenschap voortdurend ter discussie gesteld, vastgelegd en verlegd worden tijdens de zoektocht naar culturele autoriteit en wetenschappelijke legitimiteit voor sonificatie. Ik benoem de specifieke mechanismen van grenswerk die door de sonificatiegemeenschap gebruikt worden als mechanismen van boundary slipping ('grensglippen'). Wat hierbij van essentieel belang is, is dat het grenswerk van sonificatie niet zozeer gekenmerkt wordt door pogingen de grenzen tussen wetenschap en kunst op te heffen, te versterken, of te verschuiven in een bepaalde richting, maar door het vermogen om door deze grenzen heen te glippen. De beoefenaars van sonificatie navigeren over een terrein waarin reeds grenzen zijn aangebracht door andere actoren, zonder noodzakelijkerwijs hun eigen grenzen vast te leggen. Bestaande culturele conventies worden tegelijkertijd omarmd en ondermijnd, aangezien sonificatie zowel toegeeft aan bestaande conventies van wetenschappelijk representatie, als die ontwricht. De specifieke vorm die het grenswerk van sonificatie aanneemt hangt samen met de aard van het veld dat niet louter één of enkele bestaande disciplines omvat of raakt - zoals opkomende disciplines of interdisciplinaire velden neigen te doen maar juist fundamentele conventies over wetenschappelijke analyse en representatie van data in twijfel trekt. Haar grenswerk is dan ook niet alleen gericht op één of enkele weinig concurrerende disciplines, maar op wetenschap als geheel. Wil sonificatie wetenschappelijke acceptatie bereiken, dan is het niet alleen nodig dat ze vreedzaam naast andere wetenschappelijke disciplines kan bestaan, maar ook dat haar technieken en methodes binnen deze andere velden worden opgenomen - zonder echter de uitzonderlijke bekwaamheid van leden van de sonificatie-gemeenschap om dergelijke auditieve representaties te produceren ter discussie te stellen.

Hoofdstuk 4 verbindt de voorbeelden van sonificatie die besproken werden in hoofdstuk 2 met de academische gemeenschap zoals beschreven in hoofdstuk 3 door verschillende discoursen over de objectiviteit van sonificatie te onderzoeken. Het hoofdstuk begint met een terugkeer naar enkele wetenschappers uit hoofdstuk 2 die 
sonificatie gebruiken als onderdeel van hun wetenschapspopulariserende activiteiten, en analyseert hoe zij sonificatie inkaderen: als een leuke gimmick voor wetenschapspopularisering maar geen component van serieuze wetenschap. STS onderzoekers hebben aangetoond dat wetenschappers die met visualisatie werken vaak iconoclastisch zijn met betrekking tot de beelden waarmee ze werken - dat wil zeggen dat ze overvloedig gebruik van beelden maken, maar tegelijkertijd ontkennen dat deze enige epistemologische waarde hebben. Net zoals deze onderzoekers iconoclastisch zijn met betrekking tot afbeeldingen, laat ik zien dat de hier beschreven wetenschappers vaak sonoclastisch zijn met betrekking tot de geluiden die ze gebruiken en ze daardoor de status van objectieve wetenschappelijke representatie ontzeggen.

Dergelijk sonoclasme ondergraaft echter de status van sonificatie die men binnen de ICAD gemeenschap voor ogen heeft. In plaats daarvan werkt de gemeenschap aan de ontwikkeling van kaders voor sonificatie die het mogelijk moeten maken sonificatie-onderzoek te accepteren als objectief en wetenschappelijk. De leden van de gemeenschap staan echter niet op één lijn wat betreft de standaard van objectiviteit aan de hand waarvan de wetenschappelijke kwaliteit van sonificatie gemeten zou moeten worden. Twee kaders, die ik de correlation coefficients and de trained ears benaderingen heb genoemd, wedijveren hier met elkaar. Terwijl de eerste benadering gebaseerd is op een strategie waarbij gebruikers kwantitatief worden getest om vast te stellen wat de gemiddelde gebruiker nu precies kan horen in een sonificatie, bepleiten de aanhangers van de trained ears benadering dat het oordeel van experts centraal zou moeten staan. Dit laatste sluit aan bij een discours dat Daston en Galison trained judgment noemen. Terwijl met correlation coefficients objectiviteit wordt nagestreefd door het gemiddelde te nemen van vele subjectieve ervaringen, worden in de trained ears benadering subjectieve oordelen juist omarmd en wordt bovendien de tegenstelling tussen objectiviteit en subjectiviteit ter discussie gesteld. Deze verschillende kaders van objectiviteit zijn geworteld in verschillende soorten onderzoeksvragen met betrekking tot sonificatie, in verschillende disciplinaire perspectieven en in verschillende opvattingen over wie de gebruikers van sonificatie zijn. Het onvermogen van de ICAD gemeenschap om overeenstemming te bereiken over één opvatting van objectiviteit is dus tekenend voor interdisciplinaire fricties, en inderdaad, voor onenigheid over de vraag of de sonificatie-gemeenschap een wetenschappelijke discipline moet zijn met haar eigen definitie van wetenschappelijke kwaliteit, dan wel een los samengesteld, interdisciplinair conglomeraat van verschillende velden waarbinnen verschillende opvattingen naast elkaar kunnen bestaan.

Hoofdstuk 5 analyseert de instrumenten en vaardigheden die nodig zijn in sonificatieonderzoek aan de hand van vijf verschillende fases: leren werken met sonificatie, 
het kiezen of bouwen van instrumenten voor sonificatieonderzoek, het ontwerp van concrete toepassingen van sonificatie, het luisteren naar sonificatie, en het demonstrateren voor een wetenschappelijk publiek. Twee verschillende concepten spelen een rol in dit hoofdstuk: professional audition - gebaseerd op het concept 'professional vision' - en het karakter van de sonificatie-gemeenschap als dat van een gadget community. Professional audition binnen sonificatie - dat wil zeggen, het geheel van perceptuele en technologische competenties die de leden van de gemeenschap met elkaar delen - betreft vaardigheden zoals het programmeren van software en het knutselen met hardware, het anticiperen op hoe iets zou kunnen klinken, het omzetten van deze verwachtingen in concrete ontwerpen van sonificaties, en het vermogen om deze sonificaties te beluisteren en erover met een breder publiek te communiceren. De zintuiglijke vaardigheden die deel uitmaken van de professional audition van sonificatie zijn beslist niet uitsluitend auditief, maar ook visueel en tactiel; het gaat hier over activiteiten zoals knutselen, wijzen, gesticuleren, tekenen, neuriën en zingen. Tegelijkertijd wil ik hiermee het belang van specifieke auditieve vaardigheden zoals luisteren niet minimaliseren; integendeel, dit hoofdstuk benadrukt juist het belang van luistervaardigheden. Niet alleen is luisteren belangrijk, maar er bestaan ook verschillende wijzen van luisteren die in verschillende contexten gebruikt worden. Zo onderscheid ik zowel tussen verschillende doeleinden van luisteren - monitory, diagnostic en exploratory listening - als tussen verschillende manieren van luisteren - synthetic, interactive en immersive listening.

De specifieke invulling van professional audition die binnen de gemeenschap gecultiveerd wordt is nauw verbonden met het tweede concept dat ik in dit hoofdstuk hanteer: de beschouwing van de sonifcatie-gemeenschap als een gadget community. Deze term is een aanpassing van het concept instrumental community, waarmee een heterogene groep van actoren wordt beschreven die zich rond een bepaalde onderzoekstechnologie vormt. Door van een gadget community in plaats van een instrumental community te spreken, benadruk ik dat de technologie binnen deze gemeenschap niet zo zeer instrumenteel is om een bepaalde manier van wetenschappelijk onderzoek mogelijk te maken, maar soms de indruk wekt ook een doel op zich te zijn. Technologie wordt dus om de technologie zelf ontwikkeld, en de gemeenschap leeft van de fascinatie en nieuwigheid die er van deze technologie uitgaat. Het concept gadget community maakt het mogelijk te begrijpen hoe de technologische oriëntatie van deze gemeenschap bepaalde vormen van interdisciplinaire samenwerking mogelijk maakt, dan wel belemmert. De discussie over professional audition binnen sonificatie maakte al duidelijk dat bepaalde vaardigheden speciaal gewaardeerd worden, zoals het knutselen met hard- en software (en met name programma's voor elektroni- 
sche muziek die vaak in het ontwerpen van sonificaties gebruikt worden). De nadruk op deze vaardigheden maakt het makkelijker voor individuen met een langdurige interesse in dit soort technologieën - bijvoorbeeld voor mensen met een achtergrond in de elektronische muziek - om zich aan sonificatieonderzoek te wagen. Tegelijkertijd kan het individuen die niet over deze vaardigheden beschikken weerhouden om tot de gemeenschap toe te treden. Over het algemeen blijkt de gemeenschap sterker georiënteerd op het uitvinden en ontwikkelen van nieuwe technologieën en instrumenten dan het werken met en luisteren naar afgeronde sonificaties. Door deze gerichtheid wordt de disciplinaire expertise van wetenschappers in de velden waaruit data gesonificeerd worden gemarginaliseerd. Dit wil overigens niet zeggen dat sonificatie voor eens en altijd een gadget community zal blijven: een gadget community kan ook als een fase in de ontwikkeling van een gemeenschap beschouwd worden - een fase die niet ongebruikelijk is bij jonge wetenschappelijke velden. Hoewel er geen garantie is dat sonificatie deze fase zal ontgroeien en dus haar nadruk op gadgets zal verliezen, is het wel mogelijk dat degelijk toch zal gebeuren.

Het concluderende hoofdstuk 6 plaatst mijn analyse van sonificatie in een historische context en koppelt de twee in de introductie geformuleerde vragen - over de publieke fascinatie voor dit fenomeen en over de wetenschappelijke legitimiteit ervan - aan elkaar. Sonificatie als wetenschappelijk veld is nog vrij jong, en het ontstaan en de verdere ontwikkeling van het veld is nauw gekoppeld aan twee verschillende, recente ontwikkelingen: de opkomst van digitale technologieën en de veranderende relaties tussen wetenschap en publiek.

De toenemende populariteit van sonificatie in de laatste jaren heeft te maken met nieuwe digitale technologieën (audio technologieën zoals geluidssynthese-software of mp3, maar ook visualiseringtechnieken en elektronische tijdschriften), waardoor zowel het maken als het verspreiden van sonificaties gemakkelijker is dan ooit tevoren. Ook de conventies ten aanzien van wat wel en wat niet als betrouwbaar bewijsmiddel wordt beschouwd veranderen in deze context. Dit wil echter niet zeggen dat de culturele praktijken van sonificatie helemaal bepaald worden door technologische ontwikkelingen. Deze ontwikkelingen, en de manier waarop hiermee wordt omgegaan, maken deel uit van afstemmings- en onderhandelingsprocessen binnen de gemeenschap. Digitalisering heeft daarmee ook gevolgen voor de wetenschappelijke acceptatie van sonificatie: in haar streven naar academische legitimiteit moet de sonificatie-gemeenschap op deze ontwikkelingen reageren, en legitimatiestrategieën uitvinden die bij bepaalde ontwikkelingen aansluiten of daar een alternatief voor bieden.

Naast de opkomst van digitale technologieën behandel ik nog een tweede recente ontwikkeling die deel uitmaakt van de historische context van sonificatie: de verande- 
rende relatie tussen wetenschap en publiek. De afgelopen jaren is deze relatie in toenemende mate problematisch geworden. Tegenwoordig wordt het noodzakelijk geacht om het publiek bij de wetenschap te betrekken en publieke scepsis ten opzichte van wetenschap te voorkomen. Ontwikkelingen zoals de toename van interactieve tentoonstellingen in wetenschapscentra contrasteren verschillen sterk van traditionele manieren van wetenschapspopularisering: in plaats van de wetenschapper die aan een onwetend publiek kennis overdraagt, is het de bedoeling dat leken nu hun eigen, geïndividualiseerde ervaringen van wetenschap opdoen en mee naar huis nemen. Veel sonificatie-initiatieven passen goed in dit nieuwe schema van wetenschapspopularisering. De vormen van sonificatie die vooral gericht zijn op het uitlokken van publieke fascinatie voor wetenschap sluiten zonder veel moeite bij deze ontwikkelingen aan. Voor degenen die proberen om sonificatie als wetenschappelijke methode te positioneren is dit echter moeilijker, omdat voor veel wetenschappers een strikte scheiding tussen "echte wetenschap" en "populaire wetenschap" bestaat, waarbij datgene wat met popularisering (om nog maar te zwijgen van kunst) te maken heeft al bij voorbaat geen serieuze wetenschappelijke methode kan zijn. Tegelijkertijd is het voor degenen die in de wetenschappelijke acceptatie van sonificatie geïnteresseerd zijn ook niet per se gunstig om populariserings- en kunstprojecten op een afstand te houden, aangezien deze projecten mogelijkheden bieden om aandacht en financiële middelen voor sonificatie-werk te verkrijgen. Dit spanningsveld tussen de fascinatie voor en legitimiteit van sonificatie heb ik in mijn proefschrift geanalyseerd. 


\section{Curriculum Vitae}

Alexandra Supper (1983) studied sociology at the University of Vienna, and graduated in 2007 with a master thesis in science \& technology studies. During her studies, she worked as a teaching and research assistant at the Department of Social Studies of Science in Vienna for two and a half years, and spent one year as an Erasmus student at Maastricht University, where she followed courses in the Arts \& Sciences programme. From $2008 \mathbb{P} 2011$, she was employed as a $\mathrm{PhD}$ researcher at the Faculty of Arts and Social Sciences, Maastricht University, and was trained within the local Graduate School as well as the Netherlands Graduate Research School for Science, Technology and Modern Culture (WTMC). She is currently a post-doctoral researcher at the same faculty, where she does research at the crossroads between science $\&$ technology studies and sensory studies. 